\title{
O USUÁRIO E O PROCESSO DE PROJETO: CO-DESIGN EM EDIFÍCIOS DE SAÚDE
}

\author{
MICHELE CAROLINE BUENO FERRARI CAIXETA
}

Tese apresentada ao Programa de Pós-graduação em Arquitetura e Urbanismo do Instituto de Arquitetura e Urbanismo de São Carlos, da Universidade de São Paulo, como parte dos requisitos para obtenção do título de Doutor em Ciências de Arquitetura e Urbanismo. Versão Corrigida: a original encontra-se disponível no IAU-USP.

Área de Concentração: Arquitetura, Urbanismo e Tecnologia.

Orientador: Prof. Assoc. Marcio M. Fabricio (IAU-USP) Co-orientadora: Prof. Dra. Patricia Tzortzopoulos Fazenda (University of Huddersfield, UK) 
AUTORIZO A REPRODUÇÃO TOTAL OU PARCIAL DESTE TRABALHO, POR QUALQUER MEIO CONVENCIONAL OU ELETRÔNICO, PARA FINS DE ESTUDO E PESQUISA, DESDE QUE CITADA A FONTE.

Caixeta, Michele Caroline Bueno Ferrari
C1330 O usuário e o processo de projeto: Co-design em edifícios de saúde. / Michele Caroline Bueno Ferrari Caixeta; orientador Márcio Minto Fabricio; coorientadora Patrícia Tzortzopoulos Fazenda. São Carlos, 2015.

Tese (Doutorado) - Programa de Pós-Graduação em Arquitetura e Urbanismo e Área de Concentração em Arquitetura, Urbanismo e Tecnologia -- Instituto de Arquitetura e Urbanismo da Universidade de São Paulo, 2015 .

1. Arquitetura. 2. Co-Design. 3. Envolvimento de Usuários. 4. Processo de Projeto. 5. Edifícios de Saúde. 6. Eficiência Operacional. I. Título. 


\section{FOLHA DE JULGAMENTO}

Candidata: Arquiteto e Urbanista Michele Caroline Bueno Ferrari Caixeta

Título da tese: “O usuário e o processo de projeto: co-design em edifício de saúde".

Data da defesa: 26/10/2015

\section{Comissão Julgadora:}

Prof. Assoc. Márcio Minto Fabrício (Orientador)

(Instituto de Arquitetura e Urbanismo - USP)

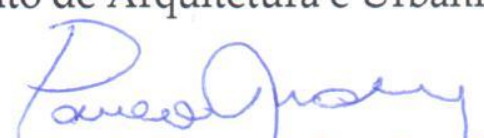

Prof. Dr. Paulo Roberto Pereira Andery

(Universidade Federal de Minas Gerais - UFMG)

Prof. Dr. Fábio Oliveira Bitencourt Filho

(Universidade Federal do Rio de Janeiro - UFRJ)

Profa. Dra. Mônica Santos Salgado

(Universidade Federal do Rio de Janeiro - UFRJ)

Profa. Dra. Ercília Hitomi Hirota

(Universidade Estadual de Londrina - UEL/PR) $\underline{\text { Resultado: }}$
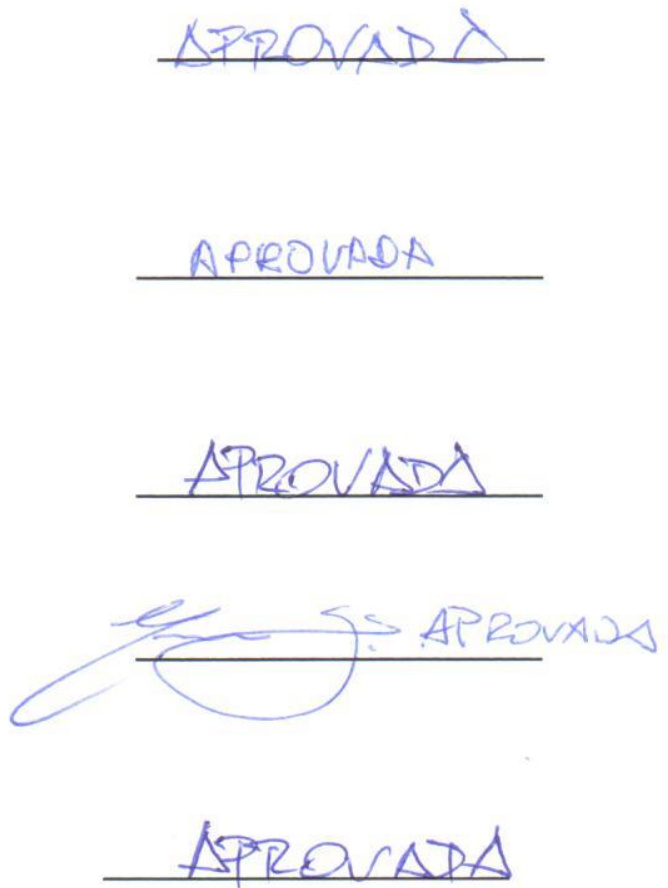

Coordenador e Presidente da Comissão de Pós-Graduação do Programa de Pós-

Graduação em Arquitetura e Urbanismo: Prof. Dr. Márcio Minto Fabrício 

Ao, Paulo, meu esposo, e nossos filhos, Felipe e Vinícius, pelo companheirismo e por fazerem minha vida tão feliz! Aos meus pais, Moacir e Idemilde, e irmãos, Michel e Max, por todo apoio. 



\section{AGRADECIMENTOS}

Em primeiro lugar, agradeço a Deus pela vida, pela saúde e por todas as conquistas maravilhosas que me concedeu.

Agradeço a meu esposo, Paulo, pelo constante apoio, amor e compreensão nestes anos de pesquisa, e aos nossos filhinhos, Felipe e Vinícius, por encherem nossas vidas de alegria.

Aos meus pais, Moacir e Idemilde, por todo amor e exemplo e por me conduzirem pelos caminhos do conhecimento sem jamais medir esforços para que eu pudesse estudar e atingir meus objetivos. Aos meus irmãos, Michel e Max, companheiros de toda minha vida, e a toda minha família, que sempre compartilhou comigo minhas lutas e conquistas. Aos meus sogros e cunhada, pelo apoio e ajuda ao longo da minha pós-graduação.

Ao Márcio Minto Fabricio, meu orientador, por todos os conselhos e pela amizade e paciência nestes anos, sempre me incentivando a ir além.

À Patrícia Tzortzopoulos Fazenda, minha co-orientadora, pela colaboração com minhas pesquisas.

Às minhas colegas de pós-graduação - verdadeiras amigas! - Carolina, Cristiane Débora, Elza, lara, Letícia, Marieli e Marina, que sempre me ajudaram e dividiram comigo as alegrias e os momentos difíceis destes anos, fazendo do laboratório um local agradável de estar.

Aos colegas, professores e funcionários do Instituto de Arquitetura e Urbanismo de São Carlos e da Escola de Engenharia de São Carlos, pelo auxílio direto ou indireto à minha formação, e pelo ambiente agradável que sempre proporcionaram.

À Universidade de São Paulo, pela estrutura e oportunidade a mim concedidas na graduação, mestrado e doutorado.

À CAPES, pelo apoio financeiro.

Ao ilustre arquiteto João Carlos Bross e sua equipe, por toda a ajuda. Dividir comigo suas experiências na área de arquitetura para saúde foi fundamental para a realização deste trabalho.

À arquiteta Márcia Bastian, da Planesa, e ao arquiteto Arthur Brito, da Kahn do Brasil, por toda a contribuição para a realização da pesquisa.

Às empresas participantes do estudo exploratório e aos avaliadores do modelo, que gentilmente se empenharam em contribuir com seus conhecimentos para o desenvolvimento deste trabalho. 
Aos membros da banca, pela disponibilidade na participação e na leitura do texto e pelos conhecimentos dispensados.

E a todos aqueles que, direta ou indiretamente, me auxiliaram durante o doutorado. 
"Nenhum projeto, não importa quão belo ou engenhoso, é bom se não atende à necessidade do usuário". 

CAIXETA, M. C. B. F. O usuário e o processo de projeto: Co-design em edifícios de saúde. 2015. Tese (Doutorado) - Instituto de Arquitetura e Urbanismo, Universidade de São Paulo, São Carlos, 2015.

Caracterizado por grande complexidade, o projeto de edifícios de assistência à saúde precisa garantir funcionalidade e eficiência operacional à edificação, através de espaços que facilitem a realização das atividades de atenção à saúde. Isto é ainda mais proeminente em países como o Brasil, onde os serviços de atenção à saúde são deficitários, principalmente na esfera pública. Para tanto, é necessário um amplo conhecimento acerca dos usuários e dos fluxos e atividades que compõem os serviços prestados, que geralmente os arquitetos não possuem. Neste contexto, e dada a complexidade dos edifícios de assistência à saúde, o envolvimento efetivo dos usuários no processo de projeto - co-design - pode contribuir para o redesenho das atividades de atenção à saúde e assim possibilitar que os arquitetos alinhem o projeto do espaço físico com o projeto dos serviços, aumentando a oferta e a qualidade do atendimento à população. No entanto, o co-design exige grandes esforços do arquiteto, relativos à coordenação e à linguagem utilizada, entre outros desafios. O problema desta pesquisa reside, portanto, na falta de amparo e dificuldades de envolver efetivamente os usuários no processo de projeto destes edifícios, como perspectiva para trazer os conhecimentos relativos à utilização da edificação ao projeto, e assim aumentar a adequação entre edifício e uso. A pesquisa aqui proposta busca, neste sentido, uma proposição inovadora de solução através da abordagem da Design Science Research (DSR) que tem como fundamento a proposta de soluções para problemas enfrentados no mundo real. A pesquisa incluiu as etapas de entendimento do tema, com revisão bibliográfica, estudo exploratório e estudos de caso em dois projetos de edifícios de saúde com co-design; proposta de uma solução e avaliação da solução. Como solução, apresenta-se um modelo conceitual de processo de projeto com codesign para auxiliar os arquitetos na promoção desta prática em edifícios de assistência à saúde. Descreve-se ainda o processo de seleção dos representantes dos usuários para as oficinas de co-design, com as questões que devem ser consideradas pela coordenação, a preparação dos usuários, a estrutura para orientar as oficinas e as revisões de fases, indicando as entradas, os métodos e instrumentos e as saídas das oficinas, e os subprodutos para análise, os critérios de passagem e o conteúdo dos relatórios de revisão, no caso das revisões de fase. O modelo foi avaliado por quatro profissionais, que são arquitetos com experiência em projetos de edifícios de saúde e pesquisadores da área. Com base nos resultados das avaliações, o modelo foi aprimorado para sua versão final.

Palavras chave: Arquitetura. Co-Design. Envolvimento de Usuários. Processo de Projeto. Edifícios de Saúde. Eficiência Operacional. 



\section{ABSTRACT}

CAIXETA, M. C. B. F. User and design process: Co-design in healthcare buildings. 2015. Thesis (PhD) - Institute of Architecture and Urban Planning, University of São Paulo, São Carlos, 2015.

Characterized by high complexity, the design of a healthcare building must ensure functionality and operational efficiency to the building through spaces that support healthcare activities. This is even more prominent in countries as Brazil, where healthcare services are deficient, especially in the public sphere. Therefore, a broad knowledge on users and service flows and activities, which architects seldom have, is required. Given the complexity of healthcare buildings, the effective involvement of users in the design process - co-design - can contribute to the redesign of healthcare activities and enable architects to align the design of physical space with that of services, which increases the supply and quality of services to the population. However, co-design requires great efforts, related to coordination and design language, among other challenges, from architects. This thesis addresses the lack of support and difficulties regarding the effective engagement of users in the design process of the healthcare buildings, as a perspective to provide knowledge on the use of the building to the design and increase the adequacy of building and use. It proposes an innovative solution through the Design Science Research (DSR), based on the proposal of solutions to problems faced in the real world. The research included the stages of understanding of the theme, through a literature review, survey and case studies in two healthcare buildings designed with co-design, development of a solution and its evaluation. A conceptual model of the design process with co-design is presented to assist architects in promoting this practice in healthcare buildings. The selection process of users' representatives is described for the co-design workshops and indicates the issues to be considered by the coordination. The study also addresses the preparation of users, a framework to guide the workshops and phase reviews, stating the inputs, methods and tools and the outputs for the workshops, the deliverables for analysis, criteria for judgment and content of revision reports, in the case of phase revisions. The model was evaluated by four professionals, who are architects and researchers skilled in healthcare building design. According to the evaluation results, the model has been enhanced to its final version.

Keywords: Architecture. Co-Design. User Involvement. Design Process. Healthcare Buildings. Operational Efficiency. 

Figura 1. Evolução da cama-maca. Fonte: Acervo do CTRS (2008)..................................... 34

Figura 2. Etapas de desenvolvimento da pesquisa, pela abordagem Design Science Research. Fonte: Elaborada pela autora. .39

Figura 3. Delineamento da pesquisa, pela abordagem DSR. Fonte: Elaborada pela autora. .46

Figura 4. Fatores determinantes da complexidade do projeto, segundo Vidal e Marle (2008), adaptados para edifícios de assistência à saúde (obras novas). Fonte: Caixeta e Fabricio (2011). .66

Figura 5. Fatores determinantes da complexidade do projeto, segundo Vidal e Marle (2008), adaptados para edifícios de assistência à saúde (obras de intervenção). Fonte: Caixeta e Fabricio (2011).

Figura 6. Modelo de Processo de Projeto Tradicional. Fonte: Mallory-Hill (2004)............. 70

Figura 7. Modelo de Processo de Projeto Tradicional, com Ciclos de Retroalimentação. Fonte: Nelson, (1996 apud MALLORY-HILL, 2004).

Figura 8. Modelo de Referência para o Gerenciamento do Processo de Projeto Integrado de Edificações. Fonte: Romano (2006).

Figura 9. Fases do Protocolo Genérico do Processo de Projeto e Construção - GDCPP. Fonte: Kagioglou et al. (2000).

Figura 10. Processo de Projeto edifícios de assistência à saúde, dentro do contexto do PDP. Fonte: Caixeta (2011).

Figura 11. Crescimento do front-end com a aproximação entre projetistas e usuários. Fonte: Sanders e Stappers (2008). .75

Figura 12. Etapa de conhecimento do programa. Fonte: Diagrama elaborado a partir do texto de Carvalho (2012). .

Figura 13. Modelo de diamante duplo. Fonte: Davies e Wilson (s.d.)..

Figura 14. Processo de planejamento dos serviços hospitalares. Fonte: Tompkins et al. (2010)

Figura 15. Esquema de Serviço da Neuro Clínica Presbiteriana. Fonte: Cliver et al. (2007). 91 Figura 16. Instrumento 'Cenários': Simulação de situação. Fonte: http://www.servicedesigntools.org/tools/42, Acesso em 17 dez. 2014............... 92

Figura 17. Modelo projeto com visão holística. Fonte: Tzortzopoulos et al. (2009). ......... 92 
Figura 18. Formas de envolvimento do usuário no processo de projeto. Fonte: Preparada a partir do texto de Wulz (1986). 108

Figura 19. Papéis dos usuários $(U)$, pesquisadores (PE) e projetistas (P) no processo de projeto centrado no usuário (à esquerda) e no co-design (à direita). Fonte: Sanders e Stappers (2008). 108

Figura 20. Cadeia de suprimentos com as diferentes categorias de usuários de edifícios. Fonte: Olsson et al. (2010)

Figura 21. Definições: Metodologia, Método e Instrumentos. Fonte: Adaptado de Sanders (2009). .120

Figura 22. Fases da Participação. Fonte: Wilcox (1994).........................................................121

Figura 23. Esquema do FfC, com seus workshops, metodologias e instrumentos. No detalhe, o modo como cada workshop é organizado. Fonte: Eriksson et al. (2012). 122

Figura 24. Jogo de Tabuleiro e Análise do fluxo de tarefas. Fonte: Garde e Van der Voort (2012) .124

Figura 25. Fases do Design Game. Fonte: Wilcox (1994). 125

Figura 26. Co-design com enfermeiras. Instrumentos para imaginar ao redor da mesa, para auxiliá-las a pensar em fluxo e não em ambientes. Fonte: Sanders e Stappers (2008) e Sanders (2009)...

Figura 27. Modelo 3D em co-design: enfermeiras na equipe de projeto de uma sala de pacientes ideal. Fonte: Sanders (2009).

Figura 28. Modelo 3D com paredes transparentes. Fonte: Sanders (2009)........................ 127

Figura 29. Velcro Modelling. Fonte: Sanders (2009).

Figura 30. Vista leste da maquete do projeto de 1942 do HCPA. Fonte: Acervo de JMM no NPD - FAU/UFRJ (SILVA, 2006). 140

Figura 31. Vista leste 2 da maquete do projeto de 1942 do HCPA. Fonte: Acervo de JMM no NPD - FAU/UFRJ (SILVA, 2006). 140

Figura 32. Obra do HCPA. Fonte: http://www.hcpa.ufrgs.br/galeria/index.html Acesso em: 25 set. 2013 . 141

Figura 33. Vista aérea da obra do HCPA. Fonte: http://www.hcpa.ufrgs.br/galeria/index.html Acesso em: 25 set. 2013............. 141

Figura 34. Vista aérea do HCPA na época da construção. Fonte: http://www.hcpa.ufrgs.br/galeria/index.html Acesso em: 25 set. 2013.............. 141

Figura 35. Vista aérea atual do HCPA. Fonte: Google Maps - https://maps.google.com.br141 
Figura 36. Subsolo: Planta da situação existente. Fonte: Imagem gentilmente cedida pela Bross Consultoria e Arquitetura.

Figura 37. Subsolo: Planta da reorganização proposta. Fonte: Imagem gentilmente cedida pela Bross Consultoria e Arquitetura

Figura 38. Térreo: Planta da situação existente. Fonte: Imagem gentilmente cedida pela Bross Consultoria e Arquitetura.

Figura 39. Térreo: Planta da reorganização proposta - circulações. Fonte: Imagem gentilmente cedida pela Bross Consultoria e Arquitetura.

Figura 40. Térreo: Planta da reorganização geral proposta. Fonte: Imagem gentilmente cedida pela Bross Consultoria e Arquitetura. 146

Figura 41. Perspectiva aérea do HCPA com o Bloco 1 (a ser reorganizado) e os anexos que serão acrescentados. Fonte: Imagem gentilmente cedida pela Bross Consultoria e Arquitetura. 146

Figura 42. Ilustração 3D do HCPA e seus anexos. Fonte: http://www.hcpa.ufrgs.br/expansao/index.php/conheca-o-projeto Acesso em 06 jul. 2015

Figura 43. Ilustração 3D do $4^{\circ}$ Pavimento do Anexo 1 do HCPA. Fonte: http://www.hcpa.ufrgs.br/expansao/index.php/conheca-o-projeto Acesso em 06 jul. 2015. 148

Figura 44. Ilustração 3D do $6^{\circ}$ Pavimento do Anexo 1 do HCPA. Fonte: http://www.hcpa.ufrgs.br/expansao/index.php/conheca-o-projeto Acesso em 06 jul. 2015. 148

Figura 45. Ilustração 3D do Térreo do Anexo 2 do HCPA. Fonte: http://www.hcpa.ufrgs.br/expansao/index.php/conheca-o-projeto Acesso em 06 jul. 2015.

Figura 46. Evolução do Processo de Projeto do HCPA. Fonte: http://www.hcpa.ufrgs.br/expansao/fique-por-dentro/10-retrospectiva-daampliacao. Acesso em 20 jul. 2015

Figura 47. Mapa de Relacionamento enviado aos usuários para preenchimento. Fonte: Gentilmente cedido pela equipe interna do HCPA. 152

Figura 48. Texto explicativo sobre os termos e os conceitos gerais utilizados no mapa de relacionamento. Fonte: Gentilmente cedido pela equipe interna do HCPA. .... 152

Figura 49. Formulário para levantamento da demanda de espaço para arquivos. Fonte: Imagem gentilmente cedida pela equipe interna do HCPA. 153 
Figura 50. Formulário de acolhimento de demandas e contribuições, enviado a representantes de todos os setores do HCPA. Fonte: Gentilmente cedido pela equipe interna do HCPA.

Figura 51. Cadeia de suprimentos do serviço de saúde: exemplo de fluxo qualitativo de atividades. Fonte: Bross (2013)

Figura 52. Cadeia de suprimentos do serviço de saúde: exemplo de fluxo quantitativo de atividades. Fonte: Bross (2013).

Figura 53. Exemplo de diagrama de bolhas para organização dos setores. Fonte: Bross (2008).

Figura 54. Exemplo de diagrama de bolhas para organização do piso/bloco/edifício. Fonte: Bross (2008).

Figura 55. Representantes dos grupos de projeto e de usuários. Fonte: Elaborada pela autora a partir de informação verbal. 158

Figura 56. Sala de exposição do projeto, com a história do HCPA entre 1930 e 1960 "Do sonho à realidade". Foto: autora. .159

Figura 57. Sala de exposição do projeto, com a história do HCPA na década de 1970 “Estruturação”. Foto: autora.

Figura 58. Sala de exposição do projeto, com a maquete do HCPA incluindo o projeto de intervenção. Foto: autora. 160

Figura 59. Sala de exposição do projeto, com detalhe para a explicação do projeto. Foto: autora. 160

Figura 60. Painel instalado na circulação para informar usuários sobre a intervenção que ocorrerá no complexo do HCPA. Foto: autora 161

Figura 61. Painel instalado na circulação para informar usuários sobre a intervenção que ocorrerá no complexo do HCPA. Foto: autora. 161

Figura 62. Fases do envolvimento dos usuários ao longo do processo de projeto de intervenção e ampliação do HCPA. Fonte: Elaborada pela autora.

Figura 63. Os usuários observam os instrumentos disponíveis no início do Gaming. Observa-se o tabuleiro com a delimitação do setor UTI, as peças disponíveis representando os ambientes necessários, e o projeto da edificação, com a localização do setor. Fonte: Foto gentilmente cedida pela Kahn do Brasil. .... 168

Figura 64. Gaming com usuários no projeto da UTI da Clínica Baum. Fonte: Foto gentilmente cedida pela Kahn do Brasil. 168

Figura 65. Idem 168 
Figura 66. Usuários co-projetando a UTI da Clínica Baum. Fonte: Foto gentilmente cedida pela Kahn do Brasil. 169

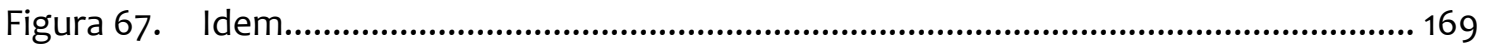

Figura 68. Detalhe do tabuleiro e das peças que compõem o Gaming. Fonte: Foto gentilmente cedida pela Kahn do Brasil. 169

Figura 69. Níveis de envolvimento adotados, em escala crescente de envolvimento, culminando com o co-design. Fonte: Damodaran (1996) e Sanders e Stappers (2008) .178

Figura 70. Estrutura para análise de métodos de envolvimento de usuários em desenvolvimento de produtos. Fonte: Kaulio (1998). 179

Figura 71. Modelo conceitual de processo de projeto com co-design. Fonte: Elaborado pela autora. .183

Figura 72. Fases do pré-desenvolvimento. Fonte: Avaliador 1. 190

Figura 73. Versão final do modelo conceitual de processo de projeto com co-design. Fonte: Elaborado pela autora.

Figura 74. Matriz de poder e interesse para classificação de stakeholders. Fonte: Ackermann e Eden (2011). 200

Figura 75. Nuvem das possíveis necessidades dos usuários. Fonte: Kujala e Kauppinen (2004) 201 

Gráfico 1. Quantidade Geral de Estabelecimentos por Nível de Atenção no Brasil. Período: Mar/2015. Fonte: CNES, Ministério da Saúde. ......................................................60

Gráfico 2. Comparação entre os leitos hospitalares existentes por mil habitantes, segundo região e esfera. Fonte: Ministério da Saúde/SAS - CNES.

Gráfico 3. Impacto e custo das decisões ao longo do processo de projeto de um edifício. Fonte: Watch (2001) ................................................................................................ 77

Gráfico 4. Custo das alterações durante o processo de projeto. Fonte: Tompkins et

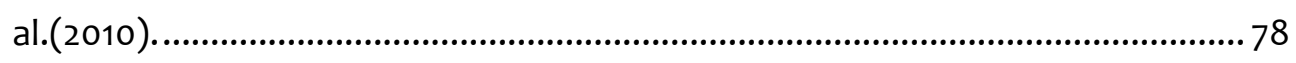

Gráfico 5. Tipos de usuários que as empresas buscam envolver no processo de projeto de edifícios de assistência à saúde, de acordo com os questionários respondidos.

Gráfico 6. Tipo de usuário envolvido com mais frequência no processo de projeto das empresas, de acordo com os questionários respondidos. .134

Gráfico 7. Níveis de envolvimento dos usuários nas alterações de projeto julgadas necessárias pela equipe técnica, de acordo com os questionários respondidos.

Gráfico 8. Nível de envolvimento dos usuários ao longo do processo de projeto de edifícios de assistência à saúde. Fonte: Elaborado pela autora. 180 



\section{LISTA DE QUADROS}

Quadro 1. Comparação das sequências de etapas da DSR propostas por diferentes autores. Fonte: Baseado em Peffers et al. (2006) e Rocha (2011).

Quadro 2. Possíveis resultados da DSR, segundo alguns autores. Fonte: Elaborado pela autora a partir dos textos citados.

Quadro 3. Organização do questionário enviado às empresas para a survey. Fonte: Elaborado pela autora, com base na pesquisa realizada em conjunto a uma iniciação científica. .50

Quadro 4. Fontes de evidência para coleta de dados do EC-1. Fonte: Elaborado pela autora.

Quadro 5. Fontes de evidência para coleta de dados do EC-2. Fonte: Elaborado pela autora.

Quadro 6. Níveis de atendimento à saúde. Fonte: Góes (2004). 59

Quadro 7. O modelo A/S. Fonte: Broadbent (1966 apud BAMFORD, 2002) e Jones (1970 apud BAMFORD, 2002)

Quadro 8. Briefing tradicional e inclusivo. Fonte: Jensen (2011)...........................................76

Quadro 9. Etapas dos projetos de edificações. Fonte: ABNT (1995a; 1995b).........................81

Quadro 10. Plano de Trabalho. Fonte: RIBA. 83

Quadro 11. Etapas de projeto de Estabelecimentos Assistenciais de Saúde, segundo informações da RDC $n^{\circ}$ 50. Fonte: Anvisa (2002).

Quadro 12. Instrumentos para suporte ao projeto de serviços. Fonte: Elaborado pela autora a partir das fontes citadas.

Quadro 13. Comparação das fases do PP propostas por diferentes modelos estudados. Fonte: Elaborado pela autora.

Quadro 14. Diversas dimensões da Participação. Fonte: Baseado em informações de Kirby et al. (2003) e Sinclair (2004)

Quadro 15. Níveis de envolvimento segundo a 'Escada de participação dos cidadãos'. Fonte: Arnstein (1969) 104

Quadro 16. Resumo dos níveis de envolvimento. Fonte: Wilcox (1994). ..............................105

Quadro 17. Níveis de envolvimento. Fonte: Wulz (1986). 107

Quadro 18. Comparação dos níveis de envolvimento em projeto propostos pelos autores citados. Fonte: Elaborado pela autora. 109

Quadro 19. Comparação das definições e termos empregados pelos quatro autores citados para este nível de participação em projeto. Fonte: Elaborado pela autora...... 110 
Quadro 20. Tipos de clientes da construção civil, segundo origem, perfil ou experiência em construção. Fonte: revisão bibliográfica apresentada por De Blois et al. (2011).

Quadro 21. Categoria de usuários de um edifício, considerando exemplos de um serviço de saúde. Fonte: Olsson et al. (2010).

Quadro 22. Comparação entre as classificações dos usuários propostas por Hyett e Jenner e Olsson et al. Fonte: Elaborado pela autora.

Quadro 23. Benefícios do co-design no projeto de serviços. Fonte: Steen et al. (2011).........117

Quadro 24. Categorias de Design Games, com destaque para a categoria abordada no presente trabalho. Fonte: Vaajakallio (2012).

Quadro 25. Instrumentos generativos e seus exemplos. Fonte: Sanders (2000) e Steen et al. (2007). .126

Quadro 26. Níveis de envolvimento adotados neste trabalho. Fonte: Elaborado pela autora. .129

Quadro 27. Principais benefícios do co-design, segundo os autores citados. Fonte: Elaborado pela autora.

Quadro 28. Perfil das Empresas que responderam ao questionário. Fonte: Elaborado pela autora, em conjunto a um trabalho de iniciação científica.

Quadro 29. Atuação do HCPA. Fonte: Dados coletados na página virtual do HCPA http://www.hcpa.ufrgs.br Acesso em 22 mai. 2013

Quadro 30. Composição

do

Anexo

1.

Fonte:

http://www.hcpa.ufrgs.br/expansao/index.php/conheca-o-projeto Acesso em 06 jul. 2015.

Quadro 31. Composição

do

Anexo

2.

Fonte:

http://www.hcpa.ufrgs.br/expansao/index.php/conheca-o-projeto Acesso em 06 jul. 2015. 148

Quadro 32. Método para descrever a cadeia de suprimentos de atenção à saúde do HCPA. Fonte: Gentilmente cedido pelo Superintendente da Bross Consultoria, João Carlos Bross 151

Quadro 33. Comparação do perfil das empresas participantes dos ECs. Fonte: Elaborado pela autora a partir de dados coletados nos ECs. 172

Quadro 34. Organização Provedora de Serviços. Fonte: Olsson et al. (2010). 177

Quadro 35. Descrição das Oficinas de Co-design - Versão inicial. Fonte: Elaborado pela autora. 186 
Quadro 36. Resumo dos instrumentos e métodos indicados. Fonte: Elaborado pela autora. 187

Quadro 37. Estrutura das Revisões de Fases. Fonte: Elaborado pela autora. 188

Quadro 38. Falhas indicadas pelos avaliadores e soluções propostas. Fonte: Elaborado pela autora.

Quadro 39. Representantes dos usuários por unidade funcional. Fonte: Elaborado pela autora.

Quadro 40. Descrição das Oficinas de Co-design - Versão Final. Fonte: Elaborado pela autora.

Quadro 41. Estrutura das Revisões de Fase - Versão Final. Fonte: Elaborado pela autora.203 

Tabela 1. Número de Profissionais de Saúde por mil habitantes. Fonte: OMS...................62 62

Tabela 2. Número de médicos e enfermeiros mil habitantes Brasil e grandes regiões, em 2005. Fonte: Ministério da Saúde/SGTES - Sistema de Informações de Recursos Humanos para o SUS (SIRH) e base demográfica do IBGE (RIPSA, 2008)......... 62

Tabela 3. Profissionais de saúde no Brasil. Fonte: CNES, março de 2015 ............................63

Tabela 4. Leitos hospitalares existentes por mil habitantes, segundo região. Período: 2010. Fonte: Ministério da Saúde/SAS - Cadastro Nacional de Estabelecimentos

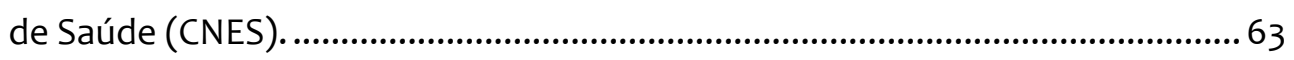

Tabela 5. Estrutura física do HCPA - Dimensionamento atual dos setores. Fonte: http://www.hcpa.ufrgs.br, Acesso em 22 mai. 2013..............................................142

Tabela 6. Número de Leitos do HCPA. Fonte: http://www.hcpa.ufrgs.br, Acesso em 22 mai. 2013 . 



\section{LISTA DE SIGLAS E ABREVIATURAS}

ABDEH

Associação Brasileira para o Desenvolvimento do Edifício Hospitalar

ABNT

Associação Brasileira de Normas Técnicas

ANS

.Agência Nacional de Saúde Suplementar

ANVISA

Agência Nacional de Vigilância Sanitária

AP

Anteprojeto

CAPES

$\mathrm{CR}$

Coordenação de Aperfeiçoamento de Pessoal de Nível Superior

DSR

.Constructive Research

EAS

Design Science Research

EBD

Estabelecimentos Assistenciais de Saúde

EP

Evidence Based Design (Projeto Baseado em Evidência)

HCPA

Estudo Preliminar

OMS

.Hospital de Clínicas de Porto Alegre

Organização Mundial de Saúde

ONU

. Organização das Nações Unidas

PB

Projeto Básico

PBA

..Projeto Básico de Arquitetura

PE

Projeto Executivo

PP

Projeto Participativo

$\mathrm{RDC}$

Resolução da Diretoria Colegiada

RIBA

Royal Institute of British Architects

SBD

Set-Based Design

SUS

Sistema Único de Saúde

$\mathrm{TI}$

.Tecnologia da Informação 

AGRADECIMENTOS

$\begin{array}{ll}\text { RESUMO } & 9\end{array}$

$\begin{array}{ll}\text { ABSTRACT } & 11\end{array}$

LISTA DE FIGURAS

LISTA DE GRÁFICOS

LISTA DE QUADROS

LISTA DE TABELAS

LISTA DE SIGLAS E ABREVIATURAS

$1 \quad$ INTRODUÇÃO

$\begin{array}{lll}1.1 & \text { Problema de Pesquisa } & 36\end{array}$

$\begin{array}{lll}1.2 & \text { JUSTIFICATIVA DA PESQUISA } & 37\end{array}$

1.3 OBJETIVOS DA PESQUISA

1.4 ESTRATÉGIA DE PESQUISA

1.5 ESTRUTURA DA TESE 39

$2 \quad$ MÉTODO DE PESQUISA

2.1 DESIGN SCIENCE RESEARCH

2.1.1 JUSTIFICATIVA DA ESCOLHA DA DSR 44

2.2 DelinEAMENTO DA PESQUISA

$\begin{array}{lll}\text { 2.2.1 } & \text { ETAPA 1: ENTENDIMENTO DO TEMA } \\ 2.2 .2 & 47\end{array}$

2.2.2 ETAPA 2: PROPOSIÇÃO DE UMA SOLUÇÃO 53

2.2.3 ETAPA 3: AVALIAÇÃO DA SOLUÇÃO 54

2.2.4 ETAPA 4: ORGANIZAÇÃO DAS CONTRIBUIÇÕES TEÓRICAS E PRÁtICAS 55

$3 \quad$ PROCESSO DE PROJETO DE EDIFÍCIOS DE ASSISTÊNCIA À SAÚDE 57

3.1 CENÁRIo ATUAL dos EdIFÍCIOS DE ASSISTÊNCIA À SAÚDE $\quad 57$

3.1.1 REDE DE ATENDIMENTO À SAÚDE NO BRASIL 58

3.2 COMPLEXIDADE DO PROJETO DE EdIFÍCIOS DE ASSISTÊNCIA À SAÚDE 64

3.3 PROCESSO de PROJETO $\quad 67$

3.3.1 PRÉ-DESENVOLVIMENTO

$\begin{array}{lll}3.3 .2 & 79\end{array}$ 
3.3.3 PÓS-DESENVOLVIMENTO $\quad 80$

3.3.4 REGULAMENTAÇÕES $\quad 80$

3.3.5 REVISÕES DE FASES $\quad 85$

3.4 Projeto de Serviços de Saúde 85

3.4.1 MODELOS E INSTRUMENTOS DE PROJETOS DE SERVIÇOS

3.5 DisCussão e SÍNTESE CONCLUSIVA 93

4 ENVOLVIMENTO DE USUÁRIOS NO PROCESSO DE PROJETO

\begin{tabular}{lllr} 
4.1 DEFINIÇÕES & & 102 \\
\hline 4.1 .1 & NÍVEIS DE ENVOLVIMENTO DE USUÁRIOS & 104 \\
4.1 .2 & TIPOS DE USUÁRIOS EM PROJETOS DE EDIFÍCIOS & 111
\end{tabular}

\begin{tabular}{lll}
4.2 & CO-DESIGN & 114 \\
\hline 4.2 .1 & JUSTIFICATIVA E BENEFÍCIOS DO CO-DESIGN & 114
\end{tabular}

4.2.2 DESAFIOS DA UTILIZAÇÃO DO CO-DESIGN

4.2.3 SELEÇÃO DE USUÁRIOS PARA CO-DESIGN

$\begin{array}{lll}\text { 4.2.4 METODOLOGIA DO CO-DESIGN } & 120\end{array}$

$\begin{array}{llr}4 \cdot 3 & \text { Discussão e SíNTESE CONCLUSIVA } & 128\end{array}$

$5 \quad$ ESTUDO EXPLORATÓRIO

$\begin{array}{ll}\text { 5.1 } & \text { RESULTADOS } \\ & 132\end{array}$

5.1.1 PRINCIPAIS RAZÕES QUE LEVAM AS EMPRESAS A ENVOLVER USUÁRIOS EM SEUS

PROJETOS 132

5.1.2 ETAPAS DO PROCESSO DE PROJETO EM QUE CONSIDERAM IMPORTANTE O

ENVOLVIMENTO DOS USUÁRIOS

5.1.3 TIPOS DE USUÁRIOS ENVOLVIDOS NO PROCESSO

5.1.4 RELACIONAMENTO COM OS USUÁRIOS 134

5.1.5 NÍVEL DE ACESSO ÀS INFORMAÇÕES REFERENTES AO PROJETO DISPONIBILIZADO PELAS EMPRESAS AOS USUÁRIOS

5.1.6 NÍVEL DE APRENDIZADO DOS USUÁRIOS COM A EXPERIÊNCIA 135

5.1.7 PRINCIPAIS BENEFÍCIOS E DESAFIOS ENFRENTADOS PELAS EMPRESAS NO ENVOLVIMENTO DE USUÁRIOS NO PROCESSO DE PROJETO.

5.1.8 Processo de PROJETO SEM ENVOLVIMENTO DE USUÁRIOS 136

5.2 DISCUSSÃO

6.1 EC-1: Projeto PARA Intervenção e Ampliação do Hospital de Clínicas de Porto AleGre HCPA. 
6.1.1 DESCRIÇÃO DA EMPRESA DE ARQUITETURA RESPONSÁVEL PELO PROJETO DE INTERVENÇÃO - BROSS CONSULTORIA E ARQUITETURA. 139

6.1.2 DESCRIÇÃO GERAL DO HCPA 140

6.1.3 O PROJETO DE INTERVENÇÃO E AMPLIAÇÃO DO HCPA 143

6.1.4 O PROCESSO DE PROJETO DE INTERVENÇÃO E AMPLIAÇÃO DO HCPA 149

6.1.5 ANÁLISE INTRA-CASO - EC-1 162

6.2 EC-2: EnVolvimento de Usuários nos Processos de Projeto da Kahn do Brasil e Projeto PARA CONSTRuÇão da Clínica BaUm, de SANTA Catarina.

6.2.1 DESCRIÇÃO DA KAHN DO BRASIL 166

6.2.2 CO-DESIGN COM USUÁRIOS: PROJETO dA CLÍNICA BAUM, SANTA CATARINA. 167

$\begin{array}{lll}\text { 6.2.3 } & \text { ANÁLISE INTRA-CASO - EC-2 } & 170\end{array}$

\begin{tabular}{clr} 
7.1 DELIMITAÇÃO DOS Focos & 176 \\
\hline 7.1 .1 & FOCO 1: TIPO DE PROJETO & 176 \\
7.1 .2 & FOCO 2: TIPOS DE USUÁRIOS & 177 \\
7.1 .3 & FOCO 3: NÍVEL DE ENVOLVIMENTO & 178
\end{tabular}

7.2 Níveis de Envolvimento X Fases do Processo de Projeto 179

$\begin{array}{llr}7.3 & \text { VERSÃO INICIAL DO MOdELO } & 183\end{array}$

7.3.1 SELEÇÃO DE REPRESENTANTES DOS USUÁRIOS

$\begin{array}{lll}7.3 .2 & \text { PREPARAÇÃO DOS USUÁRIOS } & 185\end{array}$

$\begin{array}{lll}7 \cdot 3 \cdot 3 & \text { OFICINAS DE CO-DESIGN } & 186\end{array}$

$\begin{array}{ll}7 \cdot 3 \cdot 4 & \text { GATES - REVISÕES DE FASES }\end{array}$

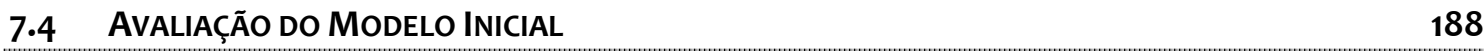

7.4.1 AVALIAÇÃO DO MODELO: RESUlTAdOS 188

7.4.2 AVALIAÇÃO DO MODELO: DISCUSSÃO 194

7.5 VERSÃo FinAL do MOdELO 196

7.5.1 SELEÇÃO dE REPRESENTANTES dOS USUÁRIOS- VERSÃO FINAL DO MODELO 197

7.5.2 DEFINIÇÃO DE METAS NORTEADORAS DO PROJETO 200

7.5.3 OFICINAS DE CO-DESIGN - VERSÃO FINAL 201

7.5.4 GATES - REVISÕES DE FASE - VERSÃO FINAL 203

7.5.5 APRESENTAÇÃo do PROJETO PARA USUÁRIOS 203

8 CONCLUSÕES $\quad 205$

$\begin{array}{llr}\text { 8.1 CONTRIBUIÇÕES DA PESQUISA } & 207\end{array}$

$\begin{array}{lll}8.2 & \text { LIMITAÇÕES DE PESQUISA } & 208\end{array}$

$\begin{array}{lr}\text { 8.3 RECOMENDAÇÕES DE TRABALHOS FUTUROS } & 209\end{array}$ 
ANEXO I. TERMOS E EXPRESSÕES EMPREGADAS NA PESQUISA

ANEXO III. TRANSCRIÇÃO DAS RESPOSTAS DO QUESTIONÁRIO 
A compreensão da atenção à saúde tem evoluído da simples ideia de um corpo livre de doenças para uma noção holística de bem-estar físico e mental. Como consequência desta evolução, observam-se modificações nas edificações de saúde, tanto em forma como em função (GESLER et al., 2004). O projeto de edificações de saúde ${ }^{1}$, tanto para obras novas como para intervenções em edificações existentes, é complexo devido a diversos fatores relacionados à qualidade do espaço físico e a necessidade de melhorar o desempenho na realização das atividades na edificação (TZORTZOPOULOS et al., 2009; CAIXETA; FABRICIO, 2013).

Comprovam-se cada vez mais os efeitos do ambiente físico no bem-estar da equipe interna dos edifícios de assistência à saúde e dos pacientes e suas famílias, assim como os impactos deste espaço no processo de cura dos pacientes (HUISMAN et al., 2012). É crescente também o reconhecimento de que a qualidade na atenção à saúde não pode ser alcançada apenas pelo conhecimento clínico auxiliado por tecnologias e conhecimentos farmacêuticos, pois é necessário ainda entender as atividades de atenção à saúde como serviços (KOSKELA et al., 2012). O alinhamento entre o projeto do edifício e o projeto dos serviços de atendimento à saúde permite o redesenho das atividades de atenção, novos modos de trabalho e ambientes focados nos pacientes, além de contribuir para o aumento da eficiência ${ }^{2}$ operacional na realização dos serviços (TZORTZOPOULOS et al., 2009).

O espaço físico também tem impactos na percepção dos pacientes sobre a qualidade dos serviços prestados. Segundo Fottleret al.(2000), a qualidade da experiência dos pacientes em relação aos serviços de atenção à saúde pode melhorar significativamente se o espaço físico for fácil de usar, limpo e seguro. Estes autores também salientam que propiciar um ambiente de trabalho agradável pode melhorar o desempenho dos empregados, por permitir que estes se concentrem em suas atividades e percebam que a organização de saúde está comprometida com a qualidade e com seu bem-estar.

O ambiente fornece uma primeira impressão da experiência em cuidado à saúde e influencia as expectativas dos clientes mesmo antes do serviço ser

\footnotetext{
${ }^{1}$ As expressões 'edifícios de saúde' e 'edificações de saúde' estão descritas no Anexo I.

${ }^{2}$ Os termos eficiência, eficácia e efetividade estão descritos no Anexo I.
} 
'experienciado'. A avaliação dos clientes sobre o serviço é geralmente baseada na primeira impressão (FOTTLER et al., 2000, p.93).

O modo de executar o projeto arquitetônico, principalmente de estabelecimentos assistenciais à saúde - EAS - é afetado por diversas questões levantadas pela necessidade de garantir funcionalidade à edificação, entre elas a adequação dos espaços ao uso - às atividades realizadas (CARVALHO, 2012). Para orientar os projetos das edificações de saúde, é preciso um amplo conhecimento acerca dos usuários e dos fluxos e atividades que compõem os serviços prestados nestes edifícios. A falta de conhecimento aprofundado sobre os usuários e os serviços pode levar a projetos que não deem suporte aos processos de realização das atividades de atenção à saúde, comprometendo a eficiência operacional da edificação.

Como exemplo da importância deste conhecimento acerca do uso, pode-se citar a evolução do projeto da cama-maca, dos Hospitais da Rede Sarah Kubitschek, de autoria do arquiteto João Filgueiras Lima - Lelé (figura 1). Ao longo de anos em contato com os hospitais e convivência com os usuários, o arquiteto pode aprimorar o projeto inicial da cama-maca, de 1974. A versão de 1997 trazia apenas melhorias relativas a materiais, mas em 2001 Lelé apresentou uma versão aumentando de três para quatro divisões móveis, por concluir que as condições dos pacientes hospitalizados se adequariam melhor a este formato. Além disto, a versão de 2001 possuía luz de cabeceira, para facilitar a leitura. O grande avanço se deu, entretanto, em 2007, quando o arquiteto desenvolveu a última versão da cama-maca com mobilidade vertical motorizada, depois de notar a dificuldade das enfermeiras em transferir pacientes das camas-maca, até então com altura fixa, para a cadeira de rodas. O controle motorizado aumentou ainda a autonomia dos pacientes, que passaram a conseguir se transferir sozinhos para a cadeira. A versão de 2007 foi, portanto, considerada adequada à forma de utilização e aos usuários (informação verbal) ${ }^{3}$.

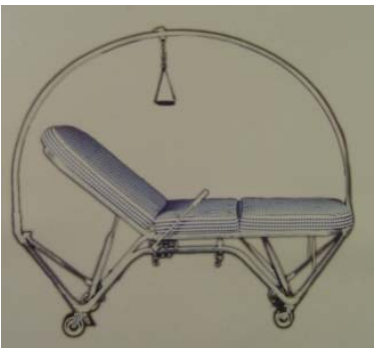

1974

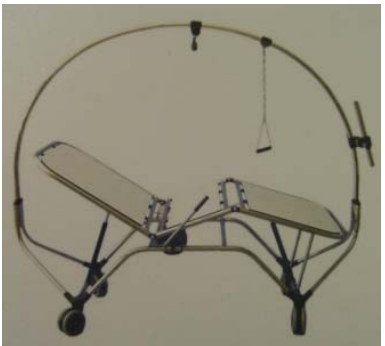

1997

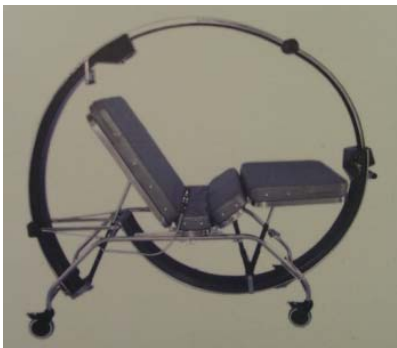

2001

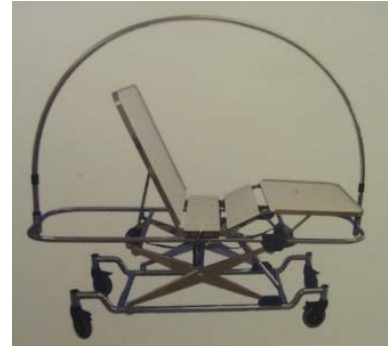

2007

Figura 1. Evolução da cama-maca. Fonte: Acervo do CTRS (2008).

\footnotetext{
${ }^{3}$ Entrevista realizada pela arquiteta DSc. Marieli Azoia Lukiantchuki com o arquiteto João Filgueiras Lima (Lelé), em Salvador, em 25 de novembro de 2011.
} 
[...] um doente com um grau maior ou menor de incapacidade tem muita dificuldade, às vezes em ser transportado da cama para a cadeira, então, por exemplo, (para o) raio $X$ ele ia da cama, que era fixa, para uma maca, da maca ele descia no elevador e ia para o raio $\mathrm{X}$, do raio $\mathrm{X}$ ele passava para a mesa de exames. Com a cama-maca ele simplesmente, a cama-maca leva ele até lá, ele só tem uma transferência. E agora tem uma cama-maca nova, que a gente está testando no Rio que ela abaixa e permite ficar na altura da cadeira, porque isso era um problema, a diferença de altura para a transferência do doente (informação verbal) ${ }^{4}$.

Apesar de sua importância, os projetistas raramente possuem estes conhecimentos acerca dos usuários e serviços em EASs, principalmente devido às grandes variações que ocorrem neste tipo de edificação. 0 envolvimento efetivo dos usuários no processo de projeto de edifícios de assistência à saúde pode ser um meio de ajudar os projetistas a conhecer o perfil e as necessidades dos usuários em cada contexto específico de projeto, e a entender os serviços. Isto pode contribuir para o aumento da eficiência na prestação de serviços e da satisfação dos usuários com a edificação final. Diversos autores defendem que abordagens de envolvimento dos usuários, como 'especialistas de suas experiências' (SLEESWIJK VISSER et al. 2005), podem alinhar adequadamente o projeto e as necessidades e preferências tanto dos usuários atuais como de usuários potenciais, e garantir desempenho de alta qualidade para as atividades na edificação (STERN et al., 2003; STEEN, KUIJT-EVERS; KLOK, 2007; SFANDYARIFARD; TZORTZOPOULOS, 2011; ANDRADE et al., 2012).

Um entendimento adequado do que representa valor para os usuários propicia não somente sua satisfação, mas também evita numerosas alterações de projeto durante o processo, que trazem frustração para os projetistas e custos adicionais ao processo (THYSSEN et al., 2010). Além disto, o envolvimento dos usuários contribui para justificar e legitimar decisões, podendo evitar divergências em relação aos resultados do projeto (OLSSON; BLAKSTAD; HANSEN, 2010).

\footnotetext{
${ }^{4}$ Entrevista realizada pela arquiteta DSc. Marieli Azoia Lukiantchuki com o Dr. Aloysio Campos da Paz Junior, no dia 25 de junho de 2009. Texto transcrito e gentilmente cedido também pela arquiteta DSc. Marieli Azoia Lukiantchuki.
} 
No Brasil, muito se divulga o déficit de serviços de atenção à saúde, principalmente na esfera pública, tanto em relação a espaço físico e leitos de internação, quanto a número de profissionais de saúde disponíveis - ver, por exemplo, Conselho Federal de Medicina (2011), Fagundes (2013), Amora (2014), Britto (2015), Costa (2015) e Perrin (2015). Neste contexto, e dada a complexidade dos edifícios de assistência à saúde, a literatura sugere que o envolvimento dos usuários no processo de projeto possa contribuir para o redesenho das atividades de atenção à saúde e assim possibilitar que os arquitetos alinhem o projeto do espaço físico com o projeto dos serviços. Desta forma, pode-se alcançar maior eficiência na operação destes edifícios, aumentando a oferta e a qualidade do atendimento à população.

No entanto, envolver usuários efetivamente no processo de projeto exige mais esforços do arquiteto, tanto em termos de coordenação, pelo maior número de pessoas e habilidades envolvidas (HOYER et al., 2010; STEEN; MANSCHOT; DE KONING, 2011), quanto em termos da linguagem utilizada, para permitir que os usuários, leigos em linguagem arquitetônica, possam compreender e participar das discussões (MALARD et al., 2002). Existem ainda outras dificuldades na promoção do envolvimento de usuários, como motivar os usuários a participar (WAGNER; PICCOLI, 2007; IEDEMA et al., 2010; GARDE; VAN DER VOORT, 2012) e prepara-los para isto (REICH et al., 1996; SVETOFT, 2006; TZORTZOPOULOS et al., 2006).

O problema de pesquisa reside, portanto, na falta de amparo e dificuldades de envolver os usuários no processo de projeto de EAS, como perspectiva para trazer os conhecimentos relativos à utilização da edificação ao projeto, e assim aumentar a adequação entre edifício e uso, atingindo maior eficiência operacional.

A presente pesquisa parte da identificação de um problema, para o qual buscará uma proposição inovadora de solução, pretendendo-se contribuir com a prática profissional da arquitetura e sua teoria. Neste contexto, a Design Science Research - DSR - desponta como abordagem apropriada para a pesquisa, por ter como fundamento a resolução de problemas enfrentados no mundo real, através de construções inovadoras, e, por fim, a contribuição com a teoria da área em questão (LUKKA, 2003). 
A ONU, intermediada pela OMS, "conceituou saúde como um direito humano fundamental, consecução do mais alto nível de vida possível” (GÓES, 2004, p. XI). Os edifícios de assistência à saúde, especificamente os hospitais, são os componentes principais do sistema de atenção à saúde em países como o Brasil, de renda baixa e média. São ainda os mais onerosos, sendo a referência de todo o sistema de saúde e foco da capacitação profissional na área (LA FORGIA; COUTTOLENC, 2009). No entanto, é notória a deficiência nos serviços de atenção à saúde no Brasil, principalmente na esfera pública, tanto em relação ao número de profissionais como em disponibilidade de espaço físico ${ }^{5}$. Portanto, a busca por eficiência operacional nas edificações disponíveis torna-se de grande importância.

Por outro lado, alia-se às questões colocadas o direito dos usuários de "ter uma influência direta sobre assuntos que Ihes digam respeito", enfatizado por Clement e Van Den Besselaar (1993, p.36). A importância das pesquisas sobre o envolvimento de usuários no processo de projeto de arquitetura precisa ser ressaltada. A literatura é abrangente em envolvimento dos usuários em áreas como políticas públicas e tecnologia da informação, mas ainda há muito que se pesquisar sobre este assunto em projetos arquitetônicos, porque neste caso, como aponta Malard et al. (2002, p.248) as decisões compartilhadas envolvem soluções técnicas e não apenas processos decisórios, o que faz da participação "uma questão teórica a ser enfrentada".

Diante do exposto, faz-se necessário buscar meios de auxiliar os arquitetos a viabilizar o envolvimento efetivo dos usuários no processo de projeto, detalhando as fases deste processo em que o envolvimento pode trazer benefícios e fornecendo instrumentos adequados para a prática. A presente pesquisa, portanto, demonstra seu valor por abordar o envolvimento dos usuários, nos âmbitos teórico e prático, esclarecendo as questões tais como definições, níveis de envolvimento, tipos de usuários e benefícios e dificuldades inerentes a esta abordagem. Além disto, propõe como solução um modelo de envolvimento dos usuários no processo de projeto de edifícios de assistência à saúde, para orientar os arquitetos ao longo do processo.

\footnotetext{
${ }^{5}$ Este tópico será detalhado na seção 3.1 .1
} 


\subsection{OBJetivos da PESQUISA}

A presente pesquisa busca uma proposição inovadora, voltada ao aspecto organizacional do processo de projeto, para projetar edifícios de assistência à saúde cujas configurações espaciais auxiliem a realização das atividades, aumentando a eficiência operacional dos serviços de saúde. Para tanto, vale-se da potencialidade que envolvimento dos usuários no processo tem em contribuir para o alinhamento entre edificação e serviços.

Como objetivos específicos, tem-se:

1. Entender as questões relacionadas ao envolvimento dos usuários - quais são os tipos de usuários em edifícios de assistência à saúde, quais os benefícios e dificuldades da prática do envolvimento - e ao processo de projeto - quais são as fases do processo de projeto em edifícios de assistência à saúde e em quais delas o envolvimento pode gerar benefícios;

2. Entender os diversos níveis de envolvimento dos usuários, delimitando seus significados com base na literatura;

3. Delimitar os focos para os quais o modelo se destinará;

4. Levantar e estudar métodos e instrumentos que auxiliem o envolvimento dos usuários, de acordo com os focos delimitados, para compor o modelo;

5. Propor um modelo que auxilie os projetistas a envolver os usuários no processo de projeto de edifícios de assistência à saúde, de acordo com os focos delimitados;

6. Avaliar o modelo proposto, com o auxílio de pesquisadores e projetistas com experiência em projetos de edifícios de assistência à saúde.

\subsection{ESTRATÉGIA DE PESQUISA}

Partindo da identificação do problema de pesquisa e dos objetivos geral e específicos, a pesquisa aqui proposta utilizou a abordagem Design Science Research, para permitir não só o estudo do tema, mas também a proposição de solução. Foi estruturada em quatro etapas, visando a atender aos objetivos específicos e, por fim, atender ao objetivo geral de apresentar uma tentativa de solução para o problema identificado.

Resumidamente, a etapa 1 buscou entender os temas relacionados à pesquisa, ou seja, as questões relativas ao processo de projeto de edifícios de assistência à saúde e ao 
envolvimento dos usuários neste processo. Este entendimento teve como finalidade atender aos objetivos específicos 1, 2, 3 e 4 . Os métodos utilizados foram revisão bibliográfica e pesquisas de campo - estudo exploratório e estudos de caso - para contemplar os temas pesquisados nos âmbitos teórico e prático.

Com base nos resultados da etapa 1 , a etapa 2 consistiu em propor uma solução para o problema identificado. Esta solução é um modelo para auxiliar os arquitetos a envolver os usuários no processo de projeto, de forma a trazer o conhecimento sobre a realização dos serviços para o processo de projeto de maneira mais efetiva, e assim melhorar o alinhamento entre projeto do espaço físico e projeto dos serviços.

$\mathrm{Na}$ etapa 3, foram realizados os testes desta solução na prática. Diante da impossibilidade de testar o modelo num projeto real - pela indisponibilidade de um processo de projeto do tipo se iniciando num momento oportuno que permitisse o emprego do modelo - foi solicitada a avaliação do modelo a profissionais e pesquisadores acadêmicos atuantes na área. As avaliações foram discutidas e as contribuições foram agregadas ao modelo, dando origem à sua versão final.

Por fim, na etapa 4 as contribuições teóricas e práticas foram organizadas, tendo como resultado final a tese de doutorado. A figura 2 apresenta uma visão geral das quatro etapas de pesquisa, que se seguem após a identificação do problema, pela abordagem DSR. A descrição completa da abordagem, a justificativa de sua escolha e o detalhamento dos métodos utilizados encontram-se no Capítulo 2, Método de Pesquisa.

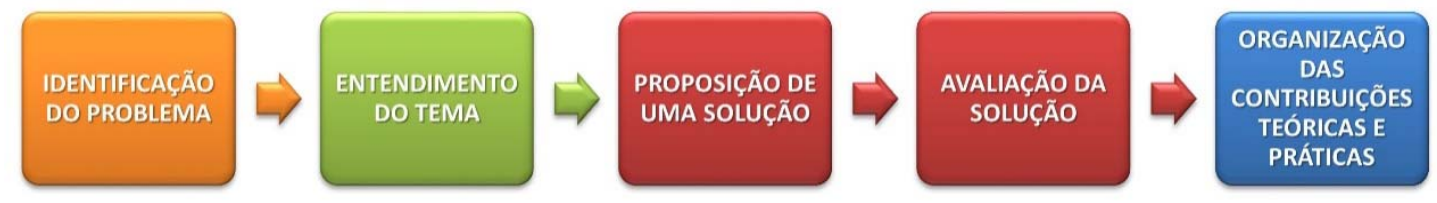

Figura 2. Etapas de desenvolvimento da pesquisa, pela abordagem Design Science Research. Fonte: Elaborada pela autora.

\subsection{EStRUTURA DA TESE}

A presente Tese está dividida em nove capítulos. O Capítulo 1 traz a introdução ao trabalho, onde se apresentam brevemente os temas envolvidos, o problema e a justificativa da pesquisa, os objetivos gerais e específicos e a estratégia de pesquisa.

O Capítulo 2 apresenta e descreve a abordagem e os métodos de pesquisa, para atender a cada um dos objetivos específicos, e por fim, ao objetivo geral da pesquisa. 
Os Capítulos 3 e 4 trazem a fundamentação teórica. O primeiro aborda o tema 'Processo de Projeto de Edifícios de Assistência à Saúde', e é um resumo das principais questões deste processo, para dar base ao tema central da pesquisa, que é o 'Envolvimento de Usuários no Processo de Projeto', abordado no capítulo 4. Neste capítulo, apresenta-se um estudo sobre os níveis de envolvimento elencados por diversos autores na literatura e os tipos de usuários em processo de projeto. Foca-se então, a partir da seção 4.2, no Co-design, abordando-se sua justificativa e benefícios, os desafios de sua aplicação, as questões referentes à seleção de usuários para participar e a metodologia proposta na literatura.

Os Capítulos 5 e 6 apresentam os resultados das pesquisas de campo. O Capítulo 5 traz os resultados do estudo exploratório e a discussão destes. O Capítulo 6 aborda os resultados dos dois estudos de caso, com as análises intra-caso e uma discussão sobre os dois casos.

No Capítulo 7, aborda-se a delimitação dos focos do modelo, para tipo de projeto, tipo de usuários e nível de envolvimento, além da proposta de nível de envolvimento adequado para cada fase do processo de projeto. Apresenta-se então o modelo de envolvimento dos usuários em processos de projeto de edifícios de assistência à saúde em sua versão inicial, seguido de sua descrição, avaliação e versão final.

Por fim, o Capítulo 8 conclui o trabalho, retomando os objetivos e apresentando como foram atingidos, e apontando as limitações da pesquisa e sugestões para pesquisas futuras.

O Capítulo 9 apresenta as referências bibliográficas da Tese.

Na sequência, os Anexos trazem o questionário utilizado no estudo exploratório, a transcrição da primeira entrevista do EC-1, o questionário utilizado para avaliação do modelo e as duas avaliações obtidas por escrito. 
Este capítulo apresenta o método utilizado para desenvolvimento desta pesquisa, com o embasamento teórico para justificar sua escolha. A abordagem central, a Design Science Research, é detalhada em etapas, apresentando os métodos auxiliares utilizados ao longo da pesquisa, como Estudo de Caso, que viabilizaram o entendimento da prática do envolvimento do usuário em projetos de edifícios de assistência à saúde, para dar suporte à produção do modelo.

\subsection{Design SCIENCE ResearCh}

De um modo geral, é possível definir 'Pesquisa' como "uma atividade que contribui para a compreensão de um fenômeno" (VAISHNAVI; KUECHLER, 2007, p.7). Pode-se dizer que as ciências naturais consistem basicamente em duas atividades: descoberta e justificativa, com o objetivo de entender a realidade. Neste contexto, enquadra-se a pesquisa tradicional nos campos biológicos, sociais, comportamentais e físicos (MARCH; SMITH, 1995).

No entanto, apenas compreender um problema não é suficiente para sua solução, é também necessário desenvolver e testar possíveis maneiras de resolvê-lo (VAN AKEN, 2004). Diferente das ciências naturais, que tentam compreender a realidade, e que são, portanto, descritivas, tem-se a Design Science, que busca a criação de artefatos para atender a propósitos humanos (MARCH; SMITH, 1995), e são prescritivas. Neste contexto, a Design Science Research (DSR) ou Constructive Research define-se como uma abordagem de pesquisa que objetiva resolver problemas enfrentados no mundo real, por meio de construções inovadoras, e, por fim, contribuir com a teoria da área (LUKKA, 2003). Como construções, o autor define todos os artefatos humanos, por exemplo, diagramas, modelos, planos, estruturas organizacionais, produtos comerciais, que não são descobertos, e sim inventados ou desenvolvidos. Outras características desta abordagem são a necessidade de aplicar e testar pelo menos parte do artefato na prática; a demanda por cooperação entre pesquisadores e pessoas que atuam na prática; o desenvolvimento do artefato a partir do conhecimento teórico existente; e o compromisso de incrementar tal teoria com os resultados obtidos 
(LUKKA, 2003). Venable (2006, p.1) define a DSR como "uma atividade inventiva e criativa de resolução de problemas, em que as novas tecnologias são os principais produtos".

No âmbito da economia e gestão da construção, diferentes disciplinas científicas contribuem para a geração do conhecimento, cujo objetivo final é conceber soluções para os problemas complexos e relevantes, que estão ligados ao contexto de projeto, produção e operação do ambiente construído. Portanto, além de uma ciência explanatória, a pesquisa em gestão da construção se enquadra na DSR (VOORDIJK, 2009).

É importante diferenciar a DSR do desenvolvimento ordinário de produtos ou projetos. Segundo Hevner et al. (2004, p.81), "a diferença está na natureza dos problemas e soluções". Em projetos ordinários, aplicam-se conhecimentos existentes para a solução de problemas, enquanto na DSR buscam-se soluções únicas ou inovadoras para problemas importantes, ou meios mais efetivos e eficientes para resolvê-los. Os autores afirmam que a clara identificação de contribuição teórica constitui a diferença chave entre projetos ordinários e a DSR.

Diversos autores discorrem sobre o processo de realização da DSR. March e Smith (1995) apresentam uma visão geral do processo baseada nas etapas de construir e avaliar a solução. Outros autores apresentam visões detalhadas em um maior número de etapas, iniciando na identificação do problema até a avaliação das soluções propostas (ROOKE, 2012). Apesar de ser crescente o interesse pelo método da DSR em pesquisas em área como sistemas de informação, seu atual estado da arte ainda não oferece uma estruturação consistente em etapas para orientar as escolhas das técnicas pelos pesquisadores (OSTROWSKI; HELFERT; GAMA, 2013). O Quadro 1 apresenta uma comparação entre diferentes proposições, baseado no trabalho de Peffers et al. (2006) e Rocha (2011). Neste quadro, as colunas indicam a sequência proposta pelo autor indicado. As etapas colocadas na mesma linha são semelhantes entre si.

Como possíveis resultados da DSR, March e Smith (1995, p.256-258) identificam quatro artefatos:

- Constructos, que são "uma conceituação utilizada para descrever os problemas dentro do domínio e para especificar as suas soluções";

- Modelos, que constituem "um conjunto de proposições ou declarações que expressam as relações entre os constructos";

- Métodos, definidos como "um conjunto de passos utilizados para executar uma tarefa"; 
- E instanciações, que são "a realização de um artefato em seu ambiente", a operacionalização de constructos, modelos e métodos.

Quadro 1. Comparação das sequências de etapas da DSR propostas por diferentes autores. Fonte: Baseado em Peffers et al. (2006) e Rocha (2011).

\begin{tabular}{|c|c|c|c|c|c|}
\hline Autor & $\begin{array}{c}\text { Kasanen, Lukka e } \\
\text { Siitonen (1993) }\end{array}$ & $\begin{array}{l}\text { March e Smith } \\
\text { (1995) }\end{array}$ & Lukka (2003) & $\begin{array}{l}\text { Hevner et al. } \\
\qquad(2004)\end{array}$ & $\begin{array}{c}\text { Vaishnavi e } \\
\text { Kuechler (2007) }\end{array}$ \\
\hline \multirow{12}{*}{ 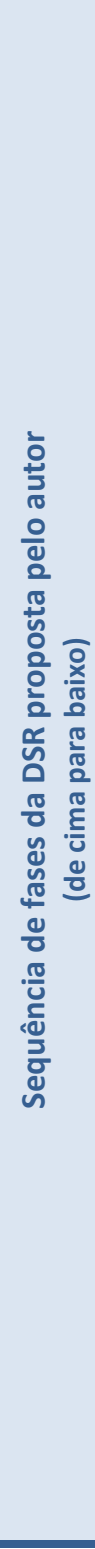 } & $\begin{array}{l}\text { 1. Encontrar um } \\
\text { problema relevante } \\
\text { na prática e com } \\
\text { potencial de } \\
\text { pesquisa }\end{array}$ & & $\begin{array}{l}\text { 1. Encontrar um } \\
\text { problema relevante } \\
\text { na prática, com } \\
\text { potencial de } \\
\text { contribuição teórica }\end{array}$ & $\begin{array}{l}\text { 1. Identificar } \\
\text { problemas } \\
\text { importantes e } \\
\text { relevantes }\end{array}$ & $\begin{array}{l}\text { 1. Consciência do } \\
\text { problema }\end{array}$ \\
\hline & & & $\begin{array}{c}\text { 2. Examinar junto às } \\
\text { organizações-alvo, o } \\
\text { potencial de longa } \\
\text { colaboração de } \\
\text { pesquisa }\end{array}$ & & \\
\hline & 2. Entender o tema & & $\begin{array}{c}\text { 3. Obter uma } \\
\text { compreensão prática } \\
\text { e teórica } \\
\text { aprofundada na área } \\
\text { do tema }\end{array}$ & & \\
\hline & $\begin{array}{l}\text { 3. Construir uma } \\
\text { solução inovadora }\end{array}$ & $\begin{array}{l}\text { 1. Criar coisas que } \\
\text { sirvam a propósitos } \\
\text { humanos }\end{array}$ & $\begin{array}{c}\text { 4. Propor e } \\
\text { desenvolver uma } \\
\text { solução inovadora }\end{array}$ & & $\begin{array}{l}\text { 2. Sugestão de um } \\
\text { projeto preliminar }\end{array}$ \\
\hline & & & & $\begin{array}{l}\text { 2. Desenvolvimento } \\
\text { do artefato }\end{array}$ & $\begin{array}{l}\text { 3. Desenvolvimento } \\
\text { e implantação do } \\
\text { projeto preliminar }\end{array}$ \\
\hline & $\begin{array}{l}\text { 4. Demonstrar que a } \\
\text { solução funciona }\end{array}$ & & $\begin{array}{l}\text { 5. Aplicar a solução e } \\
\text { testar como } \\
\text { funciona }\end{array}$ & & \\
\hline & & & $\begin{array}{c}\text { 6. Ponderar o escopo } \\
\text { de aplicabilidade da } \\
\text { solução }\end{array}$ & & \\
\hline & & $\begin{array}{c}\text { 2. Avaliar o } \\
\text { desempenho das } \\
\text { coisas durante o uso }\end{array}$ & & \multirow[t]{3}{*}{ 3. Avaliação } & \multirow{3}{*}{$\begin{array}{l}\text { 4. Avaliação do } \\
\text { projeto com os } \\
\text { critérios } \\
\text { previamente } \\
\text { definidos }\end{array}$} \\
\hline & $\begin{array}{l}\text { 5. Apresentar sua } \\
\text { ligação com a teoria } \\
\text { e a contribuição da } \\
\text { pesquisa }\end{array}$ & & $\begin{array}{c}\text { 7. Identificar e } \\
\text { analisar a } \\
\text { contribuição teórica }\end{array}$ & & \\
\hline & \multirow[t]{3}{*}{$\begin{array}{l}\text { 6. Avaliar o escopo } \\
\text { de aplicação da } \\
\text { solução }\end{array}$} & & & & \\
\hline & & & & & 5. Conclusão \\
\hline & & & & 4. Comunicação & \\
\hline
\end{tabular}

Vaishnavi e Kuechler (2007) acrescentam um possível resultado aos colocados por March e Smith, que consiste na produção de melhores teorias. Segundo os autores, a DSR pode contribuir para melhores teorias, por exemplo, porque se pode teorizar a metodologia de construção do artefato. 
Van Aken (2004) apresenta como resultado da DSR a regra tecnológica, que, num determinado campo de aplicação, liga um artefato com um resultado ou desempenho desejado, e se constitui numa parte do conhecimento geral.

Voordijk (2009, p.718) apresenta três tipos de conceitos de solução, no tangente às pesquisas em gestão e economia da construção: regras tecnológicas, que se baseiam em análise de dados estatísticos e são generalizações empíricas; regras funcionais, que são conceitos para especificar procedimentos para, em dadas circunstâncias, atingir determinados resultados; e entendimentos sócio-tecnológicos, que são "conhecimentos na inter-relação entre os processos de construção e prática social". O quadro 2 resume os possíveis resultados da DSR, de acordo com os autores citados.

Quadro 2. Possíveis resultados da DSR, segundo alguns autores. Fonte: Elaborado pela autora a partir dos textos citados.

\begin{tabular}{|c|c|c|c|c|}
\hline AUTOR & $\begin{array}{c}\text { March e Smith } \\
\text { (1995) }\end{array}$ & $\begin{array}{c}\text { Vaishnavi e } \\
\text { Kuechler (2007) }\end{array}$ & Van Aken (2004) & Voordijk (2009) \\
\hline $\begin{array}{l}\text { POSSÍVEIS } \\
\text { RESULTADOS } \\
\text { DA DSR }\end{array}$ & $\begin{array}{l}\text { Constructos; } \\
\text { Modelos; } \\
\text { Métodos; } \\
\text { Instanciações. }\end{array}$ & $\begin{array}{l}\text { Quatro artefatos de } \\
\text { March e Smith; } \\
\text { Teorias melhores. }\end{array}$ & $\begin{array}{l}\text { Regras } \\
\text { tecnológicas. }\end{array}$ & $\begin{array}{l}\text { Leis de tecnologia; } \\
\text { Regras funcionais; } \\
\text { Entendimento } \\
\text { sócio-tecnológico. }\end{array}$ \\
\hline
\end{tabular}

No que tange às contribuições, Hevner et al. (2004) destaca três áreas que devem ser claramente beneficiadas por uma DSR efetiva:

- Do artefato projetado, que muitas vezes é a própria contribuição da DSR, e pode ampliar a base de conhecimento e ou utilizar modos novos e inovadores para aplicar os conhecimentos existentes.

- Dos fundamentos da DSR: que podem ser ampliados ou melhorados pelo desenvolvimento criativo de artefatos novos e avaliados apropriadamente.

- E/ou de metodologia (da DSR na área), pelo uso e desenvolvimento criativo de métodos de medições e novas métricas de avaliação.

\subsubsection{Justificativa da escolha da DSR}

Como o presente trabalho parte da identificação de um problema real, para o qual busca uma proposição inovadora, a pesquisa meramente descritiva parece útil apenas para o 
entendimento da atual situação da prática de projetos de edifícios de assistência à saúde, abordando os atuais processos com envolvimento de usuários e seus resultados. No entanto, para atingir o objetivo central desta pesquisa, foi preciso buscar uma abordagem que permitisse propor soluções e testá-las na prática, e então contribuir com a teoria existente para esta área. Isto justificou a opção pela Design Science Research.

Ao contrário da maior parte das abordagens de pesquisa acadêmicas, que buscam o acúmulo de conhecimento teórico, a DSR tem como propósito o entendimento e resolução de problemas. Neste sentido, colabora para o estreitamento de relações entre a teoria acadêmica e a prática, pois ambos os interesses muitas vezes parecem não coincidir (HOLMSTRÖM; KETOKIVI; HAMERI, 2009). Para estes autores, permanece ilusório o objetivo de fazer pesquisa acadêmica relevante para a prática, apesar do empenho em vários campos de pesquisa, ao longo de décadas.

Embora seja uma abordagem recente (JÄRVINEN, 2007), a DSR tem sido utilizada em diversas pesquisas nas áreas de sistemas e tecnologia da informação e gerenciamento de operações, clínica médica, finanças, entre outros, principalmente na Europa (WINTER, 2008; OYEGOKE, 2011). Exemplos de utilização deste método em teses nas áreas de arquitetura e engenharia são os seguintes:

- Rocha (2011), que utiliza a DSR no estudo de soluções para a customização em massa da produção habitacional, e tem como resultado um modelo conceitual para a definição das estratégias de customização;

- Rooke (2012), cujo trabalho foca em proporcionar estratégias de orientação espacial em hospitais antigos, com sistemas longos e confusos de corredores, através da DSR;

- Schramm (2009), que estuda a utilização de simulação computacional na construção civil como ferramenta de apoio à tomada de decisão nos projetos de sistemas de produção, e tem como abordagem de pesquisa a DSR.

- Hanid (2014), que estuda a potencialidade de se abordar a DSR para desenvolvimento de soluções conceituais na construção, focando a melhoria no gerenciamento dos custos.

- Souza (2015), cuja pesquisa, que tem como abordagem a DSR, propõe boas práticas e uma estrutura conceitual para o projeto das cadeias de suprimento na construção civil. 
Além de atender ao objetivo central da pesquisa aqui proposta, a utilização de uma abordagem inovadora como a DSR proporciona o aprofundamento e disseminação dos conhecimentos da abordagem em si, e desta forma pode trazer contribuições metodológicas para a pesquisa acadêmica no país.

\subsection{DELINEAMENTO DA PESQUISA}

Segundo Hevner (2007), para que uma pesquisa em Design Science seja bem conduzida é necessário que se inicie pela identificação do problema num ambiente de aplicação real. A partir da delimitação do problema de pesquisa e do objetivo geral, já descritos, a presente pesquisa foi estruturada em quatro etapas, visando a atender aos seis objetivos específicos propostos, e assim atender ao objetivo geral de solução do problema identificado. A quarta etapa se destina à organização das contribuições e redação da tese (figura 3). Esta divisão em etapas foi baseada nas diretrizes da DSR pesquisadas na literatura.

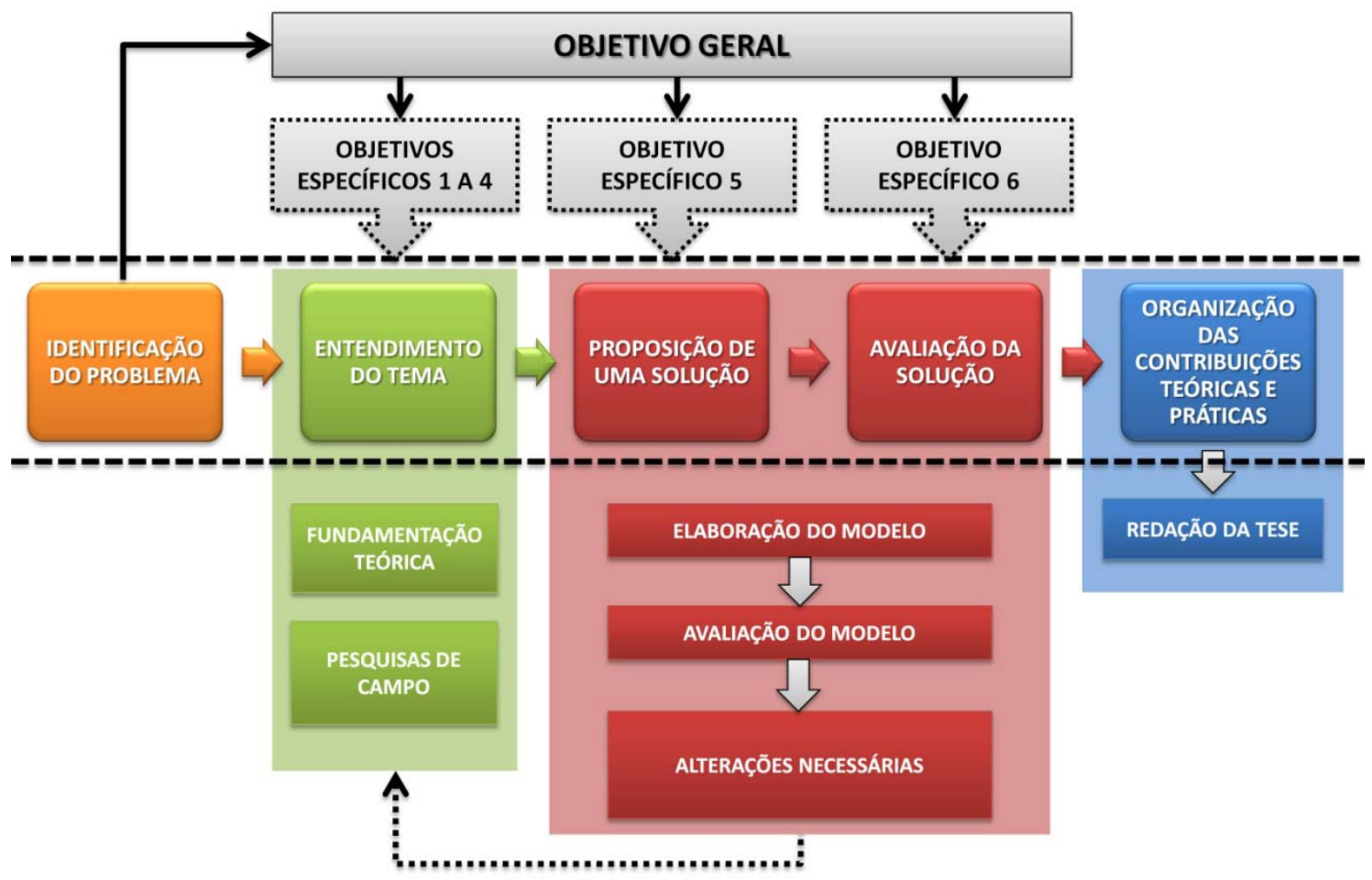

Figura 3. Delineamento da pesquisa, pela abordagem DSR. Fonte: Elaborada pela autora.

A primeira etapa foi direcionada a atender aos objetivos específicos $1,2,3$ e 4, que consistiram em entender as questões relacionadas ao envolvimento dos usuários no processo de projeto de edifícios de assistência à saúde, delimitar os focos do modelo: a que tipo de usuário se 
destinaria, que fases do processo de projeto seriam contempladas, que nível de envolvimento seria considerado adequado, bem como estudar instrumentos que dessem suporte a esta prática. Para tanto, foi estruturada em fundamentação teórica e pesquisas de campo, para investigar as questões relativas ao envolvimento tanto do ponto de vista teórico como prático.

Os conhecimentos obtidos nesta etapa foram a base para o desenvolvimento da etapa seguinte: proposição de uma solução, que buscou atender ao quinto objetivo específico: propor um modelo que auxiliasse os projetistas a envolver os usuários no processo de projeto de edifícios de assistência à saúde. Esta etapa, na verdade, ocorreu em parte concomitantemente à etapa anterior, para poder esclarecer as dúvidas que surgiram durante o desenvolvimento do modelo, através das pesquisas bibliográficas e de campo.

A terceira etapa da pesquisa consistiu em avaliar o modelo, atendendo ao sexto objetivo específico proposto. O modelo foi então aprimorado e apresentado em sua versão final.

Por fim, a última etapa consistiu na compilação e avaliação geral dos dados obtidos, organização das contribuições teóricas e práticas e redação da tese.

\subsubsection{ETAPA 1: Entendimento do Tema}

Esta etapa buscou entender as questões relacionadas ao envolvimento dos usuários no processo de projeto de edifícios de assistência à saúde, tanto do ponto de vista teórico como prático, e foi estruturada em fundamentação teórica e pesquisas de campo.

\subsubsection{Fundamentação teórica}

A revisão bibliográfica foi realizada selecionando palavras-chave relacionadas ao tema de pesquisa para levantamento em livros e artigos em anais de congressos e periódicos nacionais e internacionais, em bases de dados como Dedalus ${ }^{6}$ (Biblioteca da USP), Web of Knowledge ${ }^{7}$, Scopus $^{8}$, InfoHAB ${ }^{9}$ e Google Acadêmico ${ }^{10}$. Os textos levantados foram selecionados, lidos e em

\footnotetext{
6http://dedalus.usp.br:4500/ALEPH/por/usp/usp/dedalus/start

${ }^{7}$ http://apps.webofknowledge.com/

${ }^{8}$ http://www.scopus.com

${ }^{9}$ http://www.infohab.org.br

${ }^{10} \mathrm{http} / / /$ scholar.google.com.br
} 
sua maioria fichados, com o objetivo de sistematizar as informações e facilitar sua utilização no trabalho. A legislação pertinente à área de projetos arquitetônicos para edificações assistenciais à saúde, principalmente através da página da Agência Nacional de Vigilância Sanitária - ANVISA ${ }^{11}$, também foi estudada.

Ressalta-se que o levantamento e a revisão bibliográfica também ocorreram durante todo o desenvolvimento da pesquisa, tendo sido realizado no princípio para se delinear o estado da arte do tema em questão e permitir a preparação da pesquisa de campo, mas continuou no decorrer do trabalho, para suprir deficiências encontradas.

\subsubsection{Pesquisas de Campo}

Com o intuito de entender as questões relacionadas ao envolvimento dos usuários na prática tipos de usuário, níveis de envolvimento e benefícios e dificuldades da prática do envolvimento, relacionados com as fases do processo de projeto - foram propostos um estudo exploratório e estudos de caso. A estudo exploratório teve como objetivo mapear o contexto brasileiro em relação à prática do envolvimento dos usuários por empresas de arquitetura, enquanto os estudos de caso buscaram aprofundar o entendimento e detalhar as questões relativas ao envolvimento a partir de alguns exemplos. Foi ainda realizada uma visita à School of Built Environment, da Universidade de Salford e ao HaCIRIC ${ }^{12}$, na Inglaterra, para aprofundar conhecimentos sobre os temas relativos ao presente estudo e métodos de pesquisa científica.

\section{a) Estudo exploratório}

Este estudo teve como objetivo levantar um panorama geral sobre como e quanto, na prática, as empresas de arquitetura brasileiras envolvem o usuário no processo de projeto de edifícios de assistência à saúde. Foi estruturado como pesquisa survey, que é um método quantitativo que tem o propósito de incrementar o conhecimento científico através do estudo de dados ou

\footnotetext{
${ }^{11}$ http://www.anvisa.gov.br

${ }^{12}$ Com suporte financeiro do Engineering and Physical Sciences Research Council (EPSRC), o HaCIRIC (The Health and Care Infrastructure Research and Innovation Centre) é um centro de pesquisa em infraestrutura de serviços de saúde, onde colaboram o Imperial College London e as Universidades de Loughborough, Reading e Salford, além de parcerias adicionais, em projetos específicos, com outras universidades, a indústria e o sistema de saúde da Inglaterra (NHS). O centro se vale do conhecimento de instituições de pesquisa de ponta, num programa integrado para entender as relações entre a infraestrutura física, a tecnologia e os serviços necessários para prestação de serviços de saúde com alta qualidade e eficiência.
} 
características de uma determinada população (PINSONNEAULT; KRAEMER, 1993; FREITAS et al., 2000). Possui três características distintas (PINSONNEAULT; KRAEMER, 1993):

- Visa à produção de descrições quantitativas, focadas em determinados aspectos da população estudada;

- Utiliza questões pré-definidas e estruturadas como principal ferramenta para coleta de dados;

- Utiliza apenas uma amostra da população para coleta de dados, que deve ser suficiente para generalização dos resultados.

O estudo foi conduzido em parceria com uma pesquisa de iniciação científica ${ }^{13}$. Para elaboração do questionário, foram elencadas primeiramente as questões sobre envolvimento de usuários que estruturariam o questionário:

- Principais razões que levam as empresas a envolver usuários em seus projetos;

- Etapas do processo de projeto em que consideram importante o envolvimento dos usuários;

- Tipos de usuários envolvidos no processo;

- Relacionamento da equipe técnica de projeto com os usuários;

- Nível de acesso às informações referentes ao projeto disponibilizado pelas empresas aos usuários;

- Nível de aprendizado dos usuários com a experiência,

- Principais benefícios e desafios enfrentados pela empresa no envolvimento de usuários no processo de projeto.

De posse desta estrutura, o questionário foi formulado baseando-se no proposto por Bradwell e Marr (2008). As questões foram, em sua maioria, de múltipla escolha, e o questionário foi dividido em quatro partes, conforme mostra o Quadro 3. A cópia do questionário encontra-se no anexo 1.

\footnotetext{
${ }^{13}$ BILLERBECK, C. Projeto Participativo: Inclusão dos usuários em processos de projeto de Edifícios de Saúde. Relatório de Iniciação Científica CNPq. São Carlos: IAU-USP, 2012.
} 
Quadro 3. $\quad$ Organização do questionário enviado às empresas para a survey. Fonte: Elaborado pela autora, com base na pesquisa realizada em conjunto a uma iniciação científica ${ }^{14}$.

\begin{tabular}{|c|c|c|}
\hline & Foco & Tipos de questões \\
\hline 1a parte & $\begin{array}{l}\text { Mapear as áreas de atuação da empresa, nichos e raio de } \\
\text { atuação. }\end{array}$ & $\begin{array}{l}4 \text { de múltipla escolha, } \\
2 \text { de checkbox } \\
3 \text { discursivas. }\end{array}$ \\
\hline 2a parte & $\begin{array}{l}\text { Aspectos do envolvimento do usuário. Somente para } \\
\text { empresas que responderam que já envolveram usuários em } \\
\text { projetos de edifícios de assistência à saúde. }\end{array}$ & $\begin{array}{l}8 \text { de múltipla escolha, } \\
2 \text { de checkbox } \\
7 \text { discursivas. }\end{array}$ \\
\hline 3a parte & $\begin{array}{l}\text { Entender a razão de não envolver usuários e se existe a } \\
\text { perspectiva da prática no futuro. Somente para empresas } \\
\text { que responderam que nunca envolveram usuários em } \\
\text { projetos de edifícios de assistência à saúde. }\end{array}$ & $\begin{array}{l}2 \text { de múltipla escolha, } \\
1 \text { de checkbox } \\
1 \text { discursiva. }\end{array}$ \\
\hline 4a parte & Indicação de possível empresa atuante no segmento. & 1 discursiva. \\
\hline
\end{tabular}

Com o intuito de determinar a amostra que seria pesquisada, foram elencados alguns critérios:

- Setor de Atuação: alinhado ao objetivo da pesquisa, deveriam participar projetistas que atuem em projetos de edifícios de assistência à saúde.

- Porte: Empresas. Arquitetos autônomos foram descartados, para que se pudesse estudar o envolvimento do usuário no processo de projeto como um todo, e a relação dos usuários com diversos agentes, e não apenas com o projetista central.

- Raio de atuação: Empresas atuantes em projetos no território brasileiro, pois o objetivo era mapear o contexto do país.

Foi realizado um levantamento de empresas, baseando-se nestes critérios, por meio de pesquisa na Internet, principalmente na página da $A B D E H^{15}$, na seção de "Associados Institucionais". Os "Associados Individuais", representados por arquitetos, tecnólogos e engenheiros como pessoa física, foram descartados. No total, foram levantadas trinta e sete empresas, dentre as quais vinte e três se enquadravam nos critérios estabelecidos e foram selecionadas. Estas empresas foram então contatadas e receberam explicações sobre o objetivo da pesquisa tanto por telefone quanto por correio eletrônico, juntamente com o endereço eletrônico da página do questionário. No entanto, apenas cinco empresas responderam ao questionário. Considera-se, portanto, que este estudo não atingiu o potencial

\footnotetext{
${ }^{14}$ Idem.

${ }^{15}$ Associação Brasileira para o Desenvolvimento do Edifício Hospitalar.
} 
da pesquisa survey, mas serviu como um levantamento inicial para fornecer exemplos de como algumas empresas de arquitetura envolvem o usuário dentro do contexto brasileiro, mas não foi possível generalizar os resultados devido à limitação da pesquisa.

Como método de análise dos dados coletados, utilizou-se a estatística descritiva, que consiste em contagens de número ou frequência das respostas, medições de tendências, proporções e medições das variações (FINK, 2006). A análise, entretanto, foi limitada devido ao baixo número de respostas obtidas.

\section{b) Estudos de Caso}

Dentre os métodos de pesquisa estudados, o mais adequado para ajudar a entender as questões práticas do envolvimento do usuário por levantamento de dados de campo, foi o estudo de caso, que busca caracterizar o funcionamento de dada realidade ou organização, e entender o fenômeno dentro do seu contexto e na sua complexidade. Os estudos de caso são adequados especialmente para estudar a fundo fenômenos complexos que envolvem pesquisas com o intuito de compreender como determinados processos se desenvolvem, quais são suas causas e seus motivadores (YIN, 1994).

Os estudos de caso tiveram, portanto, o objetivo de mapear a prática do envolvimento de usuários em projetos de edifícios de assistência à saúde no contexto nacional. O nível de estudo de caso mais apropriado ao objetivo proposto foi o descritivo, segundo a classificação apresentada em (GIL, 2002). As pesquisas descritivas têm como objetivo básico, segundo este autor, descrever as características dos fenômenos para se permitir um entendimento aprofundado do objeto, que, no caso da presente pesquisa, foi o modo como se envolvem os usuários, as dificuldades, benefícios e os impactos nas etapas do processo de projeto.

Considerando o tempo disponível e a vantagem de múltiplos casos para permitir comparação entre os resultados, determinou-se a realização do estudo de caso em três empresas. A definição das unidades caso partiu do estudo exploratório, quando se teve contato com as empresas atuantes no contexto nacional, bem como se conheceu projetos em andamento que indicavam o envolvimento dos usuários. No entanto, dada a indisponibilidade de algumas empresas, só foi possível realizar o estudo em duas. Outros dois estudos de caso foram iniciados e não foi possível levantar dados relevantes para esta pesquisa, sendo, portanto, descartados. 
Seguindo as proposições de Yin (1994) e com o intuito de aumentar a confiabilidade e qualidade dos dados adquiridos, a coleta de dados foi estruturada em múltiplas fontes de evidência: entrevistas com pessoas-chave, observações diretas, análise de documentos e análise de registros em arquivo. O Quadro 4 descreve as fontes de evidência e os dados coletados por cada uma, para o EC-1, e o Quadro 5 para o EC-2.

Quadro 4. Fontes de evidência para coleta de dados do EC-1. Fonte: Elaborado pela autora.

\begin{tabular}{|c|c|c|}
\hline $\begin{array}{l}\text { FONTE DE } \\
\text { EVIDÊNCIA } \\
\text { (YIN, 2005) }\end{array}$ & DESCRIÇÃO & DADOS COLETADOS \\
\hline \multirow{4}{*}{ 点 } & $\begin{array}{l}\text { Superintendente da empresa de } \\
\text { arquitetura, responsável pelo projeto. } \\
\text { Presencial, em 11/12/2013. }\end{array}$ & $\begin{array}{l}\text { Descrição do processo de projeto; } \\
\text { Descrição geral da estratégia de envolvimento do } \\
\text { usuário; } \\
\text { Descrição dos benefícios e dificuldades do } \\
\text { envolvimento; } \\
\text { Descrição de sua visão sobre a abordagem de } \\
\text { envolvimento dos usuários; } \\
\text { Descrição do papel dos arquitetos no processo com } \\
\text { envolvimento dos usuários. }\end{array}$ \\
\hline & $\begin{array}{l}\text { Arquiteta A - participante do projeto e } \\
\text { responsável pelo levantamento da } \\
\text { edificação em Porto Alegre. } \\
\text { Presencial, em 13/12/2012. }\end{array}$ & $\begin{array}{l}\text { Descrição do processo de projeto; } \\
\text { Descrição dos procedimentos de levantamento de } \\
\text { dados da edificação para atualização do projeto; } \\
\text { Descrição da relação entre equipe de arquitetos e } \\
\text { equipe de operadores da edificação; } \\
\text { Descrição de sua visão sobre a abordagem de } \\
\text { envolvimento dos usuários. }\end{array}$ \\
\hline & $\begin{array}{l}\text { Funcionária A - Assessora de Planejamento } \\
\text { e Avaliação do HCPA } \\
\text { Por correio eletrônico, em 21/05/2013 }\end{array}$ & $\begin{array}{l}\text { Descrição do método de coleta de informações junto } \\
\text { aos usuários }\end{array}$ \\
\hline & $\begin{array}{l}\text { Presidente do HCPA. } \\
\text { Presencial, em 13/12/2012. }\end{array}$ & $\begin{array}{l}\text { Descrição de sua visão sobre o processo de projeto e } \\
\text { o envolvimento dos usuários; } \\
\text { Descrição de seu papel como coordenador do grupo } \\
\text { de usuários. }\end{array}$ \\
\hline \multirow{3}{*}{ 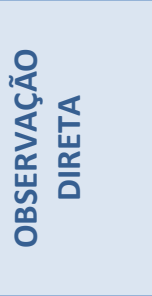 } & Visita ao HCPA. Em 13/12/2012. & Observação do espaço físico e de sua utilização. \\
\hline & $\begin{array}{l}\text { Visita à sala de exposição do projeto de } \\
\text { intervenção. } \\
\text { Em 13/12/2012. }\end{array}$ & $\begin{array}{l}\text { Observação sobre o modo como os usuários são } \\
\text { informados sobre a atual situação e as mudanças que } \\
\text { serão realizadas na edificação. }\end{array}$ \\
\hline & $\begin{array}{l}\text { Visita à sede da empresa de arquitetura. } \\
\text { Em 11/12/2012. }\end{array}$ & Observação da organização das equipes de projeto. \\
\hline \multirow{4}{*}{ 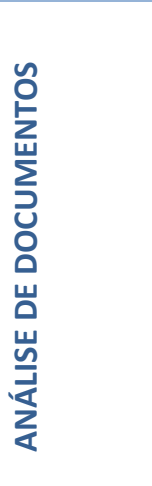 } & Projeto do hospital & $\begin{array}{l}\text { Conhecimento sobre o complexo edificado anterior e } \\
\text { o projeto para intervenção. }\end{array}$ \\
\hline & $\begin{array}{l}\text { Material de divulgação do projeto - Jornal } \\
\text { do HCPA. }\end{array}$ & $\begin{array}{l}\text { Coleta de informações adicionais sobre o projeto e o } \\
\text { modo como os usuários são informados sobre a atual } \\
\text { situação e as mudanças que serão realizadas na } \\
\text { edificação. }\end{array}$ \\
\hline & $\begin{array}{l}\text { Formulários utilizados para coleta de } \\
\text { informações junto aos usuários }\end{array}$ & $\begin{array}{l}\text { Conhecimento sobre as questões e a estratégia de } \\
\text { envolvimento dos usuários }\end{array}$ \\
\hline & Página virtual do hospital & $\begin{array}{l}\text { Coleta de informações adicionais sobre a história do } \\
\text { complexo do HCPA, os serviços oferecidos, a } \\
\text { capacidade e o perfil dos seus usuários. }\end{array}$ \\
\hline
\end{tabular}




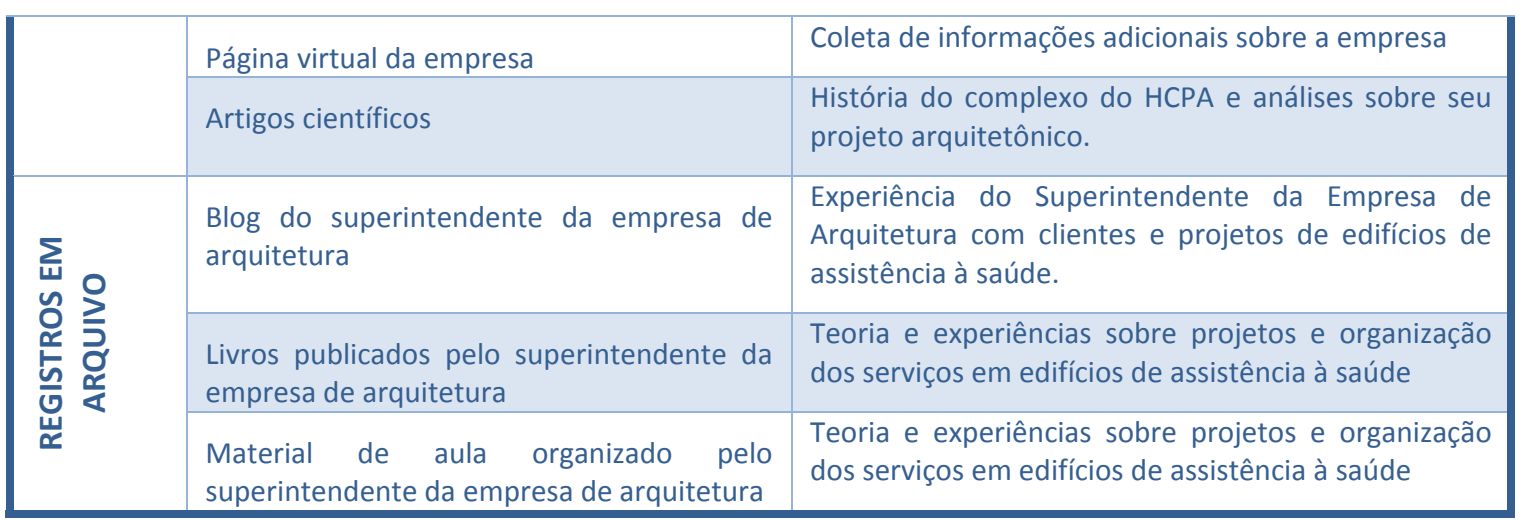

Quadro 5. Fontes de evidência para coleta de dados do EC-2. Fonte: Elaborado pela autora.

\begin{tabular}{|c|c|c|}
\hline $\begin{array}{l}\text { FONTE DE } \\
\text { EVIDÊNCIA }\end{array}$ & DESCRIÇÃO & DADOS COLETADOS \\
\hline QUESTIONÁRIO & Em 12/08/2009 & Descrição do perfil da Empresa \\
\hline ENTREVISTAS & $\begin{array}{l}\text { Diretor executivo da empresa de } \\
\text { arquitetura. } \\
\text { Por correio eletrônico, em } \\
\text { 12/12/2014 e 18/03/2015. }\end{array}$ & $\begin{array}{l}\text { Descrição geral da estratégia de envolvimento do } \\
\text { usuário utilizada pela empresa (métodos e } \\
\text { instrumentos); } \\
\text { Apresentação do Gaming no projeto da Clínica Baum. }\end{array}$ \\
\hline $\begin{array}{l}\text { ANÁLISE DE } \\
\text { DOCUMENTOS }\end{array}$ & Página virtual da empresa & $\begin{array}{l}\text { Coleta de informações adicionais sobre a empresa e } \\
\text { suas estratégias de projeto. }\end{array}$ \\
\hline $\begin{array}{l}\text { REGISTROS EM } \\
\text { ARQUIVO }\end{array}$ & Fotos do Gaming & Elucidação do método e seus instrumentos. \\
\hline
\end{tabular}

Os dados coletados em cada estudo de caso foram confrontados entre si, para análise intracaso, e posteriormente foram discutidos os resultados dos dois estudos de caso, que são complementares. A análise de dados seguiu o processo geral para pesquisas qualitativas proposto por Creswell (2012): preparação e organização dos dados coletados para análise, redução dos dados em temas e, por fim, representação dos dados por figuras e discussões.

\subsubsection{ETAPA 2: Proposição de uma Solução}

A solução proposta para promoção de aumento na eficiência operacional em edifícios de assistência à saúde foi um modelo para auxiliar os projetistas a envolver os usuários no processo de projeto destes edifícios. O objetivo do envolvimento é propiciar aos arquitetos um melhor entendimento da forma de realizar os serviços, através do conhecimento dos usuários, e melhor captação dos requisitos destes usuários, para promover o alinhamento entre espaço físico e serviços realizados, e assim produzir edificações que contribuam para o bom desempenho da realização dos serviços de saúde. 
Segundo March e Smith, em ciências naturais, modelos podem ser vistos como representações de fenômenos ou teorias. No caso aqui proposto, bem como nos modelos sugeridos por March e Smith, os modelos se referem à utilidade para solução de problemas, e não à representação da verdade.

Para o desenvolvimento do modelo, inicialmente foram delimitados seus focos (seção 7.1). O modelo então foi estruturado considerando as fases do processo de projeto em que o co-design foi indicado como nível apropriado, de acordo com a seção 7.2, e os conceitos e os dados importantes levantados na revisão bibligráfica e na pesquisa empírica.

\subsubsection{ETAPA 3: Avaliação da Solução}

Para que as soluções conceituais propostas no modelo pudessem ser avaliadas pelos profissionais que atuam na prática de projetos, seria necessário testá-las no contexto específico do ambiente construído. Este teste permite "aperfeiçoar ou ao menos trazer melhorias para o projeto, produção e operação do ambiente construído", e, em gerenciamento de construção, este é o principal propósito de pesquisa (VOORDIJK, 2009, p.718).

Dada a dificuldade de testar o modelo num projeto real, foi proposta uma avaliação deste modelo por arquitetos que atuam na prática de projetos de edifícios de assistência à saúde e por pesquisadores acadêmicos da área. Foram então destacados sete avaliadores, sendo quatro arquitetos que já haviam sido selecionados para o Estudo Exploratório e os Estudos de Caso. Os outros três avaliadores são pesquisadores da área, com publicações científicas expressivas.

O material enviado para avaliação foi composto pelo modelo, com sua apresentação resumida, e uma folha de avaliação com sete questões, apresentada no Anexo IV. Foi ainda oferecida a possibilidade de avaliar oralmente o modelo, por contato telefônico.

Dos sete avaliadores selecionados, quatro puderam avaliar o modelo, sendo que dois responderam à folha de avaliação por escrito, e dois responderam por contato telefônico. As avaliações foram transcritas na seção 7.4.1, e foi realizada uma discussão, com base nelas, que resultou no aprimoramento do modelo, apresentado então em sua versão final na seção 7.5. 


\subsubsection{ETAPA 4: Organização das Contribuições Teóricas e Práticas}

De posse dos dados levantados durante a pesquisa e do modelo finalizado, a Etapa 4 foi destinada à sintetização e organização dos resultados. Foi então possível determinar as contribuições da pesquisa para a teoria e a prática da arquitetura, bem como indicar pesquisas futuras. A fase encerrou a pesquisa com a produção da tese. 



\section{PROCESSO DE PROJETO DE EDIFÍCIOS DE ASSISTÊNCIA À SAÚDE}

Dentro do escopo do objetivo geral desta pesquisa, de aumentar a eficiência destas dos edifícios de assistência à saúde, através da promoção de espaços físicos para estas instituições que deem maior suporte para as atividades neles realizadas, apresenta-se neste capítulo a revisão bibliográfica referente ao processo de projeto de edificações de saúde. A revisão se inicia com a contextualização dos edifícios de assistência à saúde, e segue caracterizando estas edificações no Brasil. Na sequência, discute as questões que caracterizam o projeto destas edificações como complexos. Abordam-se então os aspectos do processo de projeto do espaço físico, com suas principais características, etapas e modelos. Com foco no alinhamento entre espaço físico e prestação de serviços, apresentam-se também as principais características do projeto de serviços de saúde, com revisão de modelos e instrumentos utilizados em projetos de serviços que podem ser úteis para o desenvolvimento de projeto de serviços de saúde com qualidade e que tragam maior eficiência operacional para estas edificações.

O objetivo desta revisão é, em primeiro lugar, constituir um corpo teórico que embase este trabalho e dê suporte para a coleta de dados dos estudos de caso e análise dos mesmos. Esta revisão visa também, em conjunto com a revisão bibliográfica sobre envolvimento de usuários em processo de projeto apresentada no próximo capítulo, a orientar a elaboração do modelo proposto nos objetivos da pesquisa.

\subsection{CENÁRIO ATUAL DOS EDIFÍCIOS DE ASSISTÊNCIA À SAÚDE}

No século XX, o desenvolvimento tecnológico ocorrido revolucionou a medicina, privilegiando o ambiente hospitalar como local da prática médica, de forma que a edificação deveria ser capaz de abrigar convenientemente os equipamentos para investigação, diagnóstico e terapêutica, além de poder continuamente incorporar os avanços do setor (SANTOS; BURSZTYN, 2004). A anatomia destas edificações a partir deste período conta com agrupamentos departamentais, reunidos por atividades e funções correlatas, cada um com suas próprias características e necessidades de planejamento funcional (MIQUELIN, 1992; SANTOS; BURSZTYN, 2004). 
Ainda na segunda metade do século XX, entretanto, os primeiros sinais de crise deste modelo de atenção médica começaram a aparecer (SANTOS; BURSZTYN, 2004):

- O crescente custo da tecnologia médica cria restrições de acesso;

- Aumento da demanda por tecnologia de média e alta complexidade, devido à prevalência de doenças crônico-degenerativas intensificada pelo envelhecimento da população;

- O impacto desejado sobre a saúde nem sempre é produzido pelo alto grau de especialização gerado pela tecnologia, e isto norteia a demanda por um modelo de atenção mais efetivo.

Estes autores relatam que, na virada do século XXI, busca-se um novo modelo de hospital, centrado na promoção da saúde. A princípio relacionado à ideia de um corpo livre de doenças, o entendimento de atenção à saúde evoluiu para incluir uma visão holística de bem-estar físico e mental e, como consequência, os edifícios de assistência à saúde estão mudando tanto em forma como em função (GESLER et al., 2004).

Em síntese, ao longo da evolução destes edifícios na história, a arquitetura priorizou o espaço do hospital, bem como o seu aparato médico e tecnológico, privilegiando o tratamento cada vez mais especializado da doença. O paciente em si, passivo, estava relegado a um papel de coadjuvante no processo. Eram os tempos da "arquitetura hospitalar". Assistese agora, entretanto, à mudança de foco nestes projetos, da edificação para os usuários, com novas propostas que buscam a promoção da humanização, da saúde e da qualidade de vida, dentro do que se nomeia "arquitetura da saúde" (INSTITUTO DOS ARQUITETOS DO BRASIL IAB/RJ; PROCEL/Eletrobrás, 2005).

\subsubsection{Rede de atendimento à saúde no Brasil}

No Brasil, as buscas pela solução dos problemas de saúde são numerosas e multifacetadas, destacando-se a criação do SUS - Sistema Único de Saúde - em 1990 (GÓES, 2004). A implantação do SUS foi uma estratégia para universalizar a cobertura das ações de saúde 
pública no país, pois até então era destinada apenas aos beneficiários do INAMPS ${ }^{16}$ (SOUZA, 2002). O artigo 4으, da Lei 8.080 de 19 de setembro de 1990, institui como constituintes do SUS:

“O conjunto de ações e serviços de saúde, prestados por órgãos e instituições públicas federais, estaduais e municipais, da Administração direta e indireta e das fundações mantidas pelo Poder Público".

Ainda segundo esta lei, a assistência à saúde se daria de forma "hierarquizada em níveis de complexidade crescente". Segundo Góes (2004), a legislação em vigor categoriza os níveis de atendimento em três, pelo critério de complexidade: primário, secundário e terciário. $\mathrm{O}$ quadro 6 apresenta a definição de cada nível.

Quadro 6. Níveis de atendimento à saúde. Fonte: Góes (2004)

\begin{tabular}{|c|c|c|c|}
\hline Nível & $\begin{array}{l}\text { Descrição das } \\
\text { Atividades }\end{array}$ & $\begin{array}{l}\text { Estrutura Física } \\
\text { (Estabelecimento) }\end{array}$ & Descrição do Estabelecimento \\
\hline \multirow[b]{2}{*}{ 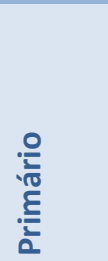 } & \multirow{2}{*}{$\begin{array}{lr}\text { Ações de promoção, } \\
\text { proteção } & \text { e } \\
\text { recuperação } & \text { da } \\
\text { saúde, de } & \text { baixa } \\
\text { complexidade } & \end{array}$} & Postos de Saúde (PS) & $\begin{array}{l}\text { Serviços básicos para agrupamentos } \\
\text { populacionais entre } 500 \text { e } 2.000 \text { hab. }\end{array}$ \\
\hline & & $\begin{array}{l}\text { Centros de Saúde (CS) / } \\
\text { Unidade Básica de Saúde (UBS) }\end{array}$ & $\begin{array}{l}\text { Serviços básicos, acrescidos de assistência } \\
\text { médica e atendimento a encaminhados } \\
\text { dos PS para agrupamentos populacionais } \\
\text { entre } 2.000 \text { e } 10.000 \text { hab. }\end{array}$ \\
\hline \multirow[b]{3}{*}{ 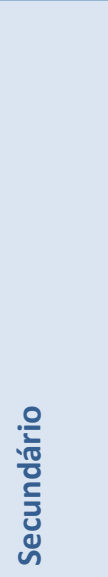 } & \multirow[t]{3}{*}{$\begin{array}{l}\text { Apoio ao nível } \\
\text { primário, acrescido } \\
\text { das clínicas básicas } \\
\text { (médica, cirúrgica, } \\
\text { obstétrica/ginecológi } \\
\text { ca e pediátrica) }\end{array}$} & Ambulatórios & $\begin{array}{l}\text { Equipamento de Referência para os CS, } \\
\text { com atendimento às quatro clínicas } \\
\text { básicas. }\end{array}$ \\
\hline & & Unidades Mistas & $\begin{array}{l}\text { Ações ambulatoriais nas quatro clínicas } \\
\text { básicas acrescido de internação } \\
\text { (geralmente de até } 24 \mathrm{~h} \text { e principalmente } \\
\text { de parturientes), para agrupamento } \\
\text { populacional entre } 10.000 \text { e } 20.000 \text { hab. }\end{array}$ \\
\hline & & Hospitais Locais/Regionais ${ }^{17}$ & $\begin{array}{l}50 \text { a } 100 \text { leitos, destinados às quatro } \\
\text { clínicas básicas, sendo referência para PS } \\
\text { e CS, para agrupamento populacional } \\
\text { entre } 50.000 \text { e } 100.000 \text { hab. }\end{array}$ \\
\hline$\frac{.0}{\frac{20}{2}}$ & $\begin{array}{lr}\text { Tratamento } & \text { dos } \\
\text { casos } & \text { mais } \\
\text { complexos } & \text { do } \\
\text { sistema } & \\
\text { (ambulatório, } & \\
\text { urgência } & \text { e } \\
\text { internação) } & \end{array}$ & Hospital de Base ou Referência & $\begin{array}{l}151 \text { a } 200 \text { leitos, com elevado índice } \\
\text { profissional e tecnológico }\end{array}$ \\
\hline
\end{tabular}

\footnotetext{
${ }^{16}$ O INAMPS - Instituto Nacional de Assistência Médica da Previdência Social - atuou até 1993, quando foi extinto e passou a integrar a estrutura do Ministério da Saúde.

${ }^{17}$ Dependendo da complexidade das tecnologias de diagnóstico e terapia que estes hospitais possuem, passam a ser considerados como de nível terciário.
} 
O gráfico 1 mostra o número de estabelecimentos no Brasil por níveis, considerando as estruturas físicas citadas no quadro 6, com o intuito de ilustrar a distribuição geral destas estruturas. Outros tipos de estabelecimentos, como clínicas e consultórios, não foram considerados.

Gráfico 1. Quantidade Geral de Estabelecimentos por Nível de Atenção no Brasil. Período: Mar/2015. Fonte: CNES, Ministério da Saúde ${ }^{18}$.

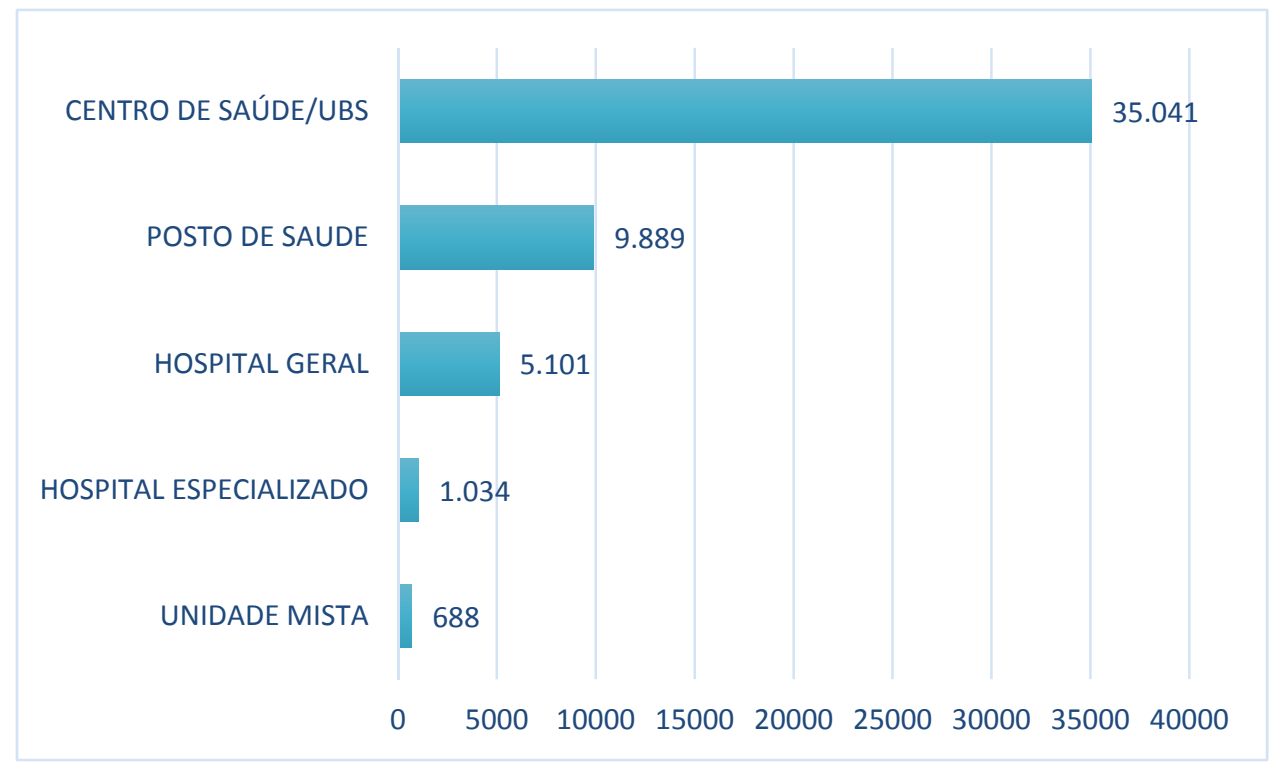

Os hospitais podem ainda ser classificados pelo seu porte, da seguinte forma (BRASIL, 1985):

- Hospital de pequeno porte: capacidade instalada de até 50 leitos.

- Hospital de médio porte: capacidade instalada de 51 a 150 leitos.

- Hospital de grande porte: capacidade instalada de 151 a 500 leitos.

- Hospital de porte especial: capacidade instalada acima de 500 leitos.

Parte da população tem buscado planos e seguros de saúde privados, devido aos "baixos investimentos em saúde e consequente queda da qualidade dos serviços" (MALTA et al., 2004, p.434). Até o ano de 1998, quando foi promulgada a Lei no 9.656, este segmento não estava normatizado, e as operadoras de planos privados utilizavam critérios próprios do mercado para atendimento aos seus beneficiários (ALBUQUERQUE et al., 2008). No ano de 2000, foi criada a Agência Nacional de Saúde Suplementar (ANS), vinculada ao Ministério da Saúde, com

\footnotetext{
${ }^{18}$ Disponível em: http://tabnet.datasus.gov.br/cgi/tabcgi.exe?cnes/cnv/atencbr.def, acesso em 15 mai. 2015.
} 
a missão de "Promover a defesa do interesse público na assistência suplementar à saúde, regular as operadoras setoriais - inclusive quanto às suas relações com prestadores e consumidores - e contribuir para o desenvolvimento das ações de saúde no país" ${ }^{\prime 19}$. O crescimento do mercado de saúde suplementar no Brasil, segundo Albuquerque et al. (2008), é pouco conhecido até o ano de 2000, mas a partir de então é composto por planos privados, regulados pela ANS, e por planos vinculados a instituições de assistência aos servidores públicos, civis e militares, não regulados pela ANS.

Muito se especula, na mídia nacional, sobre a deficiência do setor de saúde em atender às necessidades da população, tanto em termos de déficit de espaço físico, como em falta de profissionais, principalmente na esfera pública. Em relação à falta de profissionais, o déficit de médicos estimados pelo Ministério da Saúde no ano de 2013 era de 54 mil, segundo Fagundes (2013). Outros exemplos podem ser encontrados em Costa (2015) e Perrin (2015). Apesar disto, não existem padrões validados para determinar este déficit, tanto em âmbito nacional como internacional (Saúde, 2008). Outros entraves à determinação deste déficit, segundo Rede Interagencial de Informação para a Saúde - RIPSA (2008), são:

- Alguns parâmetros utilizados para comparação e determinação da quantidade mínima de médicos por habitante não podem ser aplicados a todos os contextos (por exemplo, 1/1000hab);

- Não são conhecidos processos de verificação da efetividade do exercício profissional;

- As quantificações apresentadas pelos órgãos oficiais não separam os profissionais que atendem à saúde daqueles que se encontram em atividades gerenciais.

Dada a falta de parâmetros, apresenta-se aqui uma tabela comparativa (tabela 1) entre o número de profissionais de saúde para 1000 habitantes no Brasil e em países desenvolvidos Estados Unidos, Reino Unido e Suíça - e em Cuba, cujo desempenho na atenção à saúde tem sido destacado tanto nas estatísticas da Organização Mundial da Saúde - OMS - quanto em publicações internacionais - ver, por exemplo, Campion e Morrissey (2013).

\footnotetext{
${ }^{19}$ Fonte: ANS. Disponível em: http://www.ans.gov.br/ Acesso em: 31 ago. 2015.
} 
Tabela 1. Número de Profissionais de Saúde por mil habitantes. Fonte: $\mathrm{OMS}^{20}$.

\begin{tabular}{|l|l|l|}
\hline PAÍS & MÉDICOS/1000 HAB & ENFERMEIROS $^{21}$ \\
\hline Cuba & 6,723 & 9,053 \\
\hline Suíça & 4,409 & 0,316 \\
\hline Reino Unido & 2,809 & 8,801 \\
\hline Estados Unidos & 2,452 & 9,815 \\
\hline Brasil & 1,891 & 7,601 \\
\hline
\end{tabular}

Pelos dados, nota-se que o número de médicos por mil habitantes é muito inferior ao registrado nos demais países levantados. Em relação aos enfermeiros, o Brasil está à frente apenas da Suíça, entre os países selecionados. No entanto, o número de médicos por mil habitantes na Suíça é mais de duas vezes maior do que o do Brasil. Nota-se, portanto, que o país possui, proporcionalmente à sua população, um número muito inferior de profissionais se comparado a países desenvolvidos.

É importante ressaltar a heterogeneidade do Brasil, que implica numa distribuição desigual dos recursos e dos profissionais ao longo do território nacional, conforme ilustra a Tabela 2. Em termos absolutos, o número de profissionais de saúde no Brasil está descrito na Tabela 3.

Tabela 2. Número de médicos e enfermeiros mil habitantes Brasil e grandes regiões, em 2005. Fonte: Ministério da Saúde/SGTES - Sistema de Informações de Recursos Humanos para o SUS (SIRH) e base demográfica do IBGE (RIPSA, 2008).

\begin{tabular}{|l|c|c|}
\hline REGIÃO & MÉDICOS & ENFERMEIROS \\
\hline Brasil & 1,7 & 0,6 \\
\hline Norte & 0,8 & 0,5 \\
\hline Nordeste & 1,0 & 0,5 \\
\hline Sudeste & 2,3 & 0,7 \\
\hline Sul & 1,7 & 0,7 \\
\hline Centro-Oeste & 1,7 & 0,7 \\
\hline
\end{tabular}

\footnotetext{
${ }^{20}$ Disponível em: <http://apps.who.int/gho/data/node.main.A1444?lang=en\&showonly=HWF> Acesso em 18 mai. 2015.

${ }^{21}$ Inclui enfermeiros, enfermeiro-obstetriz, técnicos e auxiliares de enfermagem.
} 
Tabela 3. Profissionais de saúde no Brasil. Fonte: CNES, março de $2015^{22}$.

\begin{tabular}{|l|c|}
\hline PROFISSIONAIS & QUANTIDADE NO BRASIL \\
\hline Médico & 964.606 \\
\hline Enfermeiro & 178.465 \\
\hline Técnico de Enfermagem & 367.014 \\
\hline Auxiliar de Enfermagem & 265.539 \\
\hline
\end{tabular}

Para mensurar o déficit de espaço físico para o atendimento à saúde, utiliza-se aqui a variável número de leitos para internação geral. Apesar de ser apenas uma das variáveis do dimensionamento assistencial à saúde da população, esta escolha permite a análise baseada em levantamentos oficiais do Ministério da Saúde e parâmetros estabelecidos em legislação. 0 artigo 20 do capítulo IV da Portaria no 2.809, de 7 de dezembro de 2012, estipula que "a necessidade de leitos hospitalares gerais é de 2,5 (dois inteiros e cinco décimos) leitos gerais para cada 1.000 (mil) habitantes". A Tabela 4 mostra que apenas as regiões Sul e CentroOeste do Brasil atingem esta proporção, se considerados os números totais de leitos existentes. Considerando-se apenas os leitos públicos disponibilizados, o número está muito abaixo do determinado em todas as regiões do país. O Gráfico 2 compara os dados para as diferentes regiões do Brasil.

Tabela 4. Leitos hospitalares existentes por mil habitantes, segundo região. Período: 2010. Fonte: Ministério da Saúde/SAS - Cadastro Nacional de Estabelecimentos de Saúde (CNES).

\begin{tabular}{|l|c|c|c|}
\hline REGIÃO & EXISTENTES & PÚBLICOS & PRIVADOS \\
\hline TOTAL & 2,42 & 0,86 & 1,56 \\
\hline Região Norte & 1,94 & 1,12 & 0,82 \\
\hline Região Nordeste & 2,29 & 1,1 & 1,19 \\
\hline Região Sudeste & 2,46 & 0,72 & 1,74 \\
\hline Região Sul & 2,73 & 0,57 & 2,16 \\
\hline Região Centro-Oeste & 2,64 & 0,96 & 1,67 \\
\hline
\end{tabular}

22 Fonte: Ministério da Saúde - Cadastro Nacional dos Estabelecimentos de Saúde do Brasil - CNES, período: Mar/2015. Disponível em: <http://tabnet.datasus.gov.br/cgi/tabcgi.exe?cnes/cnv/proc02br.def> Acesso em 18 mai. 2015. 
Gráfico 2. Comparação entre os leitos hospitalares existentes por mil habitantes, segundo região e esfera. Fonte: Ministério da Saúde/SAS - CNES.

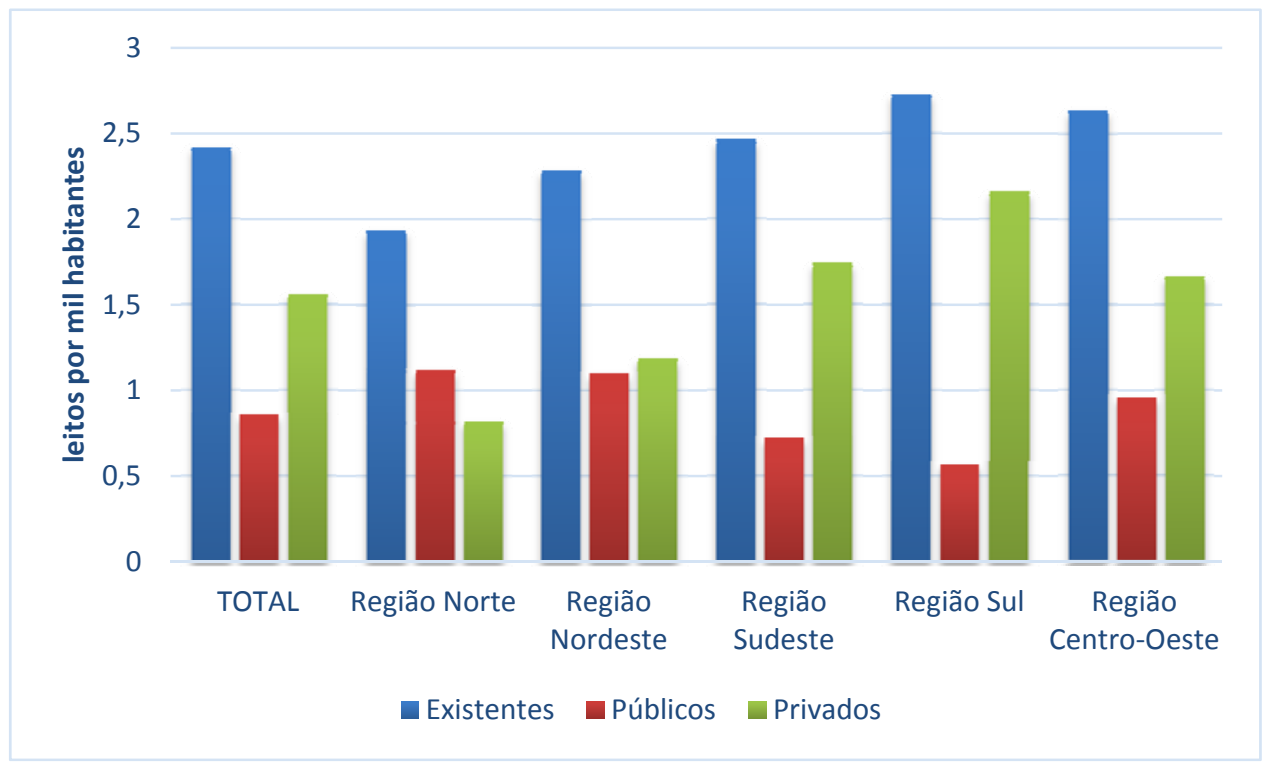

Os hospitais são os principais componentes do sistema de atenção à saúde em países de renda baixa e média, como o Brasil, e também os mais onerosos, sendo a referência de todo o sistema de saúde e foco da capacitação profissional na área (LA FORGIA; COUTTOLENC, 2009). Para estes autores, a administração de um hospital é complexa e cara devido à vasta gama de serviços oferecidos nestas instituições, que contemplam desde serviços básicos de hotelaria até cirurgias complexas e tratamentos clínicos de alta tecnologia. De um modo geral, a natureza e os altos custos do hospital se devem principalmente a fatores como o uso crescente de tecnologias médicas, o aumento do consumo de serviços de saúde e os efeitos oriundos do aumento da expectativa de vida (DEL NORD, 2005).

Neste contexto, justifica-se a busca pela eficiência operacional das edificações de saúde no país, para melhorar o desempenho das atividades de atenção à saúde com espaços que facilitem sua execução, permitam novos modos de trabalho e sejam focados nos pacientes. Isto pode permitir a redução dos custos de operação e ampliação da capacidade de atendimento, além do impacto na qualidade da atenção à saúde.

\subsection{COMPLEXIDADE do ProJeto de EdifícIOS DE ASSISTÊNCIA À SAÚdE}

"Um dos programas mais complexos a ser atendido pela composição arquitetônica", os edifícios de assistência à saúde apresentam múltiplas faces, com diversas interações, por 
concentrar na mesma edificação tanto serviços de cunho industrial - por exemplo, nutrição, transportes e lavanderia - como processos de atuação médica refinados e atividades de alta tecnologia (GÓES, 2004, p.29). Além disto, tem como ocupante principal o paciente fragilizado, que carece de relações humanas (SAMPAIO, 2005). As impressões dos pacientes em relação às configurações do espaço físico variam muito, bem como as interpretações sociais e culturais dos pacientes sobre quão eficientes e terapêuticos estes edifícios são (GESLER et al., 2004). 0 projeto de edifícios de assistência à saúde, portanto, é complexo devido a diversas questões, que envolvem a qualidade do espaço físico e a necessidade de este dar suporte aos serviços de saúde (TZORTZOPOULOS et al., 2009). Não obstante, cada edifício de saúde tem sua construção orientada por sua visão própria (BROMLEY, 2012), e possui edifício, perfil de pacientes, equipe interna, missão e serviços próprios, tornando a figura genérica apenas uma abstração (RISSE, 1999).

Vidal e Marle (2008) classificam os fatores que caracterizam a complexidade do projeto em: dimensão do projeto, variedade do projeto, interdependência dentro do sistema de projeto e elementos do contexto do projeto. Ou seja, além da dimensão, o número de variáveis do projeto e a forma como estas interagem influenciam a complexidade do projeto, bem como os fatores ligados ao seu contexto.

Baseados neste texto, Caixeta (2011) e Caixeta e Fabricio (2011) trazem esta classificação para os projetos de edifícios de assistência à saúde, apontando os fatores determinantes da complexidade do projeto para obras novas e para obras de intervenção. Em relação aos projetos de obras novas, primeiramente o grau de complexidade do processo de projeto depende da dimensão do empreendimento projetado. Em segundo, das variáveis deste projeto, que se dividem em tecnológicas - relacionadas aos sistemas prediais e aos equipamentos - e espaciais - referentes ao espaço físico. Estas variáveis estão relacionadas ao nível de atendimento à saúde da edificação, ou seja, partindo do nível primário para o terciário, aumenta o número de variáveis com que os projetistas terão que trabalhar. Em terceiro, a complexidade do projeto varia de acordo com o modo como estas variáveis interagem no projeto. Por fim, os elementos do contexto, como a disponibilidade de recursos, as características do local de implantação e de seu entorno, entre outros, também influenciam a complexidade do projeto (Figura 4). 


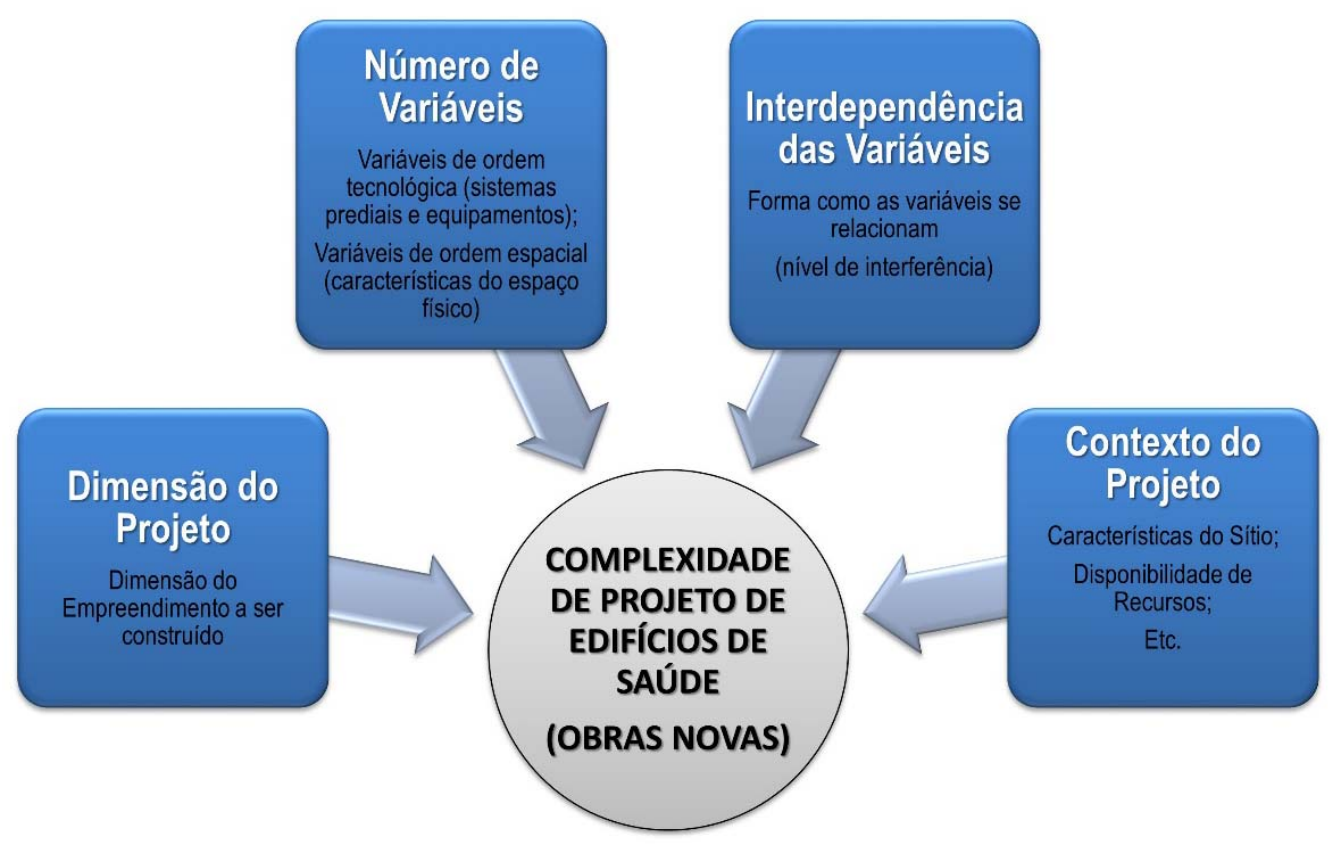

Figura 4. Fatores determinantes da complexidade do projeto, segundo Vidal e Marle (2008), adaptados para edifícios de assistência à saúde (obras novas). Fonte: Caixeta e Fabricio

(2011).

Já no caso de projetos de intervenções em edificações existentes - reformas, ampliações ou retrofits - existem diversos elementos que não podem ser alterados, tais como a morfologia do edifício, sua implantação, ou ainda elementos de valor artístico ou histórico. Desta forma, pode-se dizer que o grau de complexidade de um projeto de intervenção em edifício de saúde é maior do que em obras novas (CARVALHO; SALGADO; BASTOS, 2009). Além da dimensão do empreendimento existente, a complexidade depende, portanto, da área de abrangência da intervenção, se é apenas em um setor ou em toda a edificação. Em relação às variáveis, as de ordem tecnológica se referem aos sistemas prediais e aos equipamentos que serão afetados pela intervenção, enquanto as variáveis de ordem espacial são referentes ao modo como se intervirá no espaço físico. As interferências entre estas variáveis, da mesma forma, aumentam a dificuldade do projeto e da obra. Por último, destacam-se as questões referentes à contaminação e dificuldade de paralisação de setores críticos - como UTI e centro cirúrgico como fatores de complexidade relativos ao contexto, pois requerem maior planejamento para execução (figura 5). 


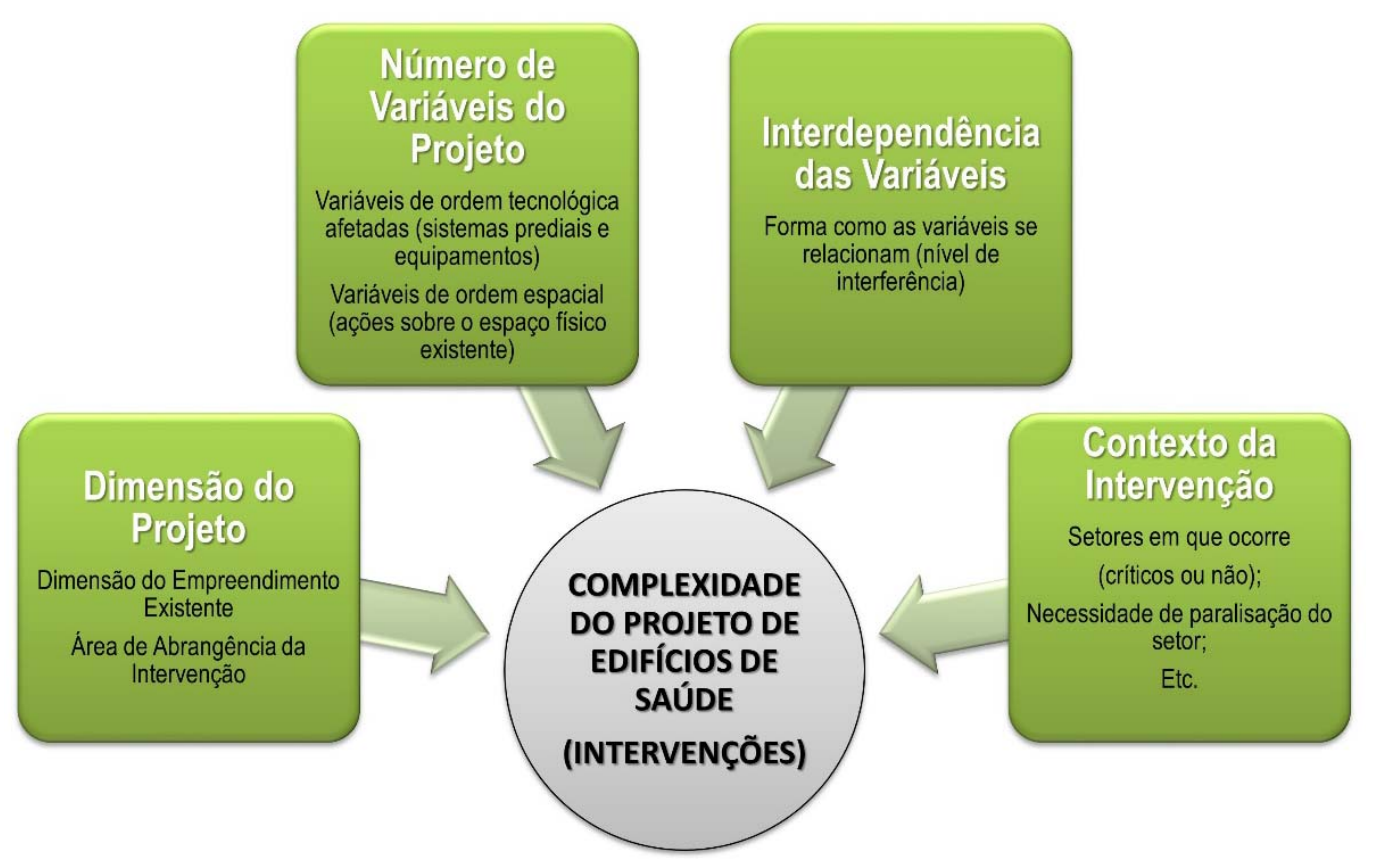

Figura 5. Fatores determinantes da complexidade do projeto, segundo Vidal e Marle (2008), adaptados para edifícios de assistência à saúde (obras de intervenção). Fonte: Caixeta e Fabricio (2011).

\subsection{Processo de Projeto}

No que se refere à garantia de qualidade dos edifícios, o processo de projeto possui um papel essencial. Diversos estudos apontam que a falta de qualidade no processo de projeto pode gerar uma série de problemas para a edificação e ser responsável pela sua baixa qualidade e atrasos durante sua construção (BIBBY; BOUCHLAGHEM; AUSTIN, 2002; ROMANO, 2006). Segundo Korkmaz et al. (2010), decisões imprecisas são tomadas pela falta de orientação do processo de projeto, fazendo com que em novos projetos se repitam erros anteriores, que geram desperdícios com retrabalho desnecessário em projeto, alterações caras e edifícios ineficientes.

O processo de projeto, segundo diversos autores citados por Romano (2003), permeia ou deve permear todo o processo desenvolvimento do produto - PDP $^{23}$, desde 0 planejamento até o uso, para permitir a retroalimentação do sistema a partir da obra, da avaliação pós-ocupação e da análise financeira do empreendimento.

\footnotetext{
${ }^{23}$ Neste trabalho, o PDP tem como produto a edificação de saúde. Segundo (Rozenfeld et al., 2006), o PDP "[...] é o processo de negócio, isto é, o conjunto de atividades capaz de transformar informações tecnológicas e de mercado em produtos/serviços [...] por meio da criação de bens e informações para produção, acompanhamento e retirada de um produto do mercado."
} 
É necessário diferenciar obras novas de intervenções em edifícios de assistência à saúde, devido a algumas diferenças importantes levantadas por Caixeta e Fabricio (2013), que afetam o processo de projeto:

- Enquanto a obra nova se inicia num terreno vazio, em intervenções é necessário investigar a edificação existente, com suas barreiras, restrições e valores;

- A macrofase de levantamento se refere a legislações incidentes sobre o projeto e, no caso de obras novas, aos dados relativos ao terreno onde a edificação será implantada e seu entorno. Já em intervenções, é necessário levantar ainda os dados referentes ao edifício existente;

- Em intervenções, existem usuários com conhecimento do edifício, que podem fornecer informações valiosas para os projetistas sobre o funcionamento do mesmo;

- As obras de intervenções não podem interromper o atendimento à saúde, o que implica em planejamento adicional para evitar contaminações da obra em setores críticos - como UTI ou centro cirúrgico - ou interrupções no seu fornecimento de eletricidade, água, gases, entre outros;

- No Brasil, nem sempre as obras de intervenções em edificações públicas se iniciam com recursos financeiros suficientes para sua conclusão. Faz-se necessário, portanto, que o planejamento permita a menor interferência no uso possível durante a intervenção, para evitar que os recursos acabem e o setor se torne inoperante.

- De acordo com Roders (2007), novas informações podem ser descobertas durante a obra intervenção, e isto pode requerer desde pequenas alterações no projeto até novas aprovações legais. Como estas alterações não são geradas por falhas no projeto, podem significar remunerações extras para a equipe.

Em projetos para edificações complexas, o planejamento e organização do processo de projeto é um aspecto de grande importância, tanto no que se refere à área de arquitetura como de engenharia (VAN AKEN, 2005). Segundo Kagioglou et al. (2000), um modelo genérico de processo pode facilitar a gestão de equipes fragmentadas na indústria da construção e melhorar a comunicação entre seus agentes, contribuindo assim para uma mudança cultural neste campo.

Como definição, 
Modelos de Projeto são as representações de filosofias ou estratégias propostas para mostrar como o projeto é e pode ser feito. Geralmente, são desenhados como diagramas de fluxos, mostrando a natureza iterativa do processo de projeto por uma corrente de retroalimentação (EVBUONWAN; SIVALOGANATHAN; JEBB, 1996, p.305).

O modelo mostra o mapeamento das ações dos projetistas do início ao fim do processo, que o levam à solução desejada (TREBILCOCK, 2009). Roozenburg e Cross (1991) apresentam sumariamente e discutem a evolução dos modelos de processo de projeto em arquitetura, com suas origens nas críticas a modelos de processo de projeto em engenharia. Estes autores acreditam que exista um 'modelo consensual' em projetos de engenharia, com variações muito sutis apresentadas por diferentes autores. Segundo este modelo consensual, o processo de projeto em engenharia é composto por quatro fases, que agrupam uma sequência de atividades. Estas fases são: esclarecimento da tarefa; projeto conceitual; desenvolvimento do projeto e projeto detalhado. Este modelo considera que, para abranger o maior número de soluções possíveis, o projeto deve partir do geral e abstrato para o particular e concreto. Além disto, para solucionar problemas complexos, estes devem ser divididos em 'subproblemas', com sub-soluções mais acessíveis, cuja 'sintetização' traz uma solução geral para o problema de projeto (ROOZENBURG; CROSS, 1991).

Nesta linha, Geoffrey Broadbent e Christopher Alexander, delinearam o processo de projeto como um mapa generalizado, indicando a sequência de atividades em 'análise, síntese e avaliação' (TREBILCOCK, 2009). O modelo resultante, chamado de Análise/Síntese, tem influência em Bacon e Descartes e é composto por quatro etapas, conforme apresentado no quadro 7 (BAMFORD, 2002).

Quadro 7. O modelo A/S. Fonte: Broadbent (1966 $6^{24}$ apud BAMFORD, 2002) e Jones (1970 25 apud BAMFORD, 2002)

\begin{tabular}{|c|c|}
\hline PRINCIPAIS ETAPAS & DESCRIÇÃO \\
\hline Briefing & Coleta de dados e definição da programação \\
\hline Análises & $\begin{array}{l}\text { Quebra do problema em partes, formulação das especificações de } \\
\text { desempenho, identificação de restrições. }\end{array}$ \\
\hline Sínteses & $\begin{array}{l}\text { Geração de ideias, união das partes de um novo modo, desenvolvimento do } \\
\text { projeto. }\end{array}$ \\
\hline Avaliação & $\begin{array}{l}\text { Verificação do desempenho das especificações e restrições, teste para } \\
\text { descoberta das consequências de colocar o novo arranjo em prática }\end{array}$ \\
\hline
\end{tabular}

\footnotetext{
${ }^{24}$ Broadbent, G. Design method in architecture. The Architects' Journal, 144(11), 1966, p. 679-685.

${ }^{25}$ Jones, J. C. Design methods: Seeds of human futures. London: John Wiley, 1970.
} 
Evbuonwan, Sivaloganathan e Jebb (1996) apresentam diversos modelos prescritivos e concluem que a maioria deles baseiam seus procedimentos em atividades de projeto, que se resumem em análise, síntese, avaliação, decisão, etc., enquanto outros se baseiam em fases de projeto - projeto conceitual, desenvolvimento e projeto detalhado. Mallory-Hill (2004) descreve a passagem do projetista por uma "cascata" de estágios sequenciais, iniciando o processo pelo briefing, até o detalhamento do projeto, construção e, por fim, ocupação (Figura $6)$.

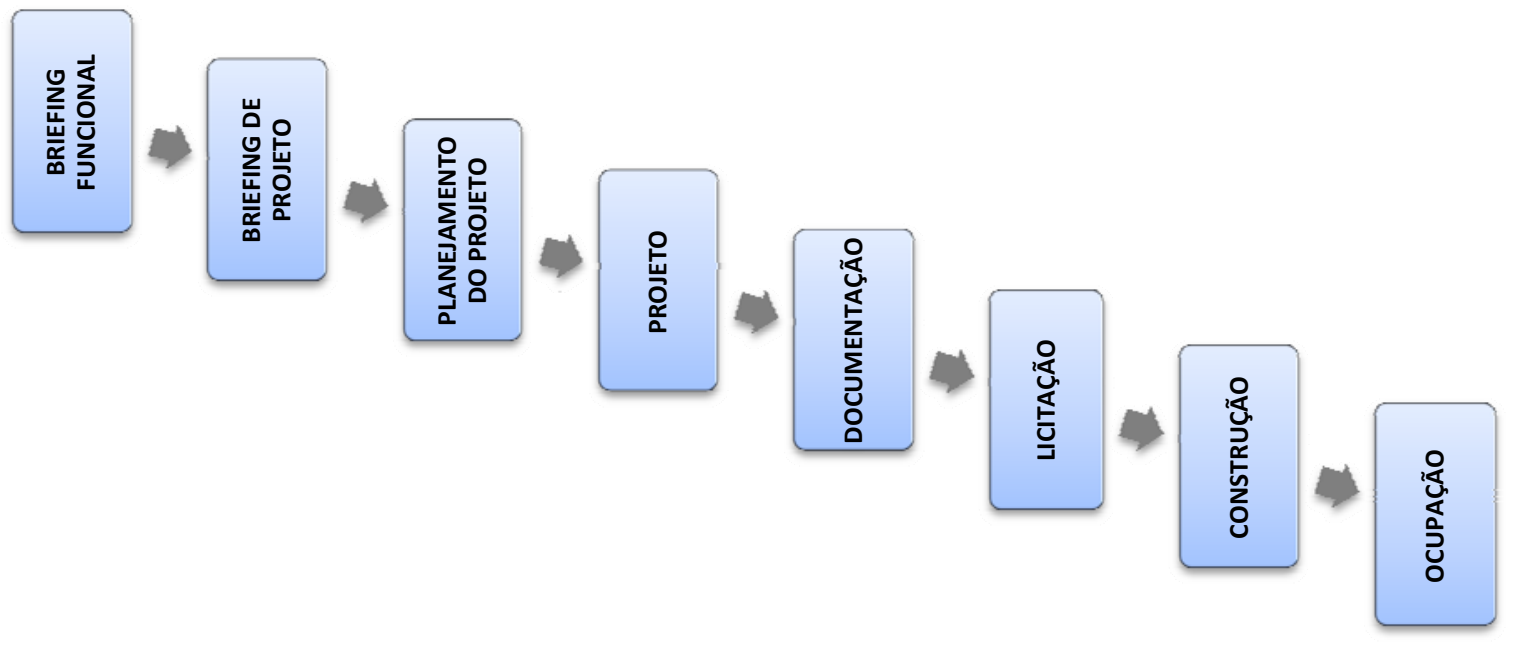

Figura 6. Modelo de Processo de Projeto Tradicional. Fonte: Mallory-Hill (2004).

Nelson (1996 ${ }^{26}$ apud MALLORY-HILL, 2004) apresenta um modelo em 'roda de retroalimentação' (figura 7), por acreditar que, com melhores mecanismos de retroalimentação do que o modelo tradicional linear, as condições de riscos entre as etapas ou a equipe de projeto, como escolha inapropriada de materiais ou um briefing inadequado, podem ser controladas com maior rigor.

\footnotetext{
${ }^{26}$ Nelson, C. E. TQM and ISO 9000 for Architects and Designers. New York: McGraw-Hill, 1996.
} 


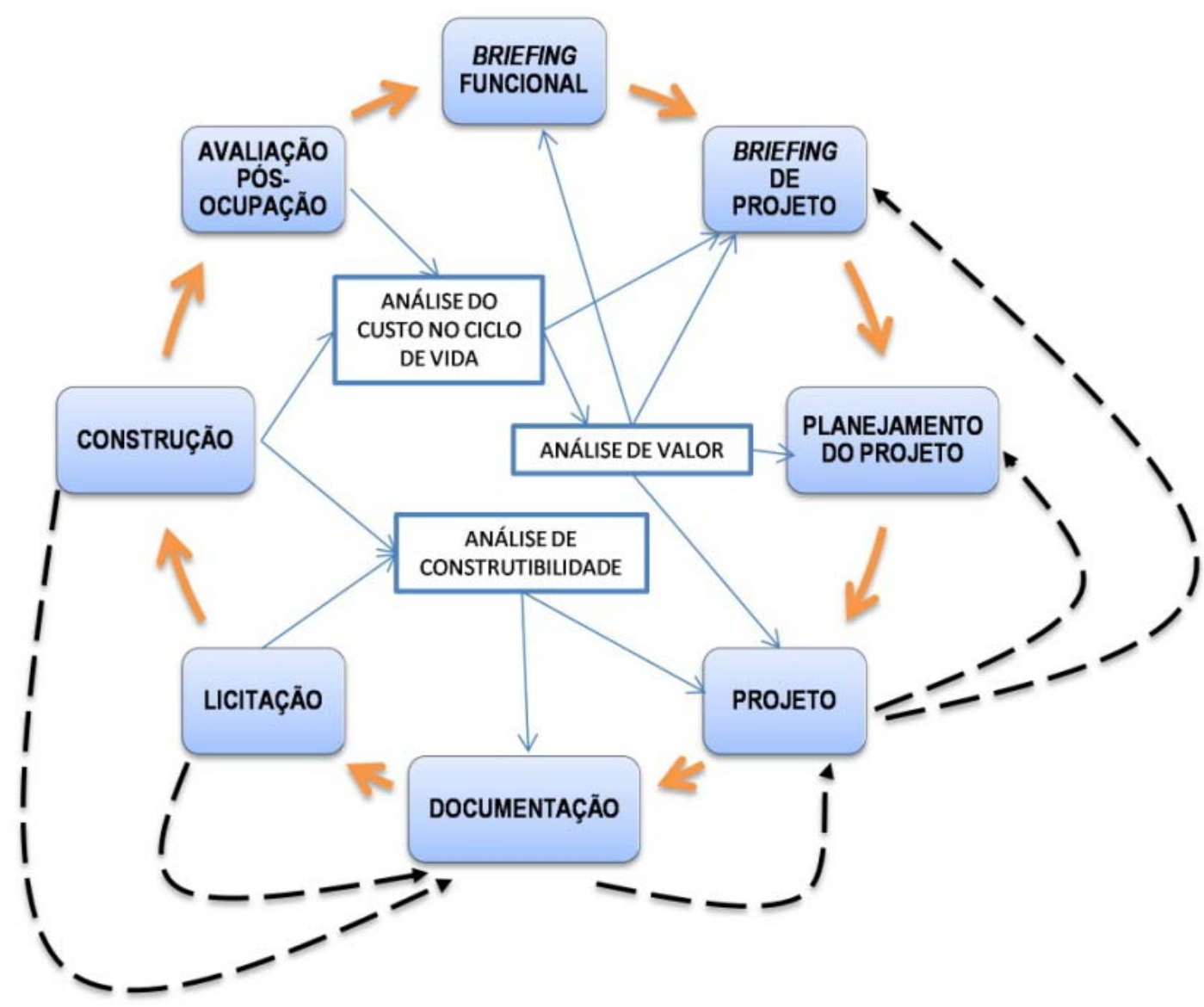

Figura 7. Modelo de Processo de Projeto Tradicional, com Ciclos de Retroalimentação. Fonte: Nelson, (1996 apud MALLORY-HILL, 2004).

Roozenburg e Cross (1991) acreditam que, no início da década de 1970 na área de arquitetura, as críticas e reformulações dos esquemas lineares, sequenciais ou de análise-síntese-avaliação se basearam na rejeição geral destes tipos de modelo.

Hillier, Musgrove e O’Sullivan (1984) propõem um novo modelo, chamado conjectura-análise $(C / A)$, que se baseia em pré-estruturas que originam os conceitos de solução, buscando o refinamento do entendimento do problema e da solução por um ciclo de conjectura-análise. Na área de metodologia em arquitetura, Bamford (2002) acredita que os modelos de processo de projeto mais importante sejam $A / S$ e $C / A$, mas que o $C / A$ é o que melhor se encaixa no contexto. No entanto, apesar de diversos estudos existentes na literatura apresentarem vários modelos de processo de projeto, nenhum deles foi aceito universalmente (ROOZENBURG; CROSS, 1991; KORKMAZ et al., 2010).

Alguns modelos mais detalhados do processo de projeto são apresentados a seguir, para servirem de base para o presente trabalho. O primeiro deles é o desenvolvido por Romano (2006), denominado Modelo de Referência para o Gerenciamento do Processo de 
Projeto Integrado de Edificações. Além da representação gráfica das fases do processo de projeto de edificações, apresentada na Figura 8, o modelo conta com uma representação descritiva, composta por de oito planilhas. Cada planilha representa uma fase do processo, detalhado por meio de sete elementos: entradas, atividades, tarefas, domínios, mecanismos, controles e saídas.

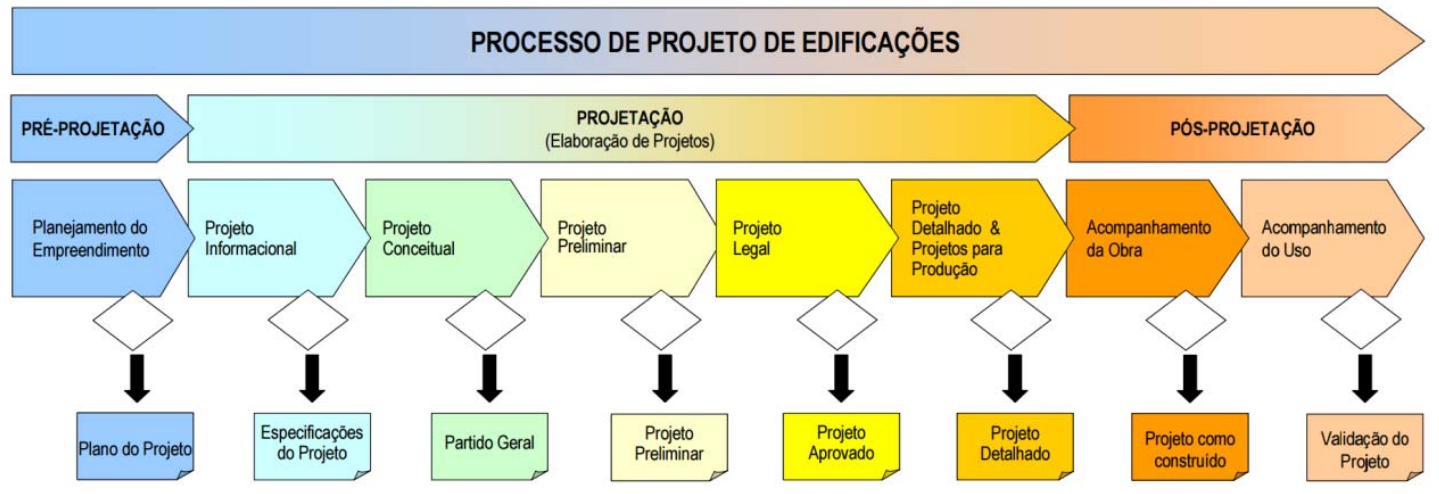

Figura 8. Modelo de Referência para o Gerenciamento do Processo de Projeto Integrado de Edificações. Fonte: Romano (2006).

Outro modelo, denominado Protocolo Genérico do Processo de Projeto e Construção - GDCPP, em inglês - foi desenvolvido considerando alguns princípios-chave, baseados na literatura e em estudos sobre os requisitos da indústria da construção civil (KAGIOGLOU et al., 2000). Estes princípios foram:

- Visão holística do projeto, para considerar o processo durante todo o ciclo de vida da edificação;

- Consistência no processo, para reduzir ambiguidades e facilitar a melhoria contínua do projeto e da construção;

- Coordenação efetiva, ao longo das atividades de cada fase do processo;

- Correção progressiva do projeto, por revisões de fases que permitem avaliar o trabalho realizado, aprovar resultados e planejar as fases seguintes;

- Envolvimento dos stakeholders e da equipe de projeto, que deverá ser multidisciplinar, para provimento das informações certas no momento adequado;

- Retroalimentação, através das revisões de fases, para viabilizar o aprendizado e o uso deste nas fases e projetos subsequentes. 
Baseado nestes princípios, o GDCPP subdivide-se em fases conforme a Figura 9. O modelo completo, com a proposição das revisões de fases e das atividades de cada fase consta no trabalho de Kagioglou et al. (2000).

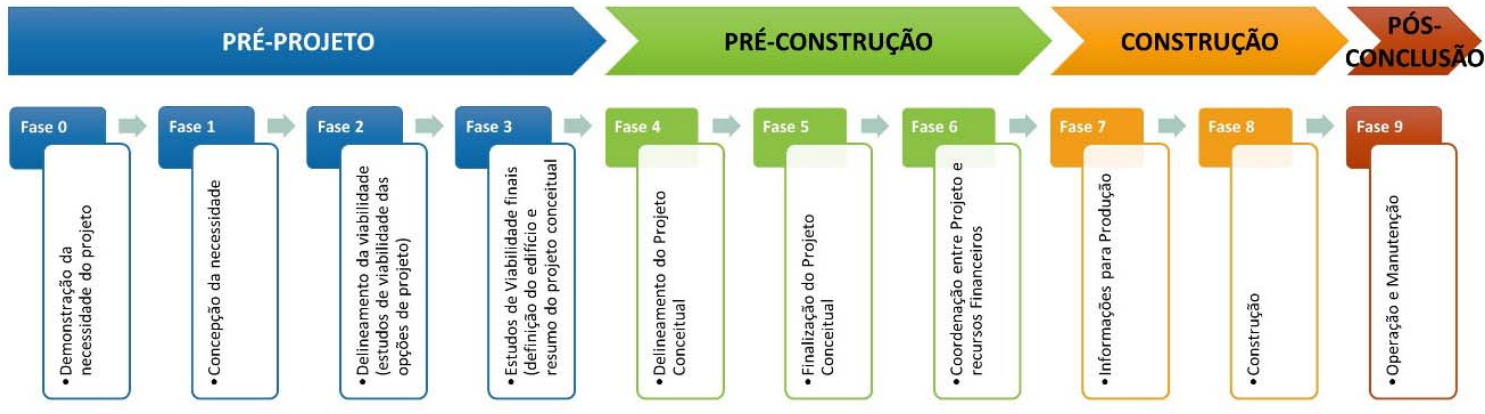

Figura 9. Fases do Protocolo Genérico do Processo de Projeto e Construção - GDCPP. Fonte: Kagioglou et al. (2000).

Em relação aos edifícios de assistência à saúde, especificamente, Dickerman e Barach (2008) descrevem o modelo tradicional do processo de projeto destes edifícios da seguinte forma:

1. O arquiteto recebe os objetivos da edificação, em termos de função e programa;

2. Traduz estes objetivos em requisitos de ambientes (programa espacial)

3. Determina as adjacências de setores;

4. Determina as adjacências de ambientes;

5. Desenvolve o projeto detalhado de cada ambiente;

6. Converte estes projetos em projetos para construção, representando o funcionamento da edificação em conjunto com os equipamentos, tecnologia e equipe.

Estes autores ressaltam que, geralmente, o planejamento de equipamentos, tecnologias, instalações, suas interfaces e impactos em relação ao fator humano ocorre nas últimas etapas do processo de projeto, e não em conjunto com a concepção da edificação.

Os diversos modelos de processo de projeto apresentados na literatura possuem pouca aplicação na prática, e muitas justificativas são encontradas na literatura para tanto. Acredita-se, por exemplo, que uma das razões é que se subestima o potencial de um processo de projeto profissional (VAN AKEN, 2005). A revisão bibliográfica apresentada por Tzortzopoulos e Sexton (2007) destaca também a atenção insuficiente aos fatores humanos relacionados à gestão do processo e a falta de motivação para colocar modelos de processos 
em prática, sem valorizar o conhecimento, os esforços e o tempo dispensados em sua elaboração.

Em pesquisa prévia - dissertação de mestrado de Caixeta (2011) - foi desenvolvido um modelo genérico para o processo de projeto de intervenções em edifícios de assistência à saúde. A Figura 10 apresenta macrofases deste modelo em relação às macrofases do PDP propostas por Rozenfeld et al. (2006).

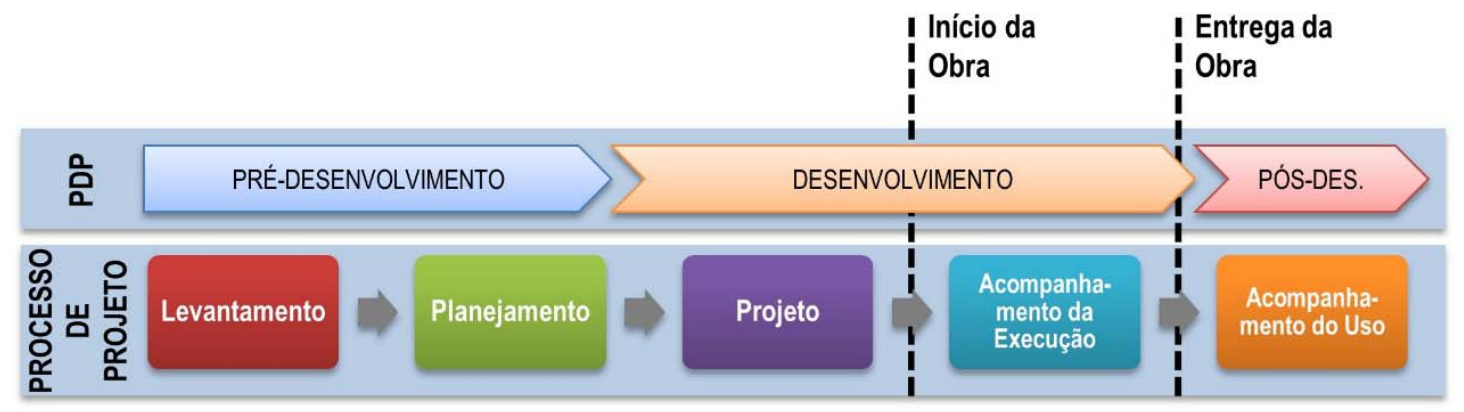

Figura 10. Processo de Projeto edifícios de assistência à saúde, dentro do contexto do PDP. Fonte: Caixeta (2011).

Na sequência, são exploradas as características específicas do processo de projeto de acordo com as macrofases de pré-desenvolvimento, desenvolvimento e pós-desenvolvimento, mostradas na Figura 10.

\subsubsection{Pré-Desenvolvimento}

O pré-desenvolvimento engloba as 'fases pré-projeto' que são relativas “às considerações estratégicas do empreendimento de qualquer projeto potencial que objetive atender às necessidades dos clientes" (KAGIOGLOU et al., 2000, p.148). Em alguns textos, são denominadas como front-end estas fases preliminares, que antecedem o projeto e construção dos edifícios, quando se tem o gerenciamento dos requisitos do projeto (TZORTZOPOULOS et al., 2006).

Frequentemente, a natureza caótica e ambígua do front-end leva os autores a chamá-lo de fuzzy front-end, como ilustrado na figura 11. Atualmente, o fuzzy front end tem recebido ênfase crescente no processo de projeto (SANDERS; STAPPERS, 2008). 


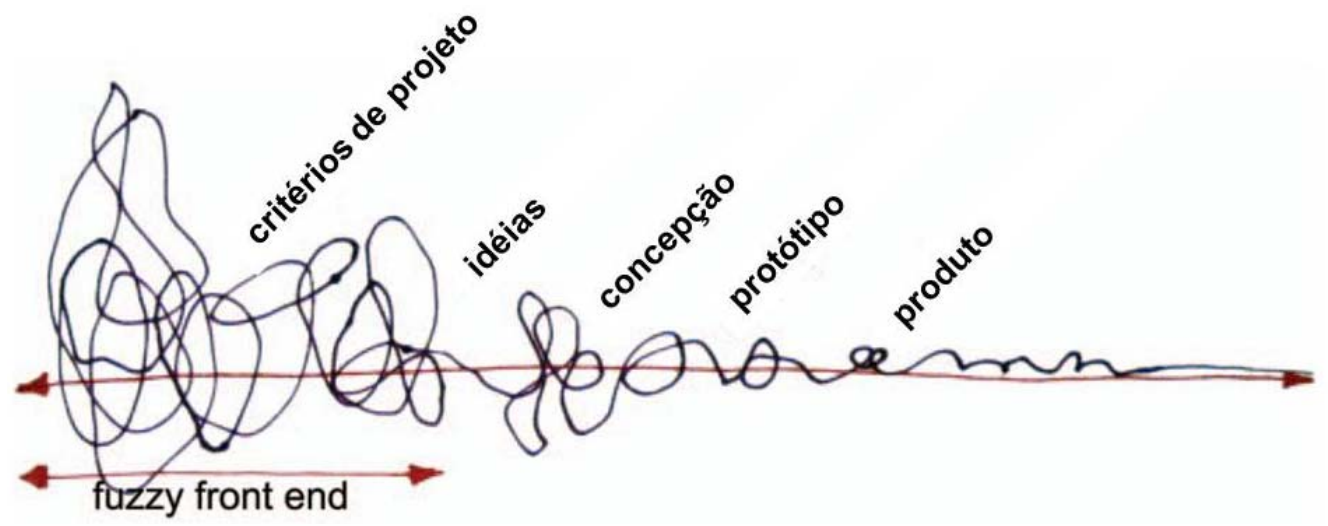

Figura 11. Crescimento do front-end com a aproximação entre projetistas e usuários. Fonte: Sanders e Stappers (2008).

Para Campobasso e Hosking (2004), os líderes de edifícios de assistência à saúde tendem a iniciar o processo de projeto diretamente focados na concepção e construção do espaço físico em si, geralmente com contatos de arquitetos com quem já se relacionam. Estes autores acreditam que o motivo para esta postura seja que o espaço físico "é o aspecto mais visível do futuro hospital" (CAMPOBASSO; HOSKING, 2004, p.222). Este procedimento não permite que o projeto seja orientado pelo serviço, e sim pela arquitetura. No entanto, os autores defendem que é necessário articular a visão geral do edifício de saúde, estabelecer os objetivos estratégicos, planejar os fundamentos da organização e alcançar um consenso antes de iniciar a concepção do espaço físico em si. Para Caixeta e Fabricio (2013), no processo de projeto de edifícios complexos como os de saúde, o projeto do espaço físico deve ser precedido pelo projeto e planejamento das atividades e serviços que serão realizados na edificação.

Na construção civil, utiliza-se o termo briefing para designar os requisitos para o projeto dos edifícios. $O$ briefing, que tem como objetivo garantir o alinhamento entre a estratégia de negócio e processo de trabalho (JENSEN, 2011), é considerado um dos mais importantes processos num projeto para construção, uma vez que, nesta etapa, as melhorias podem ampliar a satisfação dos clientes (JENSEN, 2006; AL ZAROONI; ABDOU; LEWIS, 2011; JENSEN, 2011).

A princípio, o briefing era considerado um documento estático, no entanto, acreditase atualmente que a captura de requisitos é um processo contínuo ao longo do processo de desenvolvimento do produto (TZORTZOPOULOS et al., 2006; JENSEN, 2011). Assim, tem-se como definições:

- Visão tradicional de briefing (estático, documento): antecede o projeto e os documentos resultantes contêm os requisitos dos clientes para o projeto, 
usualmente escrito por especialistas. A grande crítica é que as necessidades que surgem ao longo do processo de projeto não podem ser preditas em conferência (JENSEN, 2011).

- Briefing dinâmico, inclusivo (processo e não documento): engloba "as necessidades de todos os clientes e usuários no desenvolvimento de um componente e é um processo contínuo com mudança de foco em diferentes fases" (JENSEN, 2011, p.32).

O quadro 8 compara o briefing tradicional com o briefing inclusivo.

Quadro 8. Briefing tradicional e inclusivo. Fonte: Jensen (2011).

\begin{tabular}{|c|c|}
\hline BRIEFING TRADICIONAL & BRIEFING INCLUSIVO \\
\hline Refere-se ao novo edifício/ construção & $\begin{array}{l}\text { Refere-se às necessidades de todos os clientes/ } \\
\text { usuários no desenvolvimento de componentes }\end{array}$ \\
\hline Uma fase definida num estágio inicial & $\begin{array}{l}\text { Um processo contínuo com o foco mudando em } \\
\text { diferentes fases }\end{array}$ \\
\hline $\begin{array}{l}\text { Uma coleta de informações baseada em } \\
\text { especialistas }\end{array}$ & Um processo de aprendizagem guiada e diálogo \\
\hline $\begin{array}{l}\text { Usuário envolvido principalmente como fonte de } \\
\text { dados }\end{array}$ & $\begin{array}{l}\text { Usuário envolvido efetivamente como parte de um } \\
\text { processo de mudança da corporação/ empresa }\end{array}$ \\
\hline $\begin{array}{l}\text { O resultado é um resumo, isto é, uma } \\
\text { especificação de requisitos }\end{array}$ & $\begin{array}{l}\text { O resultado é a aceitação de soluções baseadas } \\
\text { num resumo }\end{array}$ \\
\hline
\end{tabular}

O coordenador de projeto precisa balancear os interesses dos dois grupos envolvidos no briefing: a demanda (usuários e clientes) e o suprimento (profissionais envolvidos no projeto), que possuem interesses e linguagens distintos, promovendo uma comunicação eficiente entre eles. A linguagem dos usuários foca o negócio, e dos profissionais de projeto foca a construção, com a linguagem técnica apropriada (BLYTH; WORTHINGTON, 2001).

A importância do briefing para o sucesso do projeto, em termos de qualidade, tempo, custo e funcionalidade, tem sido demonstrada em diversas pesquisas, considerando projetos de edifícios em diferentes contextos (CHANDRA; LOOSEMORE, 2011). No entanto, estes mesmos autores ressaltam uma série de problemas comuns, que podem prejudicar a efetividade do briefing, tais como uma abordagem desestruturada; dificuldade de os clientes compreenderem suas próprias necessidades; pressões sobre prazos para execução do briefing; dificuldades de comunicação, que dificulta a captura das necessidades dos usuários por parte dos projetistas; entre outros fatores. 
A complexidade dos projetos de edifícios de assistência à saúde requer maior ênfase na fase inicial do processo de projeto do que outros tipos de edifícios, para entendimento de todo o empreendimento, incluindo os tipos de serviços prestados, atividades que serão realizadas, tipos de usuários e fluxos, entre outros (CAIXETA; FABRICIO, 2013). A natureza temporária das equipes de projeto de edifícios de assistência à saúde e a terceirização de projetistas ampliam a dificuldade de compreensão das reais necessidades, pois muitas vezes estes projetistas podem não ter experiência direta no setor de saúde, marcado pela singularidade em sua cultura, práticas e estruturas de poder (CHANDRA; LOOSEMORE, 2011).

Diversos autores defendem que as decisões tomadas no início do processo de projeto de um edifício influenciam definitivamente as etapas seguintes do ciclo de vida da edificação (WATCH, 2001; ANTUNES; CALMON, 2005). Segundo Watch (2001), as decisões tomadas no início do processo de projeto são as que mais impactam o processo, ao mesmo tempo em que, se tomadas neste momento, terão um custo menor (Gráfico 3). Antunes e Calmon (2005) afirmam que alguns fatores que irão impactar o desempenho de edifício de forma decisiva são: o partido arquitetônico adotado, os elementos e componentes especificados, as definições do sistema funcional e as considerações em relação ao uso, operação e manutenção. Esses fatores também influenciam no atendimento das necessidades dos seus futuros usuários e nas facilidades de operação e procedimento da manutenção.

Gráfico 3. Impacto e custo das decisões ao longo do processo de projeto de um edifício. Fonte: Watch (2001).

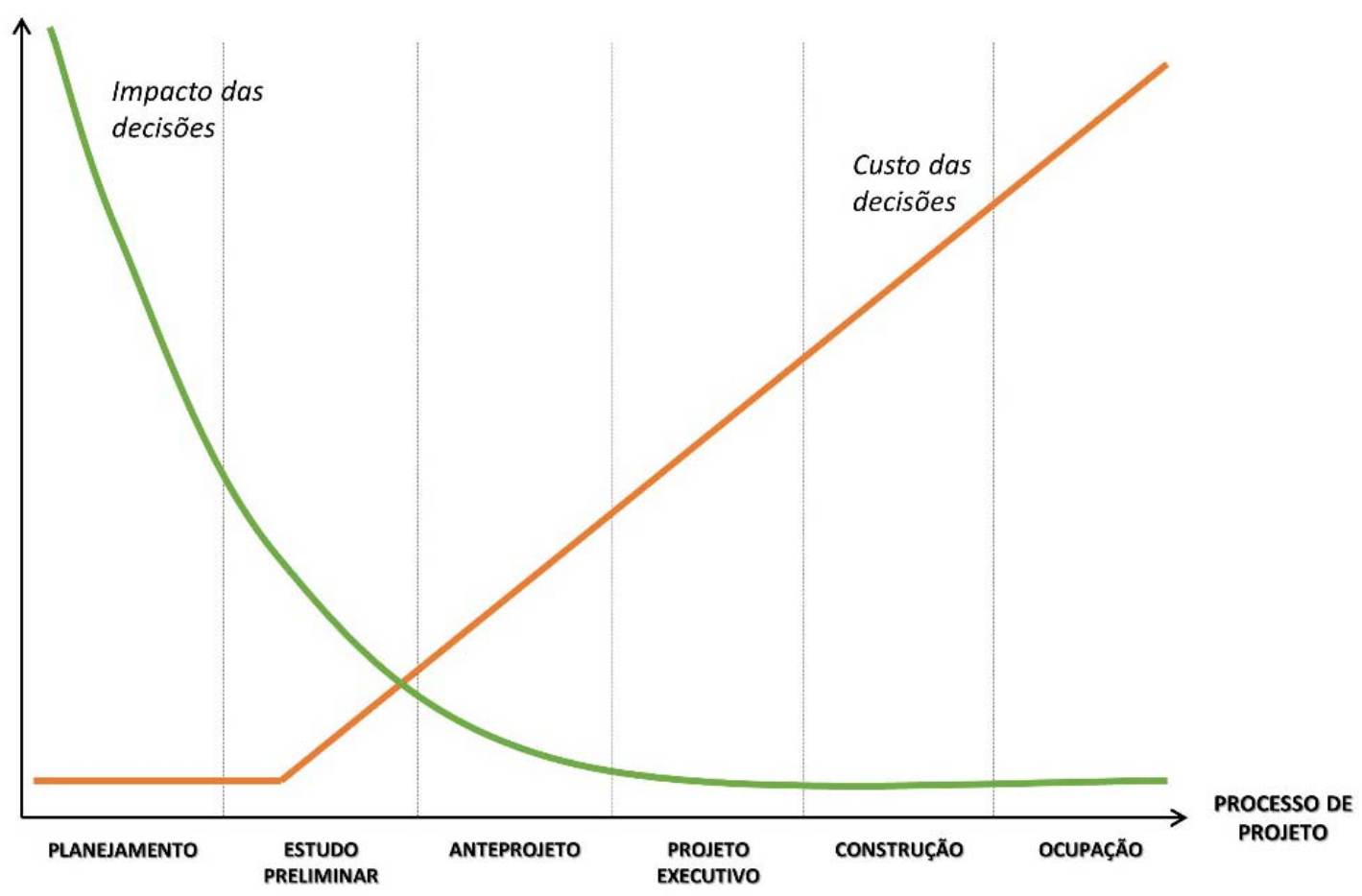


Na mesma linha, Tompkins et al. (2010) apresentam um gráfico ilustrando que, conforme o processo de projeto avança além das fases iniciais - planejamento e projeto - o custo de efetuar alterações aumenta exponencialmente (Gráfico 4).

Gráfico 4. Custo das alterações durante o processo de projeto. Fonte: Tompkins et al.(2010).

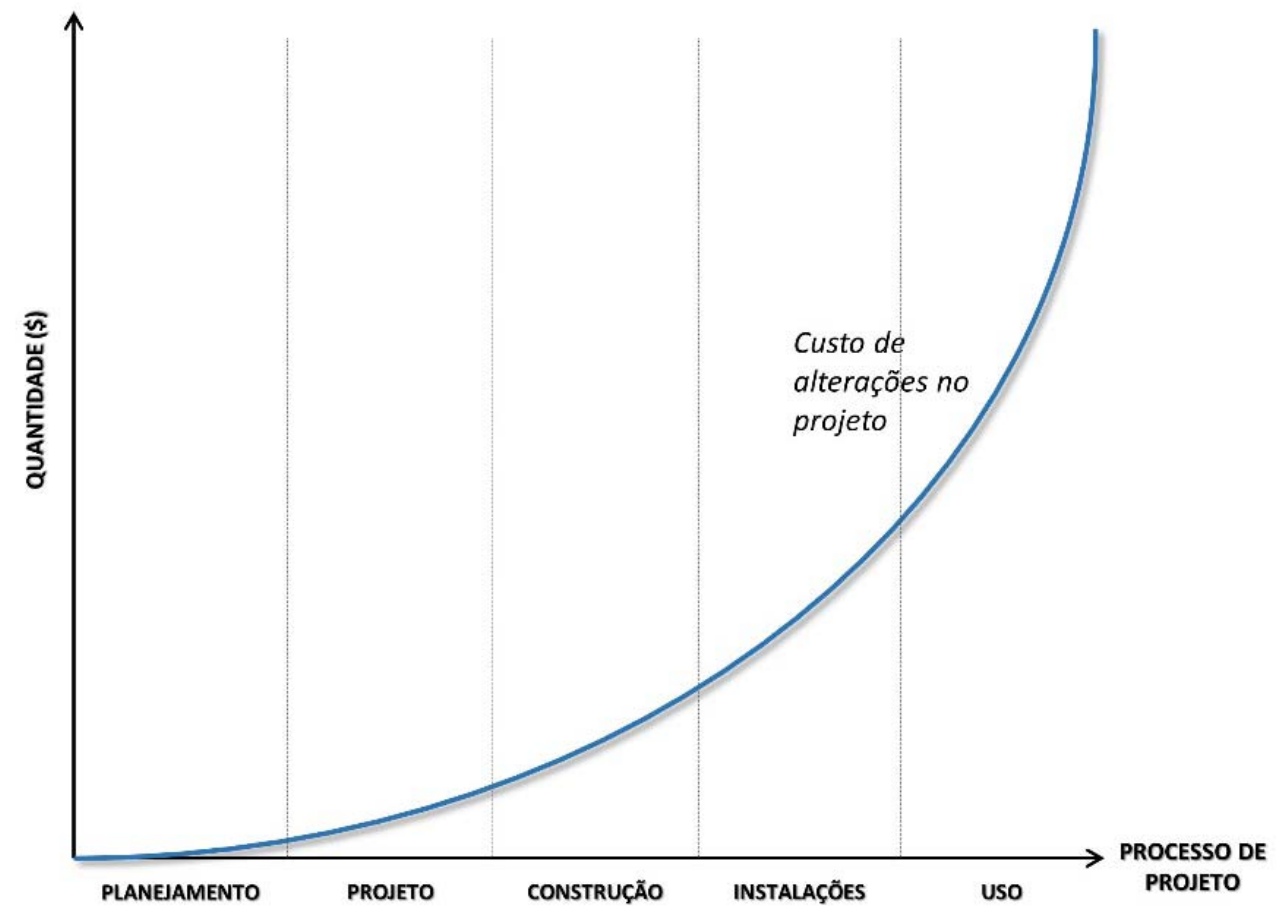

Carvalho (2012) apresenta um método para auxílio de projetos arquitetônicos de EASs, organizado nas seguintes etapas: conhecimento do programa, proposição e avaliações. Destaca-se aqui a primeira etapa, que o autor também denomina 'programação arquitetônica' e define como "conjunto de procedimentos que precedem e preparam a síntese projetual, e coincide com o que Robert Hershberger (1999) ${ }^{27}$ denominou pesquisa pré-projeto" (CARVALHO, 2012, p.12). O autor descreve métodos para realização desta etapa, e a subdivide conforme o diagrama apresentado na figura 12. Esta etapa resulta numa listagem dos espaços e atividades, ou seja, o programa arquitetônico. Segundo Carvalho, naturalmente se associam atividades a espaços em projetos arquitetônicos. Entretanto, um único espaço pode abrigar atividades distintas ou repetidas, e também uma única atividade pode requerer vários espaços diferentes, de forma que a correspondência linear entre atividade e espaço nem sempre é adequada.

\footnotetext{
${ }^{27}$ HERSHBERGER, R. Architectural programming \& predesign manager. Nova York: McGraw-Hill, 1999.
} 


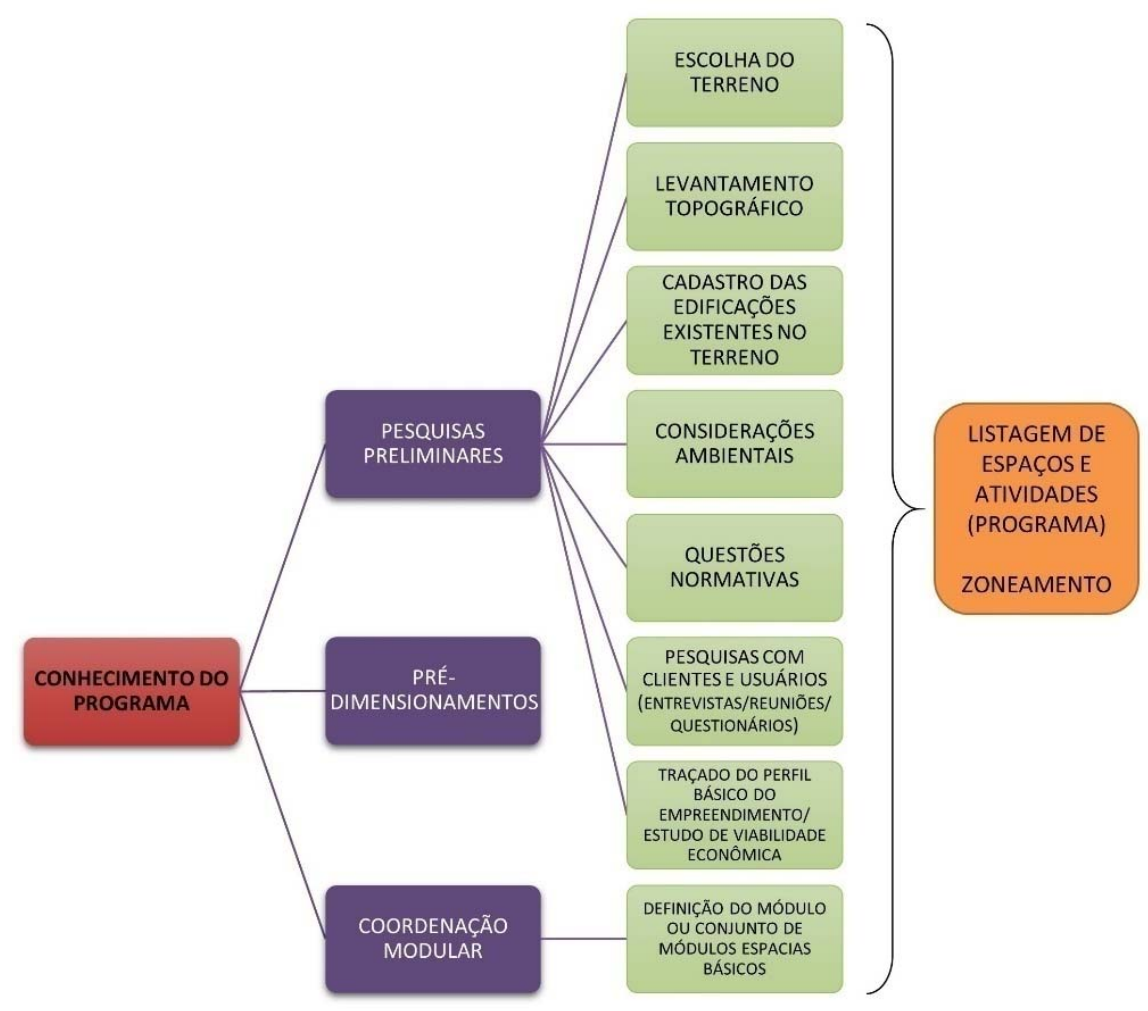

Figura 12. Etapa de conhecimento do programa. Fonte: Diagrama elaborado a partir do texto de Carvalho (2012).

\subsubsection{Desenvolvimento}

No desenvolvimento, ocorre o projeto propriamente dito da edificação e o acompanhamento da execução. Existem normas vigentes sobre a subdivisão desta macro-fase, que são abordadas e descritas na seção 3.3.4.

O desenvolvimento do plano diretor do empreendimento, para embasamento do projeto, é destacado na literatura. A definição de 'Plano Diretor', em urbanismo, engloba as exigências que são fundamentais para ordenar a cidade e se constitui como a base instrumental da política de desenvolvimento e expansão urbana (BRASIL, 2001). Especificamente em projetos de edifícios de assistência à saúde, o Plano Diretor Hospitalar (PDH) tem a função de estabelecer diretrizes de expansão do EAS, em relação aos aspectos físicos, programáticos e de infraestrutura (TOLEDO, 2002).

A importância do acompanhamento da construção é garantir, segundo Caixeta e Fabricio (2013), que os requisitos que orientaram o projeto e o projeto sejam plenamente atingidos. Em intervenções, a execução pode trazer novas informações para o projeto, que não puderam ser levantados antes das obras. Isto pode demandar a retomada do projeto para 
adequá-lo aos novos dados. Dependendo da escala das alterações, podem ser necessárias novas aprovações junto aos órgãos competentes.

O projeto 'as built', que registra eventuais alterações de projeto durante a obra, é fundamental para orientar futuras intervenções e como base documental para o acompanhamento do uso.

\subsubsection{Pós-desenvolvimento}

Após a entrega da obra, é importante realizar a Avaliação do Desempenho da Edificação e Acompanhamento da Manutenção, para prolongar a vida útil da edificação e retroalimentar o processo. Na Avaliação do Desempenho, o espaço físico é analisado em relação aos requisitos dos usuários, levantados no início do processo de projeto. Já o Acompanhamento da Manutenção tem como função garantir a qualidade da manutenção no espaço físico, por incluir na equipe profissionais de projeto que conhecem o projeto e a construção da edificação.

\subsubsection{Regulamentações}

A norma técnica NBR 13531 estabelece as atividades técnicas de projeto de engenharia e arquitetura para a construção de edifícios no Brasil. Nesta norma, são apresentadas as etapas de projeto, como "partes sucessivas em que pode ser dividido o processo de desenvolvimento das atividades técnicas do projeto de edificação e de seus elementos, instalações e componentes" (ASSOCIAÇÃO BRASILEIRA DE NORMAS TÉCNICAS - ABNT, 1995a, p.4). Já a NBR 13532, específica para projetos de arquitetura, apresenta as informações a utilizar e a produzir e os documentos a produzir para cada uma destas etapas (ABNT, 1995b). O Quadro 9 resume as informações quanto às etapas do processo de projeto apresentadas nestas duas normas. 
Quadro 9. Etapas dos projetos de edificações. Fonte: ABNT (1995a; 1995b).

\begin{tabular}{|c|c|c|c|c|}
\hline \multicolumn{2}{|r|}{$\begin{array}{l}\text { PROJETO DE EDIFICAÇÕES } \\
\text { (NBR 13531) }\end{array}$} & \multicolumn{3}{|c|}{$\begin{array}{l}\text { PROJETO DE EDIFICAÇÕES - ARQUITETURA } \\
\text { (NBR 13532) }\end{array}$} \\
\hline $\begin{array}{l}\text { ETA } \\
\text { PAS }\end{array}$ & DEFINIÇÃO & $\begin{array}{l}\text { INFORMAÇÕES A } \\
\text { UTILIZAR }\end{array}$ & $\begin{array}{l}\text { INFORMAÇÕES A } \\
\text { PRODUZIR }\end{array}$ & $\begin{array}{l}\text { DOCUMENTOS A } \\
\text { PRODUZIR }\end{array}$ \\
\hline 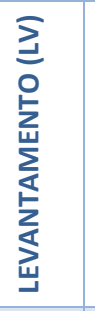 & $\begin{array}{l}\text { Coleta das informações de } \\
\text { referência que } \\
\text { representem as } \\
\text { informações preexistentes } \\
\text { que instruirão a elaboração } \\
\text { do projeto. }\end{array}$ & $\begin{array}{c}\text { - Levantamento } \\
\text { topográfico e cadastral; } \\
\text {-Outras. }\end{array}$ & $\begin{array}{l}\text { - Registros de vistorias } \\
\text { no local e de arquivos } \\
\text { cadastrais (dados da } \\
\text { vizinhança, legislação, } \\
\text { serviços públicos, } \\
\text { terreno, edificação } \\
\text { existente, etc.); } \\
\text { - Outras. }\end{array}$ & $\begin{array}{l}\text { - Desenhos: cadastrais } \\
\text { da vizinhança, terreno e } \\
\text { edificações existentes; } \\
\text { - Texto: Relatório; } \\
\text { - Fotografias; } \\
\text { - Outros. }\end{array}$ \\
\hline 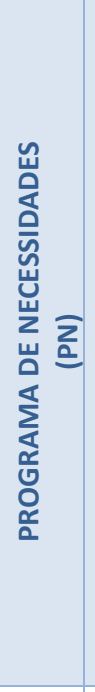 & $\begin{array}{l}\text { Determinação das } \\
\text { exigências de caráter } \\
\text { prescritivo ou de } \\
\text { desempenho (necessidades } \\
\text { e expectativas dos } \\
\text { usuários). }\end{array}$ & $\begin{array}{l}\text { - Levantamento de } \\
\text { dados para a arquitetura } \\
\text { (LV-ARQ) } \\
\text { - Outras. }\end{array}$ & $\begin{array}{l}\text { - As necessárias à } \\
\text { concepção } \\
\text { arquitetônica: nome, } \\
\text { número e dimensões } \\
\text { dos ambientes (a } \\
\text { construir, ampliar, } \\
\text { reformar, etc.), usuários, } \\
\text { características, etc., } \\
\text { - Características } \\
\text { funcionais ou das } \\
\text { atividades de cada } \\
\text { ambiente; } \\
\text {-Características dos } \\
\text { equipamentos e } \\
\text { mobiliário; } \\
\text { desempenho, exigências } \\
\text { ambientais, instalações } \\
\text { de cada ambiente. }\end{array}$ & $\begin{array}{c}\text { - Desenhos: } \\
\text { organogramas } \\
\text { funcionais e esquemas } \\
\text { básicos; } \\
\text { - Texto: Memorial (de } \\
\text { recomendações gerais) } \\
\text { - Planilha: relação } \\
\text { ambiente/ usuários/ } \\
\text { atividades/ } \\
\text { equipamento/ } \\
\text { mobiliário, incluindo } \\
\text { características, } \\
\text { exigências, dimensões e } \\
\text { quantidades. }\end{array}$ \\
\hline 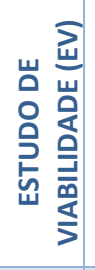 & $\begin{array}{c}\text { Elaboração de análise e } \\
\text { avaliações para seleção e } \\
\text { recomendação de } \\
\text { alternativas para a } \\
\text { concepção da edificação e } \\
\text { de seus elementos, } \\
\text { instalações e componentes. }\end{array}$ & $\begin{array}{c}\text { - LV-ARQ; } \\
\text { - PN-ARQ; } \\
\text { - Levantamento de } \\
\text { dados obtidos pelas } \\
\text { demais atividades } \\
\text { técnicas. }\end{array}$ & $\begin{array}{l}\text { - Metodologia } \\
\text { empregada; } \\
\text { - Soluções alternativas } \\
\text { (físicas e jurídico-legais); } \\
\text { - Conclusões e } \\
\text { recomendações. }\end{array}$ & $\begin{array}{l}\text { - Desenhos: esquemas } \\
\text { gráficos, diagramas e } \\
\text { histogramas; } \\
\text { - Textos: relatórios. } \\
\text { - Outros. }\end{array}$ \\
\hline 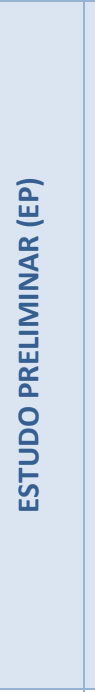 & $\begin{array}{l}\text { Concepção e representação } \\
\text { do conjunto de } \\
\text { informações técnicas } \\
\text { iniciais e aproximadas, para } \\
\text { compreensão da } \\
\text { configuração da edificação } \\
\text { (com ou sem soluções } \\
\text { alternativas). }\end{array}$ & $\begin{array}{c}\text { - PN-ARQ; } \\
\text { - PN de outras atividades } \\
\text { técnicas (se necessário); } \\
\text { - LV topográfico e } \\
\text { cadastral; } \\
\text { - LV-ARQ; } \\
\text { - EV-ARQ; } \\
\text { - Outras. }\end{array}$ & $\begin{array}{l}\text { - Sucintas e suficientes } \\
\text { para caracterização } \\
\text { geral da concepção } \\
\text { adotada (funções, usos, } \\
\text { formas, dimensões e } \\
\text { localização dos } \\
\text { ambientes), exigências } \\
\text { prescritas ou de } \\
\text { desempenho; } \\
\text { - Sucintas para } \\
\text { caracterização específica } \\
\text { de elementos } \\
\text { construtivos/ } \\
\text { componentes principais. } \\
\text { Tecnologia } \\
\text { recomendada. } \\
\text { - Soluções alternativas } \\
\text { (vantagens/ desvant.) }\end{array}$ & $\begin{array}{l}\text { - Desenhos: Planta geral } \\
\text { de implantação; planta } \\
\text { dos pavimentos; planta } \\
\text { de cobertura; cortes } \\
\text { longitudinais e } \\
\text { transversais; elevações } \\
\text { (fachadas); detalhes } \\
\text { construtivos se } \\
\text { necessário } \\
\text { - Texto: memorial } \\
\text { justificativo (opcional) } \\
\text { - Opcionais: } \\
\text { perspectivas, maquetes, } \\
\text { fotografias, recursos } \\
\text { audiovisuais, etc. }\end{array}$ \\
\hline 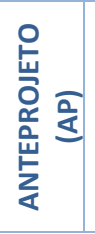 & $\begin{array}{l}\text { Concepção e representação } \\
\text { das informações técnicas } \\
\text { provisórias de } \\
\text { detalhamento da edificação } \\
\text { e de seus elementos, } \\
\text { instalações e componentes, }\end{array}$ & $\begin{array}{c}\text { - EP-ARQ; } \\
\text { - EP de outras atividades } \\
\text { técnicas (se necessário); } \\
\text { - LV topográfico e } \\
\text { cadastral; } \\
\text { - Sondagens de simples }\end{array}$ & $\begin{array}{l}\text { - Informações técnicas } \\
\text { relativas à edificação } \\
\text { (ambientes interiores e } \\
\text { exteriores), a todos os } \\
\text { elementos da edificação } \\
\text { e a seus componentes }\end{array}$ & $\begin{array}{l}\text { - Desenhos: Planta geral } \\
\text { de implantação, de } \\
\text { terraplanagem, cortes } \\
\text { de terraplanagem, } \\
\text { planta dos pavimentos, } \\
\text { de cobertura, cortes }\end{array}$ \\
\hline
\end{tabular}




\begin{tabular}{|c|c|c|c|c|}
\hline \multicolumn{2}{|r|}{$\begin{array}{l}\text { PROJETO DE EDIFICAÇÕES } \\
\text { (NBR 13531) }\end{array}$} & \multicolumn{3}{|c|}{$\begin{array}{l}\text { PROJETO DE EDIFICAÇÕES - ARQUITETURA } \\
\text { (NBR 13532) }\end{array}$} \\
\hline & $\begin{array}{c}\text { para o inter- } \\
\text { relacionamento das } \\
\text { atividades técnicas de } \\
\text { projeto e à elaboração de } \\
\text { estimativas de custo/ prazo } \\
\text { estimadas dos serviços de } \\
\text { obra. }\end{array}$ & $\begin{array}{l}\text { reconhecimento do solo } \\
\text { (LV-SDG); } \\
\text { - Outras. }\end{array}$ & $\begin{array}{c}\text { construtivos } \\
\text { considerados relevantes. }\end{array}$ & $\begin{array}{c}\text { (longit/ transversais), } \\
\text { elevações (fachadas), } \\
\text { detalhes; } \\
\text { - Texto: memorial } \\
\text { descritivo da edificação; } \\
\text { memorial descritivo dos } \\
\text { elementos, } \\
\text { componentes e } \\
\text { materiais de construção. }\end{array}$ \\
\hline 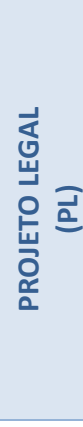 & $\begin{array}{l}\text { Representação das } \\
\text { informações técnicas para } \\
\text { análise e aprovação pelas } \\
\text { autoridades competentes e } \\
\text { obtenção de alvarás/ } \\
\text { licenças necessárias às } \\
\text { atividades de construção }\end{array}$ & $\begin{array}{c}\text { - AP-ARQ; } \\
\text { - AP de outras atividades } \\
\text { técnicas (se necessário); } \\
\text { - LV topográfico e } \\
\text { cadastral; } \\
\text {-Legislação pertinente } \\
\text { (municipal, estadual e } \\
\text { federal); } \\
\text {-Normas técnicas } \\
\text { (INMETRO e ABNT). }\end{array}$ & $\begin{array}{l}\text { - As necessárias e } \\
\text { suficientes ao } \\
\text { atendimento das } \\
\text { exigências legais para os } \\
\text { procedimentos de } \\
\text { análise/ aprovação do PL } \\
\text { e da construção (nos } \\
\text { órgãos públicos e } \\
\text { companhias } \\
\text { concessionárias de } \\
\text { serviços públicos) }\end{array}$ & $\begin{array}{l}\text { - Desenhos e textos } \\
\text { exigidos na legislação e } \\
\text { normas pertinentes, dos } \\
\text { órgãos públicos e } \\
\text { companhias } \\
\text { concessionárias a que o } \\
\text { projeto será submetido } \\
\text { para aprovação. }\end{array}$ \\
\hline 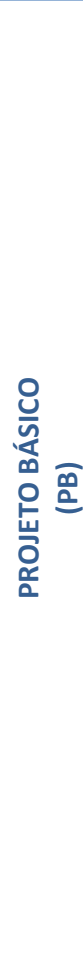 & $\begin{array}{c}\text { (Opcional) } \\
\text { Concepção e representação } \\
\text { final das informações } \\
\text { técnicas da edificação/ } \\
\text { elementos/ componentes/ } \\
\text { instalações ainda não } \\
\text { completas ou definitivas, } \\
\text { mas consideradas } \\
\text { compatíveis com os } \\
\text { projetos básicos das } \\
\text { atividades técnicas } \\
\text { necessárias e suficientes à } \\
\text { contratação dos serviços de } \\
\text { obra correspondentes. }\end{array}$ & $\begin{array}{l}\text { - AP-ARQ; } \\
\text { - AP de outras atividades } \\
\text { técnicas (se necessário); } \\
\text { - Outras. }\end{array}$ & $\begin{array}{c}\text { - As relativas à } \\
\text { edificação (ambientes } \\
\text { interiores e exteriores), } \\
\text { a todos os elementos da } \\
\text { edificação, a seus } \\
\text { componentes } \\
\text { construtivos e materiais } \\
\text { de obra; } \\
\text { - As exigências de } \\
\text { detalhamento devem } \\
\text { depender da } \\
\text { complexidade funcional } \\
\text { ou formal da edificação. }\end{array}$ & $\begin{array}{l}\text {-Desenhos: Implantação, } \\
\text { terraplanagem (planta e } \\
\text { cortes), planta dos } \\
\text { pavimentos/ cobertura, } \\
\text { cortes, elevações } \\
\text { (frontais, posteriores e } \\
\text { laterais), plantas, cortes } \\
\text { e elevações de } \\
\text { ambientes especiais; } \\
\text { detalhes de } \\
\text { componentes; } \\
\text { - Texto: memorial } \\
\text { descritivo da edificação } \\
\text { e dos elementos, } \\
\text { instalações, } \\
\text { componentes e } \\
\text { materiais de construção; } \\
\text { memorial quantitativo } \\
\text { dos componentes } \\
\text { construtivos e materiais } \\
\text { de construção. } \\
\text { - Opcionais: } \\
\text { perspectivas, maquetes, } \\
\text { fotografias, recursos } \\
\text { audiovisuais, etc. }\end{array}$ \\
\hline 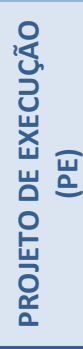 & $\begin{array}{l}\text { Concepção e representação } \\
\text { final das informações } \\
\text { técnicas da edificação/ } \\
\text { elementos/ componentes/ } \\
\text { instalações completas, } \\
\text { definitivas, necessárias e } \\
\text { suficientes à contratação e } \\
\text { execução dos serviços de } \\
\text { obra correspondentes. }\end{array}$ & $\begin{array}{l}\text { - AP-ARQ ou PB-ARQ; } \\
\text { - AP ou PB de outras } \\
\text { atividades técnicas; } \\
\text { - Outras. }\end{array}$ & Semelhantes ao PB. & Semelhantes ao PB. \\
\hline
\end{tabular}

Na Inglaterra, o Royal Institute of British architects - RIBA apresenta, em seu delineamento do Plano de Trabalho, uma organização em etapas-chave de trabalho para o processo de 
administração e projeto do edifício, bem como administração dos contratos. O quadro 10 traz as etapas deste Plano de Trabalho, com a descrição de suas principais tarefas.

\section{Quadro 10. Plano de Trabalho. Fonte: RIBA.}

\begin{tabular}{|c|c|c|}
\hline \multirow{2}{*}{ 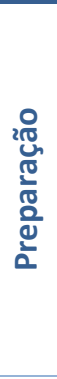 } & 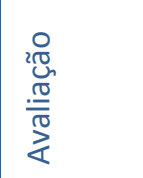 & $\begin{array}{l}\text { Identificação das necessidades e objetivos dos clientes, caso (negócio) e possíveis } \\
\text { restrições ao desenvolvimento. } \\
\text { Elaboração de estudos de viabilidade e avaliação de opções para permitir que o } \\
\text { cliente possa decidir se deseja prosseguir. }\end{array}$ \\
\hline & 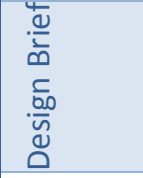 & $\begin{array}{l}\text { Desenvolvimento da indicação inicial de requisitos para o Design Brief por ou em } \\
\text { nome do cliente confirmando os principais requisitos e restrições. Identificação do } \\
\text { método de aquisição, procedimentos, estrutura organizacional e gama de consultores } \\
\text { e outros para serem contratados para o projeto. }\end{array}$ \\
\hline \multirow{3}{*}{ 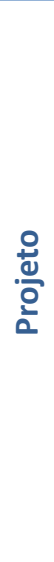 } & 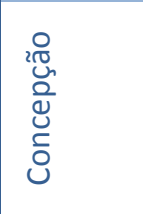 & $\begin{array}{l}\text { Implementação do Design Brief e preparação de dados adicionais. } \\
\text { Preparação do Projeto Conceitual, incluindo propostas preliminares para sistemas } \\
\text { estruturais e de serviços do edifício, especificações de esboço e um plano de custo } \\
\text { preliminar. } \\
\text { Revisão da rotina de aquisição. }\end{array}$ \\
\hline & 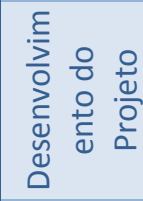 & $\begin{array}{l}\text { Desenvolvimento do Projeto Conceitual para incluir os sistemas estruturais e de } \\
\text { serviços do edifício, atualizaras especificações esboçadas e o plano de custos. } \\
\text { Finalização do Briefing de Projeto. } \\
\text { Requerimento de permissão para planejamento detalhado. }\end{array}$ \\
\hline & 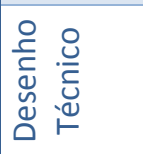 & $\begin{array}{l}\text { Preparação do(s) Desenho(s) Técnico(s) e especificações, suficientes para } \\
\text { coordenação de componentes e elementos do projeto e informações sobre os } \\
\text { padrões legais e de segurança das construções. }\end{array}$ \\
\hline \multirow{3}{*}{ 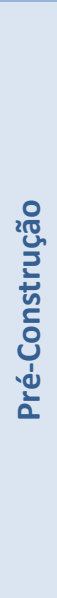 } & 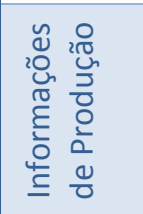 & $\begin{array}{l}\text { Preparação das informações de produção com detalhes suficientes para permitir a } \\
\text { obtenção de proposta(s). } \\
\text { Permissão para aprovações legais. } \\
\text { Preparação de informações adicionais para construção requeridas no contrato do } \\
\text { edifício. }\end{array}$ \\
\hline & 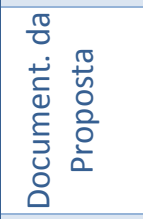 & $\begin{array}{l}\text { Preparação e/ou verificação da documentação da proposta com detalhes suficientes } \\
\text { para permitir a obtenção de um ou mais proponentes para o projeto. }\end{array}$ \\
\hline & 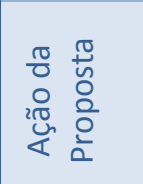 & $\begin{array}{l}\text { Identificação e avaliação de empreiteiros e / ou especialistas em potencial para o } \\
\text { projeto. } \\
\text { Obtenção e avaliação das propostas; apresentação de recomendações para o cliente. }\end{array}$ \\
\hline \multirow{2}{*}{ 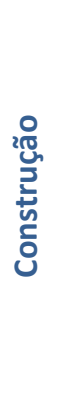 } & 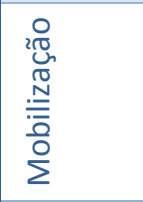 & $\begin{array}{l}\text { Emissão do Contrato, nomeação do empreiteiro. } \\
\text { Fornecimento de informações para o empreiteiro. } \\
\text { Proceder a entrega do local para o empreiteiro. }\end{array}$ \\
\hline & 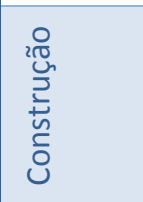 & $\begin{array}{l}\text { Administração do contrato de construção. } \\
\text { Provisão para o empreiteiro de mais informações, como e quando julgar necessário. } \\
\text { Revisão das informações fornecidas pelos empreiteiros e especialistas. }\end{array}$ \\
\hline$\stackrel{\circ}{\stackrel{M}{\supset}}$ & 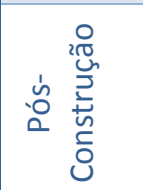 & $\begin{array}{l}\text { Administração do contrato de construção pós-conclusão e realização de inspeções } \\
\text { finais. } \\
\text { Auxílio ao usuário do edifício durante o período de ocupação inicial. } \\
\text { Avaliação do desempenho do projeto em uso. }\end{array}$ \\
\hline
\end{tabular}


No que se refere especificamente a projetos de edifícios de assistência à saúde, a ANVISA (2002), no Brasil, através da RDC no 50, divide os processos de projeto para construção, complementação, reforma ou ampliação de Estabelecimentos Assistenciais de Saúde - EAS em três etapas: estudo preliminar, projeto básico e projeto executivo. O ponto de partida para o desenvolvimento consecutivo destas etapas é o programa de necessidades físico-funcional do EAS. O Quadro 11 resume as três etapas, com suas respectivas definições e orientações para o projeto específico de arquitetura. Outras orientações específicas apresentadas pela ANVISA são referentes aos projetos complementares de instalações - elétrica e eletrônica, hidráulica e fluido-mecânica e climatização - e estruturas e fundações, que podem ser consultadas na RDC n은.

Quadro 11. Etapas de projeto de Estabelecimentos Assistenciais de Saúde, segundo informações da RDC $n^{\circ}$ 50. Fonte: Anvisa (2002).

\begin{tabular}{|c|c|c|}
\hline ETAPAS & DEFINIÇÃO & ORIENTAÇÕES PARA PROJETO DE ARQUITETURA \\
\hline 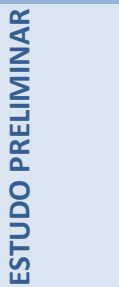 & $\begin{array}{l}\text { Estudo para assegurar a viabilidade técnica a } \\
\text { partir dos dados levantados no programa de } \\
\text { necessidades }{ }^{28} \text {, bem como de eventuais } \\
\text { condicionantes do contratante. Visa à análise e } \\
\text { escolha da solução que melhor responda e este } \\
\text { programa, sob os aspectos legais, técnicos, } \\
\text { econômicos e ambiental do empreendimento. }\end{array}$ & $\begin{array}{l}\text { Definição gráfica do partido arquitetônico, com } \\
\text { plantas, cortes e fachadas (opcional), que } \\
\text { contenham a implantação, acessos, } \\
\text { estacionamentos, sistema construtivo, zoneamento } \\
\text { das atividades, circulações, organização } \\
\text { volumétrica, número de pavimentos, atendimento } \\
\text { às normas, entre outros. }\end{array}$ \\
\hline & $\begin{array}{l}\text { Conjunto de informações técnicas necessárias e } \\
\text { suficientes para caracterizar os serviços e obras, } \\
\text { elaborado com base no estudo preliminar, e que } \\
\text { apresente o detalhamento necessário para a } \\
\text { definição e quantificação dos materiais, } \\
\text { equipamentos e serviços relativos ao } \\
\text { empreendimento. Deverá demonstrar a } \\
\text { viabilidade técnica da edificação a partir do } \\
\text { programa de necessidades e do estudo } \\
\text { preliminar desenvolvidos anteriormente, } \\
\text { possibilitar a avaliação do custo dos serviços e } \\
\text { obras, bem como permitir a definição dos } \\
\text { métodos construtivos e prazos de execução do } \\
\text { empreendimento. Solução das interferências } \\
\text { entre os sistemas e componentes da edificação. }\end{array}$ & $\begin{array}{l}\text { PBA: representação gráfica e relatório técnico/ } \\
\text { avaliado pela Vigilância Sanitária para aprovação da } \\
\text { edificação. Base para o desenvolvimento dos } \\
\text { projetos complementares de engenharia (estrutura } \\
\text { e instalações). Plantas com nomes de todos os } \\
\text { ambientes, dimensões, locação dos equipamentos, } \\
\text { etc. Em reformas e ampliações: legenda demolir/ } \\
\text { construir/ existente. Indicação de cortes, elevações, } \\
\text { ampliações e detalhes. Planta de cobertura, de } \\
\text { situação e locação com acessos de pedestres e } \\
\text { veículos. Dados cadastrais do estabelecimento, } \\
\text { memorial de arquitetura, resumo da proposta } \\
\text { assistencial, no de leitos, especificação de materiais } \\
\text { e equipamentos, soluções para abastecimento de } \\
\text { água potável, energia elétrica, etc. }\end{array}$ \\
\hline 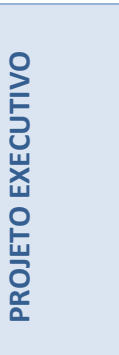 & $\begin{array}{l}\text { Conjunto de informações técnicas necessárias e } \\
\text { suficientes para a realização do } \\
\text { empreendimento, contendo de forma clara, } \\
\text { precisa e completa todas as indicações e } \\
\text { detalhes construtivos para a perfeita instalação, } \\
\text { montagem e execução dos serviços de obras. }\end{array}$ & $\begin{array}{l}\text { Desenhos necessários para descrição do edifício e } \\
\text { dos elementos externos: implantação, plantas, } \\
\text { cortes, todas as elevações, ampliações, esquadrias, } \\
\text { impermeabilização, detalhes, etc. Poderá conter, se } \\
\text { solicitado pelo contratante, cronograma com as } \\
\text { etapas lógicas da execução dos serviços e suas } \\
\text { interfaces, manual de operação e manutenção das } \\
\text { instalações, orçamento analítico da obra e } \\
\text { cronograma físico-financeiro. }\end{array}$ \\
\hline
\end{tabular}

\footnotetext{
28 "Conjunto de características e condições necessárias ao desenvolvimento das atividades dos usuários da edificação que, adequadamente consideradas, definem e originam a proposição para oempreendimento a ser realizado. Deve conter a listagem de todos os ambientes necessários ao desenvolvimento dessas atividades" (ANVISA, 2002, p.3).
} 


\subsubsection{Revisões de Fases}

Cooper (2011) define Gates - revisões de fases - como pontos para verificação e controle da qualidade do PDP, quando são avaliados os resultados e determinados os critérios para as fases seguintes do processo. Sua origem remonta à teoria de Stage-Gate, desenvolvida por Robert G. Cooper, em 1986 (MELLO et al., 2012). A teoria de Stage-Gate representa "um mapeamento conceitual e operacional para levar o projeto de novos produtos da ideia ao seu lançamento e além", visando à melhoria da efetividade e eficiência no gerenciamento do PDP (COOPER, 2011, p.83).

Cooper (2011) ainda destaca os três elementos principais que caracterizam as revisões de fases:

- Os deliverables, ou produtos da fase em questão;

- Os critérios, que permitem a passagem para a próxima fase;

- E os resultados da revisão, que aprovam ou não a passagem, e incluem um plano de ação para a próxima revisão.

As revisões de fases, além de permitirem que o projeto seja continuamente corrigido, são de grande valia para a retroalimentação do processo, pois o aprendizado com os erros e acertos avaliados nestas revisões pode ser utilizado pela equipe de processo tanto nas fases subsequentes como em projetos posteriores (KAGIOGLOU et al., 2000). Assim, a abordagem 'stage-gate' faz com que o planejamento e os procedimentos de revisão sejam consistentes, durante o processo de projeto (KAGIOGLOU et al., 2000).

\subsection{Projeto de Serviços de Saúde}

A existência do ambiente construído visa ao apoio das atividades dos usuários que o ocupam (VISCHER, 2008). Segundo Dickerman e Barach (2008), são substanciais os efeitos exercidos pelo ambiente das edificações de saúde sobre a efetividade dos profissionais de saúde e a eficiência no cuidado, entre outros aspectos. Neste contexto, nota-se uma "consciência crescente dos edifícios como estruturas físicas para os processos de trabalho, que tanto podem obstruir como ser projetadas para dar suporte às necessidades dinâmicas da 
organização" (JENSEN, 2016, p.119). Como exemplo, uma pesquisa realizada na Inglaterra pela Commission of Architecture and the Built Environment - CABE, mostrou que $86 \%$ dos chefes de enfermagem classificaram o impacto do projeto dos edifícios de assistência à saúde no desempenho da equipe de enfermagem como 'muito importante' ou 'importante'. Além disto, 93\% consideraram como 'muito importante' ou 'importante' o projeto e a organização do ambiente interno dos edifícios de assistência à saúde neste desempenho, sendo este o aspecto mais crucial (CABE, 2004).

Segundo Moritz (2005), o escopo de projeto vem se estendendo de apenas contemplar características físicas de ambientes, edifícios, produtos, etc., para englobar a experiência dos clientes com os serviços, espaços, produtos e os processos que estão por trás destas experiências.

Por outro lado, o reconhecimento de que a assistência à saúde não pode ser realizada de maneira excelente apenas com conhecimento clínico apoiado por tecnologia e farmacêutica é crescente. Acredita-se que são necessários conhecimentos e habilidades para entender a assistência à saúde como produção e serviços, ou seja, a prática do negócio de organizar e prestar atendimento em saúde (KOSKELA et al., 2012).

Portanto, para permitir novos modos de trabalho, proporcionar ambientes focados no cuidado aos pacientes e reestruturar a assistência à saúde é importante que haja alinhamento entre o projeto da edificação e o projeto dos serviços de saúde (FRANCIS, 2002; TZORTZOPOULOS et al., 2009). Se não há alinhamento, as atividades de cuidado à saúde podem ser prejudicadas (TZORTZOPOULOS et al., 2006). Como alinhamento, estes autores definem o estabelecimento da estratégia e o modo de operação do edifício de saúde, de modo que a equipe de projeto receba as informações necessárias para o projeto do edifício no momento em que precisa, o que significa que o desenvolvimento dos requisitos dos serviços e do edifício acabam acontecendo ao mesmo tempo.

Como definição, "Projeto de Serviços é o projeto de toda a experiência de um serviço, bem como o projeto do processo e da estratégia de fornecer tal serviço" (MORITZ, 2005, p.39). Ainda segundo este autor, o projeto de serviços aumenta a eficiência da organização, pois busca o seu melhor desempenho através do balanceamento entre a redução de custos de operação e o aumento da qualidade da experiência dos usuários. 


\subsubsection{Modelos e Instrumentos de Projetos de Serviços}

Diversos modelos e instrumentos de projetos de serviços foram encontrados na literatura. São apresentados abaixo alguns que melhor se enquadraram no escopo deste trabalho, por focarem no processo de produção dos serviços e/ou em serviços de assistência à saúde.

Como definição para modelos, adota-se aqui a mesma utilizada para modelos de processo de projeto, na seção 3.3 , sendo o foco o projeto de serviços e não o projeto do edifício.

O modelo Diamante Duplo (Double Diamond), desenvolvido pelo Design Council ${ }^{29}$, no Reino Unido, é composto por quatro fases, ilustrando pontos de expansão de possibilidades e pontos onde se faz necessário afunilar e focar nos objetivos (figura 13). Estas fases são:

- Descobrir: as ideias iniciais são desenvolvidas e se identifica as necessidades dos usuários;

- Definir: refinamento das ideias da fase anterior, definindo as prioridades;

- Desenvolver: criação e teste de soluções para as necessidades definidas

- Entregar: nesta fase, o projeto dos serviços é finalizado, entregue e avaliado.

${ }^{29}$ www.designcouncil.org.uk / www.keepingconnected.co.uk 


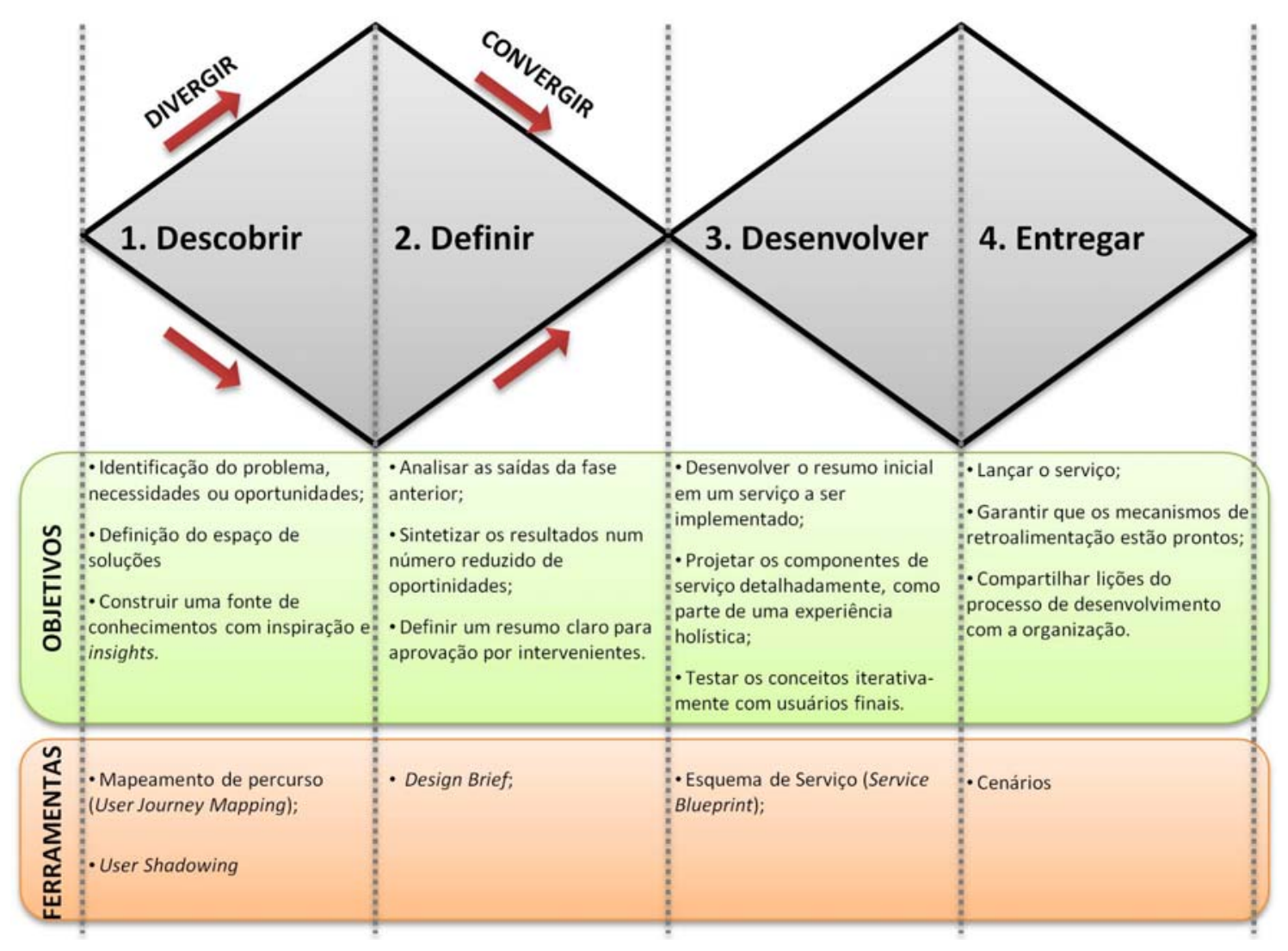

Figura 13. Modelo de diamante duplo. Fonte: Davies e Wilson (s.d.).

Tompkins et al. (2010) propõem um modelo circular para descrever o processo de planejamento dos serviços de hospitais, considerando três fases: na primeira, ocorre a definição das demandas; na segunda, o desenvolvimento do plano de serviços e na terceira, sua implantação e manutenção (figura 14). 


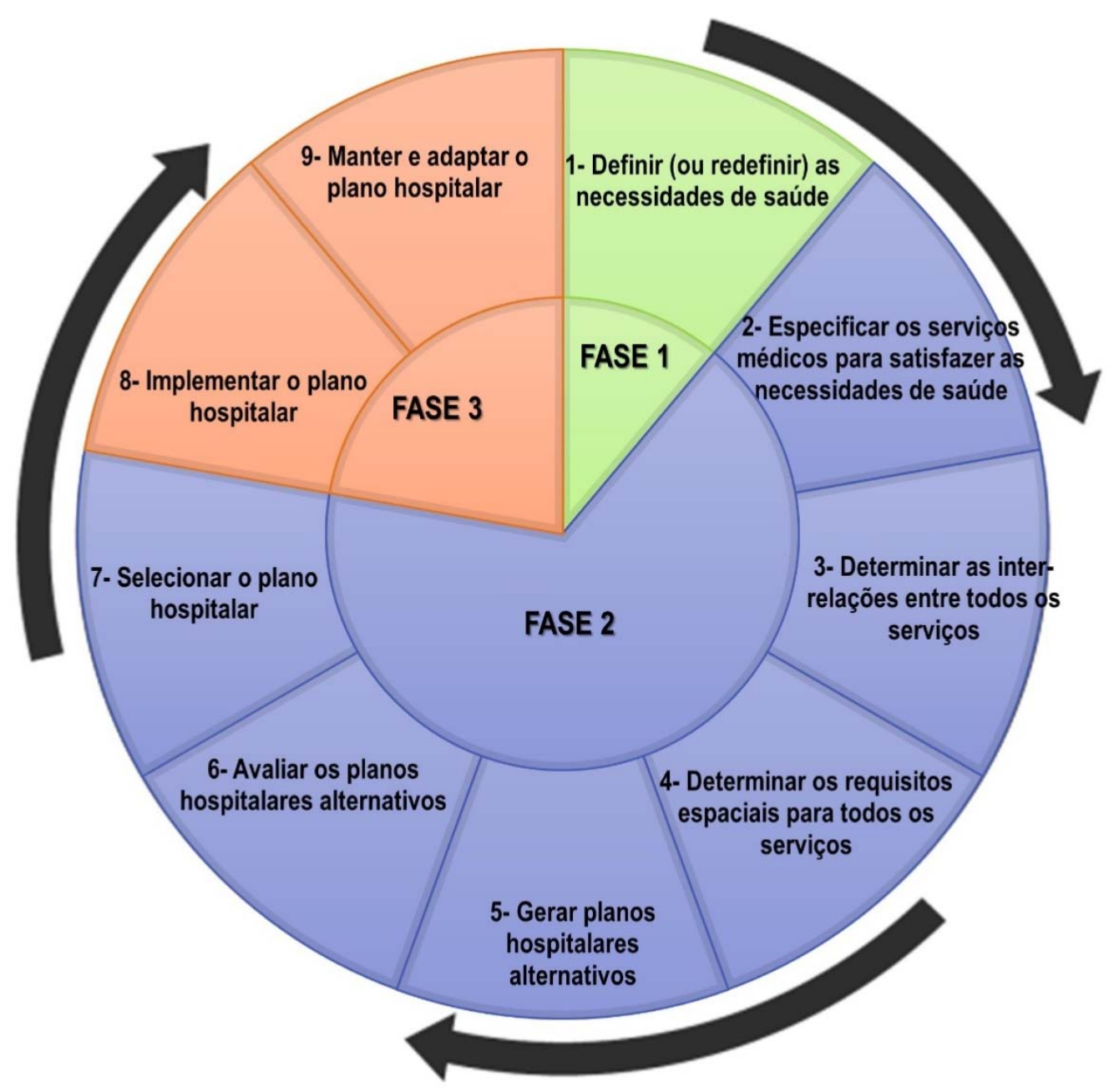

Figura 14. Processo de planejamento dos serviços hospitalares. Fonte: Tompkins et al. (2010).

Para dar suporte ao projeto de serviços, diversos instrumentos são encontrados tanto na literatura como em páginas virtuais de instituições que realizam ou dão suporte a este tipo de projeto $^{30}$ (Quadro 12). Apesar de que, originalmente, estes instrumentos foram desenvolvidos para serviços em geral, muitos deles têm sido aplicados, com êxito, em projetos de serviços de saúde. Exemplo disto é o projeto da Presbyterian Neuro Clinic, onde foi utilizado o 'Esquema de Serviço' - Service Blueprint - para descrever o processo das atividades de atenção à saúde (figura 15). Após a visita a clínica, com entrevistas com membros da equipe interna e pacientes, foi possível montar o esquema de serviços para descrever seu processo de atenção, contemplando todos os papéis desempenhados pela equipe para suporte ao longo do processo, bem como a experiência completa vivenciada pelos pacientes durante a permanência na clínica. Este esquema evidenciou os gargalos existentes na realização das atividades, como a dependência da figura do médico chefe para o sistema e o caos nas

\footnotetext{
${ }^{30}$ Algumas instituições pesquisadas: $\underline{w w w . s e r v i c e d e s i g n t o o l s . o r g, ~ w w w . b s b d . o r g . u k, ~ w w w . d e s i g n c o u n c i l . o r g . u k . ~}$
} 
atividades da equipe nos bastidores. Relativo aos pacientes, ficou demonstrada a falta de engajamento destes com a equipe durante o tempo de espera (CLIVER et al., 2007). Este estudo permitiu a adoção de medidas de melhoria dos serviços, bem como reconfigurações no espaço físico para aumentar a qualidade da atenção prestada.

Quadro 12. Instrumentos para suporte ao projeto de serviços. Fonte: Elaborado pela autora a partir das fontes citadas.

\begin{tabular}{|c|c|c|}
\hline INSTRUMENTO & OBJETIVO & DESCRIÇÃO \\
\hline $\begin{array}{l}\text { Entrevistas Contextuais } \\
\text { Fonte: Moritz, (2005) }\end{array}$ & $\begin{array}{l}\text { Levantar dados qualitativos } \\
\text { sobre o uso dos serviços }\end{array}$ & $\begin{array}{l}\text { Realização de entrevistas com } \\
\text { usuários enquanto eles } \\
\text { realizam tarefas afins ao } \\
\text { serviço em questão. }\end{array}$ \\
\hline $\begin{array}{l}\text { User Shadowing } \\
\text { Fonte: } \\
\text { www.keepingconnected.co.uk }\end{array}$ & $\begin{array}{l}\text { Entender as reais necessidades } \\
\text { dos usuários; identificar } \\
\text { barreiras e novas } \\
\text { oportunidades para o serviço, } \\
\text { entre outros. }\end{array}$ & $\begin{array}{l}\text { Consiste no acompanhamento } \\
\text { dos usuários pelo pesquisador } \\
\text { enquanto utilizam um } \\
\text { determinado serviço. }\end{array}$ \\
\hline $\begin{array}{l}\text { Cenários } \\
\text { Fonte: www.designcouncil.org.uk, } \\
\text { www.bsbd.org.uk/cards/roleplaying }\end{array}$ & $\begin{array}{l}\text { Entender o contexto em que o } \\
\text { serviço é executado, para } \\
\text { poder aperfeiçoá-lo. }\end{array}$ & $\begin{array}{l}\text { Atividade de projeto em que } \\
\text { certas situações ou serviços } \\
\text { podem ser visualizados e } \\
\text { compreendidos } \\
\text { intervenientes. }\end{array}$ \\
\hline $\begin{array}{l}\text { Mapeamento de percurso } \\
\text { (User Journey Mapping) } \\
\text { Fonte: } \\
\text { www.keepingconnected.co.uk }\end{array}$ & $\begin{array}{l}\text { Identificação dos elementos } \\
\text { chave do serviço, das áreas } \\
\text { problemáticas e entendimento } \\
\text { das interfaces entre os } \\
\text { diferentes elementos em } \\
\text { relação ao tempo. }\end{array}$ & \\
\hline $\begin{array}{l}\text { Esquema de Serviço } \\
\text { (Service Blueprint) } \\
\text { Fonte: Moritz (2005); } \\
\text { www.keepingconnected.co.uk }\end{array}$ & $\begin{array}{l}\text { Definir os diversos percursos } \\
\text { do serviço, tempos de } \\
\text { execução, demandas e } \\
\text { produtos, sendo essencial para } \\
\text { o planejamento e projeto dos } \\
\text { serviços. }\end{array}$ & $\begin{array}{l}\text { Modelos e diagramas de } \\
\text { processo contemplando todos } \\
\text { os detalhes do serviço, e } \\
\text { demonstrando as interfaces } \\
\text { entre os diferentes elementos. } \\
\text { Permite a sobreposição de } \\
\text { todos os percursos possíveis } \\
\text { para o serviço, para melhor } \\
\text { visualização. }\end{array}$ \\
\hline
\end{tabular}




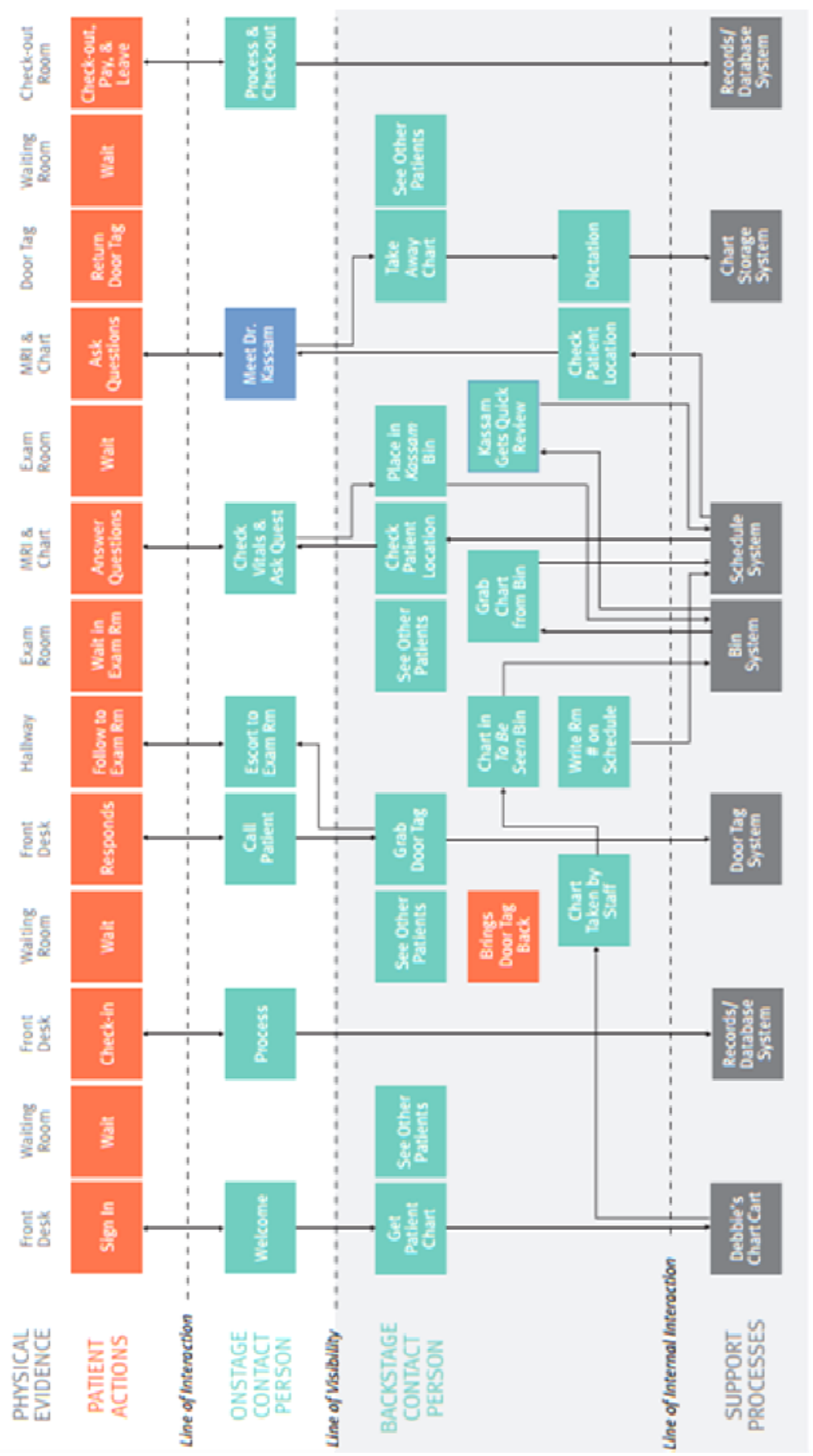

Figura 15. Esquema de Serviço da Neuro Clínica Presbiteriana. Fonte: Cliver et al. (2007).

Em outro exemplo, o instrumento 'Cenários' foi utilizado pelo IDEO ${ }^{31}$ num projeto de serviços médicos para simular atividades interdependentes que a equipe das salas de operação demandava. Para tanto, foram envolvidos enfermeiros, médicos anestesistas e pacientes, e cada membro assumiu um papel e se comportou como tal. Foi então possível simular situações

${ }^{31}$ IDEO é uma empresa de projeto, que auxilia na inovação e crescimento de organizações públicas e privadas, através de abordagens baseadas em projeto centrado no usuário. <http://www.ideo.com> Acesso em 17 dez. 2014. 
específicas, e a equipe pode imagina-las, para visualizar os pontos que necessitavam de melhoria ou solução ${ }^{32}$, conforme ilustra a figura 16.

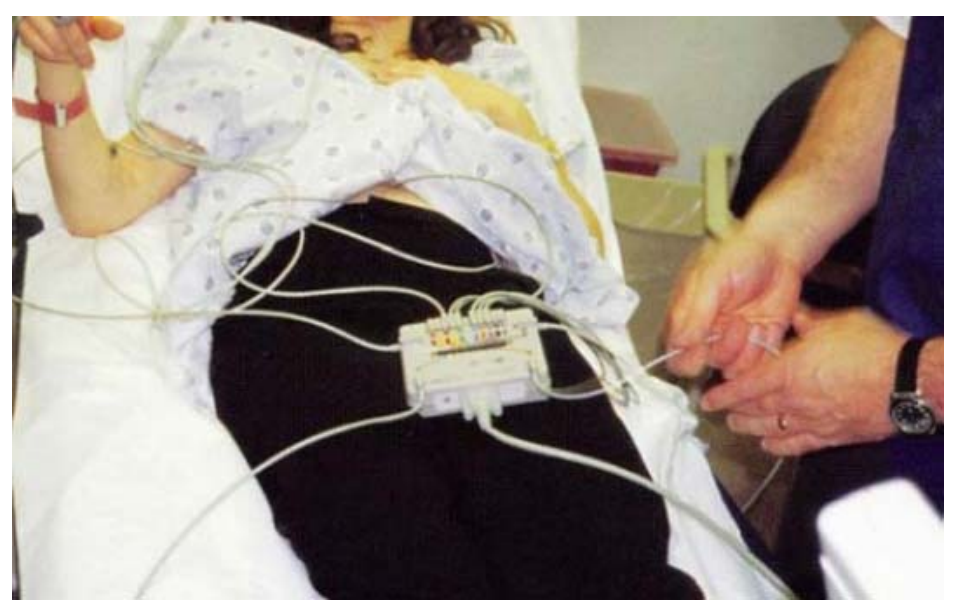

Figura 16. Instrumento 'Cenários': Simulação de situação. Fonte: http://www.servicedesigntools.org/tools/42, Acesso em 17 dez. 2014.

Buscando uma nova visão teórica da eficiência e efetividade operacional no projeto de edifícios de assistência à saúde, Tzortzopoulos et al. (2009) elaboram o modelo genérico da Figura 17, que representa uma perspectiva holística e sistemática da integração entre projetos dos serviços de saúde e da edificação de saúde.

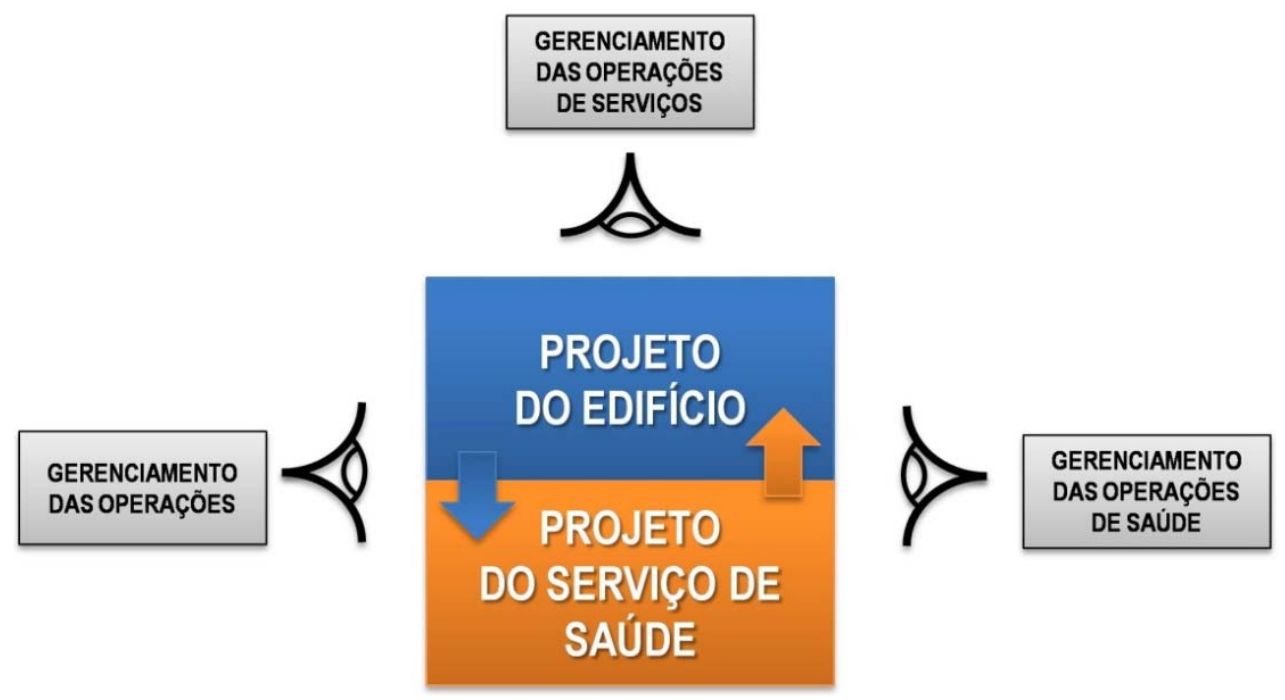

Figura 17. Modelo projeto com visão holística. Fonte: Tzortzopoulos et al. (2009).

O modelo propõe que a integração entre planejamento e execução dos projetos da edificação de saúde e dos serviços de saúde traz valor ao empreendimento, como por exemplo, “[...] o

\footnotetext{
${ }^{32}$ Fonte: Service Design Tools <http://www.servicedesigntools.org/tools/42> Acesso em 17 dez. 2014.
} 
estabelecimento de serviços racionalizados que são realizados em edificações apropriadas, melhorando a experiência de profissionais de saúde e pacientes e dando suporte para a eficiência operacional" (TZORTZOPOULOS et al., 2009, p.48). Os autores apresentam, na revisão bibliográfica, as seguintes definições:

- Gerenciamento de operações: atividades focadas no entendimento e melhoria do processo, que incluem a identificação de problemas e causas, desperdícios e ineficiências.

- Gerenciamento das operações de serviços: relativo aos serviços prestados aos clientes e usuários, para melhoria do processo pela sua gestão e entendimento das necessidades dos clientes e usuários.

- Gerenciamento das operações de saúde: relativo às atividades de prestação de serviços de saúde aos clientes, de maneira eficaz e eficiente.

\subsection{Discussão e Síntese Conclusiva}

Este capítulo apresentou a revisão bibliográfica sobre o aspecto organizacional do processo de projeto de edifícios de assistência à saúde, iniciando com a apresentação do cenário atual dos projetos destes edifícios e adentrando pelas características do processo de projeto propriamente dito, com suas etapas e modelos. Em seguida, abordaram-se os aspectos do projeto de serviços de saúde, com seus modelos e instrumentos específicos. A escolha da abordagem tanto do processo de projeto do edifício como dos serviços se justifica pela natureza complexa dos edifícios de assistência à saúde, fortemente atreladas às questões operacionais e à funcionalidade. Pelo exposto, a busca pela eficiência pressupõe a integração do planejamento dos projetos do espaço físico e dos serviços, e se justifica pelos altos custos de operação das instituições de saúde, por sua complexidade e pela extrema importância da atenção à saúde para o ser humano. O alinhamento entre o projeto do edifício e o projeto dos serviços nele prestados pode melhorar seu desempenho, facilitando a realização das atividades e promovendo o redesenho da atenção à saúde, o que pode ter impactos positivos na recuperação dos pacientes. Assim, o que se busca neste trabalho é aumentar a eficiência focando na esfera operacional dos serviços de saúde.

Em termos de espaço físico, a qualidade do processo de projeto influencia a qualidade da edificação final. $\mathrm{O}$ processo de projeto deve permear todo o processo de desenvolvimento do produto - edificação - tanto para viabilizar a retroalimentação do sistema 
como para permitir que os profissionais de projeto possam resolver possíveis impasses que surjam durante a execução no canteiro de obras, sem perder de vista os critérios e requisitos elencados durante a concepção.

Foram apresentados diversos modelos do processo de projeto, ilustrando sucintamente sua evolução. Os modelos são importantes para o planejamento e organização do processo de projeto, facilitando a gestão da equipe multidisciplinar envolvida e contribuindo para a eficiência do processo. Embora possam trazer muitos benefícios para o processo de projeto, os diversos modelos encontrados na literatura possuem pouca aplicação na prática, e nenhum modelo recente tem se consagrado como referência para a academia ou a indústria da construção. Pela revisão bibliográfica, acredita-se que isto ocorra porque o potencial dos modelos para a melhoria dos processos seja subestimado.

$\mathrm{Na}$ sequência, foram apresentados os delineamentos de processo de projeto propostos por normas brasileiras - ABNT e ANVISA - e pelo RIBA, da Inglaterra. Tanto a ABNT como a ANVISA, nos textos estudados, abordam apenas as etapas de projeto anteriores ao início da obra, enquanto o plano de trabalho apresentado pelo RIBA aborda o processo de projeto ao longo de todo o PDP, incluindo a obra e o acompanhamento do uso, como é considerado neste trabalho. O quadro 13 compara as fases dos principais modelos e delineamentos de processo de projeto em construção civil, levantados nesta revisão. O quadro também traz as fases que são propostas para o desenvolvimento da presente pesquisa, baseados nos modelos apresentados e na evolução da pesquisa anterior da autora dissertação de mestrado de Caixeta (2011). 
Quadro 13. Comparação das fases do PP propostas por diferentes modelos estudados. Fonte: Elaborado pela autora.

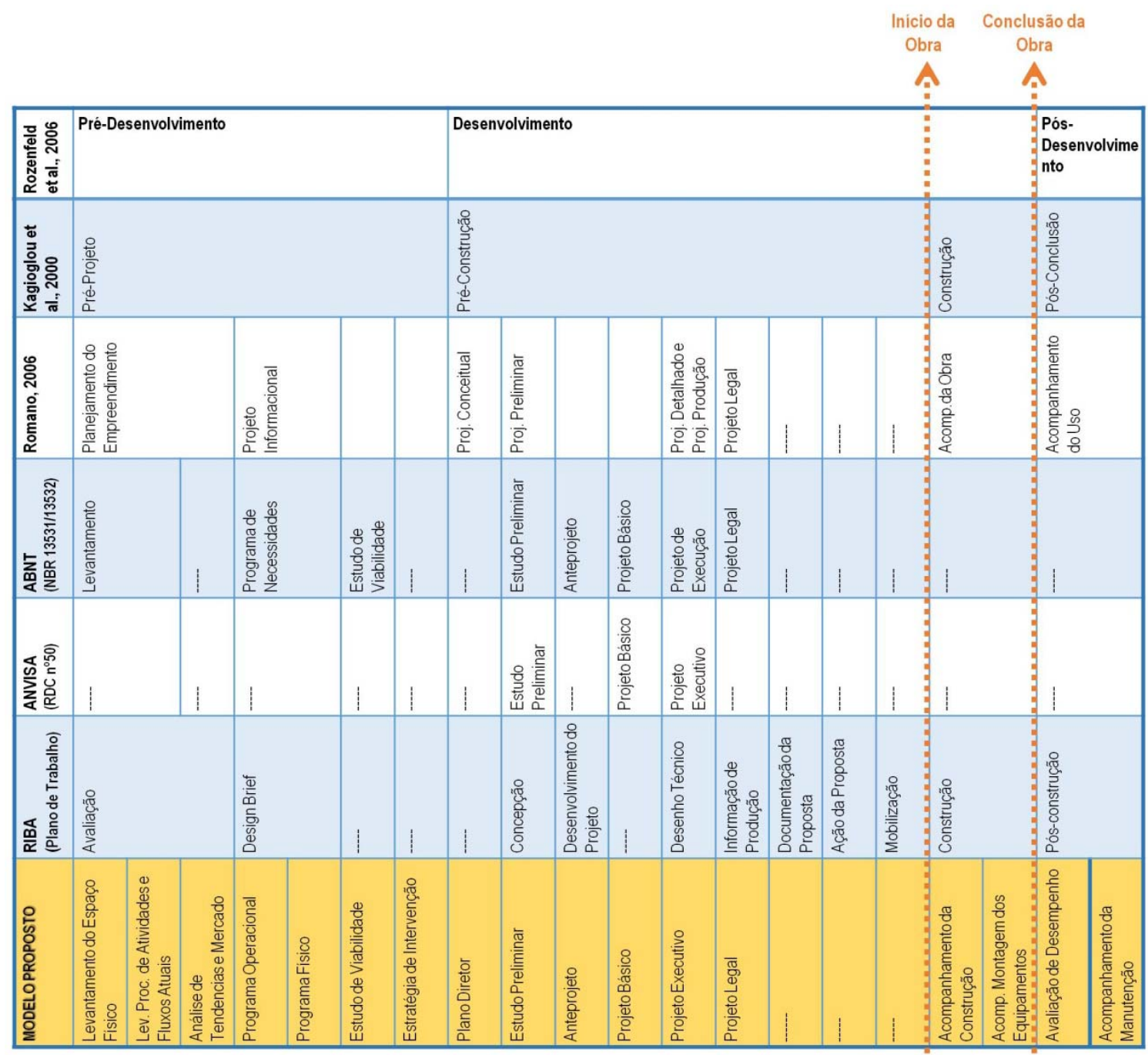

As fases do modelo assumidas nesta pesquisa são caracterizadas a seguir:

- Levantamento do espaço físico e Levantamento dos processos de atividades e fluxos atuais: levantamentos cadastrais do espaço físico e dos serviços existentes. Os subprodutos são plantas cadastrais e outros documentos que descrevam a atual situação da edificação e das atividades nela desenvolvidas. Pode-se dizer que estes levantamentos são exclusivos de projetos de intervenções, pois em obras novas não existem edificações a se levantar. Como exceção, existem os casos em que a obra nova se destina a um novo edifício para um estabelecimento já existente, onde se pode levantar os serviços e fluxos de atividades realizados a título de informação para os projetistas. 
- Análises de tendências e mercado: A análise de tendências permite incorporar as evoluções do atendimento à saúde ao projeto, para que os ambientes sejam projetados de modo a permitir adaptações às mudanças previstas e, assim, prolongar sua vida útil (BROSS, 2010). Por esta análise, podem-se antever quais setores necessitarão de ampliações e quais ambientes de apoio deverão ser ampliados em conjunto para viabilizar a expansão do serviço. A partir disto, é possível prever espaços suficientes para estas ampliações num determinado prazo, sejam através de vazios ou de recursos de flexibilidade como 'soft/hard spaces' ${ }^{33}$ (CAIXETA, 2011). Já a análise de mercado possibilita adequar os serviços de saúde para o perfil de seus usuários potenciais.

- Programa operacional: A fase de desenvolvimento do Programa Operacional se caracteriza pela descrição dos serviços, ou seja, do funcionamento do edifício, com foco nas atividades que comporão os processos de produção nos diferentes setores (BROSS, 2008). Assim, nesta fase esboça-se o projeto dos serviços, com determinação dos setores e dos fluxos das atividades, que orientará o projeto do espaço físico.

- Programa físico: baseado no programa operacional, traz os ambientes que comporão os setores e o pré-dimensionamento da edificação. Conforme apresentado na seção 3.3.4, o Regulamento Técnico em vigor ${ }^{34}$, da Anvisa, nomeia o subproduto desta fase como 'Programa de Necessidades'. No entanto, com base nos resultados da pesquisa aqui realizada, optou-se por não utilizar este termo, por se referir a um documento estático, que nem sempre reflete o processo de planejamento operacional e físico da edificação.

- Estudo de viabilidade: Este estudo traz os custos de projetos, aquisição de terreno, equipamentos, despesas e receitas operacionais, permitindo assim a indicação de fluxo de caixa e valor da taxa interna de retorno (LIMA-GONÇALVES; ACHÉ, 1999).

- Estratégia de intervenção: Esta fase é específica de obras de intervenção. Nela se planeja a execução das obras com o menor impacto possível nos serviços, minimizando as interferências entre uso e obra.

- Plano diretor: No presente trabalho, o foco é o plano diretor do espaço físico, que delineia a implantação da edificação no terreno e as propostas de crescimento possíveis, de acordo com a estratégia de negócio do empreendimento (BROSS, 2010).

\footnotetext{
${ }^{33}$ Neste recurso de flexibilidade, posicionam-se ambientes menos complexos - por exemplo, a administração (soft spaces) - adjacentes a ambientes com maior complexidade de instalações - por exemplo, centro cirúrgico e laboratórios clínicos (hard spaces). Deste modo, é possível relocar os soft spaces para outras áreas e permitir a expansão dos hard spaces contíguos (Pressler, 2006; Carr, 2011).

${ }^{34}$ RDC №. 50, DE 21 DE FEVEREIRO DE 2002 - Regulamento Técnico para Planejamento, Programação, Elaboração e Avaliação de Projetos Físicos de Estabelecimentos Assistenciais de Saúde.
} 
- Estudo preliminar (arquitetura): é a fase em que o conjunto das informações técnicas iniciais e aproximadas é concebido e representado, buscando-se demonstrar a configuração básica da edificação (ABNT, 1995). Nesta fase, portanto, as informações levantadas até o momento são traduzidas em desenho técnico, na forma de concepção inicial, com base no plano diretor e nos programas operacional e físico.

- Anteprojeto (arquitetura): nesta fase, as informações técnicas provisórias de detalhamento da edificação e de seus elementos são concebidas e representadas (ABNT, 1995).

- Projeto básico (arquitetura): é a fase em que se produz o conjunto das informações técnicas que são necessárias e suficientes para descrever os serviços e a obra, apresentando-se o detalhamento necessário para a definição e quantificação do empreendimento, seus componentes e serviços (ANVISA, 2002).

- Projeto executivo (arquitetura): esta fase tem como objetivo o desenvolvimento do corpo de informações técnicas necessárias para a realização do empreendimento (ANVISA, 2002).

- Projeto legal: esta fase produz os documentos necessários para aprovação do projeto junto aos órgãos competentes - prefeitura municipal, ANVISA, corpo de bombeiros, entre outros.

- Acompanhamento da construção: fase em que os projetistas acompanham a execução dos projetos no canteiro de obras. Em intervenções, a execução pode trazer novas informações para o projeto, que não puderam ser levantados antes das obras. Isto pode demandar a retomada do projeto para adequá-lo aos novos dados. Dependendo da escala das alterações, podem ser necessárias novas aprovações junto aos órgãos competentes.

- Acompanhamento da montagem dos equipamentos: Nesta fase, ocorre a montagem dos equipamentos na edificação construída.

- Avaliação de desempenho: Fase em que os profissionais de projeto levantam dados sobre o desempenho da edificação em relação aos requisitos dos usuários, para poder avaliar como a edificação responde a estes requisitos.

- Acompanhamento da manutenção: esta fase propicia a qualidade da manutenção no espaço físico, pela presença de profissionais de projeto com conhecimento da edificação em questão, além de permitir o aprendizado dos projetistas e a retroalimentação do processo.

O alinhamento entre projeto da edificação e projeto dos serviços pressupõe que haja um planejamento inicial que oriente todo o processo, de modo que estes dois âmbitos sejam 
atrelados da melhor forma possível. Assim, busca-se uma edificação que siga as normas e os princípios de qualidade do ambiente construído, sem perder de vista os critérios que agreguem funcionalidade e permitam que a edificação facilite a realização das atividades propostas. O projeto dos serviços auxilia na busca pela qualidade da atenção à saúde, pois para garantir a qualidade é necessário entender a prática do negócio de organizar e prestar atendimento em saúde, como produção e serviços, como foi colocado anteriormente.

Outro conceito destacado neste capítulo são as revisões de fases ou Gates, necessárias para que o projeto seja continuamente corrigido e o processo retroalimentado.

Para melhor entender a estratégia de projeto de serviços, foram estudados modelos e instrumentos utilizados pela indústria neste tipo de projeto. Apesar de terem sido desenvolvidos originalmente com foco na produção de serviços em geral, os instrumentos aqui apresentados aparentam ser muito úteis e apropriadas para o desenvolvimento de projetos de serviços de saúde, uma vez que foram verificados exemplos bem-sucedidos de aplicação nesta área.

Portanto, este capítulo contribui para a consolidação do referencial teórico relativo ao processo de projeto, definindo as fases que serão consideradas ao longo da pesquisa. Serve de base para o estudo do envolvimento de usuários neste processo, que é abordado no capítulo seguinte. 


\section{ENVOLVIMENTO DE USUÁRIOS NO PROCESSO DE PROJETO}

A prática de envolver usuários na tomada de decisões remonta à década de 1870 nos Estados Unidos, na área de administração pública, sob a denominação de 'participação pública' (WULZ, 1986). Na década de 1960, nota-se nos Estados Unidos e na Inglaterra um aumento na noção de responsabilidade social, buscando a participação do público na definição dos seus espaços físicos. Estabeleceram-se centros de projeto comunitários para permitir que os menos favorecidos participassem do planejamento de seus espaços (Sanoff, 2006). A partir de 1970, diversos Mandados para Participação Pública se difundem, e seus princípios incluem os direitos dos indivíduos de "serem informados, consultados e poderem expressar suas opiniões sobre as decisões governamentais" (BRODY; GODSCHALK; BURBY, 2003, p.246). Um dos textos pioneiros nos Estados Unidos sobre participação de usuários, de 1969, focado em administração pública e muito citado, apresenta a seguinte definição para participação:

\footnotetext{
É a redistribuição do poder que permite que os cidadãos menos favorecidos, atualmente excluídos dos processos políticos e econômicos, serem deliberativamente incluídos no futuro [...] é o meio pelo qual eles podem induzir reformas sociais significativas que os permitem compartilhar benefícios com a sociedade mais abastada (ARNSTEIN, 1969, p.216).
}

Ainda na década de 1960, alguns países da Europa, principalmente a Suécia, vivenciavam a crítica ao planejamento centralizado, com usuários descontentes pelo distanciamento entre planejadores e população. Neste cenário, a participação do usuário na administração pública apresentava-se como uma saída (WULZ, 1986). A primeira sanção completa e oficial utilizando o termo 'participação' data de 1968, quando foi publicado o Town and Country Planning Act (DAMER; HAGUE, 1971). Neste mesmo ano, o mandado oficial dado ao Sr. A. M. Skeffington pelo Ministro da Habitação e Governo Local apoiava firmemente a participação pública: 
[...] para analisar e informar sobre os melhores métodos, incluindo publicidade, de garantir a participação do público nas etapas formativas na constituição do desenvolvimento de planos para a sua área ${ }^{35}$.

Com a publicação do Skeffington Report, em 1969, debates sobre a noção de participação pública foram estimulados, tanto entre o público como entre os profissionais de planejamento (DAMER; HAGUE, 1971; JOHNSON, 1979; BAKER, COAFFEE; SHERRIFF, 2007).

O conceito de participação dos usuários também passou a permear outros setores além da administração pública a partir da década de 1970. Motivado por um compromisso Marxista, entre as décadas de 1970 e 1980, teve origem na Escandinávia o Projeto Participativo, para promover democracia no ambiente de trabalho através do fortalecimento democrático dos trabalhadores (KUHN; MULLER, 1993; SPINUZZI, 2005; SANOFF, 2006). Segundo estes autores, uma vez que seriam introduzidas novas tecnologias no ambiente de trabalho, profissionais de informática, dirigentes sindicais e membros do Sindicato dos Metalúrgicos de Ferro buscaram parcerias para permitir que os trabalhadores pudessem ter voz na configuração da forma e escopo destas tecnologias. Neste contexto, Ehn (1992) apresenta uma filosofia de projeto, chamada 'Tool perspective' que defendia que os conhecimentos de profissionais de projeto em conjunto com os de usuários experientes e qualificados deveriam ser a base do projeto computacional. Apesar de não possuírem visão sobre novas possibilidades técnicas, os usuários possuíam o conhecimento prático necessário. Os profissionais de projetos computacionais necessitavam deste conhecimento para compreender o processo de trabalho específico que utilizaria o instrumento.

Neste período, o projeto participativo é descrito pela aliança denominada Computer Professionals for Social Responsability (CPSR) como:

[...] uma abordagem para avaliação, projeto e desenvolvimento de sistemas tecnológicos e organizacionais que premia o envolvimento ativo de práticos do ambiente de trabalho nos processos de projeto e tomada de decisão (SANOFF, 2006, p.132).

Em 1971, houve uma conferência em Manchester, Inglaterra, denominada 'Design Participation', promovida pela Design Research Society, onde foram apresentados trabalhos

\footnotetext{
${ }^{35}$ People and Planning. Report of the Skeffington Committee on Public Participation in Planning, HMSO, 1969. Apud (Damer e Hague, 1971).
} 
sobre a prática e o ensino do projeto participativo nas áreas de economia, projeto, arquitetura, planejamento, ciências da edificação, pesquisa em projeto e engenharia mecânica. Nesta conferência, reconheceu-se a necessidade da participação dos usuários para reorientar os projetos (SANDERS; STAPPERS, 2008).

No fim da década de 1980 e início da década de 1990, diversas alterações mudaram o modo como o projeto participativo era visto na Europa, e sua abordagem na América do Norte teve outro foco. O European Participatory Design surgiu na democracia progressiva social da Escandinávia e foi concebido por acadêmicos. Seu foco, portanto, era a participação democrática e tinha pouca preocupação com os interesses econômicos e com a produção de sistemas reais. Por outro lado, na América do Norte, a Joint Application Design e outras abordagens similares, que cresceram com base na indústria norte-americana e desvinculadas da academia, focavam no aumento da eficiência e efetividade do projeto técnico, para atender aos interesses mercadológicos. Como consequência, o European Participatory Design e a Joint Application Design, se desenvolveram isoladamente, e seus projetistas trabalhavam quase sem interação em suas respectivas tradições, por mais de uma década (ASARO, 2000).

A participação dos usuários também é abordada na área de desenvolvimento de serviços. De acordo com Alam (2002), muitas indústrias de serviços têm reconhecido a necessidade de incluir as reais necessidades dos usuários no desenvolvimento de novos serviços, com o intuito de permanecer competitivas num mercado marcado por rápidas mudanças, consumidores mais exigentes, déficit de competência e tecnologias emergentes como a propagação da internet e do e-commerce. O sucesso do novo produto pode aumentar com a interação dos consumidores no desenvolvimento, principalmente nos primeiros e nos últimos estágios de desenvolvimento, com colaboração e troca de informações, além de se poderem atingir inovações superiores em desenvolvimento de produtos orientados ao consumidor (GRUNER; HOMBURG, 2000; ALAM, 2002).

Por fim, esta breve revisão das origens da participação dos usuários em diversas áreas - seja na tomada de decisões em administração pública, no projeto de novas tecnologias de informação ou no desenvolvimento de serviços - permite identificar que as razões que motivaram esta prática foram de cunho político - promoção de democracia - ou relacionadas com a qualidade do produto final:

- Direito dos usuários de serem informados sobre projetos/ decisões que lhes afetarão;

- Direito de voz dos usuários (promoção de democracia);

- Distribuição de poder. 
- Aproveitamento do conhecimento prático dos usuários;

- Aumento da eficiência dos projetos;

- Entender as reais necessidades dos usuários.

Tomando como exemplo a Suécia, Granath, Lindahl e Rehal (1996) argumentam que o projeto participativo, até o início da década de 1970, estava relacionado principalmente a questões de democracia, e que a partir de então, nota-se um interesse crescente em desenvolver métodos e instrumentos para utilizar o projeto participativo com outros fins.

Neste capítulo, apresenta-se a revisão bibliográfica sobre o envolvimento de usuários no processo de projeto. Partindo da origem histórica apresentada, detalham-se aqui as definições relativas a esta prática, em termos de níveis de envolvimento e tipos de usuários. Na sequência, aborda-se o recorte realizado nesta pesquisa, que foca o co-design como nível de envolvimento a ser estudado, elencando os benefícios para o processo de projeto e para a edificação e os serviços resultantes, em contraponto aos desafios enfrentados em sua utilização. Por fim, apresentam-se as questões referentes à seleção dos usuários que serão envolvidos no processo e a metodologia necessária para a viabilização do co-design. 0 capítulo se encerra com a discussão dos principais pontos abordados e a síntese conclusiva, situando os achados no contexto geral do trabalho.

\subsection{DeFINIÇÕES}

Apesar de muitos textos, em diferentes áreas, abordarem a participação de usuários ao longo das últimas décadas, ainda falta uma definição clara do termo (KUJALA, 2003; MAGNUSSON; MATTHING; KRISTENSSON, 2003). O termo participação tem sido utilizado "para descrever uma grande variedade de atividades, que ocorrem em circunstâncias muito distintas" (SINCLAIR, 2004, p.108). Algumas definições encontradas ainda parecem muito gerais, como a apresentada por Wulz (1986, p.153), que define participação como um "conceito geral cobrindo diferentes formas de tomada de decisão por um número de partes envolvidas". Um pouco mais detalhadas, são a definição de Granath, Lindahl e Rehal (1996, p.1):

Projeto participativo se refere a um processo de projeto onde diferentes intervenientes, de algum modo, são envolvidos no processo de projeto para melhorar o próprio processo de projeto ou os resultados deste processo. 
E de Wilcox (1994, p.50):

Um processo em que indivíduos, grupos ou organizações são consultados ou tem a oportunidade de se tornar ativamente envolvidos em um projeto ou programa de atividade.

Em ambas as definições não se especificam ao certo o nível de envolvimento ou o papel dos usuários, que se pressupõem fundamentais para a programação das atividades de projeto e coordenação do processo. De acordo com Kirbyet al. (2003) e Sinclair (2004), a participação é multidimensional, e apontam dimensões-chave para sua compreensão. Apesar destes textos tratarem de participação de crianças, algumas dimensões apresentadas por eles podem ser estendidas para outros usuários em projetos de edifícios, como mostra o quadro 14.

Quadro 14. Diversas dimensões da Participação. Fonte: Baseado em informações de Kirby et al. (2003) e Sinclair (2004)

\begin{tabular}{|l|l|}
\hline DIMENSÃO DE PARTICIPAÇÃO & \multicolumn{1}{|c|}{ DESCRIÇÃO } \\
\hline Tipos de usuários & $\begin{array}{l}\text { Grupos de Usuários são distintos entre si, e estas diferenças } \\
\text { podem afetar a forma de participação. }\end{array}$ \\
\hline Nível de Envolvimento & $\begin{array}{l}\text { O nível de envolvimento dos usuários varia (SINCLAIR, 2004). Há } \\
\text { vários textos na literatura com modelos de participação em forma } \\
\text { de escada, com diferentes níveis de envolvimento (ver, por } \\
\text { exemplo, Arnstein(1969)). Além disto, atividades diferentes } \\
\text { podem requerer diferentes níveis de envolvimento (SHIER, 2001). }\end{array}$ \\
\hline $\begin{array}{l}\text { Natureza das Atividades de } \\
\text { Participação }\end{array}$ & $\begin{array}{l}\text { Existem diversas formas, com características específicas, para } \\
\text { realização das atividades de participação. }\end{array}$ \\
\hline
\end{tabular}

O termo 'envolvimento dos usuários', semelhantemente ao proposto por Kaulio (1998), representa as interações possíveis entre os usuários e o processo de projeto. Segundo alguns autores, o termo 'envolvimento' é geral e abrange uma série de níveis, cada um representando a relação entre usuários e provedores de serviços, com diferentes níveis de poder (ARNSTEIN, 1969; KUJALA, 2003; BAGGOTT, 2005). Com o intuito de se construir uma definição mais clara e estabelecer o recorte a ser estudado, a revisão bibliográfica traz, na sequência, a dimensão dos níveis de envolvimento, seguida pelos tipos de usuários em projetos de edifícios de assistência à saúde. 


\subsubsection{Níveis de Envolvimento de Usuários}

No campo da administração pública, Arnstein propõe uma escada com oito degraus "correspondendo à extensão do poder dos cidadãos em determinar o produto final" (ARNSTEIN, 1969, p.217). Apesar de a representação ser uma simplificação, ela permite visualizar que existem diversos níveis de envolvimento (quadro 15). A autora ressalta que nenhum grupo é homogêneo, nem dos detentores de poder, nem dos menos-favorecidos, e que reúnem pontos de vista divergentes, subgrupos com rupturas significantes e interesses concorrentes. No entanto, os menos favorecidos geralmente tem uma percepção do poder como um sistema monolítico, e os detentores do poder os consideram como massa, sem entender suas diferenças, o que justifica a representação simplificada proposta.

Quadro 15. Níveis de envolvimento segundo a 'Escada de participação dos cidadãos'. Fonte: Arnstein (1969).

\begin{tabular}{|c|c|c|}
\hline & $\begin{array}{l}\text { DEGRAUS DA } \\
\text { ESCADA }\end{array}$ & DESCRIÇÃO \\
\hline \multirow[t]{3}{*}{$\begin{array}{l}\text { PODER DO } \\
\text { CIDADÃO }\end{array}$} & $\begin{array}{l}\text { Controle pelo } \\
\text { cidadão }\end{array}$ & $\begin{array}{l}\text { Controle absoluto não é possível nem para os governantes, então o } \\
\text { que as pessoas requerem é um grau de controle em que um } \\
\text { programa ou instituição possam ser governados por elas, assim } \\
\text { como ter controle de políticas ou aspectos gerenciais entre outros. }\end{array}$ \\
\hline & $\begin{array}{l}\text { Delegação de } \\
\text { Poder }\end{array}$ & $\begin{array}{l}\text { Os cidadãos possuem poder dominante na tomada de decisões } \\
\text { referentes a programas ou planejamentos particulares. As } \\
\text { diferenças são resolvidas com os detentores de poder negociando e } \\
\text { não respondendo à pressão das classes. }\end{array}$ \\
\hline & Parceria & $\begin{array}{l}\text { Distribuição do poder entre cidadãos e detentores do poder, por } \\
\text { meio de negociação. Através de conselhos de política conjunta, } \\
\text { mecanismos para solução de impasses e comitês de planejamento, } \\
\text { há consenso no compartilhamento de planejamento e } \\
\text { responsabilidades de tomada de decisão. Algumas condições da } \\
\text { comunidade propiciam o funcionamento efetivo da parceria: (1) } \\
\text { Base de poder organizada; (2) condições de pagamento de } \\
\text { honorários para os representantes; (3) condições de contratar seus } \\
\text { próprios técnicos, advogados e organizadores. }\end{array}$ \\
\hline \multirow{3}{*}{$\begin{array}{l}\text { TOKENISMO } \\
\text { (Os menos } \\
\text { favorecidos podem } \\
\text { ouvir e ter voz, mas } \\
\text { não se tem garantia } \\
\text { de que suas } \\
\text { observações serão } \\
\text { atendidas) }\end{array}$} & Pacificação & $\begin{array}{l}\text { Apesar de ainda configurar tokenismo, neste estágio os cidadãos } \\
\text { começam a ter um pouco de influência. Os menos favorecidos } \\
\text { podem opinar, mas a decisão final sobre a legitimidade e viabilidade } \\
\text { da opinião ainda é dos detentores de poder. A maior parte dos } \\
\text { programas de participação está deste nível para baixo. }\end{array}$ \\
\hline & Consulta & $\begin{array}{l}\text { Para legitimar a participação é importante tanto informar como } \\
\text { solicitar opinião dos cidadãos, mas isto precisa ocorrer } \\
\text { paralelamente a outros métodos para que haja garantia de que as } \\
\text { opiniões serão efetivamente consideradas. Métodos mais comuns: } \\
\text { pesquisas de atitude, audiências públicas e reuniões de vizinhança. }\end{array}$ \\
\hline & Informação & $\begin{array}{l}\text { Apesar da informação dos cidadãos sobre seus direitos, } \\
\text { responsabilidades e opções ser um passo inicial muito importante }\end{array}$ \\
\hline
\end{tabular}

\footnotetext{
36 “1. A política de fazer só um esforço superficial ou gesto simbólico para a realização de um objetivo, como a integração racial. / 2. A prática de contratação ou nomeação de um número simbólico de pessoas de grupos subrepresentados, a fim de desviar as críticas ou de acordo com as regras de ação afirmativa". Fonte: Disponível em: http://www.thefreedictionary.com/tokenism, Acesso em: 31 out 2012.
} 


\begin{tabular}{|c|c|c|}
\hline & $\begin{array}{c}\text { DEGRAUS DA } \\
\text { ESCADA }\end{array}$ & DESCRIÇÃO \\
\hline & & $\begin{array}{l}\text { para a participação, frequentemente esta informação se dá em } \\
\text { estágios avançados do planejamento e apenas dos oficiais para os } \\
\text { cidadãos, sem estes poderem negociar ou retroalimentar o sistema. } \\
\text { Meios usados: panfletos, propagandas, etc. }\end{array}$ \\
\hline \multirow{2}{*}{$\begin{array}{c}\text { NÃO } \\
\text { PARTICIPAÇÃo } \\
\text { (Permitir que as } \\
\text { pessoas sejam } \\
\text { 'educadas' ou } \\
\text { 'curadas' pelos } \\
\text { detentores de } \\
\text { poder, sem } \\
\text { participação no } \\
\text { planejamento) }\end{array}$} & Terapia & $\begin{array}{l}\text { Os cidadãos menos favorecidos são submetidos a terapias de grupo } \\
\text { pelos administradores (especialistas em saúde mental, que os } \\
\text { consideram patológicos), sob a falsa ilusão de participação no } \\
\text { planejamento. A autora destaca que a particularidade desta forma } \\
\text { de participação é que o foco das longas atividades a que os cidadãos } \\
\text { são submetidos não é a mudança da vitimização e racismo que } \\
\text { geram suas patologias, mas a "cura" destas. }\end{array}$ \\
\hline & Manipulação & $\begin{array}{l}\text { Distorção do conceito de participação, organizando as pessoas em } \\
\text { conselhos consultivos ou comitês de assessoramento para } \\
\text { aprovação de planejamentos dos quais não participaram, como } \\
\text { massa de manobra para legitimar as decisões dos detentores de } \\
\text { poder. }\end{array}$ \\
\hline
\end{tabular}

Wilcox (1994) parte dos níveis do modelo de Arnstein e faz uma adaptação para cinco níveis, ao invés de oito: informação; consulta; decisão compartilhada; ação compartilhada e suporte a interesses de comunidades independentes. O autor não considera que exista algum nível melhor que outro, mas que cada nível é apropriado para satisfazer a interesses distintos em diferentes momentos. 0 quadro 16 resume as características, métodos, benefícios e questões de cada nível. Há ainda o modelo de Hart, que faz uma releitura da escada de Arnstein, voltada para a participação de crianças (HART, 1992).

Quadro 16. Resumo dos níveis de envolvimento. Fonte: Wilcox (1994).

\begin{tabular}{|c|c|c|c|c|c|}
\hline NÍVEL & INFORMAÇÃO & CONSULTA & $\begin{array}{c}\text { DECISÃO } \\
\text { COMPARTILHADA }\end{array}$ & $\begin{array}{c}\text { AÇÃO } \\
\text { COMPARTILHADA }\end{array}$ & $\begin{array}{l}\text { SUPORTE AOS } \\
\text { INTERESSES }\end{array}$ \\
\hline $\begin{array}{l}\text { Processo } \\
\text { Típico }\end{array}$ & $\begin{array}{l}\text { Apresentação e } \\
\text { Promoção }\end{array}$ & $\begin{array}{l}\text { Comunicação e } \\
\text { Retroalimentação }\end{array}$ & $\begin{array}{l}\text { Construção de } \\
\text { consenso }\end{array}$ & $\begin{array}{l}\text { Construção de } \\
\text { parceria }\end{array}$ & $\begin{array}{l}\text { Desenvolvimento } \\
\text { comunitário }\end{array}$ \\
\hline $\begin{array}{l}\text { Métodos } \\
\text { Típicos }\end{array}$ & $\begin{array}{l}\text { Folheto } \\
\text { Mídia } \\
\text { Vídeo }\end{array}$ & $\begin{array}{l}\text { Pesquisas } \\
\text { Reuniões }\end{array}$ & $\begin{array}{l}\text { Workshops } \\
\text { Planejamento } \\
\text { para escolha } \\
\text { estratégica real }\end{array}$ & $\begin{array}{l}\text { Instâncias de } \\
\text { parcerias }\end{array}$ & $\begin{array}{l}\text { Conselho } \\
\text { Suporte } \\
\text { Financiamento }\end{array}$ \\
\hline $\begin{array}{l}\text { Postura do } \\
\text { Iniciador }\end{array}$ & $\begin{array}{l}\text { ‘Aqui está o que } \\
\text { vamos fazer' }\end{array}$ & $\begin{array}{l}\text { 'Estas são nossas } \\
\text { opções - o que } \\
\text { vocês acham?' }\end{array}$ & $\begin{array}{l}\text { 'Queremos } \\
\text { desenvolver } \\
\text { opções e decidir } \\
\text { as ações em } \\
\text { conjunto' }\end{array}$ & $\begin{array}{l}\text { 'Queremos juntos } \\
\text { efetuar decisões } \\
\text { conjuntas' }\end{array}$ & $\begin{array}{lr}\text { 'Podemos ajuda- } \\
\text { los a atingir o que } \\
\text { vocês querem } \\
\text { dentror destas } \\
\text { diretrizes' }\end{array}$ \\
\hline $\begin{array}{l}\text { Benefícios } \\
\text { do } \\
\text { Iniciador }\end{array}$ & $\begin{array}{l}\text { Aparentemente } \\
\text { menor esforço }\end{array}$ & $\begin{array}{l}\text { Aumenta as } \\
\text { chances de acerto }\end{array}$ & $\begin{array}{l}\text { Novas ideias e } \\
\text { comprometiment } \\
\text { o de outras } \\
\text { pessoas }\end{array}$ & $\begin{array}{l}\text { Traz recursos } \\
\text { adicionais }\end{array}$ & $\begin{array}{l}\text { Desenvolve } \\
\text { capacidade na } \\
\text { comunidade e } \\
\text { pode reduzir } \\
\text { chamadas em } \\
\text { serviços }\end{array}$ \\
\hline $\begin{array}{l}\text { Questões } \\
\text { para o } \\
\text { Iniciador }\end{array}$ & $\begin{array}{l}\text { As pessoas } \\
\text { aceitarão a } \\
\text { consulta? }\end{array}$ & $\begin{array}{l}\text { As opções são } \\
\text { realistas? Existem } \\
\text { outras? }\end{array}$ & $\begin{array}{lr}\text { Temos } & \text { modos } \\
\text { similares } & \text { de } \\
\text { decisão? } & \text { Nós } \\
\text { conhecemos } & \text { e } \\
\text { confiamos } & \text { nos } \\
\text { outros? } & \\
\end{array}$ & $\begin{array}{l}\text { Como será o } \\
\text { balanceamento } \\
\text { do controle? } \\
\text { Podemos } \\
\text { trabalhar juntos? }\end{array}$ & $\begin{array}{l}\text { Nossos objetivos } \\
\text { serão atingidos } \\
\text { tanto quanto os } \\
\text { outros } \\
\text { interesses? }\end{array}$ \\
\hline
\end{tabular}


Choguill (1996) apresenta uma adaptação da escada de Arnstein para países em desenvolvimento, com os mesmos oito degraus, mas com alteração da terminologia, argumentando que esta se adéqua melhor ao contexto destes países.

Tritter e McCallum (2006) consideram que a 'escada de participação' de Arnstein está desatualizada, apesar de muitos textos em administração pública se basearem nela, principalmente na área de serviços de saúde, e cita os modelos de Wilcox e Choguill como releituras sem crítica de Arnstein. Uma das críticas é que a escada de Arnstein só considera como medida de nível de participação o poder de tomar decisões, e que o objetivo do engajamento dos cidadãos é este controle. Os autores propõem um modelo mais abrangente, pois acreditam que "o envolvimento e fortalecimento dos usuários são fenômenos complexos através dos quais os indivíduos formulam meios e ações que refletem o grau desejado de participação nos processos decisórios individuais e sociais" (TRITTER; MCCALLUM, 2006, p.157). Os autores acreditam que quando não há compatibilidade entre expectativa e método, o envolvimento dos usuários fica mais suscetível às falhas. Diferente de Arnstein, concluem "que o envolvimento do usuário requer estruturas dinâmicas e processos legitimados tanto pelos participantes quanto pelos não participantes" (TRITTER; MCCALLUM, 2006, p.157). Os autores apresentam também criticam a conceituação simplificada dos protagonistas, as falhas na consideração do processo e dos resultados e a falta de métodos e sistemas de retroalimentação.

$\mathrm{Na}$ área de projetos de tecnologia de informação, a revisão bibliográfica levantou os seguintes níveis de envolvimento dos usuários (DAMODARAN, 1996):

- Informativo: nível em que os usuários apenas fornecem ou recebem informações;

- Consultivo: neste nível, os usuários são envolvidos para comentar um serviço ou conjunto de componentes pré-definidos; e

- Participativo: quando os usuários influenciam decisões relativas a todo o sistema.

Uma abordagem que tem sido apresentada em várias áreas, como em design (HO; LEE, 2012) e desenvolvimento de produtos (KAULIO, 1998), apresenta o envolvimento dos usuários em projeto em três diferentes níveis:

- Projeto para Usuários: Os usuários são passivos e os profissionais de projeto controlam o processo como um todo;

- Projeto com Usuários: Os usuários participam ativamente como projetistas, compartilhando o processo com os profissionais de projeto; 
- Projeto por Usuários: Os usuários podem se tornar projetistas e colaboradores, uma vez que os profissionais de projeto os capacitam para controlar o processo.

Na área específica de arquitetura, Wulz (1986) apresenta uma visualização do envolvimento do usuário em dois polos opostos que, apesar de não serem comumente aplicados, servem para ilustrar os extremos do processo de projeto arquitetônico: de um lado, a tomada de decisões é feita exclusivamente pelo arquiteto e, do outro lado, o usuário toma as decisões sem intervenção do projetista. Os estágios de influência do arquiteto ou do usuário formam uma escala entre os dois polos, que é recíproca, pois "a diminuição da influência do arquiteto é seguida pelo aumento da influência do usuário" (WULZ, 1986, p.155). Os pontos desta escala são representados pelos níveis de envolvimento, que são denominados como representação, questionário, regionalismo, diálogo, alternativa, co-decisão e auto-decisão, conforme descritos no quadro 17 e na figura 18.

Quadro 17. Níveis de envolvimento. Fonte: Wulz (1986).

\begin{tabular}{|c|c|c|}
\hline $\begin{array}{l}\text { FORMA DE } \\
\text { ENVOLVIM. }\end{array}$ & DESCRIÇÃO & EXEMPLO DE APLICAÇÃO \\
\hline Representação & $\begin{array}{l}\text { Forma de participação mais passiva, onde o arquiteto se coloca } \\
\text { no lugar do usuário para considerar suas necessidades e } \\
\text { aspirações ("base da existência da profissão do arquiteto", está } \\
\text { presente em todas as outras). }\end{array}$ & $\begin{array}{l}\text { Projetos com usuário } \\
\text { final anônimo } \\
\text { (planejamento urbano ou } \\
\text { edifícios } \\
\text { apartamentos). }\end{array}$ \\
\hline Questionário & $\begin{array}{l}\text { Pressupõe estudos sistemáticos, tratados estatisticamente, } \\
\text { sobre as características e requisitos comuns dos clientes, que } \\
\text { serão estruturados e generalizados. }\end{array}$ & $\begin{array}{l}\text { Produção em massa de } \\
\text { edifícios habitacionais } \\
\text { (1930s), que reforçou a } \\
\text { separação entre } \\
\text { cliente/usuário e entre } \\
\text { usuário/arquiteto. }\end{array}$ \\
\hline Regionalismo & $\begin{array}{l}\text { Foca as qualidades simbólicas e arquitetônicas de uma área } \\
\text { específica, combinando representação e questionário. } \\
\text { Diferencia-se da representação pela maneira sistematizada de } \\
\text { levantar as características da arquitetura do local do projeto, e } \\
\text { do questionário, por considerar as características culturais e } \\
\text { específicas, dentro de uma área geográfica limitada. Origens: } \\
\text { repúdio dos usuários à uniformização da arquitetura das áreas } \\
\text { residenciais, ocorrida nos anos } 1960 \text { s em partes da Europa. }\end{array}$ & \\
\hline Diálogo & $\begin{array}{l}\text { Baseando-se em conversas informais, o arquiteto utiliza o } \\
\text { conhecimento do usuário no processo e lhe fornece informações } \\
\text { sobre as propostas iniciais, para comentários nas primeiras fases } \\
\text { do processo. Mas as decisões finais são tomadas apenas pelo } \\
\text { arquiteto. Objetivos: democratização do planejamento, } \\
\text { alimentação do projeto com sugestões do usuário, } \\
\text { conhecimento das características regionais e fim do anonimato } \\
\text { tanto do arquiteto como do usuário. }\end{array}$ & \\
\hline Alternativa & $\begin{array}{l}\text { Sem anonimato, os usuários escolhem uma alternativa dentro } \\
\text { de uma estrutura fixa, e o arquiteto apresenta as soluções numa } \\
\text { linguagem que os leigos consigam entender. Em casos onde a } \\
\text { escolha afeta um número maior de pessoas, a decisão pode ser } \\
\text { feita por meio de voto, o que pode provocar a insatisfação de }\end{array}$ & \\
\hline
\end{tabular}




\begin{tabular}{|c|c|c|}
\hline & minorias com opiniões divergentes. & \\
\hline Co-decisão & $\begin{array}{l}\text { O usuário tem poder de decisão balanceado com o do arquiteto, } \\
\text { e está envolvido desde o início do processo. Para viabilizar a } \\
\text { participação ativa e direta do usuário depende que os envolvidos } \\
\text { se conheçam individualmente, estejam dispostos e tenham } \\
\text { tempo de participar de todo o processo, além dos usuários } \\
\text { custearem eventuais acréscimos no período de planejamento. }\end{array}$ & \\
\hline Auto-decisão & $\begin{array}{l}\text { Os próprios usuários tomam as decisões, com o arquiteto no } \\
\text { papel de garantir que os requisitos da sociedade sejam } \\
\text { respeitados. Como objetivo último, almeja-se uma situação ideal } \\
\text { de evitar e abolir a intervenção das autoridades, que se dão, por } \\
\text { exemplo, por regulamentações, normas e leis. Pressupõe que as } \\
\text { pessoas são entidades criativas e que a forma pura de } \\
\text { democracia seja a independência de todas as formas de } \\
\text { intervenção autoritária. }\end{array}$ & $\begin{array}{l}\text { Formas de auto- } \\
\text { construção - finalização } \\
\text { de obras inacabadas que } \\
\text { possuam pelo menos } \\
\text { estrutura, instalações e } \\
\text { cobertura, onde o } \\
\text { arquiteto é visto como } \\
\text { consultor - e autoajuda. }\end{array}$ \\
\hline
\end{tabular}

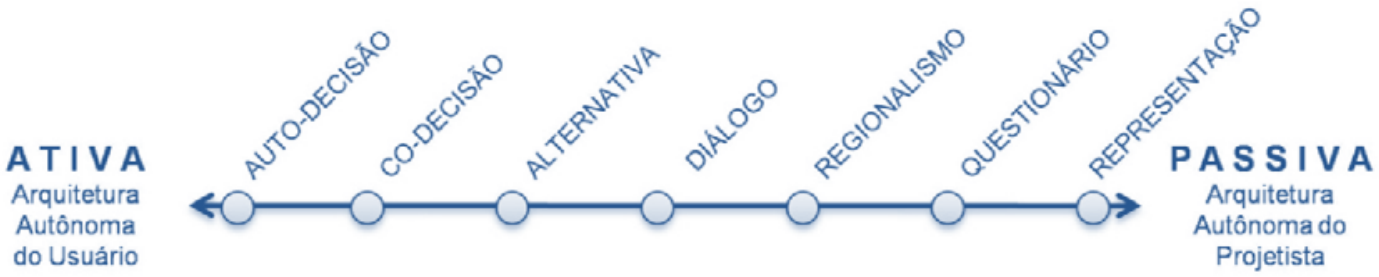

Figura 18. Formas de envolvimento do usuário no processo de projeto. Fonte: Preparada a partir do texto de Wulz (1986).

Numa outra abordagem, Sanders e Stappers (2008) descrevem dois níveis de envolvimento dos usuários em processo de projeto: projeto centrado no usuário e co-design. No processo de projeto centrado no usuário, o pesquisador observa e entrevista o usuário, para ampliar seus conhecimentos sobre ele e informar os projetistas. O usuário é visto, portanto, como um objeto de estudo passivo. Já no co-design, os usuários são tidos como parceiros, e desenvolvem um papel importante no desenvolvimento do conhecimento, na geração de ideias, entre outros. A Figura 19 ilustra os dois níveis descritos pelos autores.

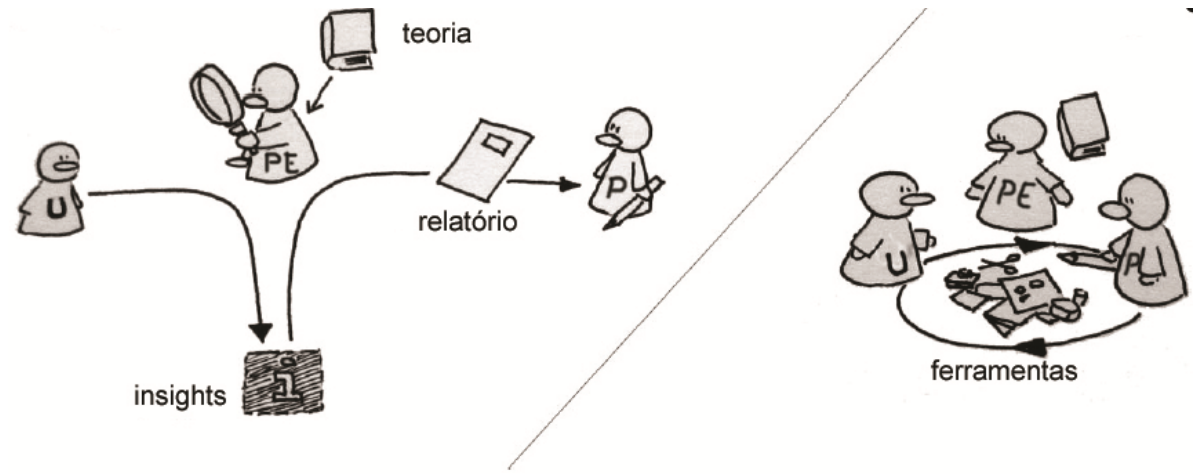

Figura 19. Papéis dos usuários (U), pesquisadores (PE) e projetistas (P) no processo de projeto centrado no usuário (à esquerda) e no co-design (à direita). Fonte: Sanders e Stappers (2008). 
Em âmbito nacional, diversos textos utilizam o termo 'projeto participativo' para descrever o envolvimento dos usuários em processo de projeto arquitetônico, com sentido semelhante ao proposto por Damodaran (1996). Em Lana (2007), a descrição apresentada refere-se ao projeto arquitetônico com participação ativa do usuário final, que não é somente provedor de recursos ou fornecedor do programa de necessidades, mas compartilha as decisões com o arquiteto ao longo do processo. A autora ressalta, entretanto, que não se trata de coautoria, mas de compartilhamento de decisões.

Para comparar as diversas abordagens sobre níveis de participação apresentadas, o quadro 18 sintetiza os níveis de participação em projeto propostos por cada autor, permitindo uma melhor visualização dos mesmos.

Quadro 18. Comparação dos níveis de envolvimento em projeto propostos pelos autores citados. Fonte: Elaborado pela autora.

\begin{tabular}{|c|c|c|c|c|c|c|c|}
\hline AUTORES & \multicolumn{6}{|c|}{ NÍVEIS DE ENVOLVIMENTO DOS USUÁRIOS } & \\
\hline $\begin{array}{l}\text { Damodaran } \\
(1996)\end{array}$ & & \multicolumn{2}{|l|}{ Informativo } & Consultivo & Participativo & & \\
\hline Lana (2007) & & & & & $\begin{array}{c}\text { Projeto } \\
\text { Participativo }\end{array}$ & & \\
\hline $\begin{array}{l}\text { Kaulio (1998); } \\
\text { Ho e Lee (2012) }\end{array}$ & \multicolumn{5}{|c|}{ Projeto para Usuărios } & $\begin{array}{l}\text { Projeto com } \\
\text { Usuários }\end{array}$ & $\begin{array}{l}\text { Projeto por } \\
\text { Usuários }\end{array}$ \\
\hline Wulz (1986) & Representação & Questionário & Regionalismo & Diálogo & Alternativa & Co-decisão & Autodecisão \\
\hline $\begin{array}{l}\text { Sanders e } \\
\text { Stappers (2008) }\end{array}$ & & \multicolumn{4}{|c|}{ Projeto Centrado no Usuário } & Co-design & \\
\hline
\end{tabular}

As propostas dos autores citados, relativas ao nível de envolvimento dos usuários, foram organizadas no quadro de forma que, conforme se caminha nas linhas da esquerda para a direita, o nível de envolvimento dos usuários aumenta, enquanto o envolvimento dos profissionais de projeto diminui. O quadro foi dividido em três colunas: uma anterior à linha 1, uma entre as linhas 1 e 2 e a última após a linha 2, de acordo com as características apresentadas a seguir.

Os níveis compreendidos na coluna anterior à linha 1 representam a forma mais passiva do envolvimento dos usuários, que são totalmente anônimos. O projeto é realizado, no caso da 'Representação' proposta por Wulz (1986), com o arquiteto se colocando no lugar do usuário para considerar suas necessidades. Neste caso, a presente pesquisa considera que não há participação do usuário. O 'Projeto para Usuários', de Kaulio (1998) e Ho e Lee (2012), inicia-se na primeira coluna e se estende para a coluna central, por se referir tanto a processos sem participação do usuário, como àqueles onde há um nível mínimo de participação destes. 
$\mathrm{Na}$ coluna central, entre as linhas 1 e 2, encontram-se os níveis de coparticipação entre usuários e profissionais de projeto, sendo que, quanto mais próximo se está da linha 2, maior a participação efetiva e poder de tomada de decisão dos usuários. Ainda nesta coluna central observa-se, adjacente à linha 2, que há uma concordância de níveis para os quatro trabalhos citados, que, apesar de nomenclatura diferente, descrevem o envolvimento efetivo dos usuários no processo de projeto. No presente trabalho, o termo adotado para este nível é co-design, por ser o mais usual na literatura e o que melhor reflete as características deste nível de envolvimento. O quadro 19 retoma e compara a descrição deste nível, segundo os textos citados, demonstrando que o mesmo possui características semelhantes nas quatro definições.

Quadro 19. Comparação das definições e termos empregados pelos quatro autores citados para este nível de participação em projeto. Fonte: Elaborado pela autora.

\begin{tabular}{|c|c|c|}
\hline \multicolumn{2}{|c|}{ AUTOR } & \multicolumn{1}{|c|}{ DESCRIÇÃO DO NÍVEL DE PARTICIPAÇÃO } \\
\hline $\begin{array}{c}\text { Projeto com } \\
\text { Usuários }\end{array}$ & $\begin{array}{l}\text { Kaulio(1998); Bergvall-Kareborn } \\
\text { e Stahlbrost (2008); Ho e } \\
\text { Lee(2012). }\end{array}$ & $\begin{array}{l}\text { Usuários participam ativamente como projetistas, } \\
\text { compartilhando o processo com os profissionais de projeto. }\end{array}$ \\
\hline Co-decisão & Wulz (1986). & $\begin{array}{l}\text { Usuários tem participação ativa e direta desde o início do } \\
\text { processo de projeto, e poder de decisão balanceado com o } \\
\text { do arquiteto. }\end{array}$ \\
\hline Co-design & Sanders e Stappers (2008) & $\begin{array}{l}\text { Usuários são tidos como parceiros, e desenvolvem um papel } \\
\text { importante no desenvolvimento do conhecimento. }\end{array}$ \\
\hline
\end{tabular}

Por fim, a coluna situada após a linha 2 indica que o envolvimento dos projetistas é mínimo, cabendo o controle do processo aos usuários. Os projetistas podem participar eventualmente como consultores.

Tendo em vista que os diferentes níveis de envolvimento possuem características próprias, com benefícios e dificuldades distintos, e, portanto, requerem diferentes instrumentos e métodos de aplicação, levanta-se a necessidade de estabelecer um nível de envolvimento para ser o foco da pesquisa. Isto se justifica para que se possa alcançar o detalhamento necessário a uma pesquisa de doutorado, evitando assim que se trabalhe com variáveis demais para se aprofundar, resultando num trabalho superficial. Pela revisão bibliográfica nota-se que há muito mais trabalhos disponíveis em relação aos níveis com menor envolvimento. Existem instrumentos consolidados, como entrevistas e grupo focal, para atender aos níveis informativo e consultivo, por exemplo. No entanto, para o nível de codesign ainda há menos trabalhos disponíveis, apesar deste nível de envolvimento 
aparentemente poder trazer benefícios significativos para o processo de projeto. Dada esta lacuna, a presente pesquisa focará em co-design.

De acordo com Kleinsmann e Valkenburg (2008), o objetivo do co-design é a criação de um conhecimento compartilhado entre os diversos membros da equipe multidisciplinar, através da exploração dos conhecimentos de cada um, para desenvolvimento de um novo produto.

Em co-design, no contexto de projetos de serviços, o prefixo 'co' indica uma ampla colaboração, envolvendo tanto usuários como equipes internas da organização em diálogos sobre os serviços prestados, buscando melhorias nos produtos ou serviços de maneiras novas ou inovadoras (FORLIZZI; BATTARBEE, 2004; BATE; ROBERT, 2007). Isto não implica em tornar os usuários em especialistas em projetos, mas envolvê-los na discussão no papel de usuários com experiência nos serviços (BATE; ROBERT, 2007).

\subsubsection{Tipos de Usuários em projetos de Edifícios}

Quando se fala em envolvimento de usuários, White (1996) destaca a importância de se questionar quem são os usuários, dando a dimensão de que estes não formam um grupo homogêneo. O termo usuário é amplo e complexo, e abrange muitos grupos distintos, com valores e necessidades diversas e muitas vezes conflitantes, embora possa aparentar se referir a uma única pessoa ou um grupo bem definido de pessoas (BERTELSEN; EMMITT, 2005; JENSEN, 2006; OLSSON; BLAKSTAD; HANSEN, 2010; JENSEN, 2011).

Para abordar a questão de usuários de edifícios, dentro do contexto do processo de projeto, é importante também definir os termos 'cliente' e 'stakeholder'. As organizações ou os indivíduos que encomendam uma obra de infraestrutura ou um edifício são denominados clientes (DE BLOIS et al., 2011). Estes autores identificam diferentes tipos de clientes da construção, por meio de revisão bibliográfica, de acordo com sua origem, perfil e experiência, conforme resume o quadro 20. 
Quadro 20. Tipos de clientes da construção civil, segundo origem, perfil ou experiência em construção. Fonte: revisão bibliográfica apresentada por De Blois et al. (2011).

\begin{tabular}{|c|l|l|l|}
\hline CRITÉRIO & \multicolumn{1}{|c|}{ ORIGEM } & \multicolumn{1}{|c|}{$\begin{array}{c}\text { PERFIL } \\
\text { (Razão para demandar um } \\
\text { edifício) }\end{array}$} & $\begin{array}{c}\text { EXPERIÊNCIA EM } \\
\text { CONSTRUÇÃO }\end{array}$ \\
\hline $\begin{array}{c}\text { Tipos de } \\
\text { cliente }\end{array}$ & $\begin{array}{l}\text { - Cliente individual } \\
\text { - Cliente corporativo }\end{array}$ & $\begin{array}{l}\text { - Cliente Primário } \\
\text { (investidor, que constrói para } \\
\text { venda, aluguel, etc.) } \\
\text { - Cliente público } \\
\text { (utiliza o edifício para realizar } \\
\text { suas atividades) }\end{array}$ & $\begin{array}{l}\text { - Cliente experiente } \\
\text { - Cliente inexperiente }\end{array}$ \\
\hline
\end{tabular}

Para Newcombe (2003), o surgimento do conceito de 'stakeholder' amplia o escopo da definição de cliente, uma vez que passa a considerar também, por exemplo, os usuários do serviço. O termo 'stakeholder' pode ser traduzido livremente como 'interveniente'. Segundo o Project Management Institute - PMI (2000, p.16), stakeholders

[...] são indivíduos ou organizações que estão ativamente envolvidas no projeto, ou cujos interesses podem ser positiva ou negativamente afetados pelo resultado da execução do projeto ou de sua conclusão; também podem exercer influência sobre o projeto e seus resultados.

Wilcox (1994) lista exemplos de sakeholders como os que se beneficiam das propostas, os que são negativamente afetados, os que decidem, os que podem ajudar ou dificultar as propostas e os que possuem habilidades, dinheiro ou outros recursos envolvidos.

De acordo com Olsson, Blakstad e Hansen (2010), usuários são stakeholders. Estes autores estudaram diversos projetos de edifícios na Noruega, juntamente com revisões bibliográficas internacionais sobre o assunto, para mapear as categorias de usuários ao longo das etapas do processo de projeto, iniciando pelo briefing, projeto, construção até durante a etapa de uso. Como resultado, levantaram diversos tipos de usuários baseando-se numa abordagem de cadeia de suprimentos das atividades realizadas no edifício: olha-se para os diferentes usuários em um número de passos desta cadeia, originando-se no edifício em si (proprietários do edifício). Segue-se, então, pelas atividades que ocorrem subsequentemente: operação do edifício, que tem como cliente a organização provedora do edifício, que por sua vez tem como cliente os usuários diretos do serviço. Estes, por fim, tem relação ou como clientes os usuários indiretos do serviço. A figura 20 ilustra as categorias de usuários ao longo desta cadeia de suprimentos. 

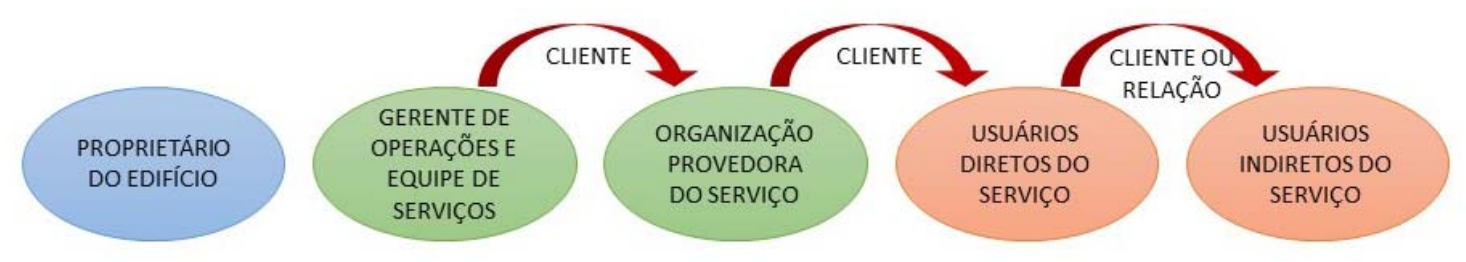

Figura 20. Cadeia de suprimentos com as diferentes categorias de usuários de edifícios. Fonte: Olsson et al. (2010).

O quadro 21 descreve cada uma destas categorias e fornece exemplos, considerando um edifício de saúde.

Quadro 21. Categoria de usuários de um edifício, considerando exemplos de um serviço de saúde. Fonte: Olsson et al. (2010).

\begin{tabular}{|c|c|c|}
\hline CATEGORIA DE USUÁRIO & DESCRIÇÃO & EXEMPLO \\
\hline Proprietários do edifício & $\begin{array}{l}\text { Sofrem impactos em sua propriedade, embora } \\
\text { nem sempre estejam envolvidos na operação } \\
\text { do edifício. }\end{array}$ & --- \\
\hline $\begin{array}{l}\text { Gerente de operações e equipe de } \\
\text { serviços }\end{array}$ & $\begin{array}{l}\text { 'Operam o edifício' (gerenciam a edificação, } \\
\text { realizam manutenções, entre outros), na } \\
\text { 'esfera de suprimentos', agindo em função dos } \\
\text { demais usuários, que estão geralmente na } \\
\text { esfera da 'demanda'. }\end{array}$ & $\begin{array}{l}\text { Equipes } \\
\text { manutenção, } \\
\text { limpeza, etc. }\end{array}$ \\
\hline \multirow[t]{2}{*}{ Organização Provedora do Serviço } & $\begin{array}{l}\text { Gerente: responsáveis pela administração da } \\
\text { organização provedora. }\end{array}$ & Gerência do EAS. \\
\hline & Empregados: proveem os serviços. & Médicos e Enfermeiros. \\
\hline Usuários diretos do Serviço & $\begin{array}{l}\text { Beneficiam-se dos serviços fornecidos pelo } \\
\text { grupo anterior. }\end{array}$ & Pacientes. \\
\hline Usuários indiretos do Serviço & Possuem relação com os usuários diretos. & Familiares de pacientes. \\
\hline
\end{tabular}

Hyett e Jenner (2008 ${ }^{37}$ apud COLLINGE, 2012) dividem os usuários de edifícios de assistência à saúde em três grupos: pacientes, visitantes e equipe interna. Destes, o grupo que permanece mais tempo na edificação é a equipe interna (BECKER; POE JR., 1980), e muitas vezes está mais familiarizada com a edificação e seu funcionamento. Comparada à classificação proposta por Olsson et al.(2010), temos:

\footnotetext{
${ }^{37}$ HYETT, P., JENNER, J. Rebuilding Britain's Health Service. In: PRASAD, S. (ed) Changing Hospital Architecture". London: RIBA Enterprises Limited, 2008.
} 
Quadro 22. Comparação entre as classificações dos usuários propostas por Hyett e Jenner e Olsson et al. Fonte: Elaborado pela autora.

\begin{tabular}{|c|c|c|}
\hline Autores & Hyett e Jenner (2008) & Olsson et al.(2010) \\
\hline \multirow{5}{*}{ 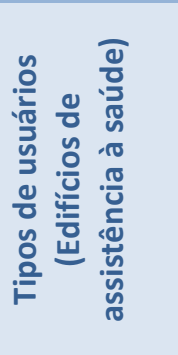 } & \multirow{3}{*}{ Equipe Interna } & Proprietários do edifício \\
\hline & & Gerente de operações e equipe de serviços \\
\hline & & Organização Provedora do Serviço \\
\hline & Pacientes & Usuários diretos do Serviço \\
\hline & Visitantes & Usuários indiretos do Serviço \\
\hline
\end{tabular}

Considerando a bibliografia pesquisada, adota-se para o presente trabalho a classificação apresentada por Olsson et al. (2010), por se considerar a que se adéqua ao perfil dos edifícios de assistência à saúde com mais precisão, e com detalhamento considerado adequado para esta pesquisa.

\subsection{CO-DESIGN}

Esta seção apresenta a revisão bibliográfica específica sobre co-design, aprofundando a exposição e discussão das suas principais características e peculiaridades. Inicia-se com a apresentação das razões que justificam o emprego do co-design, ou seja, os benefícios que este pode trazer para a eficiência operacional dos serviços do edifício de saúde. Em seguida, abordam-se os desafios de sua implantação, em termos de processo de projeto. Apresentamse então as questões relativas à seleção dos usuários para o co-design e, por fim, são elencados métodos e instrumentos utilizados. O objetivo desta seção é aprofundar os conhecimentos específicos sobre co-design, para embasar as pesquisas de campo e as demais etapas deste trabalho.

\subsubsection{Justificativa e Benefícios do Co-design}

Central para toda a noção de 'participação do usuário' é o direito das pessoas a ter uma influência direta sobre assuntos que lhes digam respeito, em seu trabalho (CLEMENT; VAN DEN BESSELAAR, 1993, p.36). 
Esta seção inicia-se apresentando benefícios e justificativas gerais extraídas de textos que abordam o projeto participativo, mas que são aplicáveis também ao co-design. Na sequência, abordam-se questões específicas ao co-design.

No projeto e desenvolvimento de outros produtos - não edifícios - já é comum o emprego de processos orientados ao cliente, pois o diálogo durante o processo criativo ajuda a determinar o máximo de diretrizes possíveis antes de se iniciar a produção (SVETOFT, 2006). No contexto do processo de projeto, a participação dos usuários ajuda a detectar suas reais necessidades, expectativas e preferências, que estão em constante evolução, e também corrobora para garantir alta qualidade no desempenho das edificações no futuro (STERN et al., 2003; STEEN; KUIJT-EVERS; KLOK, 2007; SFANDYARIFARD; TZORTZOPOULOS, 2011). Outro aspecto que justifica a participação dos usuários é sua contribuição para legitimar as decisões tomadas durante o processo de projeto, podendo evitar, desta fora, discordâncias em relação aos resultados do projeto (OLSSON et al., 2010).

Vários autores discorrem sobre fatores que justificam a busca por participação dos usuários, destacando os benefícios que esta prática pode trazer. Johnson (1979) acredita que o arquiteto pode propiciar um processo de trabalho conjunto com o usuário e gerar uma situação de aprendizagem mútua, onde o arquiteto pode se inteirar das necessidades, aspirações e problemas vivenciados pela comunidade. Por sua vez, a comunidade pode aprender a utilizar melhor os recursos disponíveis, e a buscar uma gama maior de soluções para seus problemas particulares, através de uma visão ampliada dos mesmos.

A abordagem participativa também é eficaz, segundo Baek e Lee (2008), quando os usuários são crianças, uma vez que permite que os projetistas lidem com as habilidades imaturas de linguagem e timidez destes usuários, por olhar para o problema a partir do ponto de vista da criança.

Diversos benefícios para o processo de projeto, descritos nas áreas de tecnologia de informação e desenvolvimento de serviços, se aplicam à área de arquitetura, e podem ser aqui citados. Damodaran (1996) elenca alguns destes benefícios, esperados pela participação dos usuários:

- Melhoria da qualidade do produto, por proporcionar um maior conhecimento dos reais requisitos dos usuários;

- Prevenção de inclusão de itens dispendiosos, que os usuários não podem utilizar ou simplesmente não requerem;

- Melhoria nos níveis de aceitação;

- Maior entendimento do sistema pelos usuários, resultando no uso mais efetivo. 
Barreto (2005, p.20) discorre sobre a importância da participação dos usuários no campo específico de arquitetura e urbanismo:

O que é aparente desde as críticas ao modernismo da Carta de Atenas e da obra dos grandes mestres da arquitetura até a metade do século 20 é que o arquiteto isolado não detém todas as informações necessárias ao projeto de arquitetura e de urbanismo e que a promoção da qualidade ambiental ocorre através de processos sociais mais amplos, que não se restringem ao projeto de arquitetura e urbanismo, mas que devem contar com sua participação. Dessa forma, a participação do usuário envolve desenvolvimentos que, num certo sentido, enriquecem e renovam a própria disciplina do projeto.

Quando as informações certas chegam às pessoas certas no tempo certo, o projeto tem sucesso (KAGIOGLOU et al., 2000). Segundo estes autores, há tempos a indústria reconhece a importância de equipes multidisciplinares no processo de desenvolvimento de produtos, cujas decisões tomadas em conjunto nas fases iniciais reduzem a probabilidade de dificuldades na produção e alterações onerosas nas fases posteriores. Semelhantemente, na construção de edifícios, o envolvimento ativo dos participantes pode facilitar a comunicação e permitir que a tomada de decisões seja apropriada e no tempo certo, principalmente se este envolvimento se der nas primeiras fases do processo de projeto (KAGIOGLOU et al., 2000). Segundo Arias et al. (2000), em projetos complexos, há um requisito de conhecimento que geralmente está distribuído entre os diversos stakeholders, pois é maior do que uma única pessoa pode possuir. Neste sentido, o processo de projeto de edifícios de assistência à saúde, por sua complexidade já abordada, pressupõe uma equipe multidisciplinar de profissionais para a etapa de projeto, e o co-design inclui, nesta equipe, o usuário como 'especialista de suas experiências' (SLEESWIJK VISSER et al. 2005), podendo facilitar ainda mais a identificação apropriada de seus requisitos.

Steen, Manschot e De Koning (2011) apresentam um quadro resumindo os benefícios específicos do co-design para projetos de serviços, a partir de três estudos de caso e revisão bibliográfica. Os benefícios foram categorizados em relação ao projeto de serviços, aos consumidores e usuários e à organização (Quadro 23).

Quando o projeto do edifício está atrelado a um processo de mudança organizacional da empresa ou instituição que abriga, torna-se ainda mais importante envolver os usuários (LAHTINEN et al., 2014). Em edifícios de assistência à saúde, podem ser destacadas duas 
vantagens em utilizar a abordagem do co-design para envolver a equipe interna no redesenho dos serviços: por um lado, incluir no projeto a valiosa experiência que possuem no cuidado diário e, por outro, aumentar o comprometimento da equipe na criação de uma nova situação de trabalho (DAVIES, 2004; GARDE; VAN DER VOORT, 2012).

Por fim, o co-design permite ajustar o projeto para o contexto específico do projeto em questão. A ideia de um edifício de saúde genérico é uma abstração, uma vez que cada edifício de saúde tem seu próprio espaço físico, pacientes, equipes de funcionários e financiadores (RISSE, 1999). Portanto, cada edifício requer uma visão única para orientar sua construção (BROMLEY, 2012).

\section{Quadro 23. Benefícios do co-design no projeto de serviços. Fonte: Steen et al. (2011).}

\begin{tabular}{|c|c|c|c|}
\hline & $\begin{array}{c}\text { Benefícios para o projeto de } \\
\text { serviços }\end{array}$ & $\begin{array}{c}\text { Benefícios para os } \\
\text { consumidores e usuários dos } \\
\text { serviços }\end{array}$ & Benefícios para a organização \\
\hline 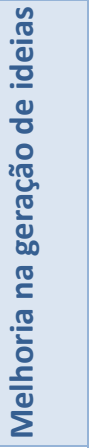 & $\begin{array}{l}\text { Ideias com maior } \\
\text { originalidade e valor para o } \\
\text { usuário; } \\
\text { Melhor conhecimento das } \\
\text { necessidades dos clientes e } \\
\text { usuários (mudando visões } \\
\text { existentes ou validando } \\
\text { conceitos); } \\
\text { Melhor geração de ideias. }\end{array}$ & & $\begin{array}{l}\text { Melhoria na criatividade; } \\
\text { Melhoria do foco em clientes } \\
\text { e usuários e, por ex., melhor } \\
\text { disseminação dos dados sobre } \\
\text { as necessidades dos clientes e } \\
\text { usuários; } \\
\text { Melhor cooperação entre } \\
\text { diferentes pessoas e } \\
\text { organizações, e entre as } \\
\text { disciplinas. }\end{array}$ \\
\hline 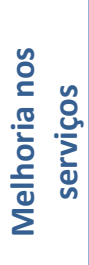 & $\begin{array}{l}\text { Maior qualidade da definição } \\
\text { dos serviços; } \\
\text { Inovações mais bem- } \\
\text { sucedidas, (redução do risco } \\
\text { de falha do produto). }\end{array}$ & $\begin{array}{l}\text { Melhor ajuste entre serviço e } \\
\text { necessidades dos clientes e } \\
\text { usuários, e melhor experiência } \\
\text { nos serviços; } \\
\text { Maior qualidade nos serviços; } \\
\text { Serviços mais diferenciados. }\end{array}$ & \\
\hline 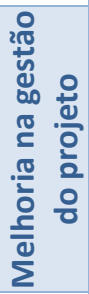 & $\begin{array}{l}\text { Melhor tomada de decisões; } \\
\text { Custos de desenvolvimento } \\
\text { menores; } \\
\text { Redução do tempo de } \\
\text { desenvolvimento; } \\
\text { Melhorias contínuas. }\end{array}$ & & \\
\hline 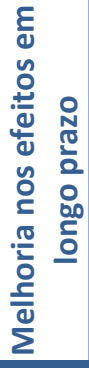 & & $\begin{array}{l}\text { Maior satisfação dos clientes } \\
\text { ou usuários; } \\
\text { Maior fidelidade dos clientes } \\
\text { ou usuários; } \\
\text { Educação dos usuários. }\end{array}$ & $\begin{array}{l}\text { Inovações bem-sucedidas; } \\
\text { Melhoria nas inovações; } \\
\text { Maior apoio e entusiasmo } \\
\text { para inovações e mudanças; } \\
\text { Melhores relações entre } \\
\text { provedor de serviços e } \\
\text { usuários; } \\
\text { Melhores relações públicas. }\end{array}$ \\
\hline
\end{tabular}




\subsection{2

Semelhantemente à seção anterior, esta seção inicia-se apresentando os desafios da utilização que são comuns ao projeto participativo e ao co-design, seguidas pelas questões que são exclusivas ao co-design.

Malard et al. (2002) destacam a operacionalização como 'a grande questão metodológica' do projeto participativo. Para estes autores, os instrumentos metodológicos usuais de projeto de arquitetura e urbanismo não são suficientes para solucionar esta questão. Para justificar, discutem a dificuldade de leigos compreenderem o objeto como um todo através dos códigos de representação em arquitetura seja em plantas, cortes e fachadas, ou em perspectivas - que limitam a visualização e o entendimento de alguns ângulos - ou até mesmo em maquetes, que apesar de apresentarem mais efetivamente a ideia do objeto, levam a ilusões devido aos problemas de escala.

Discutindo a psicologia da representação pictórica, GOMBRICH $(1995)^{38}$ demonstra que representamos através do conhecimento que temos da natureza e, na medida em que aprendemos a ver, aprendemos também a representar; vemos, portanto, apenas aquilo que conhecemos. [...] Fica, então, a pergunta: se o leigo não consegue compreender a inteireza do objeto imaginado, como então conseguiria participar de sua imaginação? (MALARD et al., 2002, p.247).

Estes autores ainda colocam que a literatura disponível foca a participação nos processos decisórios, relativos ao planejamento e gestão urbanos, que são, em sua maioria, decisões sobre políticas a serem adotadas. No caso de projetos arquitetônicos, as decisões compartilhadas envolvem soluções técnicas, o que faz da participação "uma questão teórica a ser enfrentada", e não apenas um desafio metodológico.

O primeiro ponto a se destacar, portanto, é a importância de preparar os usuários para participar, para que esta abordagem não sirva apenas para manipular e "legitimar as decisões do arquiteto e de outros técnicos envolvidos no processo" (MALARD et al., 2002, p.247). A importância da preparação também é discutida por outros autores na literatura (REICH et al., 1996; SVETOFT, 2006; TZORTZOPOULOS et al., 2006). Tzortzopouloset al. (2006)

\footnotetext{
${ }^{38} \mathrm{GOMBRICH}$, E.H. Arte e llusão: um estudo da psicologia da representação pictórica. (Trad.) Raul de Sá Barbosa. São Paulo: Martins Fontes, 1995.
} 
defendem a necessidade do apoio adequado, durante as primeiras etapas do processo de projeto, para que os clientes da construção possam entender e desempenhar as atividades que Ihes cabem, principalmente em projetos de serviços de saúde, que influenciarão o projeto do edifício respectivo. Os conhecimentos básicos que estes clientes precisam possuir incluem, por exemplo, etapas do processo de projeto e as decisões a serem tomadas em cada uma delas, além das consequências de se fazer alterações.

Em segundo lugar, o projeto com participação dos usuários requer mais do arquiteto do que o projeto tradicional em que foi treinado, pois para abrir o processo de projeto para uma discussão com usuários é necessária muita autoconfiança, uma vez que normalmente a tomada de decisões ocorre num nível interno e intuitivo (JOHNSON, 1979). Assim, os profissionais de projeto necessitam de conhecimentos adicionais em diversas outras disciplinas e habilidade para traduzir e viabilizar as ideias oriundas dos usuários em projetos, do edifício e dos serviços (JOHNSON, 1979; MAGNUSSON; MATTHING; KRISTENSSON, 2003). Consequentemente, a participação dos usuários no processo de projeto requer tempo e, portanto, recursos financeiros (SVETOFT, 2006).

Em terceiro lugar, destaca-se a redução do controle dos arquitetos sobre o projeto, devido à participação de um maior número de pessoas no processo; em quarto lugar, o aumento da complexidade deste processo, pela necessidade de gerenciar diferentes interesses e objetivos, o que implica em esforços adicionais de coordenação (HOYER et al., 2010; STEEN et al., 2011).

Em relação específica ao co-design, é necessário um gerenciamento criterioso para garantir o comprometimento e a motivação dos usuários (GARDE; VAN DER VOORT, 2012). Estudos indicam que, geralmente, os usuários não se comprometem inteiramente com o processo de projeto, devido a seus compromissos de trabalho (WAGNER; PICCOLI, 2007; IEDEMA et al., 2010).

\subsubsection{Seleção de usuários para Co-design}

A identificação correta dos grupos de usuários e a seleção das pessoas apropriadas para participar, em papéis e etapas apropriadas, são fundamentais para o sucesso do projeto, para que as reais necessidades dos usuários possam ser definidas (WILSON et al., 1997; KUJALA; KAUPPINEN, 2004; STEEN et al., 2011). Isto porque, para o mesmo serviço, cada usuário pode apresentar expectativas e necessidades próprias, que não podem ser padronizadas (Moritz, 2005). Wilson et al. (1997) apontam que é necessário escolher usuários com diferentes idades, 
conhecimentos e condições de serviço, não bastando escolher usuários de setores de trabalho diferentes, ou com o maior nível de conhecimento.

Ressalta-se a importância de se determinar o tipo de participação dos usuários. Segundo Ives e Olson (1984), a participação pode ser direta ou indireta. Na participação direta, são envolvidos no processo de desenvolvimento os próprios usuários do sistema. Já na participação indireta, participam somente representantes destes usuários.

\subsubsection{Metodologia do Co-design}

No contexto de co-design, Sanders (2009) define instrumentos, métodos e metodologias dentro de uma hierarquia, conforme mostra a figura 21.

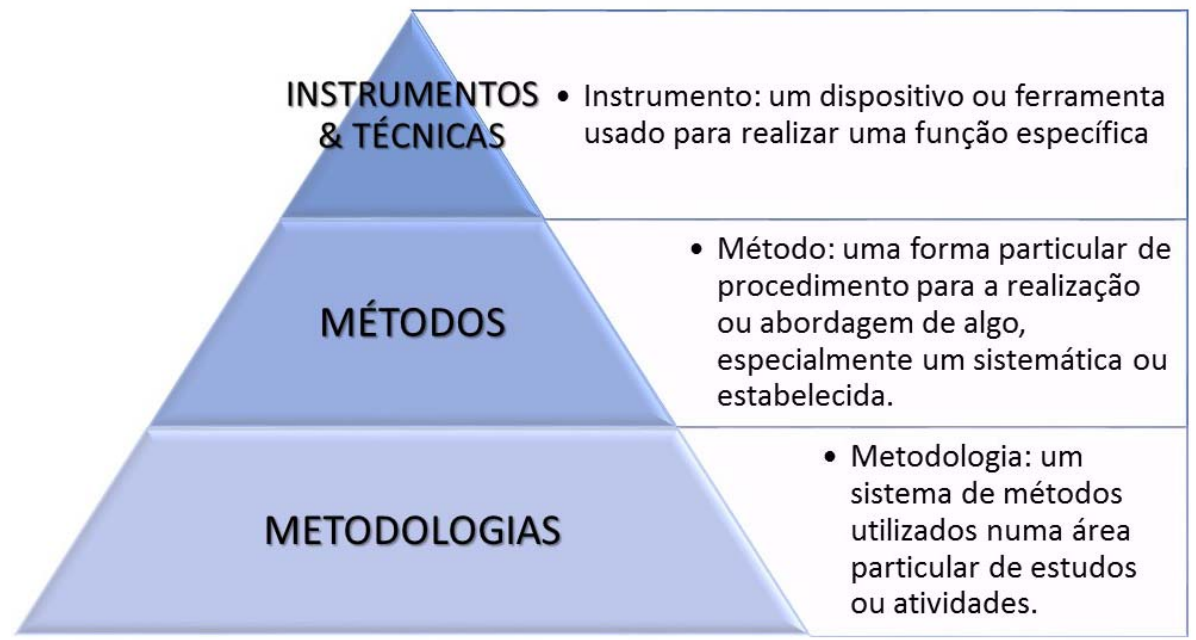

Figura 21. Definições: Metodologia, Método e Instrumentos. Fonte: Adaptado de Sanders (2009).

Da figura, depreende-se aqui como metodologia o conjunto de métodos utilizados para a abordagem de co-design.

'Método', por definição, é "um modo de proceder", é a ordem a ser seguida para alcançar um determinado objetivo (BUENO, 1990). A utilização de métodos estratégicos de participação dos usuários no processo de projeto facilita a criação de espaços que viabilizem o seu uso efetivo e, por consequência, levem a um cuidado melhor dos pacientes (ERIKSSON; FRÖST; RYD, 2012). Estes métodos precisam propiciar, segundo estes autores, a captura das especificações certas, dos modos de trabalho e dos requisitos espaciais. De acordo com Davies 
e Wilson (s.d.), os métodos devem ser entendidos como estruturas adaptáveis para cada situação, e não tomados como protocolos rígidos a se seguir mecanicamente.

Segundo Hanington (2003) e Lahtinen et al. (2014), a abordagem participativa não possui métodos de aplicação próprios, mas utiliza métodos variados adotados em diversas disciplinas, adaptando-os ao seu contexto. Lahtinen et al. (2014) afirmam que os métodos de participação precisam, entre outras coisas, dar suporte para elucidar os conceitos e documentos do projeto, promover decisões coletivas e soluções novas e criativas, permitir rápida aplicação devido ao prazo limitado de projeto, viabilizar análises dos efeitos das soluções de projeto além de, em caso de mudança organizacional, permitir a avaliação do processo de mudança e, se necessário, a correção de seu curso.

Na área de administração pública, Wilcox (1994) propõe um guia com uma sequência de quatro fases principais no processo de participação. Defende que a participação não pode ser alcançada com pesquisas ou simples reuniões, mas se constitui num processo que requer tempo para que as pessoas ou os grupos entendam a proposta e o que precisam fazer. As fases são apresentadas na figura 22.

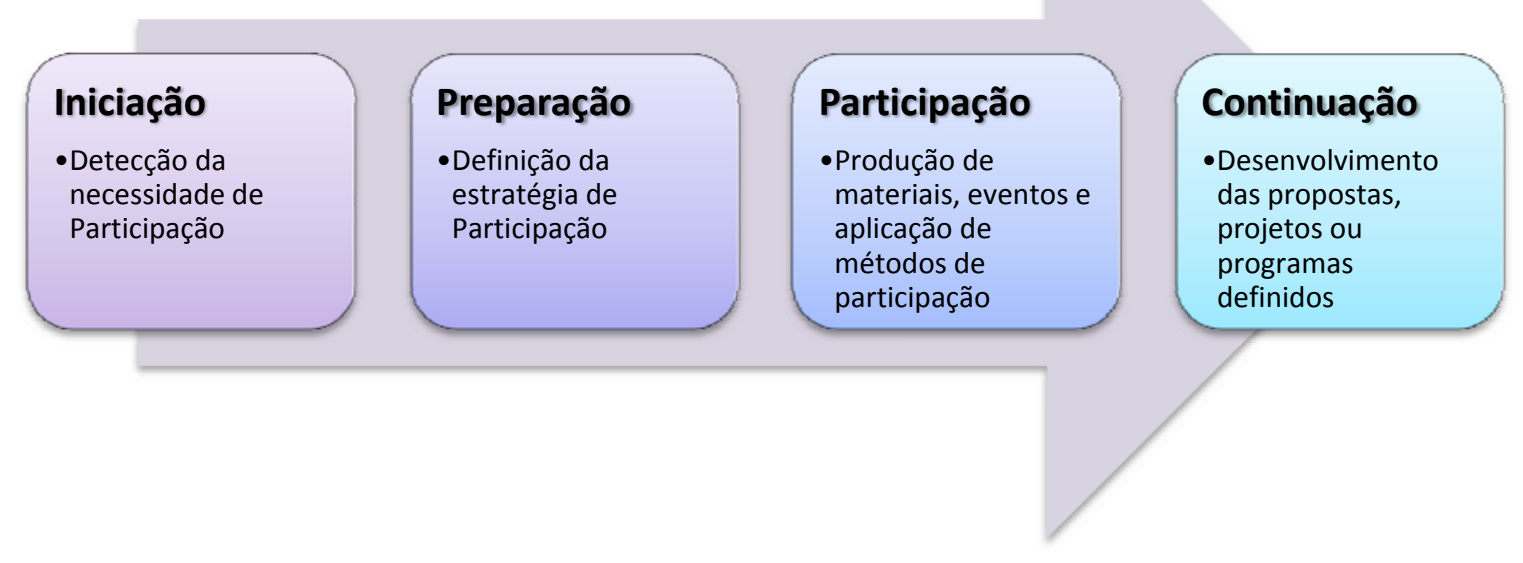

Figura 22. Fases da Participação. Fonte: Wilcox (1994).

Outro exemplo de método é o 'Framework for co-design' - FfC - apresentado por Eriksson et al. (2012). Este método, que pode ser traduzido livremente como 'Estrutura para Projeto Participativo', foi desenvolvido para ajudar arquitetos "a envolver usuários e seus conhecimentos no processo de projeto de uma forma mais estratégica". Estrutura-se em workshops, metodologias e instrumentos, com colaboração efetiva entre profissionais e usuários, para permitir que a identificação das reais necessidades e a proposta de soluções ocorram simultaneamente. Nos casos estudados por estes autores, o FfC envolveu, a princípio, 
um grupo amplo de usuários para aumentar a credibilidade do resultado. Este grupo produziu materiais que foram posteriormente desenvolvidos por um grupo menor. Nas diferentes aplicações, o FfC foi composto por três a cinco workshops com estrutura similar, como mostra a figura 23. Foram organizados por grupos de dois ou três arquitetos, que planejaram e prepararam os materiais e as atividades, orientaram os usuários durante os workshops. As discussões resultantes foram documentadas e trabalhadas por estes arquitetos entre os workshops, para gerar dados para discussões mais focadas e até mesmo propostas de organizações espaciais mais concretas.

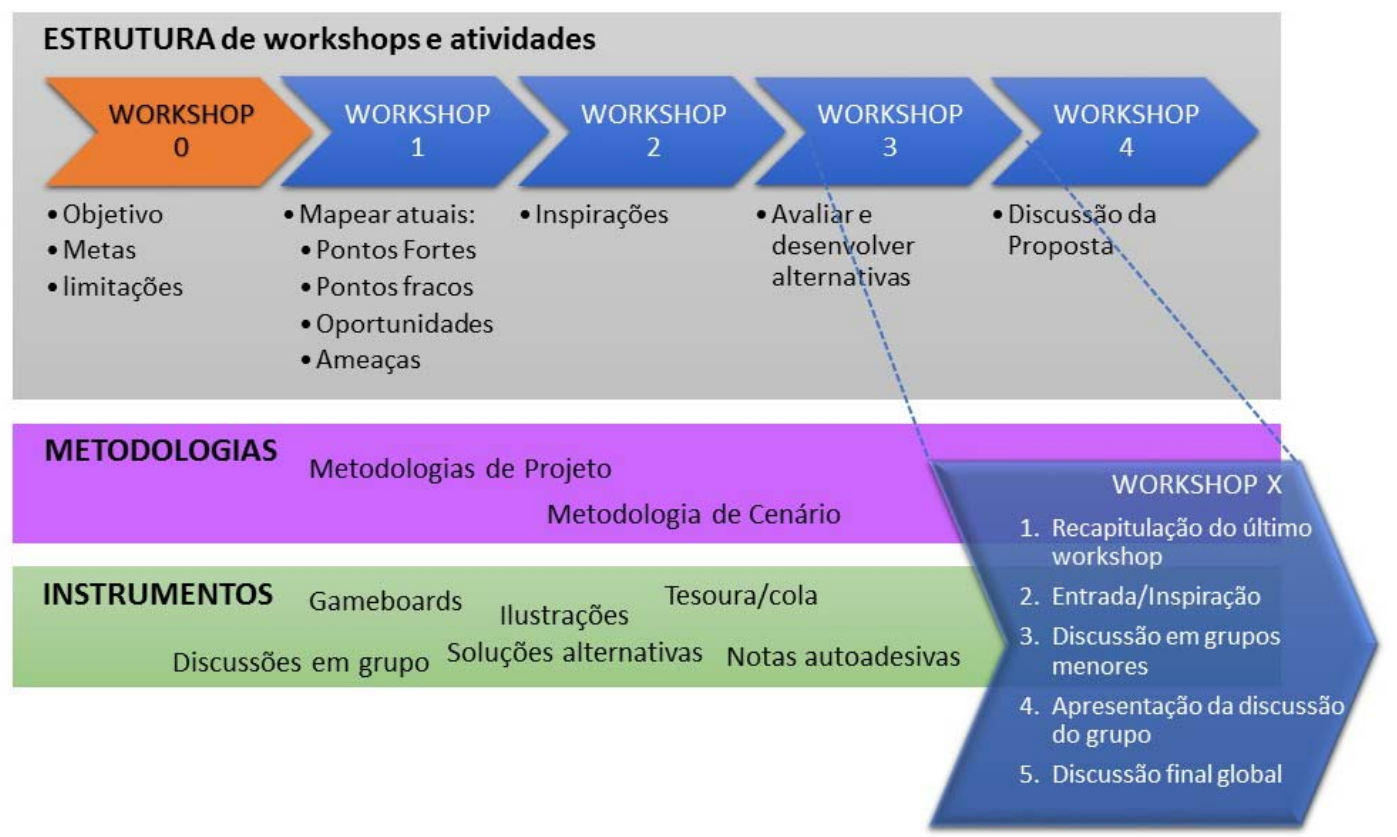

Figura 23. Esquema do $\mathrm{FfC}$, com seus workshops, metodologias e instrumentos. No detalhe, o modo como cada workshop é organizado. Fonte: Eriksson et al. (2012).

Outro método muito citado na literatura é o Design Games (BRANDT; MESSETER, 2004; BRANDT, 2006; GARDE; VAN DER VOORT, 2012; VAAJAKALLIO, 2012). Em co-design com diversos tipos de usuários, este método pode ser usado para estruturar as atividades de projeto sem restringir a criatividade, através da delimitação de 'regras do jogo' (BRANDT; MESSETER, 2004). De acordo com Brandt (2006), existem diversas descrições de design games, adaptadas às características dos diversos contextos aplicáveis, e não há uma definição clara do método.

Foram selecionados para este trabalho alguns exemplos de design games que melhor se adéquam ao co-design de serviços e edifícios de assistência à saúde. Esta seleção se baseou na classificação de proposta por Vaajakallio (2012), que estabelece quatro categorias de 
Design Games. O quadro 24 traz esta classificação e ressalta a categoria que será abordada nesta revisão.

Brandt (2006) apresenta algumas características comuns aos design games exploratórios:

- Raramente existe competição/campeão;

- Os jogos são orientados por regras e peças físicas;

- São relativos à viabilização da participação;

- São envolventes e divertidos, propiciando um ambiente informal mais produtivo para a criatividade.

Quadro 24. Categorias de Design Games, com destaque para a categoria abordada no presente trabalho. Fonte: Vaajakallio (2012).

\begin{tabular}{|c|c|c|c|c|}
\hline & $\begin{array}{l}\text { DESIGN GAMES } \\
\text { COMO UM } \\
\text { INSTRUMENTO DE } \\
\text { PESQUISA }\end{array}$ & $\begin{array}{c}\text { DESIGN GAMES } \\
\text { PARA } \\
\text { DESENVOLVER } \\
\text { COMPETÊNCIAS EM } \\
\text { PROJETO }\end{array}$ & $\begin{array}{l}\text { DESIGN GAMES } \\
\text { PARA EMPODERAR } \\
\text { USUÁRIOS }\end{array}$ & $\begin{array}{l}\text { DESIGN GAMES } \\
\text { PARA ENVOLVER } \\
\text { STAKEHOLDERS } \\
\text { MÚLTIPLOS }\end{array}$ \\
\hline $\begin{array}{l}\text { PESQUISADORES / } \\
\text { GRUPO DE } \\
\text { PESQUISA }\end{array}$ & Habraken \& Gross & $\begin{array}{l}\text { Iversen \& Buur (e } \\
\text { seus orientados) }\end{array}$ & Ehn \& Sjögren & $\begin{array}{l}\text { Buur } \\
\text { Söndergaard; } \\
\text { Johansson; } \\
\text { (BRANDT; } \\
\text { MESSETER, 2004) }\end{array}$ \\
\hline FOCO & $\begin{array}{l}\text { Estudo do processo } \\
\text { de projeto e dos } \\
\text { conceitos } \\
\text { projetistas }\end{array}$ & $\begin{array}{lr}\text { Ênfase } & \text { nas } \\
\text { interações } & \text { sociais } \\
\text { no PP } & \\
\end{array}$ & $\begin{array}{l}\text { Empoderamento } \\
\text { dos usuários no PP }\end{array}$ & $\begin{array}{l}\text { Co-design com } \\
\text { stakeholders } \\
\text { múltiplos }\end{array}$ \\
\hline CONTEXTO & $\begin{array}{l}\text { Pesquisa em } \\
\text { projeto/arquitetura }\end{array}$ & $\begin{array}{l}\text { Educação em } \\
\text { projeto (interação) }\end{array}$ & $\begin{array}{l}\text { Projeto do ambiente } \\
\text { de trabalho / } \\
\text { trabalho baseado } \\
\text { em computação }\end{array}$ & $\begin{array}{l}\text { Raízes do projeto de } \\
\text { interação } \\
\text { (atualmente } \\
\text { domínio amplo de } \\
\text { projeto) }\end{array}$ \\
\hline JOGADORES & $\begin{array}{l}\text { Pesquisadores em } \\
\text { Projeto }\end{array}$ & $\begin{array}{l}\text { Estudantes } \\
\text { Projeto }\end{array}$ & Usuários & $\begin{array}{l}\text { Stakeholders } \\
\text { usuários }\end{array}$ \\
\hline EXEMPLOS & $\begin{array}{ll}\text { Design } & \text { Games } \\
\text { conceituais } & \end{array}$ & $\begin{array}{l}\text { Curso: "Projeto é } \\
\text { um Jogo" }\end{array}$ & $\begin{array}{l}\text { Jogos } \\
\text { Organizacionais }\end{array}$ & $\begin{array}{l}\text { Design Games } \\
\text { exploratórios }\end{array}$ \\
\hline
\end{tabular}

Entre os diversos exemplos propostos por esta autora para Design Games exploratórios, destaca-se aqui o que melhor se adéqua ao co-design de projeto de edifícios de assistência à saúde, que é o Design Game baseado em Cenários. O instrumento Cenário tem sido muito utilizado em projetos, segundo a revisão apresentada por Brandt, e descreve uma interpretação particular do uso em que se permitem alterações e negociações. 
Garde e Van der Voort (2012) descrevem um exemplo de Design Game baseado em Cenário, que foi a peça central dos workshops de co-design realizados para envolver enfermeiras no projeto dos serviços de um grande hospital. Este jogo se baseou na combinação de um jogo de tabuleiro e na análise de cartas de tarefas, que se completam e permitem verificação mútua. Por um lado, a análise do fluxo de tarefas leva em conta gerenciamento do tempo, distribuição de pessoal, fluxo de informação e cronologia, estruturando assim o processo de trabalho. Por outro, os usuários podem visualizar o procedimento através do jogo de tabuleiro. Portanto, podem-se avaliar os procedimentos desenvolvidos pela interação entre o fluxo de tarefas e as figuras do jogo.

Em termos de instrumentos, o jogo de tabuleiro era composto pelo projeto arquitetônico da enfermaria do novo edifício, montado sobre um grande tabuleiro; peças em diversas cores representando as diferentes funções dos membros da equipe interna, peças relativas a materiais - como carrinhos, por exemplo - e as cartas de problemas, que orientavam o jogo através de questões a serem resolvidas usando a organização de trabalho proposta. A análise dos fluxos de tarefas utilizou cartas que correspondiam às diferentes atividades, que permitiam a construção do fluxo. Entre os benefícios deste método os autores destacam o envolvimento concomitante de diferentes usuários, favorecendo a discussão; a eficiência em termos de tempo despendido; a possibilidade de novos procedimentos serem projetados por usuários e a visualização clara das consequências das alterações dos procedimentos (Figura 24).

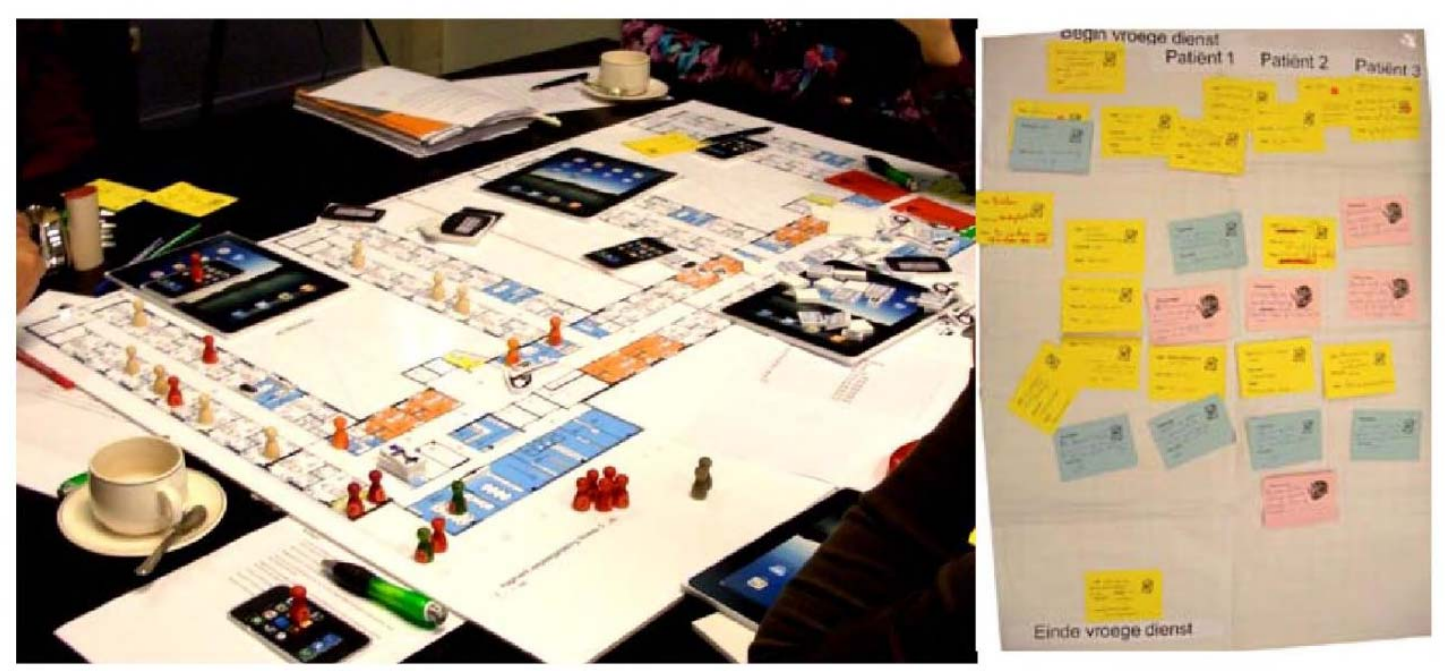

Figura 24. Jogo de Tabuleiro e Análise do fluxo de tarefas. Fonte: Garde e Van der Voort (2012)

Wilcox (1994) descreve um Design Game que também utiliza um tabuleiro com uma planta em escala do local do projeto, aplicado à área de projetos de edifícios. Para criar o seu próprio 
projeto, a equipe - que inclui usuários - utiliza peças móveis em escala. Segundo o autor, este jogo é útil principalmente quando o local de implantação não é muito grande e tem limites definidos, quando a equipe possui vastos conhecimentos e quando o projeto já está em andamento. Entre os benefícios, o autor destaca que o processo favorece o consenso, permite o envolvimento de muitas pessoas mesmo em projetos complexos, podendo aumentar, portanto, a credibilidade da equipe de gerenciamento, e facilita a manutenção e a gestão em longo prazo pela construção do sentimento de posse. A figura 25 detalha as fases do jogo.
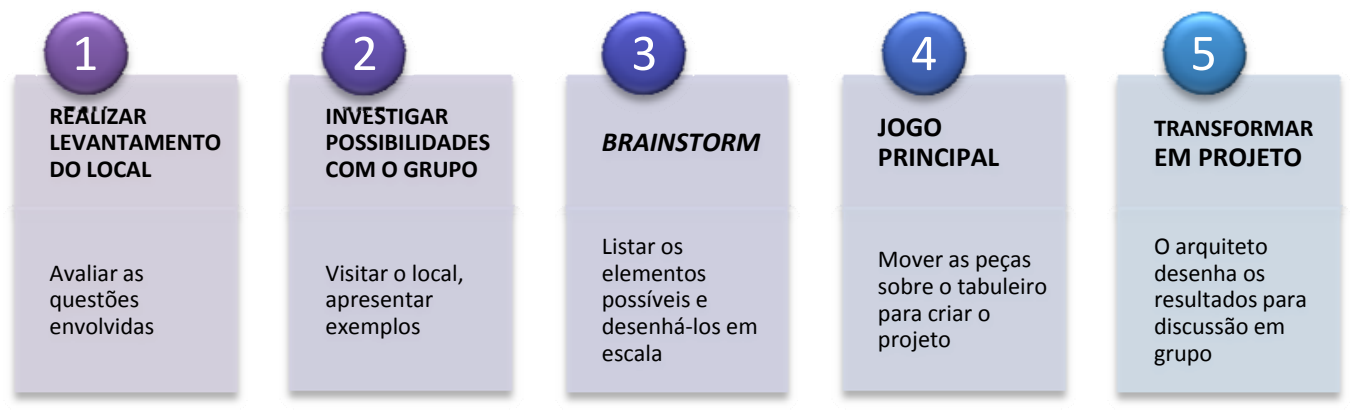

Figura 25. Fases do Design Game. Fonte: Wilcox (1994).

Segundo Eriksson et al.(2012), os arquitetos podem oferecer instrumentos aos usuários durante a aplicação dos métodos de participação. Estes instrumentos dão suporte para que os usuários entendam suas reais necessidades e requisitos, relativos ao seu ambiente físico de trabalho, e possam se expressar e ser parte da equipe de projeto (SANDERS; STAPPERS, 2008; ERIKSSON et al., 2012). Desde o fim dos anos 1990, muitos instrumentos de co-design e processos pelos quais estes podem ser aplicados têm sido pesquisados tanto por grupos ligados à academia como por aqueles atuantes em consultoria em projeto (SANDERS; STAPPERS, 2008).

Os 'instrumentos generativos' - Generative Tools - descritos por Sanders (2000), Sleeswijk Visseret al. (2005) e Sanders (2006) - referem-se a uma nova linguagem de projeto para o codesign, a ser utilizada pelos stakeholders e projetistas nas primeiras etapas do processo de projeto - o fuzzy frot-end - para se comunicarem de modo visual e direto (SANDERS, 2006).

A linguagem de projeto é generativa no sentido que com ela, as pessoas podem expressar um número infinito de ideias (por exemplo, sonhos, insights, oportunidades, etc.) através de um conjunto limitado de itens de estímulo. Portanto, a abordagem de instrumentos generativos é um 
caminho para preencher o fuzzy front end com as ideias, sonhos e insights das pessoas que serão servidas pelo projeto (SANDERS, 2006, p.6).

A utilização dos instrumentos generativos para co-design pressupõe que os profissionais de projeto forneçam diversos materiais que os usuários utilizarão para se expressar. 0 quadro 25 elenca alguns destes instrumentos e fornece exemplos de aplicação.

Quadro 25. Instrumentos generativos e seus exemplos. Fonte: Sanders (2000) e Steen et al. (2007).

\begin{tabular}{|l|l|}
\hline \multicolumn{1}{|c|}{ FUNÇÃO } & \multicolumn{1}{|c|}{ EXEMPLO } \\
\hline Instrumentos para lembrar & $\begin{array}{l}\text { Imagens e textos através dos quais os usuários poderão representar } \\
\text { uma situação. Por exemplo, "Como são geralmente suas noites } \\
\text { durante a semana?" }\end{array}$ \\
\hline Instrumentos para pensar & $\begin{array}{l}\text { Diagramas que permitam esboçar um ciclo para responder à questão: } \\
\text { "Como você espera que seu trabalho seja no futuro?" }\end{array}$ \\
\hline Instrumentos para mapear & $\begin{array}{l}\text { Diagramas que permitam criar soluções. "Crie uma loja de animais de } \\
\text { estimação que atenda suas necessidades como dono de cão (gato, } \\
\text { etc.)". }\end{array}$ \\
\hline $\begin{array}{l}\text { Instrumentos } \\
\text { imaginar }\end{array}$ & $\begin{array}{l}\text { Ajudam a imaginar e expressar como uma situação futura poderá ser. } \\
\text { "Qual a sensação de seu ambiente de trabalho no futuro?" }\end{array}$ \\
\hline Instrumentos para sentir & $\begin{array}{l}\text { Ajudam os usuários a expressar suas emoções. "Utilize figuras e } \\
\text { palavras para mostrar uma experiência relacionada à saúde em seu } \\
\text { passado". }\end{array}$ \\
\hline
\end{tabular}

Para ilustrar, temos exemplos em Sanders (2009), que apresenta um conjunto de instrumentos para imaginar, através do qual um grupo de enfermeiras estrutura o futuro fluxo ideal de informação, materiais e pessoas no pavimento dos pacientes. A autora ressalta que o importante é que as enfermeiras pensem sobre os fluxos e a experiência neste espaço futuro, e não tentem projetar as salas ou o pavimento. O papel do arquiteto/pesquisador, neste caso, é orientar os usuários a se deterem no que realmente é importante (Figura 26). 

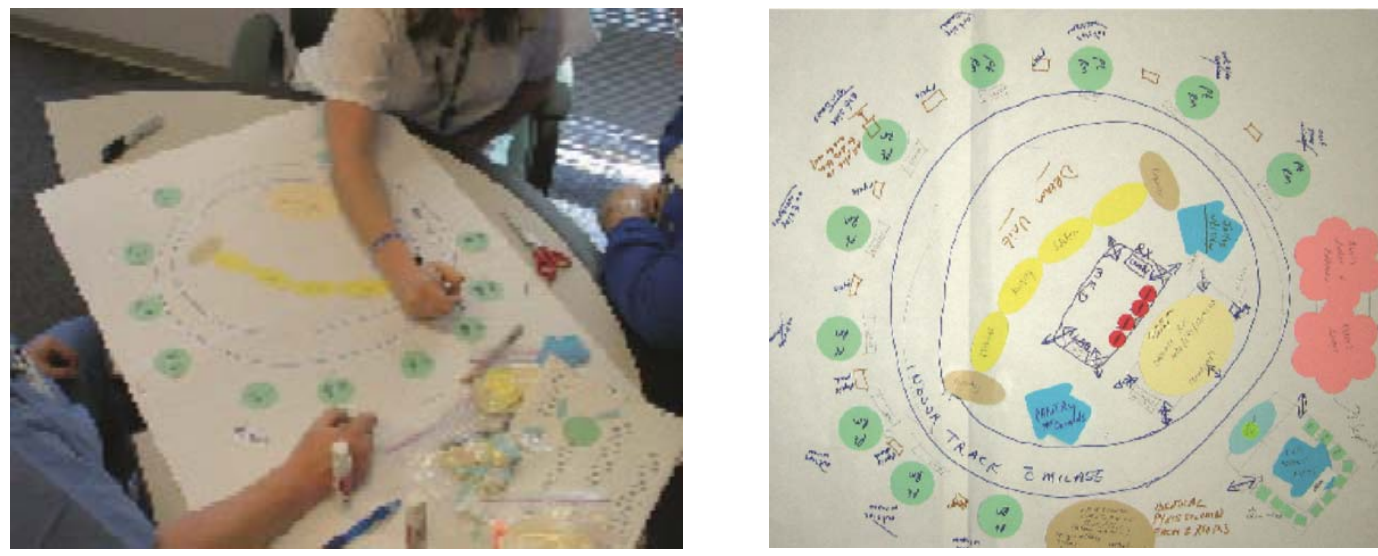

Figura 26. Co-design com enfermeiras. Instrumentos para imaginar ao redor da mesa, para auxiliá-las a pensar em fluxo e não em ambientes. Fonte: Sanders e Stappers (2008) e Sanders (2009).

São também utilizados modelos 3D para dar suporte ao co-design (SANDERS, 2009), com diversas configurações possíveis, como os apresentados nas figuras 27, 28 e 29. Dentre elas está o Velcro Modelling (figura 29), que possui peças com fixadores que permitem que a equipe de projeto teste diversas configurações diferentes sobre uma base dada (HANINGTON, 2003; SANDERS, 2009).
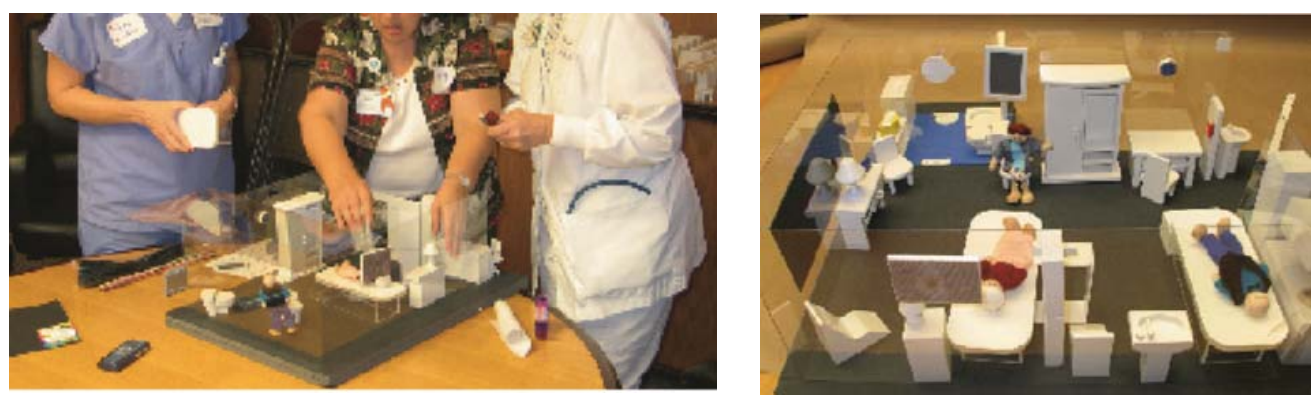

Figura 27. Modelo 3D em co-design: enfermeiras na equipe de projeto de uma sala de pacientes ideal. Fonte: Sanders (2009).

Figura 28. Modelo 3D com paredes transparentes. Fonte: Sanders (2009).

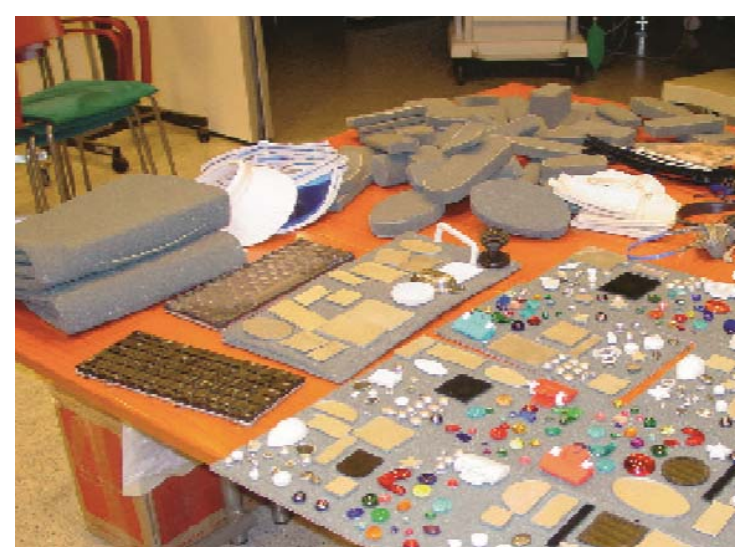

Figura 29. Velcro Modelling. Fonte: Sanders (2009). 


\subsection{Discussão e Síntese Conclusiva}

Neste capítulo foi apresentada a revisão sobre participação dos usuários em processos de projeto, fazendo um recorte para o co-design, que é entendido como o nível de envolvimento efetivo dos usuários no processo, tidos como parceiros dos profissionais de projeto. $\mathrm{O}$ intuito foi constituir um corpo teórico com a síntese dos principais benefícios e desafios desta abordagem, bem como sua metodologia. Este capítulo serve de base para orientar as pesquisas de campo e a elaboração do modelo proposto, bem como as análises dos dados que serão levantados.

A visão geral sobre as origens do envolvimento dos usuários em diversas áreas permite identificar que as razões que motivaram esta prática estavam relacionadas à promoção de democracia e à qualidade do produto final.

A revisão bibliográfica mostrou que ainda falta uma definição clara sobre a participação dos usuários em projetos, pois a expressão aparece na literatura com significados amplos e genéricos. Com o intuito de elucidar a expressão, foram investigados os níveis de envolvimento em projetos de edifícios. Para tanto, foram primeiramente apresentados alguns modelos em forma de 'escada de participação'. Apesar de amplamente difundidos, estes modelos foram criticados por, por exemplo, só considerar o poder de tomar decisões como medida de nível de participação; ter o controle das decisões como único objetivo da participação (TRITTER; McCALLUM, 2006), e ter sua utilidade limitada, levando ao entendimento de que os degraus mais altos, que indicam mais participação, sejam melhores que os níveis inferiores (SINCLAIR, 2004). Segundo Lightfoot e Sloper (2001 ${ }^{39}$ apud SFANDYARIFARD, 2013), estes modelos de Arnstein e Hart deixam de considerar tipos de usuários, métodos e resultados, que são fatores chave no envolvimento de usuários.

Posteriormente, foram apresentadas outras propostas de classificação de níveis de envolvimento dos usuários, utilizadas em diversas áreas, e por fim definições específicas da área de arquitetura e urbanismo. Estas classificações foram organizadas no quadro 18, com o intuito de comparar as diversas proposições e estabelecer um padrão de níveis para este trabalho. Dado o objetivo central do presente trabalho, esta análise permitiu definir o codesign como foco em termos de nível de envolvimento.

A classificação geral dos diversos níveis de envolvimento mostrou-se complexa, com várias propostas distintas. Com base na revisão e com o intuito de sistematizar os termos

\footnotetext{
${ }^{39}$ Lightfoot, J. Sloper, P. "Involving Children and Young People With a Chronic Illness or Physical Disability". In Local Decisions About Health Services Development. Phase One: Report on National Survey of Health Authorities and NHS Trusts. University of York, York, 2001.
} 
utilizados neste trabalho, adotam-se os níveis de envolvimento dos usuários conforme o Quadro 26. Ressalta-se que só forma considerados os níveis em que existe algum envolvimento tanto dos usuários como dos projetistas, ou seja, os que se enquadrariam entre as linhas 1 e 2 do Quadro 18, apresentado na seção 4.1.1.

Quadro 26. Níveis de envolvimento adotados neste trabalho. Fonte: Elaborado pela autora.

\begin{tabular}{|c|c|c|}
\hline $\begin{array}{l}\text { NÍVEL DE } \\
\text { ENVOLVIMENTO }\end{array}$ & DESCRIÇÃO & FONTE \\
\hline Informativo & Usuários fornecem e/ou recebe informações & \multirow{3}{*}{$\begin{array}{l}\text { Damodaran } \\
\text { (1996) }\end{array}$} \\
\hline Consultivo & $\begin{array}{l}\text { Usuários comentam um serviço pré-definido ou conjunto } \\
\text { de componentes }\end{array}$ & \\
\hline Participativo & Usuários influenciam decisões relativas a todo o sistema & \\
\hline Co-Design & $\begin{array}{l}\text { Usuários são tidos como parceiros, e desenvolvem um } \\
\text { papel importante no desenvolvimento do conhecimento. }\end{array}$ & $\begin{array}{l}\text { Sanders } \\
\text { Stappers (2008) }\end{array}$ \\
\hline
\end{tabular}

Diversos benefícios que justificam a abordagem de co-design foram identificados na literatura, sendo alguns específicos do co-design e outros comuns também ao projeto participativo. 0 quadro 27 resume os principais. Defende-se, na presente pesquisa, com base na revisão bibliográfica, que o co-design permite adaptar o edifício de saúde à realidade local, para o contexto dos usuários.

Quadro 27. Principais benefícios do co-design, segundo os autores citados. Fonte: Elaborado pela autora.

\begin{tabular}{|l|l|l|}
\hline \multicolumn{1}{|c|}{ FONTE } & $\begin{array}{c}\text { BENEFÍCIOS COMUNS AO } \\
\text { PROJETO PARTICIPATIVO E AO } \\
\text { CO-DESIGN }\end{array}$ & $\begin{array}{c}\text { BENEFÍCIOS ESPECÍFICOS DO } \\
\text { CO-DESIGN }\end{array}$ \\
\hline $\begin{array}{l}\text { Damodaran (1996); Stern et al. } \\
\text { (2003); Steen et al. (2007); } \\
\text { Sfandyarifard e Tzortzopoulos } \\
\text { (2011) }\end{array}$ & $\begin{array}{l}\text { Detectar as reais necessidades dos } \\
\text { usuários }\end{array}$ & \\
\hline $\begin{array}{l}\text { Olsson et al.(2010) } \\
\text { Kagioglou et al.(2000) }\end{array}$ & $\begin{array}{l}\text { Legitimar as decisões do projeto } \\
\text { Permitir que as decisões de projeto } \\
\text { sejam apropriadas e tomadas no } \\
\text { tempo certo }\end{array}$ & \\
\hline $\begin{array}{l}\text { Arias et al. (2000); Sleeswijk } \\
\text { Visseret al. (2005) }\end{array}$ & $\begin{array}{l}\text { Incluir, no projeto, conhecimentos } \\
\text { que os arquitetos não possuem }\end{array}$ \\
\hline $\begin{array}{l}\text { Steen et al. (2011) } \\
\text { (20) projo de ideias no projeto com }\end{array}$ \\
\hline
\end{tabular}

Por outro lado, a abordagem do co-design traz consigo diversos desafios em sua implantação. A maior parte da literatura disponível na área tem seu foco em processos planejamento e 
gestão urbanos, em que o envolvimento dos usuários se refere a decisões sobre políticas a serem adotadas, e não a soluções técnicas, como é o caso específico dos projetos arquitetônicos (MALARD et al., 2002). Segundo diversos autores já citados, é de fundamental importância preparar os usuários para participar. Para garantir a viabilidade das soluções propostas por usuários no co-design é necessário o estabelecimento de certos limites, sem que se privem os usuários de contribuírem com soluções criativas, e este é o desafio geral do codesign (GARDE; VAN DER VOORT, 2012). Estes autores enfatizam a importância de estabelecer a liberdade em um grau apropriado, para que se chegue a resultados úteis sem impedir a criatividade. Caso contrário, a abordagem pode servir como forma de legitimar as decisões dos projetistas, sem trazer os benefícios esperados (MALARD et al., 2002).

Outras dificuldades do projeto participativo e do co-design encontradas na literatura são: a maior demanda por tempo e recursos financeiros (SVETOFT, 2006), a redução do controle dos arquitetos sobre o projeto, devido à participação de um maior número de pessoas no processo, e o aumento da complexidade deste processo, demandando maior coordenação (HOYER et al., 2010; STEEN et al., 2011). No entanto, Damodaran (1996) coloca que, apesar dos altos gastos com pesquisa e gerenciamento de um projeto com participação efetiva dos usuários, podem-se atingir grandes recompensas.

No que tange à metodologia do co-design, a revisão levantou que a grande questão é promover uma linguagem comum no projeto, para que usuários e profissionais de projeto possam entender e se expressar, para viabilizar o envolvimento efetivo de todas as partes (MALARD et al., 2002; KLEINSMANN; VALKENBURG, 2008; VAAJAKALLIO, 2012). A capacidade de comunicação da equipe multidisciplinar é a chave do processo, pois se o conhecimento não puder ser criado e compartilhado pelos diferentes membros desta equipe, então não haverá um projeto em conjunto (KLEINSMANN; VALKENBURG, 2008).

Ressalta-se ainda que, tanto no que se refere aos métodos, como aos exemplos de aplicação estudados, as atividades do co-design se concentram no nas primeiras etapas do processo de projeto, referentes ao planejamento e ao início dos projetos. 


\section{ESTUDO EXPLORATÓRIO}

Este estudo foi conduzido conforme a descrição no capítulo 2.2.1.2, seção A. Das vinte e três empresas que receberam o questionário, apenas cinco o responderam. São apresentados, a seguir, os resultados alcançados, e a transcrição completa das respostas encontra-se no Anexo 3. Em primeiro lugar, o questionário buscou caracterizar o perfil das empresas atuantes em projetos de edifícios de assistência à saúde. Os resultados para esta questão são apresentados no Quadro 28.

Quadro 28. Perfil das Empresas que responderam ao questionário. Fonte: Elaborado pela autora, em conjunto a um trabalho de iniciação científica ${ }^{40}$.

\begin{tabular}{|c|c|c|c|c|c|}
\hline & EMPRESA A & EMPRESA B & EMPRESA C & EMPRESA D & EMPRESA E \\
\hline $\begin{array}{l}\text { Áreas de atuação } \\
\text { da empresa }\end{array}$ & $\begin{array}{l}\text { Projeto de } \\
\text { Arquitetura }\end{array}$ & $\begin{array}{c}\text { Projetos } \\
\text { Complementare } \\
\text { s (Estruturas, } \\
\text { Instalações, } \\
\text { Paisagismo, } \\
\text { etc.), } \\
\text { Acompanhame } \\
\text { nto /Direção de } \\
\text { Obra }\end{array}$ & $\begin{array}{c}\text { Projeto de } \\
\text { Arquitetura, } \\
\text { Coordenação de } \\
\text { Projetos, } \\
\text { Acompanhame } \\
\text { nto /Direção de } \\
\text { Obra }\end{array}$ & $\begin{array}{l}\text { Projeto de } \\
\text { Arquitetura }\end{array}$ & $\begin{array}{l}\text { Projeto de } \\
\text { Arquitetura }\end{array}$ \\
\hline № de Projetistas & 6 & 4 & 16 & 200 & 70 \\
\hline $\begin{array}{l}\text { Tempo de } \\
\text { atuação }\end{array}$ & 30 anos & 13 Anos & 52 anos & 37 anos & 25 anos \\
\hline Raio de Atuação & Nacional & Nacional & Nacional & Nacional & Nacional \\
\hline $\begin{array}{l}\text { Principais } \\
\text { clientes }\end{array}$ & Setor Público & Setor Privado & Setor Privado & Setor Público & Setor Privado \\
\hline $\begin{array}{l}\text { Nicho de } \\
\text { Atuação }\end{array}$ & $\begin{array}{c}\text { Projetos } \\
\text { Residenciais }\end{array}$ & $\begin{array}{c}\text { Projeto Rede de } \\
\text { Gases } \\
\text { Medicinais }\end{array}$ & $\begin{array}{c}\text { Projetos } \\
\text { Residenciais, } \\
\text { Comerciais, } \\
\text { Serviços, } \\
\text { Edifícios de } \\
\text { assistência à } \\
\text { saúde, } \\
\text { Industriais }\end{array}$ & $\begin{array}{c}\text { Projetos } \\
\text { Comerciais, } \\
\text { Serviços, } \\
\text { Projetos de } \\
\text { Edifícios de } \\
\text { assistência à } \\
\text { saúde, Projetos } \\
\text { Industriais }\end{array}$ & $\begin{array}{c}\text { Projetos } \\
\text { Residenciais, } \\
\text { Comerciais, } \\
\text { Serviços, } \\
\text { Edifícios de } \\
\text { assistência à } \\
\text { saúde }\end{array}$ \\
\hline $\begin{array}{c}\text { Níveis de } \\
\text { empreendimento } \\
\text { (edificações de } \\
\text { saúde) }\end{array}$ & Nível Primário & $\begin{array}{l}\text { Níveis Primário, } \\
\text { Secundário e } \\
\text { Terciário }\end{array}$ & $\begin{array}{l}\text { Níveis Primário, } \\
\text { Secundário e } \\
\text { Terciário }\end{array}$ & $\begin{array}{c}\text { Níveis } \\
\text { Secundário e } \\
\text { Terciário }\end{array}$ & $\begin{array}{l}\text { Níveis Primário, } \\
\text { Secundário e } \\
\text { Terciário }\end{array}$ \\
\hline $\begin{array}{c}\text { Desenvolve } \\
\text { projetos de EAS } \\
\text { com participação } \\
\text { de usuários? }\end{array}$ & Sim & Sim & Sim & Não & Sim \\
\hline
\end{tabular}

40 BILLERBECK, C. Projeto Participativo: Inclusão dos usuários em processos de projeto de Edifícios de Saúde. Relatório de Iniciação Científica CNPq. São Carlos: IAU-USP, 2012. 
Após análise das respostas das empresas ao questionário, foi possível analisar os pontos-chave que motivaram o estudo, descritos no capítulo 2.2.1.2, seção A.

\subsection{RESULTADOS}

5.1.1

Principais razões que levam as empresas a envolver usuários em seus projetos

Das empresas que responderam ao questionário, quatro desenvolvem ou já desenvolveram projetos de edifícios de assistência à saúde com a inclusão de usuários. A principal razão apontada para o envolvimento é adquirir maior conhecimento sobre os usuários. A Empresa C ressaltou que este conhecimento ajuda a consolidar o programa de necessidades e a Empresa E afirma que o envolvimento se dá em projetos de reformas.

\subsubsection{Etapas do processo de projeto em que consideram importante o} envolvimento dos usuários

O questionário enviado apresentava uma divisão do processo de projeto em seis etapas: planejamento/briefing , estudo preliminar, anteprojeto, projeto básico, projeto executivo e execução. A maior parte das empresas - três - envolve o usuário durante o planejamento/briefing, e uma delas - Empresa E - envolve o usuário no Estudo Preliminar e no Projeto Executivo.

Quanto à opinião das empresas em relação a qual etapa julgam essencial o envolvimento dos usuários, não houve padronização nas respostas obtidas:

- Empresas A e C: consideram essencial o envolvimento dos usuários no Planejamento/briefing;

- Empresa B: na etapa de Anteprojeto;

- Empresa E: no Estudo preliminar. 
Do ponto de vista das empresas, nota-se uma tendência em valorizar o envolvimento dos usuários nas etapas iniciais do processo de projeto, quando ocorre a coleta de dados e o planejamento. Este envolvimento parece não continuar nas demais etapas do processo, e não houve registros de participação durante a execução.

\subsubsection{Tipos de usuários envolvidos no processo}

Duas questões foram colocadas no questionário com o objetivo de abordar os tipos de usuários envolvidos. A primeira questão era de múltipla escolha, permitindo assinalar mais de uma resposta, com as seguintes opções: equipe médica, enfermeiros, funcionários administrativos, pacientes internos, pacientes externos, familiares dos pacientes, habitantes do raio de atendimento da unidade de saúde e outros. As respostas indicam que as empresas buscam apenas o envolvimento de usuários que fazem parte da equipe da edificação de saúde, não sendo considerados usuários que utilizam os serviços - pacientes e visitantes - conforme ilustra o Gráfico 5.

Gráfico 5. Tipos de usuários que as empresas buscam envolver no processo de projeto de edifícios de assistência à saúde, de acordo com os questionários respondidos.

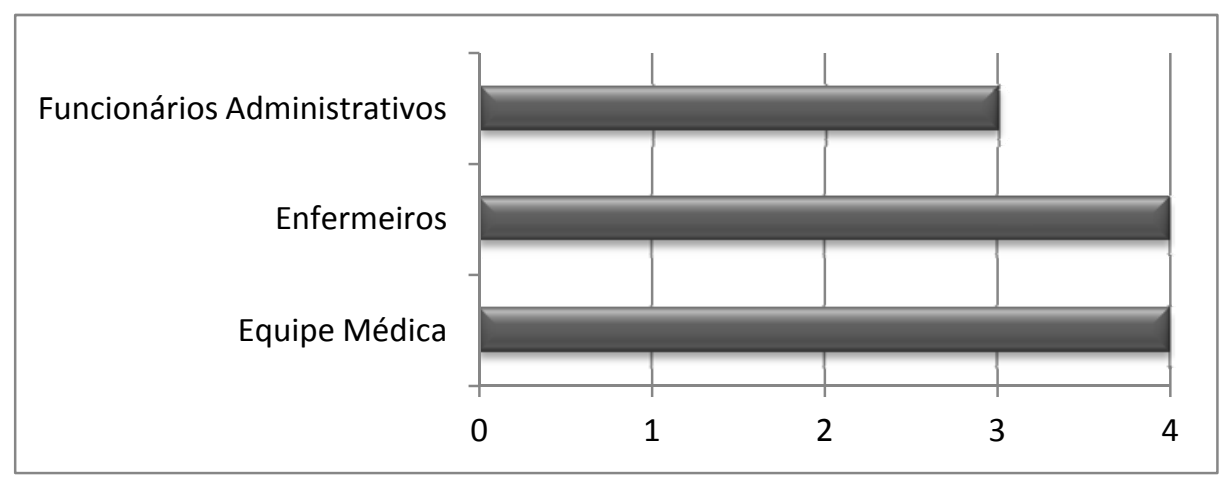

A segunda questão solicitava a indicação do tipo de usuário que as empresas buscavam envolver no processo de projeto com mais frequência, dentre os indicados na questão anterior. As respostas variaram, conforme mostra o Gráfico 6. 
Gráfico 6. Tipo de usuário envolvido com mais frequência no processo de projeto das empresas, de acordo com os questionários respondidos.

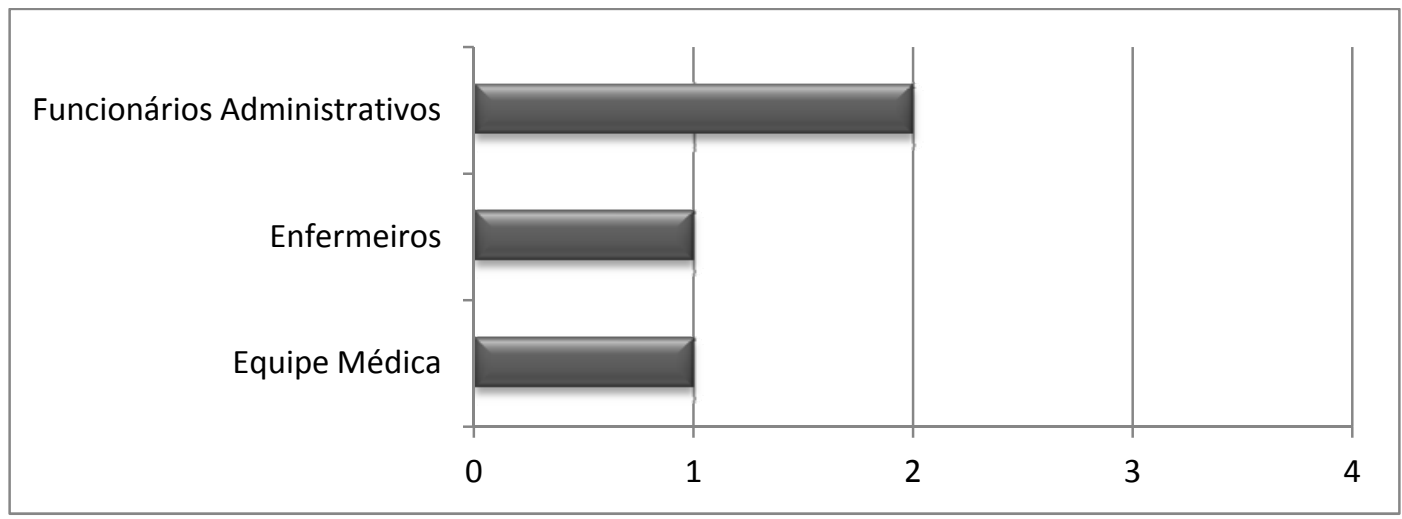

\subsubsection{Relacionamento com os usuários}

Três questões foram formuladas para avaliar o tipo de relacionamento da equipe de projeto com os usuários envolvidos no processo. A questão 16 abordava o nível de relacionamento, dividida em três opções: mínimo - os usuários foram contatados para obter respostas específicas, feedbacks; moderado - os usuários foram consultados em muitas etapas do desenvolvimento do projeto; e alto, indicando que os usuários foram consultados e envolvidos em todas as etapas da elaboração do projeto. Pelas respostas, verifica-se a tendência de pouco contato entre equipe técnica e usuários, com duas empresas indicando a opção de contato mínimo e uma indicando contato moderado. A empresa que indicou completo envolvimento entre equipe e usuário havia indicado anteriormente que só envolve usuários na etapa de Planejamento/ briefing. Deste modo, depreende-se que nenhuma das empresas tem envolvimento efetivo dos usuários durante o processo de projeto como um todo.

A questão 17 complementa as anteriores, buscando determinar quando se dá, especificamente, o início do envolvimento dos usuários. As respostas indicam que os usuários começam a ser envolvidos antes, durante ou logo após a etapa de planejamento.

Em relação à comunicação da equipe técnica com os usuários envolvidos no processo, duas empresas indicaram não encontrar dificuldades, contra duas respostas alegando dificuldades. Uma das empresas mencionou dificuldades apenas para os usuários visualizarem os espaços em planta, ou seja, a representação técnica do projeto. 


\subsubsection{Nível de acesso às informações referentes ao projeto}

\section{disponibilizado pelas empresas aos usuários}

Quando questionadas sobre o nível de informação que os usuários receberam sobre as discussões de projeto realizadas pela equipe técnica, das quais eles não participaram, as empresas se dividiram nas respostas, com metade indicando pouca informação e a outra metade indicando que as informações estavam totalmente disponíveis.

Em relação às alterações de projeto que a equipe técnica julgou necessárias, em discussões em que os usuários não participaram, o nível de envolvimento dos usuários variou bastante, com respostas indicando desde nenhuma informação aos usuários até a abertura para discussão das alterações, conforme mostra o Gráfico 7.

Gráfico 7. Níveis de envolvimento dos usuários nas alterações de projeto julgadas necessárias pela equipe técnica, de acordo com os questionários respondidos.

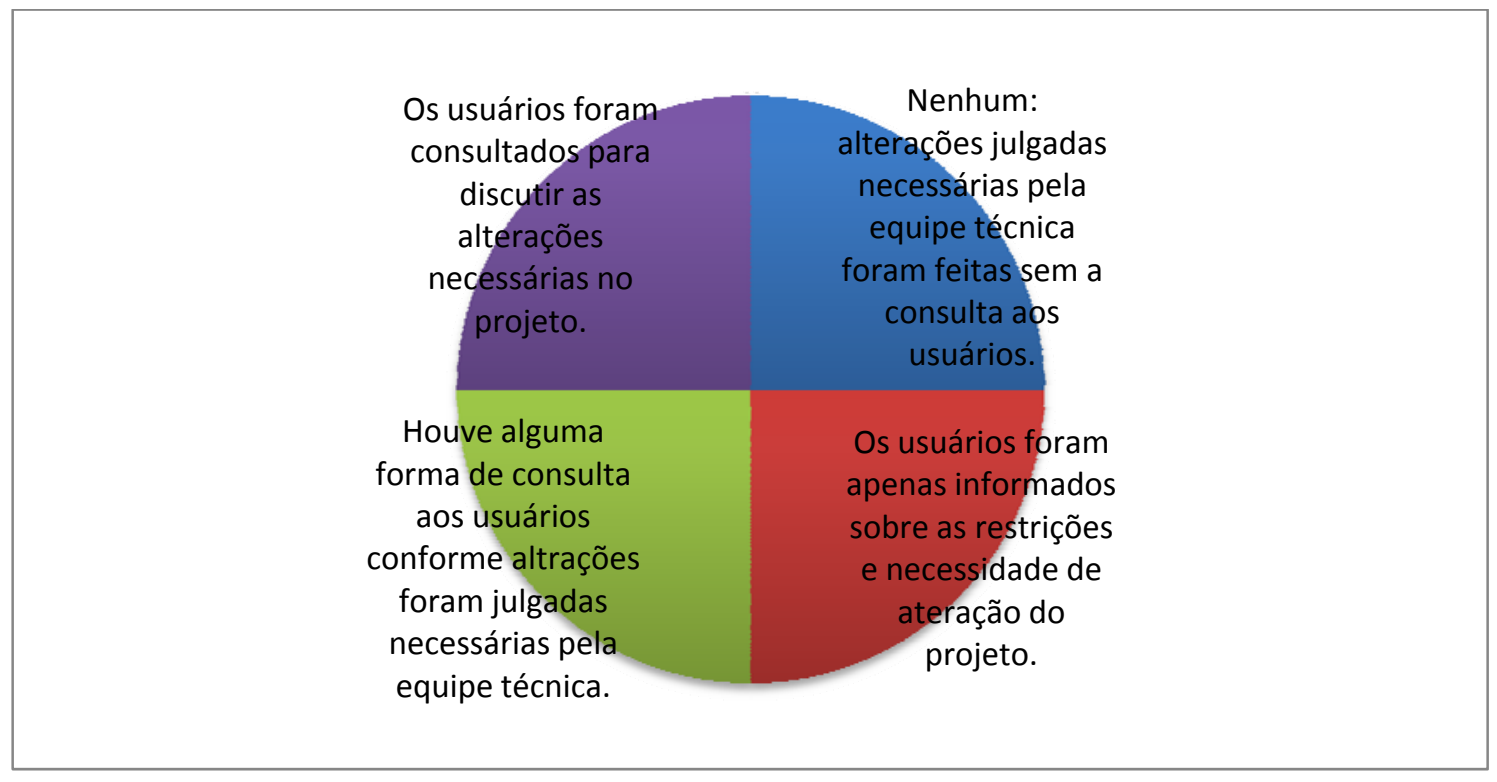

5.1.6 Nível de aprendizado dos usuários com a experiência

Em relação ao nível do aprendizado sobre os processos de projeto e serviços em edifícios de assistência à saúde dos usuários envolvidos neste processo, a maioria das empresas classificou como aprendizado mínimo - três respostas - contra uma resposta indicando aprendizado alto. Como aprendizado mínimo, o questionário considerava que os usuários aprenderam o necessário para poder participar, e como aprendizado alto julgava-se que os usuários 
obtiveram uma ampla visão sobre o processo de projeto de um edifício de saúde e de serviços de saúde. A empresa que julgou o aprendizado como alto foi a única que indicou maior nível de relacionamento entre equipe técnica e usuários envolvidos, de modo que se pode considerar que relacionamentos mais estreitos entre equipes de projeto e usuários podem levar a um maior aprendizado durante o processo, e facilitar a participação.

\subsubsection{Principais benefícios e desafios enfrentados pelas empresas no} envolvimento de usuários no processo de projeto.

Com relação aos pontos positivos do envolvimento, foram obtidas três respostas, e todas indicavam melhor atendimento às necessidades dos usuários, destacando-se a resposta da Empresa E:

Melhor entendimento nos processos internos do hospital, que resultou num projeto que atende às necessidades da equipe médica e pacientes.

Quando solicitadas para destacar os principais benefícios do envolvimento, duas empresas também colocaram o melhor entendimento das necessidades dos usuários, e uma empresa destacou a conclusão correta do projeto, sem necessidades de alteração durante a obra.

Quanto às barreiras e dificuldades de envolvimento, foram obtidas três respostas, sendo que duas empresas afirmam não encontrar barreiras ou dificuldades, e a terceira empresa coloca que:

Muitas pessoas dão opinião no projeto, onde muitas vezes só visualizam a parte de interesse delas, causando grande conflito de interesses que deve ser intermediado pela equipe administrativa e arquitetos.

\subsubsection{Processo de Projeto sem envolvimento de usuários}

Das empresas que responderam ao questionário, apenas uma afirmou nunca ter envolvido usuários em seu processo de projeto. A razão apontada é que "nem sempre o cliente tem definido a equipe que vai ocupar/administrar o prédio". Portanto, não existe um 
posicionamento contra o envolvimento, e a empresa acredita que, num futuro próximo, provavelmente irá envolver usuários em seus processos.

\subsection{DISCUSSÃO}

Apesar de apenas uma parcela pequena das empresas que responderem ao questionário e não ser possível generalizar os resultados para o contexto brasileiro, as respostas foram relevantes para descrever práticas de grandes empresas, e acredita-se que se aproximam do comportamento geral das empresas atuantes em processos de projeto de edifícios de assistência à saúde no Brasil. A maior contribuição deste estudo, entretanto, foi dar suporte para a escolha das empresas para a realização dos estudos de caso, pelo levantamento das empresas que atuam em processos de projeto de EAS, indicação de quais já envolveram usuários no processo e quais estão abertas a colaboração em pesquisas científicas. 



\subsection{EC-1: Projeto para Intervenção e Amplação do Hospital de CLínICAS de Porto AleGRe - HCPA.}

O primeiro estudo de caso foi realizado no Hospital de Clínicas de Porto Alegre - HCPA, tendo como objeto de estudo o projeto para intervenção e ampliação do edifício principal do complexo. As fontes de evidência para coleta de dados foram descritas no capítulo 2.

\subsubsection{Descrição da Empresa de Arquitetura responsável pelo projeto de} intervenção - Bross Consultoria e Arquitetura.

Localizada na cidade de São Paulo, a Empresa responsável pelo projeto de intervenção no HCPA. A Bross desenvolveu o plano diretor e o projeto de intervenção, com exceção do projeto executivo. Em mais de cinquenta anos de existência, atua em edificações de saúde, campi universitários, edifícios de educação e consultoria, e é responsável por diversos projetos, em âmbito internacional, dos quais se pode citar:

- Edifícios de assistência à saúde, com destaque para Hospital Beneficência Portuguesa (reorganização), Hospital das Clínicas da UNICAMP, Hospital Universitário de Marília, Centro Universitário UNIFOR, Centro de Atenção à Saúde da Universidade Federal de Juiz de Fora, Hospital Universitário da Universidade Federal do Pará, Hospital Universitário do Piauí, Centro Médico de Campinas, Complexo de Saúde Alda Teixeira em Aracajú, Higienópolis Medical Center, Hospital AMICO de Santo André, Hospital Beneficência Portuguesa, Hospital Unimed em diversas cidades, Maternidade São Luiz, Hospital de Ponta Delgada em Portugal, entre outros.

- Traçados Urbanísticos, dimensionamento dos setores e edifícios e infraestrutura da Unicamp e Puccamp, em Campinas-SP, e UEL, em Londrina-PR, etc.

- Planos Diretores para Clínica Multiperfil na Angola, Hospital Geral em Aracajú/SE, Sociedade Beneficência Alemã em São Paulo, etc. 
A equipe que forma a empresa é constituída pelo diretor e fundador da empresa, um diretor de projetos e uma coordenadora de projetos, que já estão juntos há 20 anos. Além destes, existe uma equipe multidisciplinar de projetos, com arquitetos, consultores hospitalares, ecologistas, economistas, médico, profissionais ligados à epidemiologia, bioestatística, analista de mercado, entre outros. Esta equipe se complementa por profissionais externos à empresa.

\subsubsection{Descrição geral do HCPA}

O projeto do Hospital de Clínicas de Porto Alegre iniciou-se em 1942, com autoria do arquiteto Jorge Machado Moreira. A proposta inicial do arquiteto destacava um grande bloco principal, que nascia do solo sobre pilares de 'ordem colossal'. O bloco possuía dez pavimentos-tipo e suas duas fachadas maiores, orientadas para leste e para oeste com leve inclinação para nordeste e sudoeste, eram constituídas por grelhas quebra-sol. Havia ainda duas torres de base oval, destinadas às circulações verticais, e uma galeria perpendicular posterior, que conectava o bloco principal ao auditório e aos dois blocos horizontais paralelos, um sobre pilotis do estacionamento e outro no nível do solo, com duas rampas oblíquas nas extremidades (LUCCAS 2006). As figuras 30 e 31 ilustram a primeira versão do projeto de Jorge Moreira.
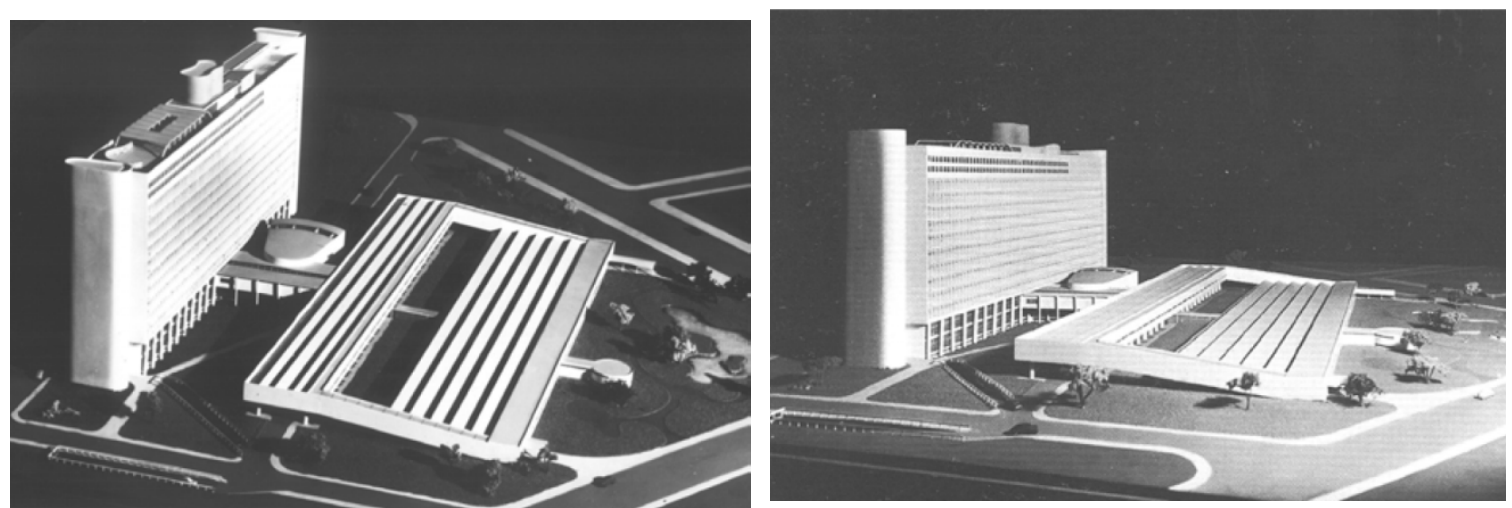

Figura 30. Vista leste da maquete do projeto de 1942 do HCPA. Fonte: Acervo de JMM no NPD - FAU/UFRJ (SILVA, 2006).

Figura 31. Vista leste 2 da maquete do projeto de 1942 do HCPA. Fonte: Acervo de JMM no NPD - FAU/UFRJ (SILVA, 2006).

A construção do HCPA foi iniciada em 1958 (figuras 32, 33 e 34), contando com alterações substanciais no projeto inicial (LUCCAS, 2006). A figura 35 mostra o Hospital em 2013. 

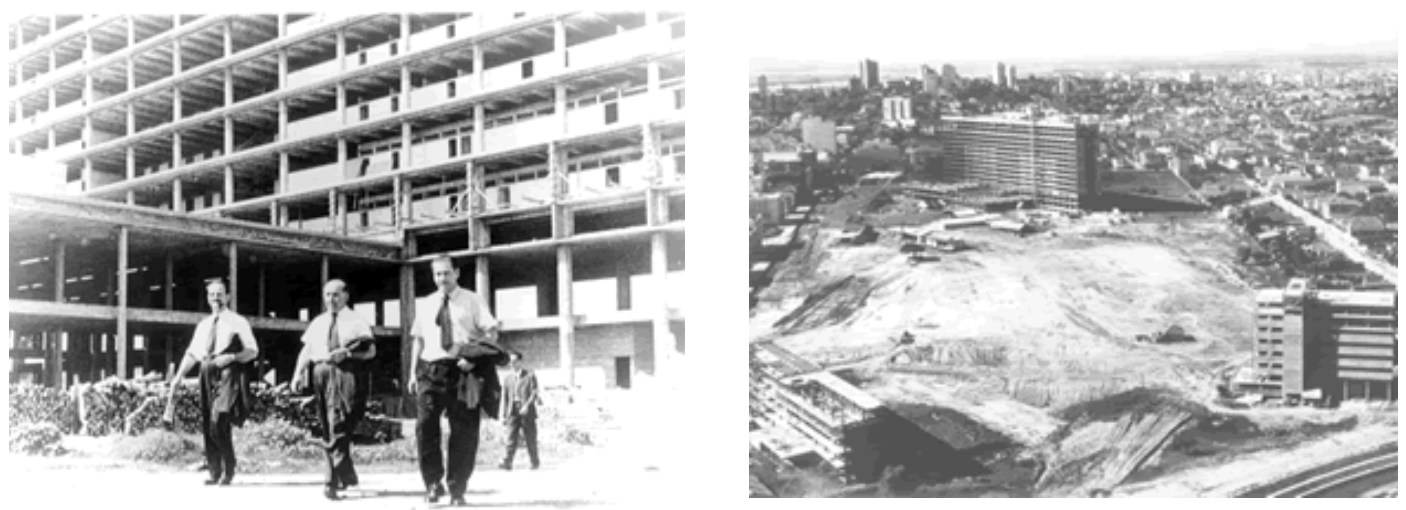

Figura 32. Obra do HCPA. Fonte: http://www.hcpa.ufrgs.br/galeria/index.html Acesso em: 25 set. 2013.

Figura 33. Vista aérea da obra do HCPA. Fonte: http://www.hcpa.ufrgs.br/galeria/index.html Acesso em: 25 set. 2013.
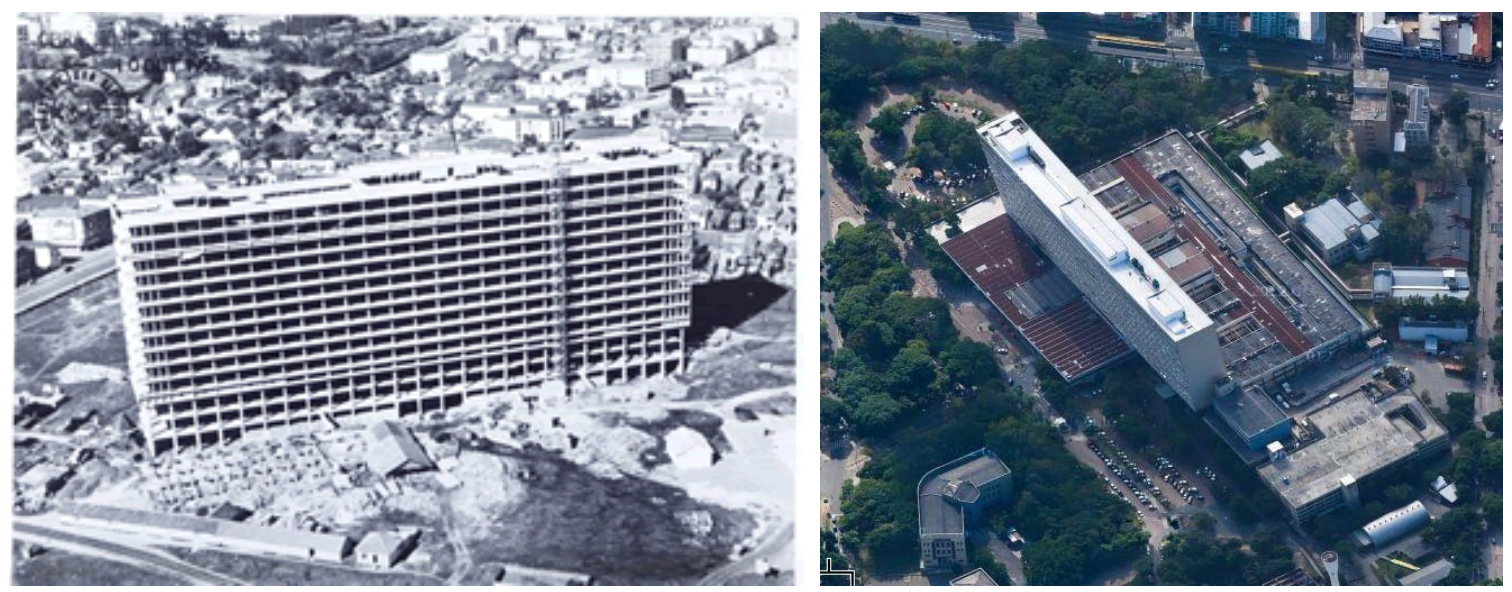

Figura 34. Vista aérea do HCPA na época da construção. Fonte: http://www.hcpa.ufrgs.br/galeria/index.html Acesso em: 25 set. 2013.

Figura 35. Vista aérea atual do HCPA. Fonte: Google Maps - https://maps.google.com.br

Atualmente o HCPA atua em assistência em saúde, ensino e pesquisa, conforme descrição apresentada no Quadro 29. A Tabela 5 apresenta a estrutura física do HCPA, com o dimensionamento atual dos 19 setores. O complexo do Hospital de Clínicas possui, atualmente, $128.338,36 \mathrm{~m}^{2}$ de área construída, com 795 leitos regulares e 93 leitos de apoio, discriminados na Tabela 6. 
Quadro 29. Atuação do HCPA. Fonte: Dados coletados na página virtual do HCPA http://www.hcpa.ufrgs.br Acesso em 22 mai. 2013.

\begin{tabular}{|c|l|}
\hline ATUAÇÃO & \multicolumn{1}{|c|}{ DESCRIÇÃO } \\
\hline Assistência & $\begin{array}{l}\text { Hospital público, geral e universitário. Atendimento com cerca de sessenta } \\
\text { especialidades, disponibilizando desde os procedimentos mais simples até os mais } \\
\text { complexos. Os pacientes são oriundos, prioritariamente, do SUS. }\end{array}$ \\
\hline Ensino & $\begin{array}{l}\text { A estrutura do HCPA dá suporte ao desenvolvimento de atividades de ensino nos níveis } \\
\text { médio, de graduação e pós-graduação, através do vínculo acadêmico do HCPA com a } \\
\text { UFRGS. }\end{array}$ \\
\hline Pesquisa & $\begin{array}{l}\text { O HCPA desenvolve pesquisas biomédicas, clínicas e epidemiológicas, em conjunto com } \\
\text { diversos programas de pós-graduação. }\end{array}$ \\
\hline
\end{tabular}

Tabela 5. Estrutura física do HCPA - Dimensionamento atual dos setores. Fonte: http://www.hcpa.ufrgs.br, Acesso em 22 mai. 2013.

\begin{tabular}{|c|c|c|c|}
\hline \multicolumn{2}{|r|}{ SETORES } & \multirow{2}{*}{$\begin{array}{l}\text { № DE AMBIENTES } \\
12 \text { salas }\end{array}$} & \multirow{2}{*}{$\begin{array}{l}\text { TOTAL DE } \\
\text { AMBIENTES } \\
33 \text { Salas }\end{array}$} \\
\hline \multirow{3}{*}{$\begin{array}{l}\text { CENTRO } \\
\text { CIRÚRGICO }\end{array}$} & Cirurgia & & \\
\hline & Cirurgia Ambulatorial & 16 salas & \\
\hline & Procedimentos Obstétricos & 5 salas & \\
\hline \multirow{2}{*}{ AMBULATÓRIO } & Ambulatórios I e II & 124 consultórios & \multirow[t]{2}{*}{139 consultórios } \\
\hline & Outras áreas de atendimento ambulatorial & 15 consultórios & \\
\hline \multirow{3}{*}{ EMERGÊNCIA } & Consultas & 9 consultórios & \multirow[t]{3}{*}{23 ambientes } \\
\hline & Procedimentos/Exames & 7 ambientes & \\
\hline & Observação: & 7 ambientes & \\
\hline \multicolumn{2}{|l|}{ HEMOTERAPIA } & -- & 13 salas \\
\hline \multicolumn{2}{|l|}{ HOSPITAL-DIA } & -- & 19 postos \\
\hline \multicolumn{2}{|c|}{ CENTRO DE ATENÇÃO PSICOSSOCIAL (CAPS) } & -- & 11 postos \\
\hline \multicolumn{2}{|c|}{ MEDICINA NUCLEAR } & -- & 5 postos \\
\hline \multicolumn{2}{|c|}{ CENTRO DE PESQUISA CLÍNICA } & -- & 36 postos \\
\hline \multicolumn{2}{|c|}{ CENTRO DE PESQUISA EXPERIMENTAL } & -- & 21 ambientes \\
\hline \multicolumn{2}{|c|}{ NÚCLEO DE PESQUISA } & -- & 10 ambientes \\
\hline \multicolumn{2}{|c|}{ UNIDADE DE RADIOTERAPIA } & -- & 13 postos \\
\hline \multicolumn{2}{|c|}{ UNIDADE DE QUIMIOTERAPIA } & -- & 20 postos \\
\hline \multicolumn{2}{|c|}{ UNIDADE DE HEMODIÁLISE } & -- & 24 postos \\
\hline \multicolumn{2}{|c|}{ UNIDADE DE HEMODINÂMICA } & -- & 2 salas \\
\hline \multicolumn{2}{|c|}{ UNIDADE BÁSICA DE SAÚDE } & -- & 23 postos \\
\hline \multicolumn{2}{|c|}{ CASA DE APOIO } & -- & 54 camas \\
\hline \multicolumn{2}{|l|}{ CRECHE } & -- & 240 vagas \\
\hline \multicolumn{2}{|l|}{ RECREAÇÃO } & -- & 3 salas \\
\hline \multicolumn{2}{|l|}{ AUDITÓRIO } & -- & 10 ambientes \\
\hline
\end{tabular}


Tabela 6. Número de Leitos do HCPA. Fonte: http://www.hcpa.ufrgs.br, Acesso em 22 mai. 2013.

\begin{tabular}{|c|c|c|c|}
\hline SETOR & \multicolumn{3}{|c|}{ NÚMERO DE LEITOS } \\
\hline Unidades de Internação & \multicolumn{2}{|l|}{672} & 795 \\
\hline \multirow{3}{*}{ Centro de Tratamento Intensivo } & Adultos: 34 & \multirow[t]{3}{*}{67} & \\
\hline & Pediátricos: 13 & & \\
\hline & Neonatal: 20 & & \\
\hline \multirow{3}{*}{ Emergência } & Adultos: 41 & \multirow[t]{3}{*}{56} & \\
\hline & Obstétrica: 6 & & \\
\hline & Pediátricos: 9 & & \\
\hline $\begin{array}{l}\text { Leitos de Apoio (Recuperação Cirúrgica, Berçário, } \\
\text { Pré-parto) }\end{array}$ & \multicolumn{3}{|l|}{93} \\
\hline
\end{tabular}

\subsubsection{O Projeto de Intervenção e ampliação do HCPA}

Do pensamento do 'puxadinho', uma hora caiu a ficha de entender, e até de aprender que o nome disso [que nós precisávamos] era um plano diretor de reestruturação física do hospital (informação verbal) ${ }^{41}$.

Cerca de meio século após sua inauguração, o HCPA havia passado por diversas reformas pontuais para atender a problemas emergenciais que requeriam adequação do espaço físico. Estas reformas eram realizadas sem consideração da edificação como um todo, muitas como 'puxadinhos' da edificação ${ }^{42}$. O projeto de intervenção no HCPA, apresentado aqui, inclui a reorganização tanto operacional como do espaço físico existente. O plano diretor físico que foi realizado prevê a reorganização do edifício existente e um acréscimo de $68 \%$ na área do complexo, passando dos atuais $128.338 \mathrm{~m}^{2}$ para $215.665 \mathrm{~m}^{2}$, pela construção de novos anexos para as atividades de ensino, pesquisa, assistenciais, administrativas e de apoio ${ }^{43}$ (figuras 36 a 45).

\footnotetext{
${ }^{41}$ Entrevista realizada com o Presidente do HCPA, em Porto Alegre, no dia 13 de dezembro de 2012.

${ }^{42}$ Idem.

${ }^{43}$ Fonte: INFORMATIVO INTERNO DO HOSPITAL DE CLÍNICAS DE PORTO ALEGRE, № 34, agosto/2011, p. 4-5.
} 


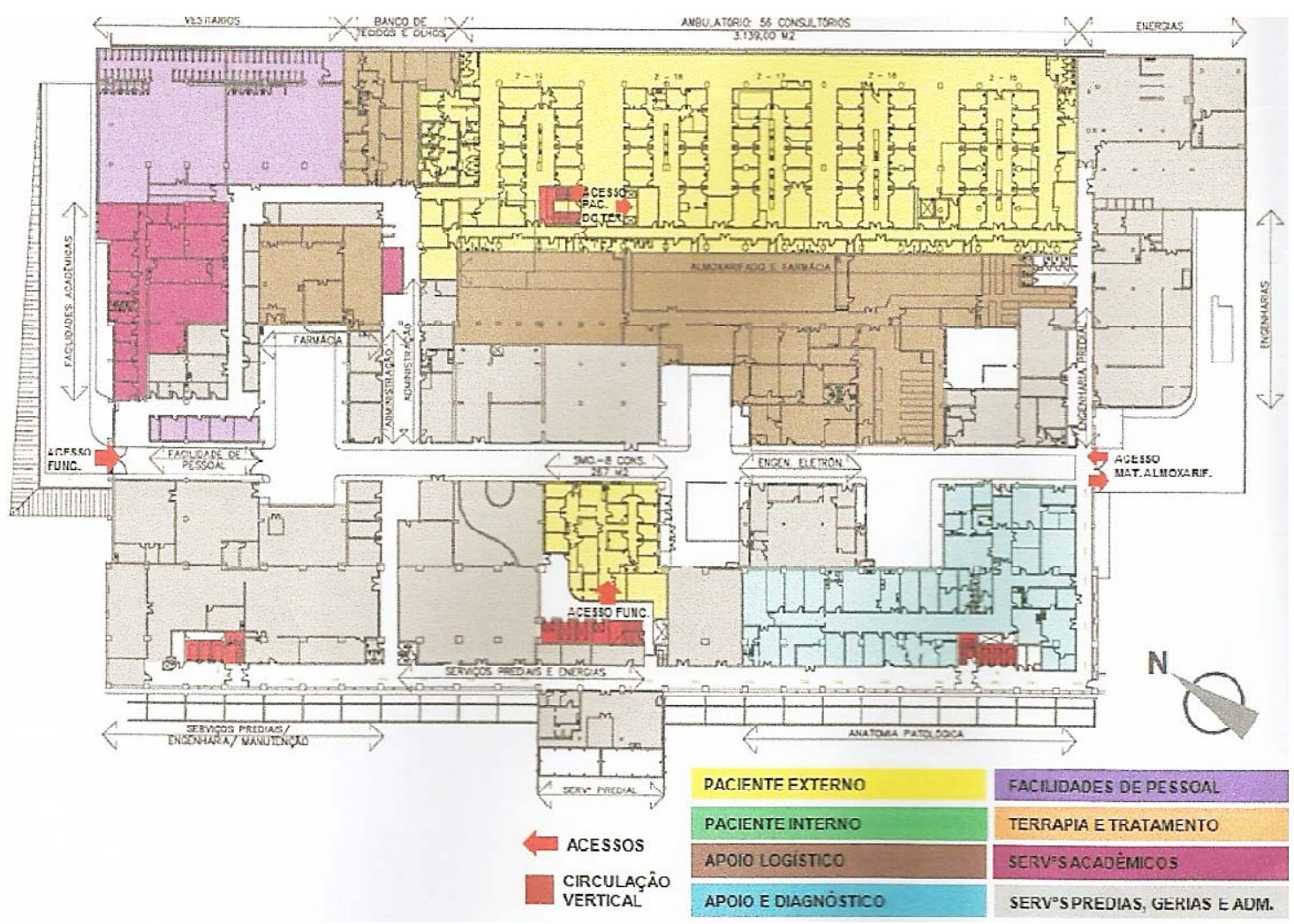

Figura 36. Subsolo: Planta da situação existente. Fonte: Imagem gentilmente cedida pela Bross Consultoria e Arquitetura.

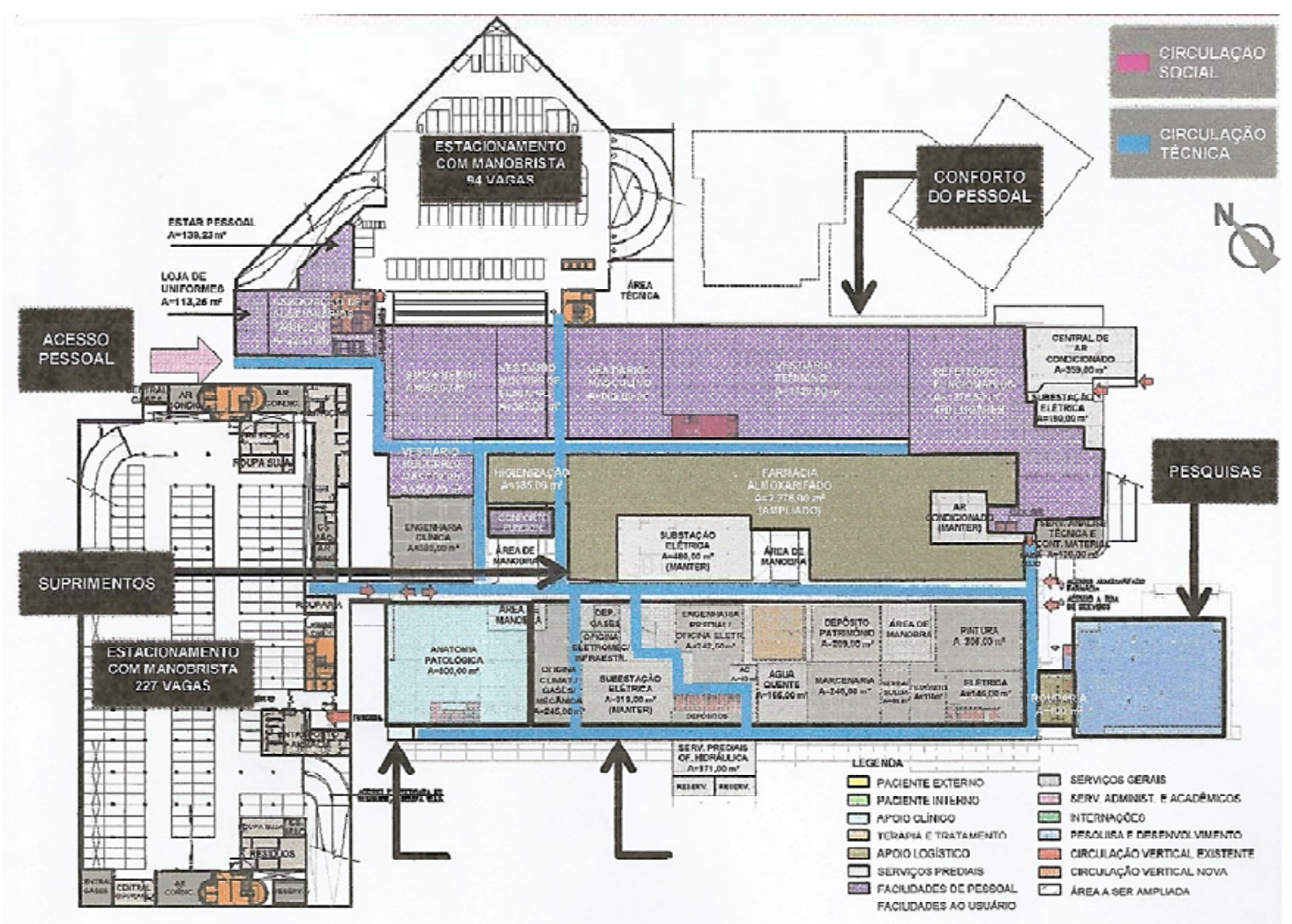

Figura 37. Subsolo: Planta da reorganização proposta. Fonte: Imagem gentilmente cedida pela Bross Consultoria e Arquitetura. 


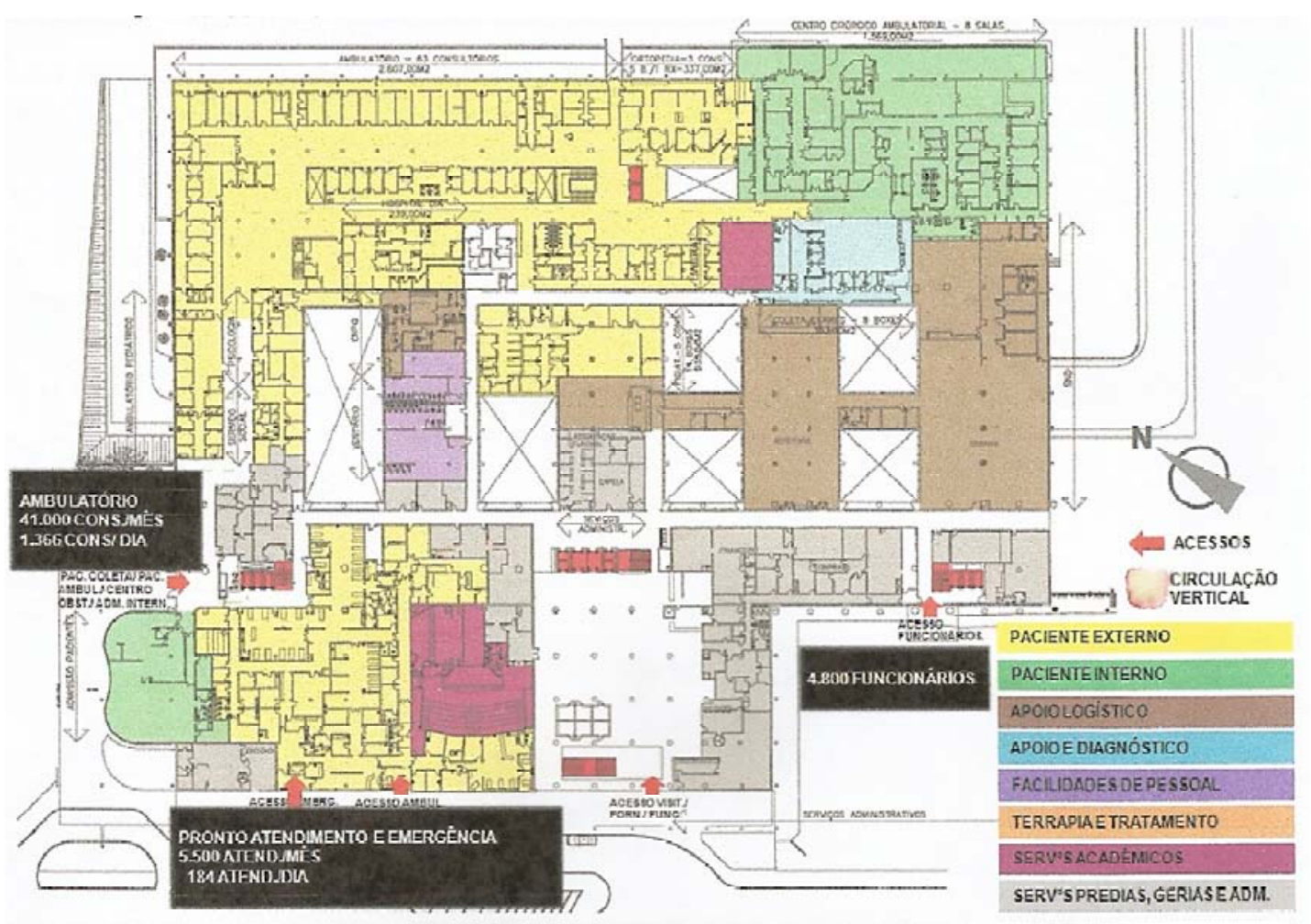

Figura 38. Térreo: Planta da situação existente. Fonte: Imagem gentilmente cedida pela Bross Consultoria e Arquitetura.

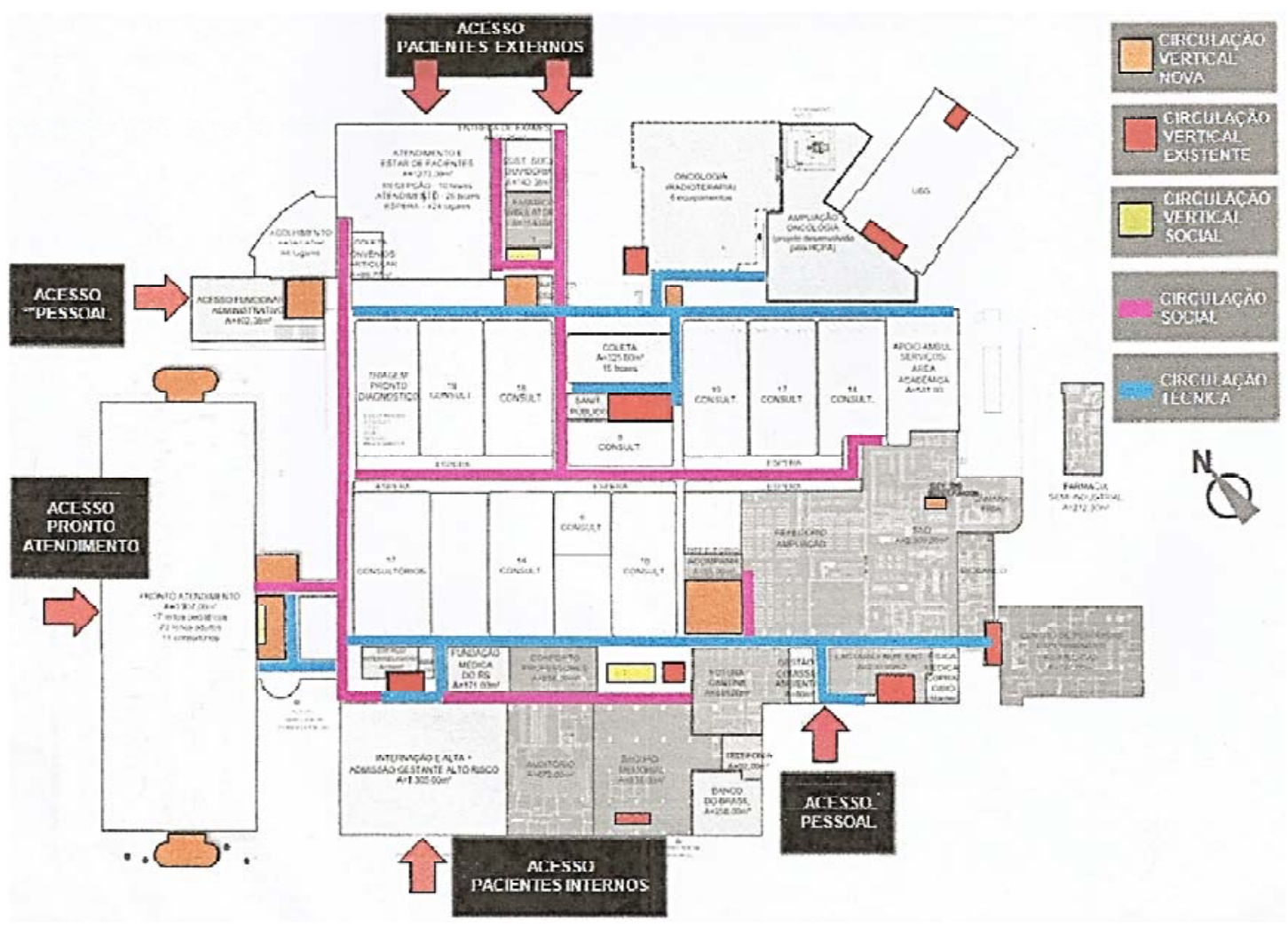

Figura 39. Térreo: Planta da reorganização proposta - circulações. Fonte: Imagem gentilmente cedida pela Bross Consultoria e Arquitetura. 


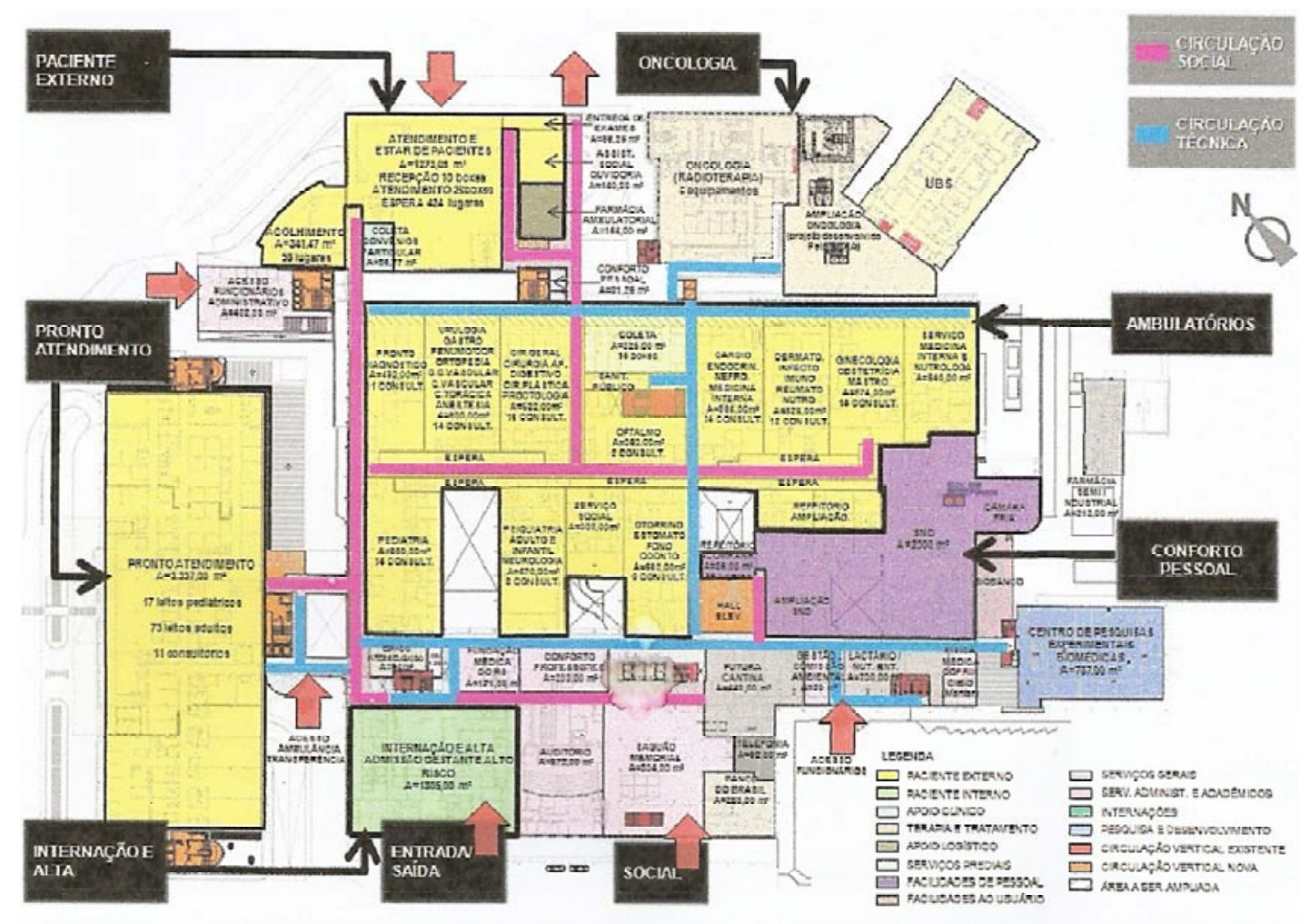

Figura 40. Térreo: Planta da reorganização geral proposta. Fonte: Imagem gentilmente cedida pela Bross Consultoria e Arquitetura.

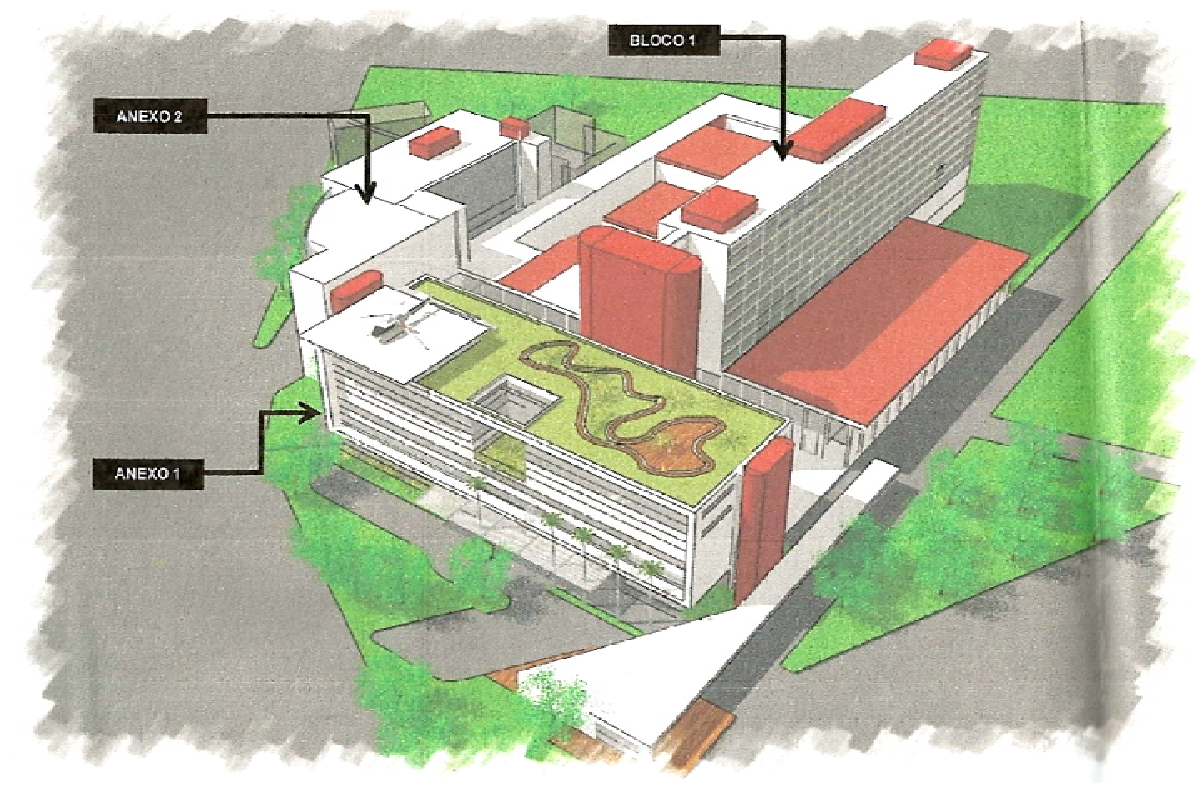

Figura 41. Perspectiva aérea do HCPA com o Bloco 1 (a ser reorganizado) e os anexos que serão acrescentados. Fonte: Imagem gentilmente cedida pela Bross Consultoria e Arquitetura. 


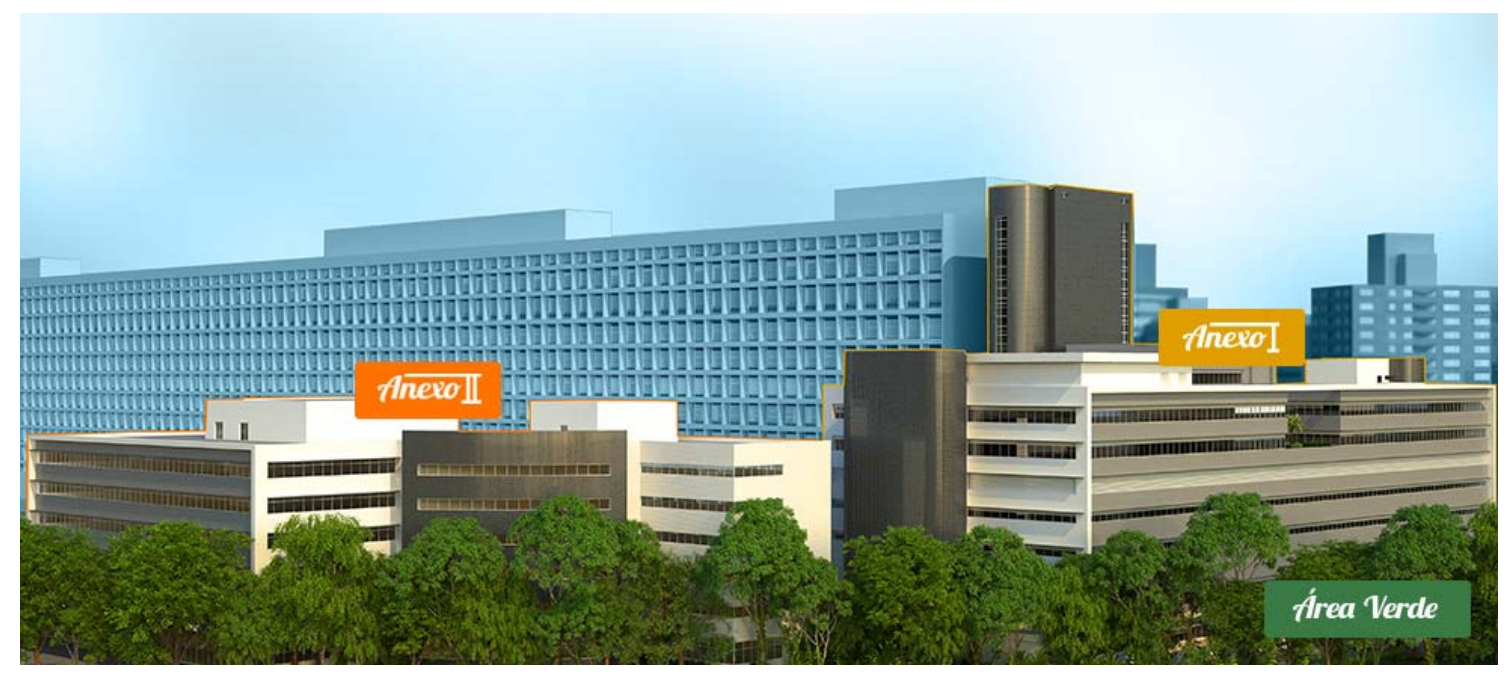

Figura 42. Ilustração 3D do HCPA e seus anexos. Fonte:

http://www.hcpa.ufrgs.br/expansao/index.php/conheca-o-projeto Acesso em 06 jul. 2015.

O Anexo 1 possuirá 53.981,65 metros quadrados de área construída, divididos em sete pavimentos mais dois subsolos, conforme descrito no Quadro 30.

Quadro 30. Composição do Anexo 1. Fonte:

http://www.hcpa.ufrgs.br/expansao/index.php/conheca-o-projeto Acesso em 06 jul. 2015.

\begin{tabular}{|c|c|}
\hline PAVIMENTO & DESCRIÇÃO \\
\hline Subsolos 1 e 2 & 504 vagas de estacionamento \\
\hline Térreo & Emergência com 5.159,92 m2 \\
\hline 2o Pavimento & $\begin{array}{l}\text { Hemodinâmica: } 4 \text { salas } \\
\text { Vestiário de barreira } \\
\text { Anestesiologia }\end{array}$ \\
\hline 3ㅇ Pavimento & Recuperação pós-anestésica: 90 leitos e 60 poltronas \\
\hline 4으 Pavimento & $\begin{array}{l}\text { Bloco Cirúrgico e Centro Cirúrgico Ambulatorial: } 41 \text { salas de } \\
\text { procedimentos / Ressonância Magnética }\end{array}$ \\
\hline 5o Pavimento & $\begin{array}{l}\text { Centro de Material Esterilizado } \\
\text { Laboratório de Patologia } \\
\text { Salas de Aula e de Estudos }\end{array}$ \\
\hline 6o Pavimento & $\begin{array}{l}\text { Centro de Material Esterilizado/ Laboratório de Patologia } \\
\text { Centro de Tratamento Intensivo: } 55 \text { leitos }\end{array}$ \\
\hline 7으 Pavimento & Centro de Tratamento Intensivo: 55 leitos \\
\hline
\end{tabular}




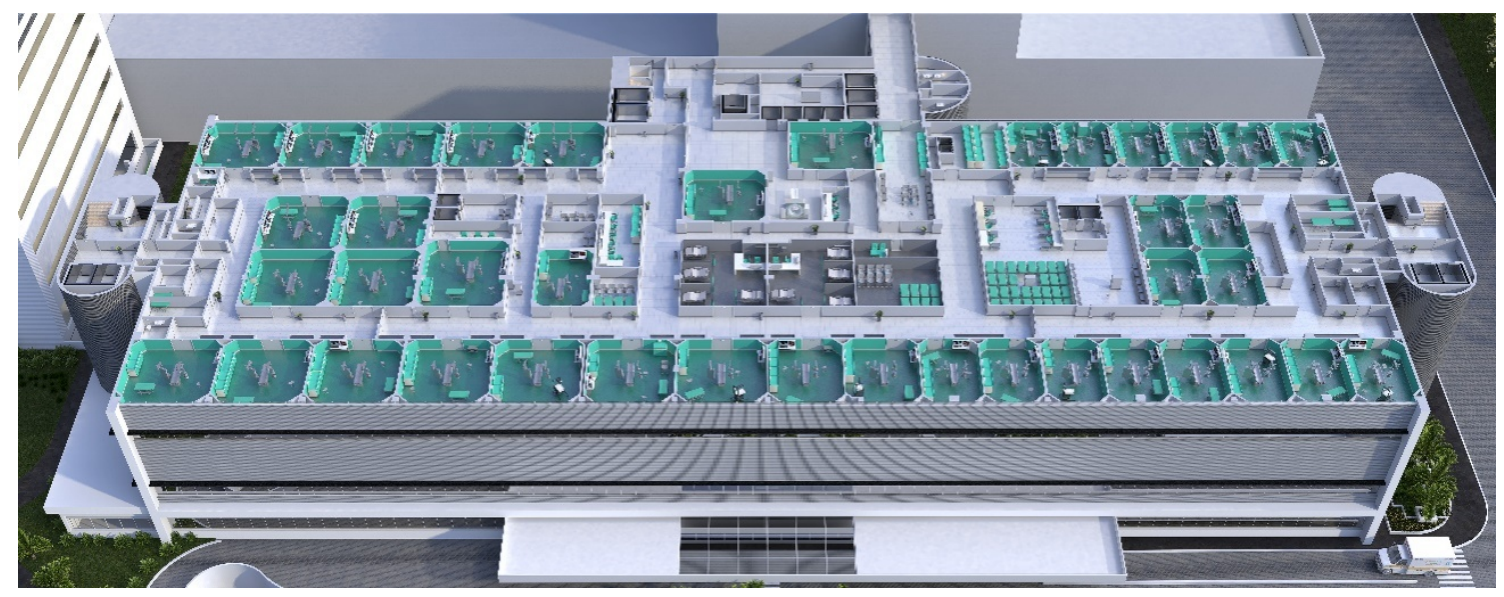

Figura 43. Ilustração 3D do $4^{\circ}$ Pavimento do Anexo 1 do HCPA. Fonte: http://www.hcpa.ufrgs.br/expansao/index.php/conheca-o-projeto Acesso em 06 jul. 2015.

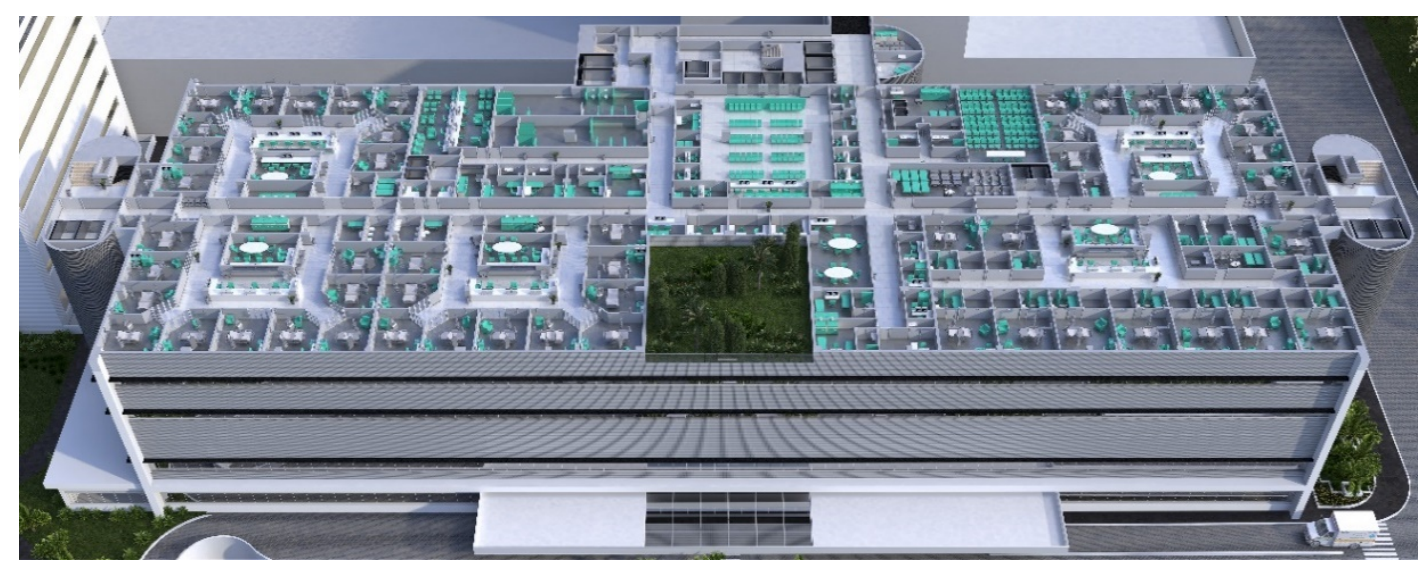

Figura 44. Ilustração 3D do $6^{\circ}$ Pavimento do Anexo 1 do HCPA. Fonte: http://www.hcpa.ufrgs.br/expansao/index.php/conheca-o-projeto Acesso em 06 jul. 2015.

O Anexo 2 possuirá 30.118 metros quadrados, em seis pavimentos e dois subsolos, descritos no Quadro 31.

Quadro 31. Composição do Anexo 2. Fonte:

http://www.hcpa.ufrgs.br/expansao/index.php/conheca-o-projeto Acesso em 06 jul. 2015.

\begin{tabular}{|c|c|}
\hline PAVIMENTO & DESCRIÇÃO \\
\hline Subsolos 1 e 2 & 218 vagas de estacionamento \\
\hline Térreo & $\begin{array}{l}\text { Atendimento ambulatorial } \\
\text { Recepção e Registro de Pacientes }\end{array}$ \\
\hline 20 Pavimento & $\begin{array}{l}\text { Endoscopia: } 10 \text { leitos } \\
\text { Diálise: } 34 \text { leitos adultos e } 2 \text { pediátricos }\end{array}$ \\
\hline 3으 Pavimento & $\begin{array}{l}\text { Hospital-dia: } 16 \text { leitos adultos e } 4 \text { pediátricos } \\
\text { Novas instalações da Fisiatria }\end{array}$ \\
\hline 4ㅇ, 5ㅇ e 6ㅇ Pavimentos & Serviços administrativos/ Salas de aula e de estudos / Auditório \\
\hline
\end{tabular}




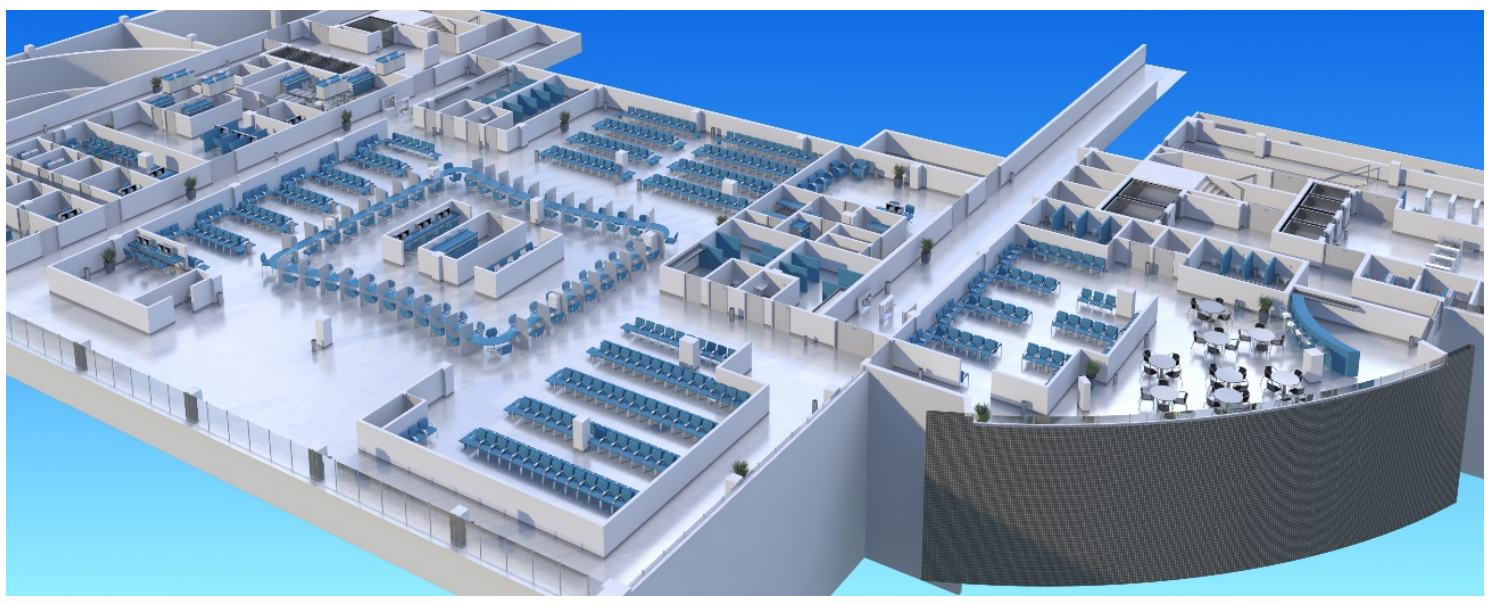

Figura 45. Ilustração 3D do Térreo do Anexo 2 do HCPA. Fonte:

http://www.hcpa.ufrgs.br/expansao/index.php/conheca-o-projeto Acesso em 06 jul. 2015.

\subsubsection{O Processo de Projeto de Intervenção e ampliação do HCPA}

O anúncio da meta de intervenção no HCPA ocorreu em 15 de dezembro de 2008. A partir de então, iniciou-se o processo de contratação de empresas e de desenvolvimento do projeto para ampliar e reorganizar o espaço físico do hospital existente. A figura 46 ilustra a linha do tempo do processo de projeto.

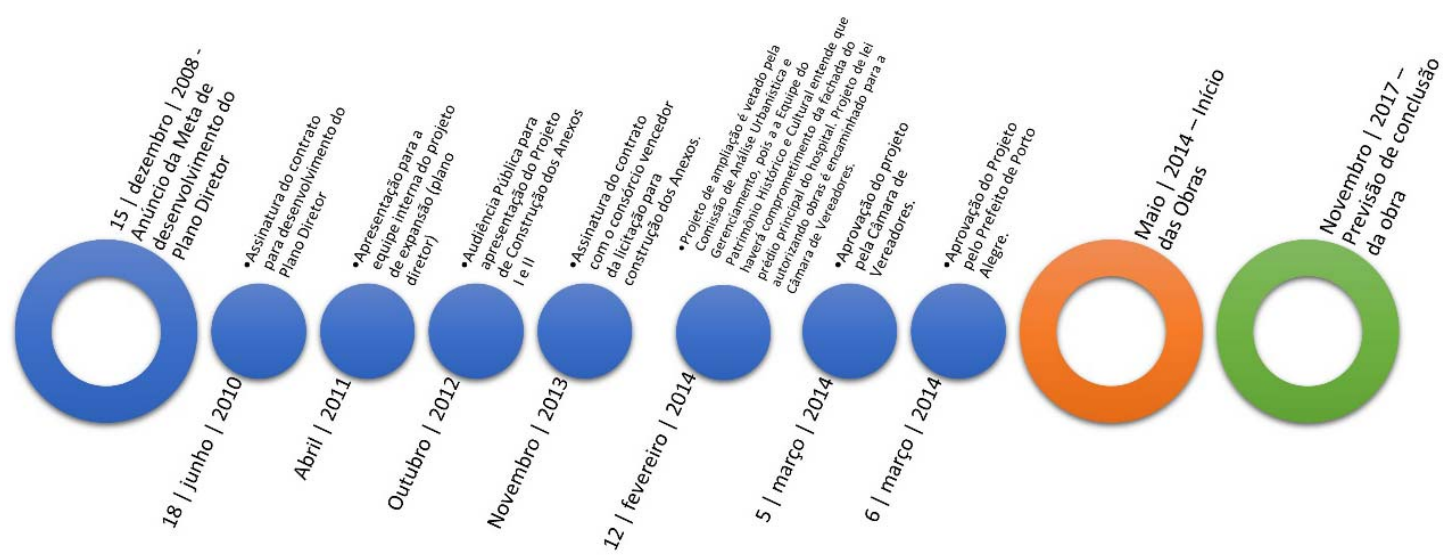

Figura 46. Evolução do Processo de Projeto do HCPA. Fonte: http://www.hcpa.ufrgs.br/expansao/fique-por-dentro/10-retrospectiva-da-ampliacao.

Acesso em 20 jul. 2015.

Em 18 de junho de 2010, foi assinado o contrato para desenvolvimento do Plano Diretor físico com a Bross. Segundo o presidente do HCPA, a vasta experiência desta Empresa em projetos de edifícios de assistência à saúde, sentida pela equipe do HCPA durante o processo de projeto, foi fundamental para trazer confiança aos usuários no processo de 
projeto, e também para auxiliar o presidente - enquanto coordenador dos usuários - durante o processo de projeto, em questões como conciliação de conflitos de requisitos.

Foram ministradas palestras pelo superintendente da empresa, o arq. João Carlos Bross, para a equipe interna do hospital, com o objetivo de esclarecer definições gerais sobre o processo de projeto e prepara-los para serem envolvidos neste processo. A empresa envolveu no processo de projeto os usuários que faziam parte da equipe do hospital, tais como médicos, enfermeiros, outros profissionais de saúde que trabalham no hospital e funcionários administrativos e de serviços. Usuários que não fazem parte da equipe do hospital, como pacientes e visitantes, não foram envolvidos. De acordo com a empresa de arquitetura, usuários que não trabalham no hospital não permanecem em seu espaço físico por tempo suficiente para conhecê-lo a ponto de contribuir com dados relevantes para o processo e para a melhoria da eficiência na realização das atividades. Quanto maior o número de usuários envolvidos, mais caro será o processo e maiores serão os esforços da equipe, e a chance de o envolvimento deste tipo de usuário trazer benefícios para a eficiência operacional é menor em relação à equipe interna do hospital.

Com o intuito de promover um espaço físico para reuniões e discussões sobre o projeto, estreitar as relações e estimular o envolvimento de usuários no processo, foi estabelecida uma sala dentro do Hospital destinada a este fim, de fácil acesso para a equipe interna.

O processo de projeto desenvolvido pela empresa se inicia com o planejamento do modelo de prestação de serviços, dada a complexidade e singularidade de cada edifício de saúde, e a necessidade de funcionalidade e eficiência nas atividades realizadas. Esta etapa precede o projeto do espaço físico em si, e é caracterizada pela descrição das atividades que são e serão realizadas na edificação, no formato de uma linha de produção. Para entender e descrever como ocorriam as atividades realizadas no edifício, ou seja, a sua utilização, foi utilizado um método descrito pelo diretor geral da empresa de arquitetura no Quadro 32. É fundamental que a equipe de projeto tenha esta compreensão para poder propor melhorias na organização dos espaços e na realização das atividades, aumentando a eficiência operacional do edifício. O método tem a finalidade de analisar e descrever a 'cadeia de suprimentos' considerando cada processo - consultas médicas, exames, cirurgias, entre outros - como um 'elo' que compõe cada macro-processo, que por sua vez compõe a cadeia de suprimentos de atenção à saúde. O método é dividido em quatro etapas: identificação, projeto dos macro-processos, medição e análise. Arquitetos com conhecimento de produção de serviços orientaram e estimularam o envolvimento dos usuários. 
Quadro 32. Método para descrever a cadeia de suprimentos de atenção à saúde do HCPA. Fonte: Gentilmente cedido pelo Superintendente da Bross Consultoria, João Carlos Bross.

\begin{tabular}{|c|c|c|}
\hline ETAPA & ATIVIDADE & DESCRIÇÃO \\
\hline 10 & Identificação & $\begin{array}{l}\text { Identificação de todas as unidades de produção existentes para } \\
\text { compor a cadeia de suprimentos de atenção à saúde }\end{array}$ \\
\hline 20 & $\begin{array}{l}\text { Descrição dos } \\
\text { Macro-processos }\end{array}$ & $\begin{array}{l}\text { 10 Macro-processo: Emergência: O macro-processo foi desenhado } \\
\text { para descrever os elos e as demandas qualitativas e de tempo, para } \\
\text { listar os fluxos mais críticos, de acordo com o 'caso' e o 'estado' de } \\
\text { cada paciente. Exemplos de fluxos: } \\
\text { Distúrbios cardíacos: UTI e hemodinâmica } \\
\text { Politrauma: tomografia e cirurgia } \\
\text { Problemas cardiorrespiratórios: UTI } \\
\text { 2o Macro-processo: Ambulatório: Foi desenhado mostrando } \\
\text { numericamente as qualidades de tipos de serviços, com distâncias } \\
\text { e tempos consumidos. } \\
\text { 3o Macro-processo: Enfermaria: similar ao ambulatório. }\end{array}$ \\
\hline 3음 & Medições & $\begin{array}{l}\text { Foram medidos tempos, frequências de movimentos, distâncias e a } \\
\text { capacidade de operação de cada setor. }\end{array}$ \\
\hline 40 & Análise & $\begin{array}{l}\text { As capacidades de cada 'elo' na cadeira de atenção foram } \\
\text { analisadas para determinar "restrições" que impedem fluidez do } \\
\text { fluxo. }\end{array}$ \\
\hline
\end{tabular}

Por este método, foram identificadas todas as unidades de produção disponíveis para fornecer a cadeia assistencial, além das circulações e fluxos existentes, com base na nomenclatura estabelecida pela RDC no 50. Inicialmente, foi realizado o levantamento do espaço físico para atualização das plantas do hospital. Para este levantamento, foram contratados arquitetos da cidade de Porto Alegre, liderados pela Arquiteta A, que foi entrevistada na coleta de dados do EC-1. Este levantamento não contou com envolvimento dos usuários, apenas com visitas dos arquitetos a todos os setores do HCPA, para observação, tomadas de medidas dos ambientes e levantamento dos equipamentos existentes. O levantamento levou em torno de três meses, e a equipe foi responsável por coletar in loco todos os dados solicitados pela Empresa, em São Paulo. Para a troca de informações entre a equipe de arquitetos em Porto Alegre e a Bross, foi utilizado um portal de extranet, com perfil criado especificamente para o projeto do HCPA. Os subprodutos desta fase foram as plantas atualizadas da edificação existente, produzidos pela equipe de Porto Alegre, conforme o padrão estabelecido pela Empresa.

Além do levantamento físico, para completar a descrição da cadeia de suprimentos, os usuários, representando as diferentes unidades de produção do hospital, receberam um mapa de relacionamento, para orientar a descrição dos processos internos de seus setores, identificando os fornecedores, os processos internos, e os 'clientes' de cada setor (Figura 47). O mapa veio acompanhado de um texto explicativo sobre os termos e os conceitos gerais 
utilizados (Figura 48). Os formulários respondidos foram enviados aos representantes da equipe de usuários, que organizaram os dados e os forneceram à equipe de projeto. Os usuários também receberam um formulário para dimensionamento da demanda de espaço para arquivos, muito importante em projetos de hospitais (Figura 49).

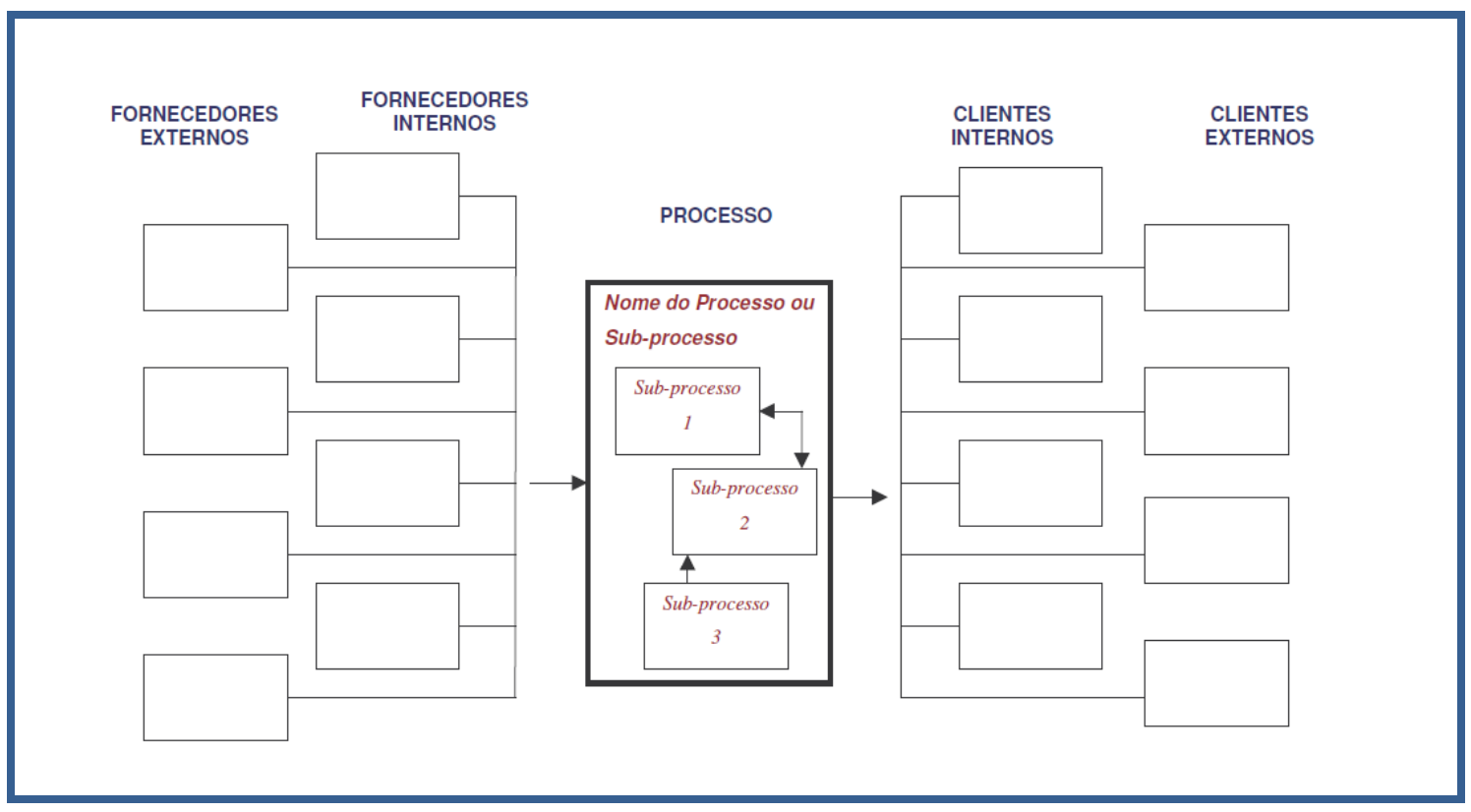

Figura 47. Mapa de Relacionamento enviado aos usuários para preenchimento. Fonte: Gentilmente cedido pela equipe interna do HCPA.

Cliente, fornecedor, processo e produto/serviços

Os processos sáo um conjunto de atividades exercidas para produzir serviços e ou produtos para atender às necessidades dos clientes. A análise dos clientes, fornecedores $\theta$ produtos/serviços de um processo proporciona um entendimento da identidade do processo. A fronteira a ser estudada fica entåo mais clara e situa-se entre o iníclo e o têrmino do processo, invadindo, se necessário, áreas distintas do organograma.

- PRODUTO - Resultado do meu trabalho (bens, serviços, informaçoes) enquanto fornecedor, para ser entregue ao meu cliente.

- CLIENTE - Todo aquele que recebe o resultado do trabalho (bens, serviços, informaçöes).

- FORNECEDOR - Todo aquele que entrega produtos (bens, serviços, informaçoes) para serem processados.

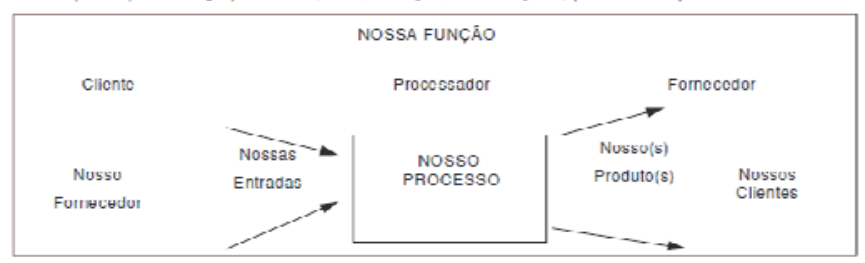

o Diagrama do Tripo

O Diagrama TRIPOL de Juran mostra que a parte externa do processo é formada por áreas que fornecem ou que recebem algum tipo de produto'serviç do processo alvo. Essas areas podem ser internas ou externas à organizacao. Quando internas sao chamadas de clentes-intemos ou fornecedores-internos, quando externas săo chamadas de clientes-externos ou fornecedores-externos. O mesmo empenho que existe para atender aos clientes-externos deve existir também dentro dos processos da organização para atender aos clientes-internos.

Observa-se que a grande diferença entre um fornecedor-interno e um fornecedor-externo é que o primeiro năo pode ser facilmente substituido, pois é parte integrante da organização; o mesmo năo ocorre com o segundo. Assim sendo, a maneira mais eficiente de termos parcerias reais com os fornecedores-internos e

comprometé-los com as inowaçoes e consclentizá-los da importáncla de seus produtos/serviços para com o processo alvo.
É importante que os produtos/serviços tenham pouca variabilidade para que o cliente sempre saiba o que exatamente receberá do processo. Assim, é importante o treinamento contínuo das pessoas do processo em relaçào as rotinas estabelecidas e definidas em manuais de fácil acesso.

Figura 48. Texto explicativo sobre os termos e os conceitos gerais utilizados no mapa de relacionamento. Fonte: Gentilmente cedido pela equipe interna do HCPA. 


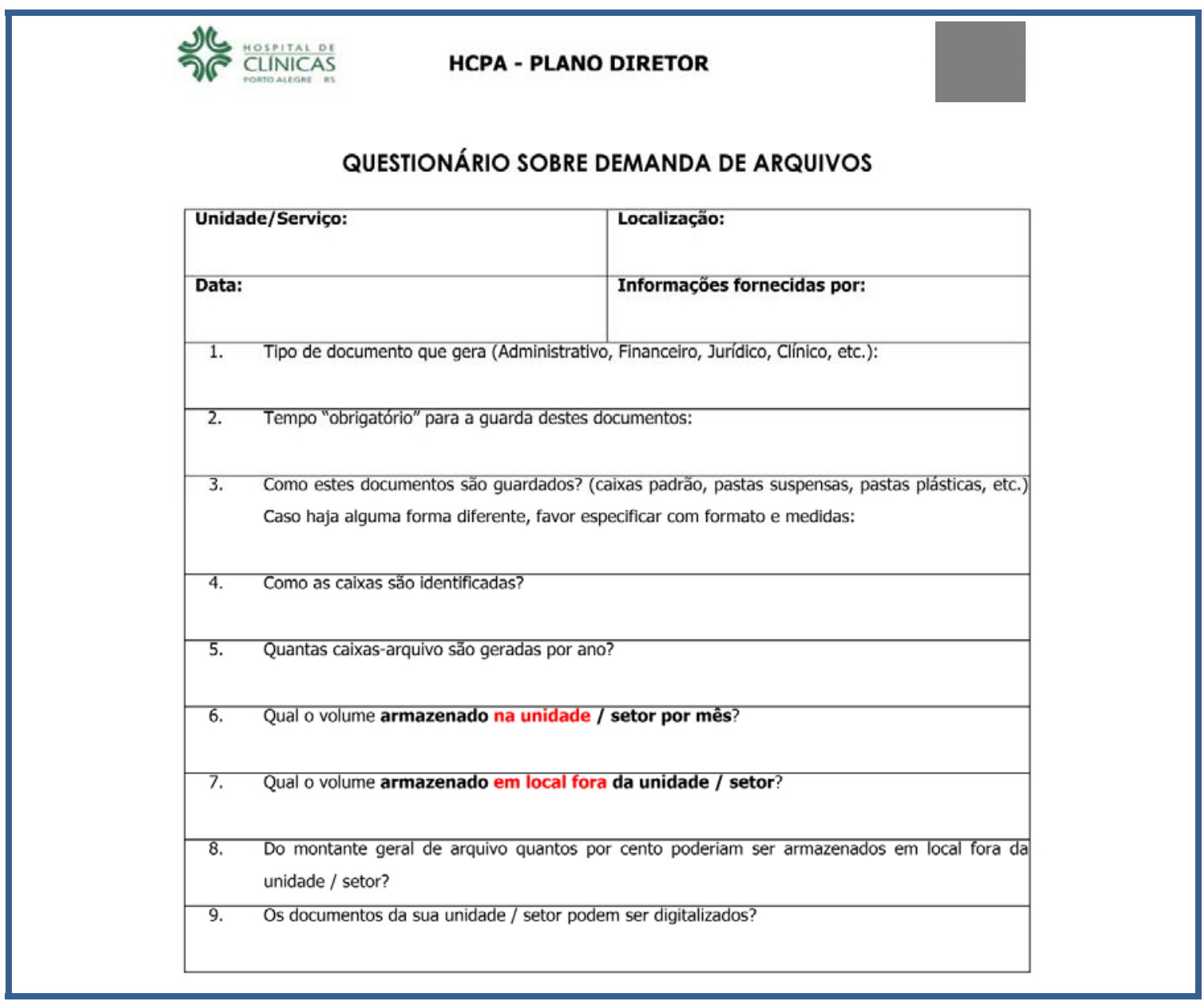

Figura 49. Formulário para levantamento da demanda de espaço para arquivos. Fonte: Imagem gentilmente cedida pela equipe interna do HCPA.

Posteriormente, os usuários receberam formulários para preenchimento de suas necessidades e requisitos, bem como para descrever os fluxos e atividades desenvolvidas, em conjunto com os demais usuários do seu setor. O objetivo deste procedimento foi "dar voz" a todos os membros da equipe interna do hospital (Figura 50). Os formulários respondidos foram enviados aos chefes de cada setor funcional, e, posteriormente, à Funcionária A responsável por todo o processo de envio e recebimento dos formulários. De acordo com os dados levantados no EC-1, três arquitetos da Bross fizeram algumas viagens a Porto Alegre para discutir e trabalhar os dados provenientes dos questionários com os chefes de cada setor funcional. O presidente do hospital participou ativamente deste processo, auxiliando a equipe nas decisões sobre as demandas levantadas, com o intuito de apurar os dados e resolver conflitos, definindo assim diretrizes para o plano diretor.

Em relação ao acolhimento de demandas, outra dificuldade levantada pelo presidente do HCPA é que o comportamento dos usuários em relação ao seu ambiente de trabalho é errático, sujeito a influências de situações e fatores externos. Segundo ele, um 
fazendo avaliação clínica, gestantes em pré-natal, crianças realizando controles, etc. Os macroprocessos são então organizados de acordo com os fluxos quantitativos e qualitativos de atividades (figuras 51 e 52).

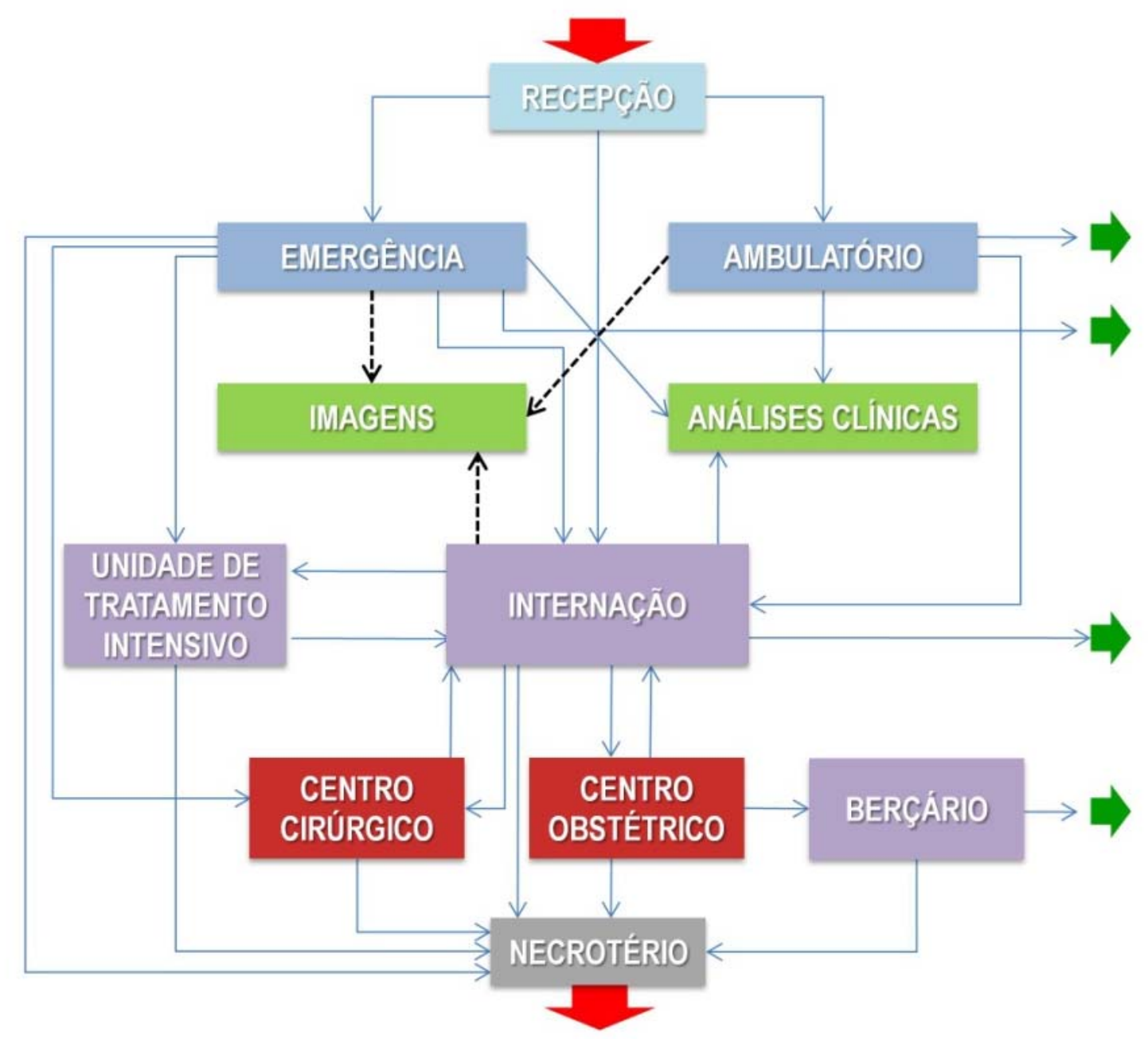

Figura 51. Cadeia de suprimentos do serviço de saúde: exemplo de fluxo qualitativo de atividades. Fonte: Bross (2013). 


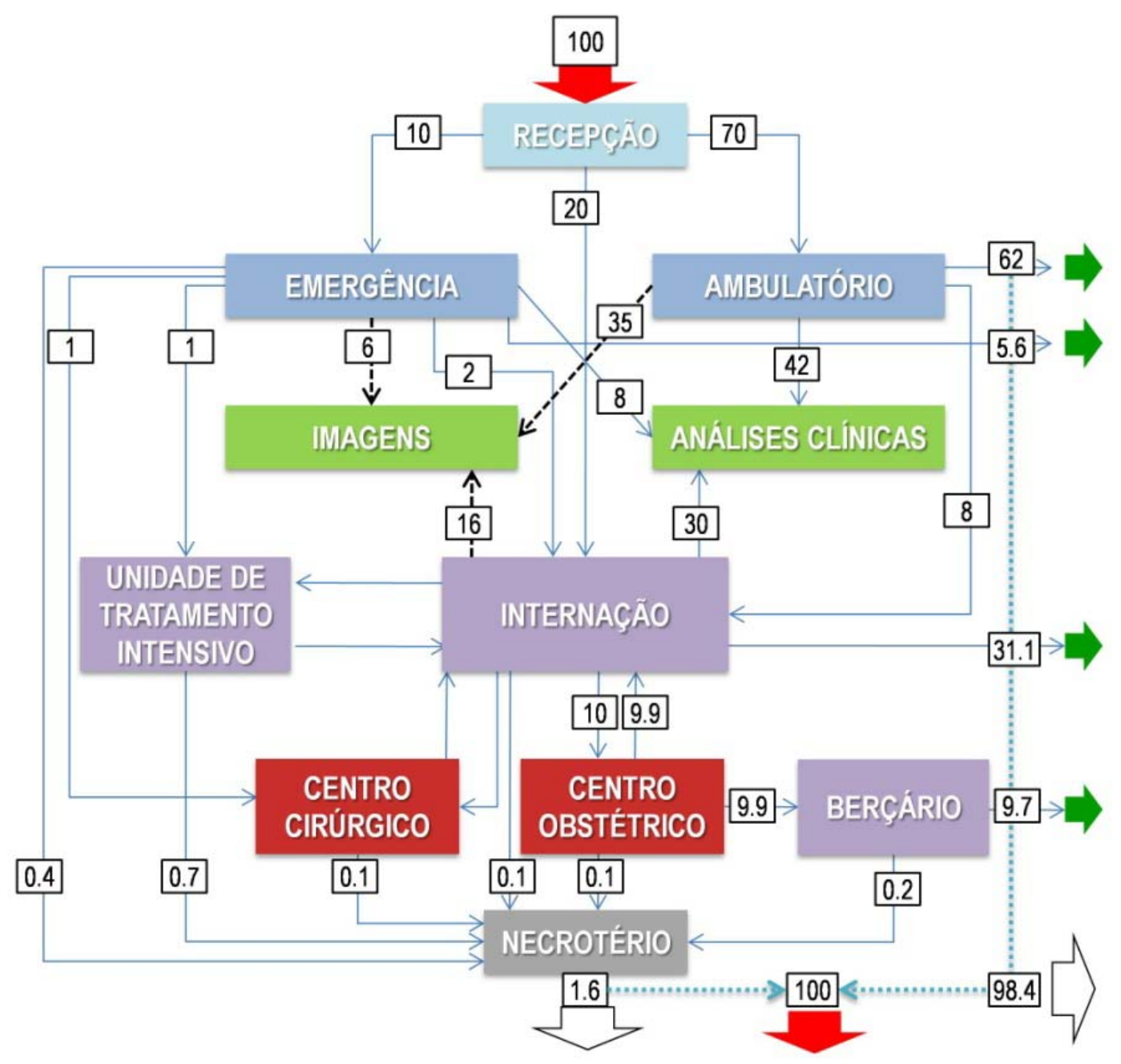

Figura 52. Cadeia de suprimentos do serviço de saúde: exemplo de fluxo quantitativo de atividades. Fonte: Bross (2013).

Com a descrição da cadeia de suprimentos como um todo, a equipe de projeto pode reorganizar a estrutura espacial do edifício para reduzir tempo na realização das atividades, e, consequentemente, aumentar a eficiência operacional. Para esta reorganização, foi definido um programa operacional, com envolvimento dos usuários em nível de co-design. Este programa inclui a operação do edifício, suas unidades, fluxos e atividades. $O$ instrumento utilizado nas reuniões de projeto foi diagramas de bolhas, para simplificar a representação e facilitar a compreensão dos usuários, que então podem co-projetar os serviços com os arquitetos. A organização das atividades, fluxos e unidades resultantes das discussões com os diagramas de bolhas é a base para o desenvolvimento do projeto do espaço físico, que é a etapa posterior. Não foram disponibilizados os diagramas realizados neste projeto, mas as figuras 53 e 54 mostram exemplos destes diagramas. 


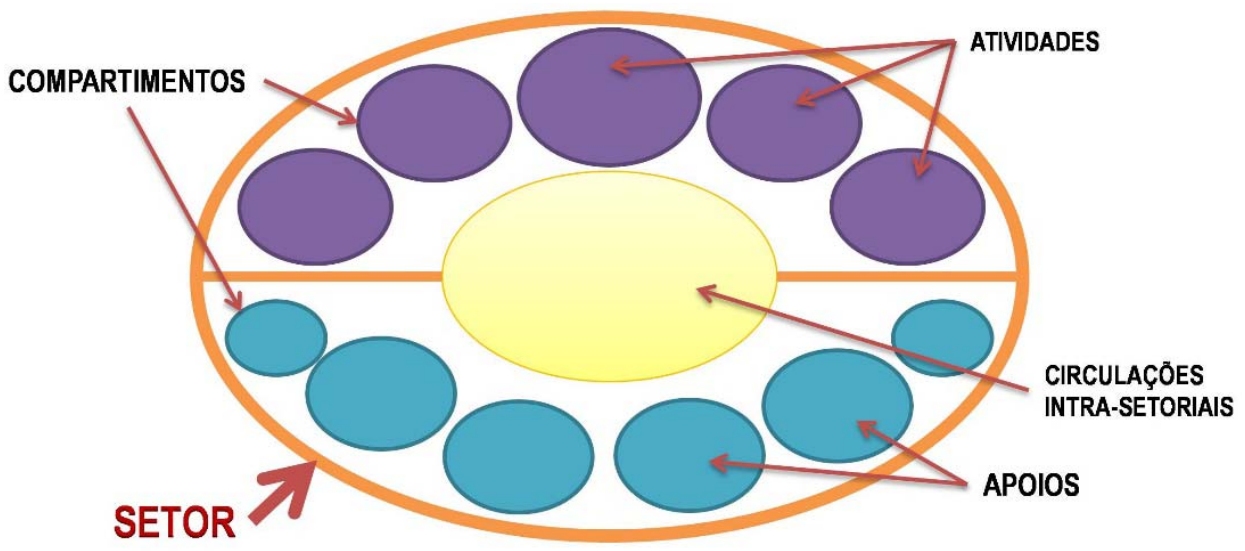

Figura 53. Exemplo de diagrama de bolhas para organização dos setores. Fonte: Bross (2008).

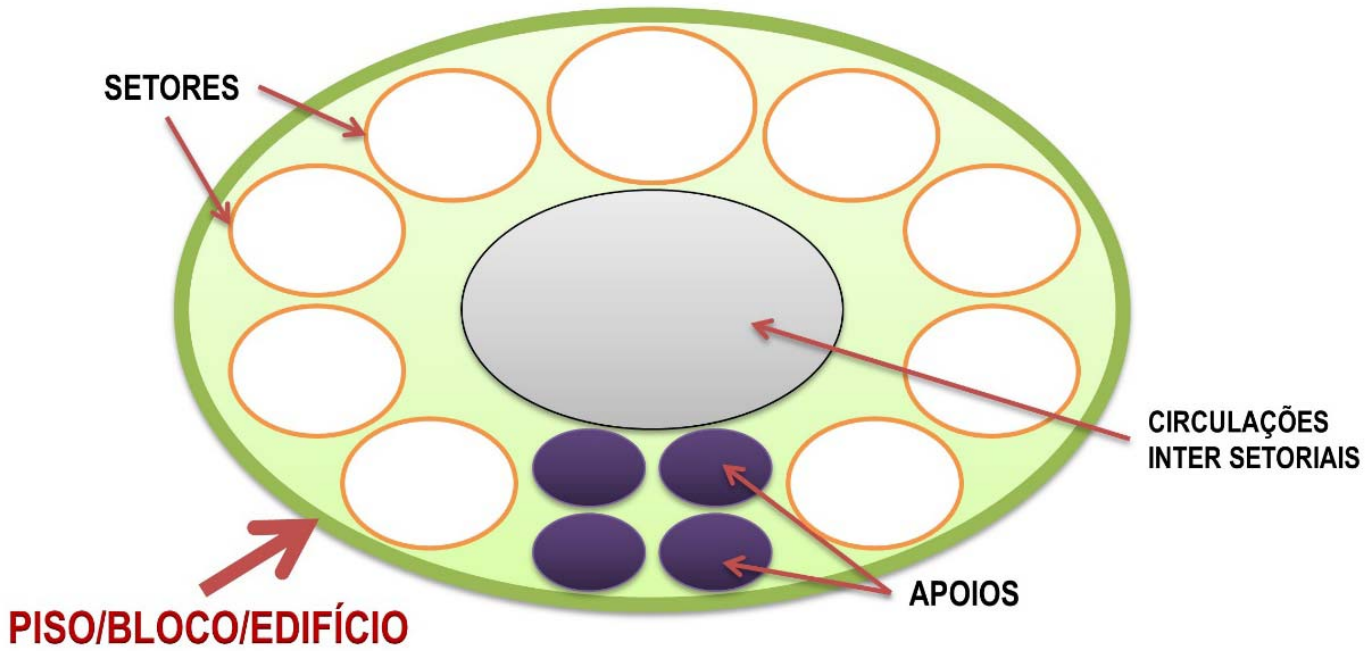

Figura 54. Exemplo de diagrama de bolhas para organização do piso/bloco/edifício. Fonte: Bross (2008).

Para viabilizar o co-design, foram definidos representantes da equipe de projeto e do grupo de usuários - a equipe interna era então formada por cerca de 5.200 funcionários - de modo a restringir o número de participantes nas reuniões a uma quantidade que se pudesse coordenar e atingir resultados satisfatórios. Esta definição ocorreu no início do processo de projeto, e foi importante para a comunicação entre os dois grupos. Estes representantes são encarregados de coletar as informações de seus respectivos grupos e discuti-las com os representantes do outro grupo, comunicando as decisões tomadas ao grupo de origem. Também tomam decisões por seus grupos, quando necessário (Figura 55). 


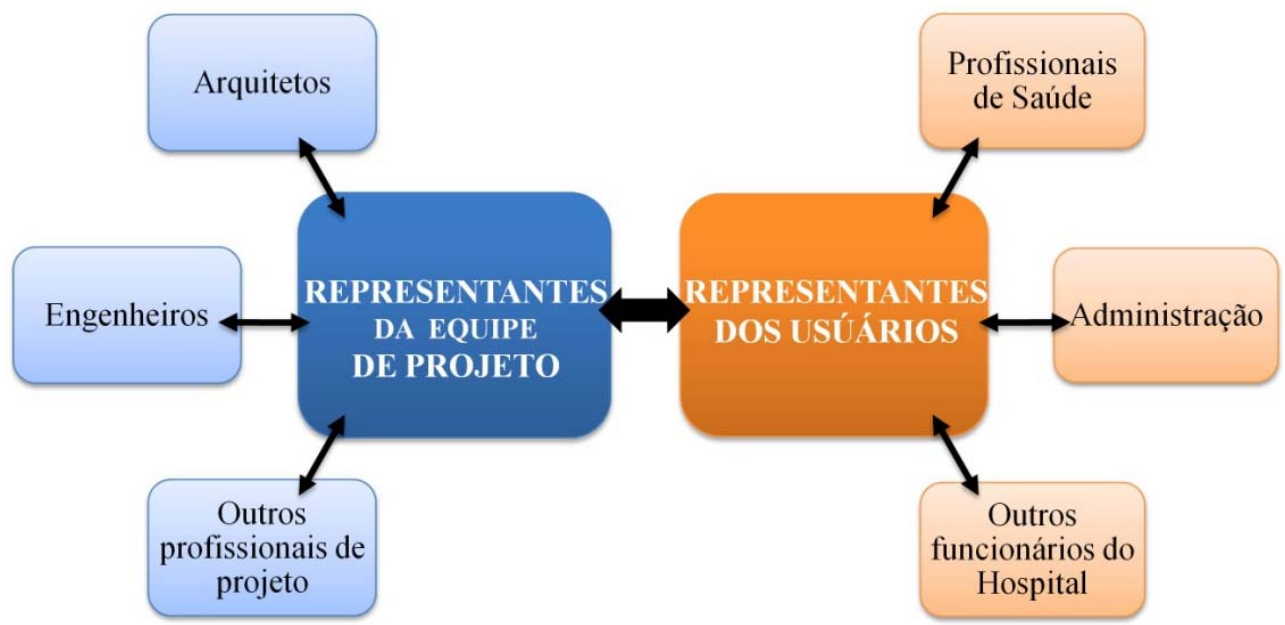

Figura 55. Representantes dos grupos de projeto e de usuários. Fonte: Elaborada pela autora a partir de informação verbal ${ }^{44}$.

É importante, de acordo com os arquitetos, a presença de um coordenador efetivo entre os representantes dos usuários, para resolver requisitos e necessidades conflitantes, bem como para estabelecer um prazo máximo para que os usuários forneçam requisitos e sugestões, devido ao grande número de usuários e ao fato de que há uma tendência de estes trazerem novos requisitos ao longo de todo o processo. Este coordenador, que no projeto do HCPA foi o presidente do hospital, teve papel fundamental tanto na conciliação dos requisitos como no auxílio ao cumprimento de prazos do processo.

Antes da conclusão do plano diretor, foram realizadas algumas apresentações do projeto para informar os usuários sobre o projeto. Estas apresentações foram abertas e toda a equipe interna foi convidada a participar. Com a conclusão do plano diretor, foi proferida uma palestra no anfiteatro do HCPA para expor o plano diretor físico elaborado à equipe interna do hospital. Ao término do projeto básico, a administração do HCPA organizou uma sala junto à recepção do hospital para expor a história do hospital ao longo de sua existência e o projeto para a intervenção, com o propósito de informar os usuários sobre as alterações e ampliações que ao complexo irá sofrer, e também de mostrar o resultado do processo em que foram envolvidos (figuras 56 a 59). Além disto, foram colocados painéis em diversos pontos das circulações do HCPA, com informações sobre o projeto (figuras 60 e 61).

\footnotetext{
${ }^{44}$ Informação fornecida por João Carlos Bross, em São Paulo, em 11 de dezembro de 2013.
} 


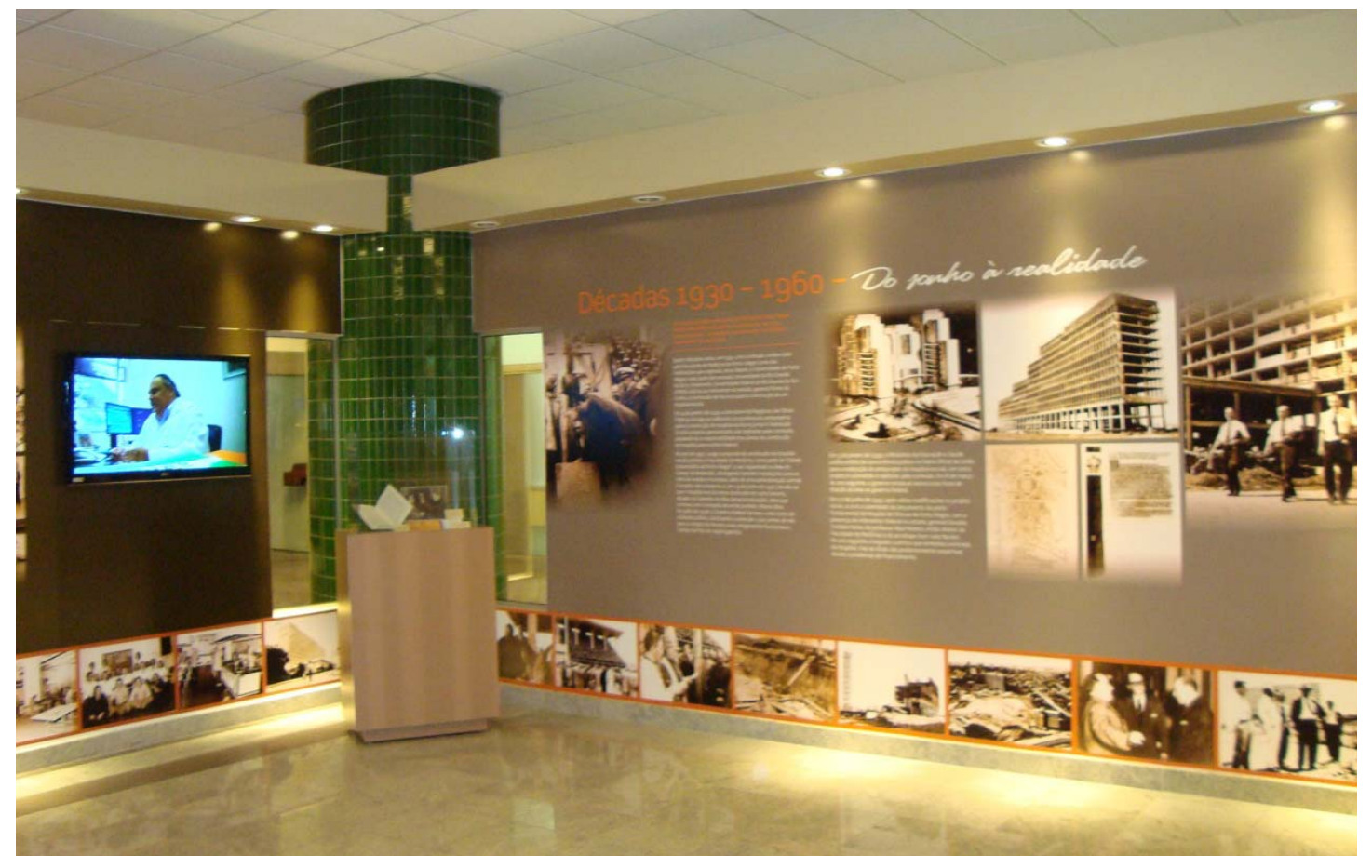

Figura 56. Sala de exposição do projeto, com a história do HCPA entre 1930 e 1960 "Do sonho à realidade". Foto: autora.

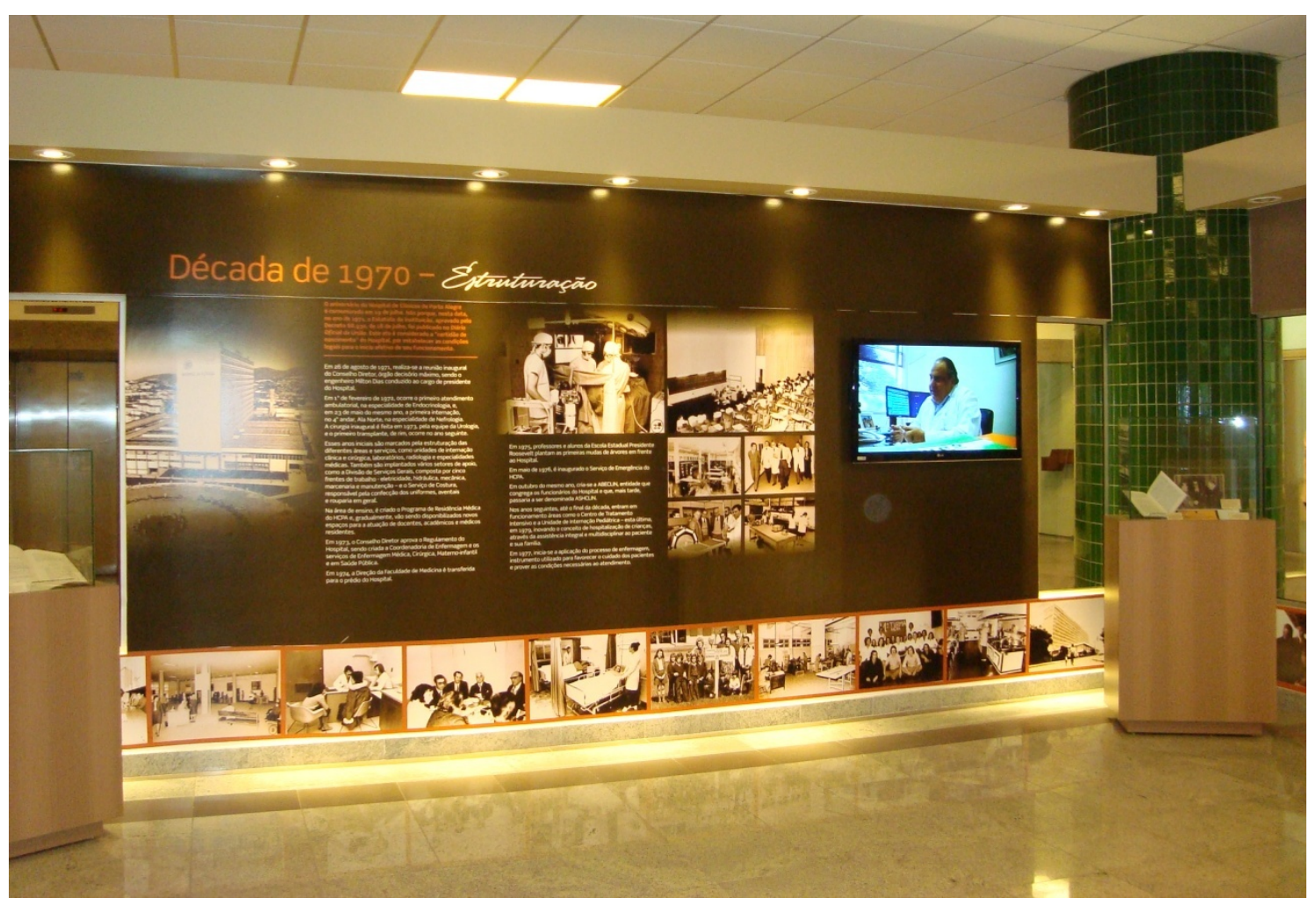

Figura 57. Sala de exposição do projeto, com a história do HCPA na década de 1970 “Estruturação". Foto: autora. 


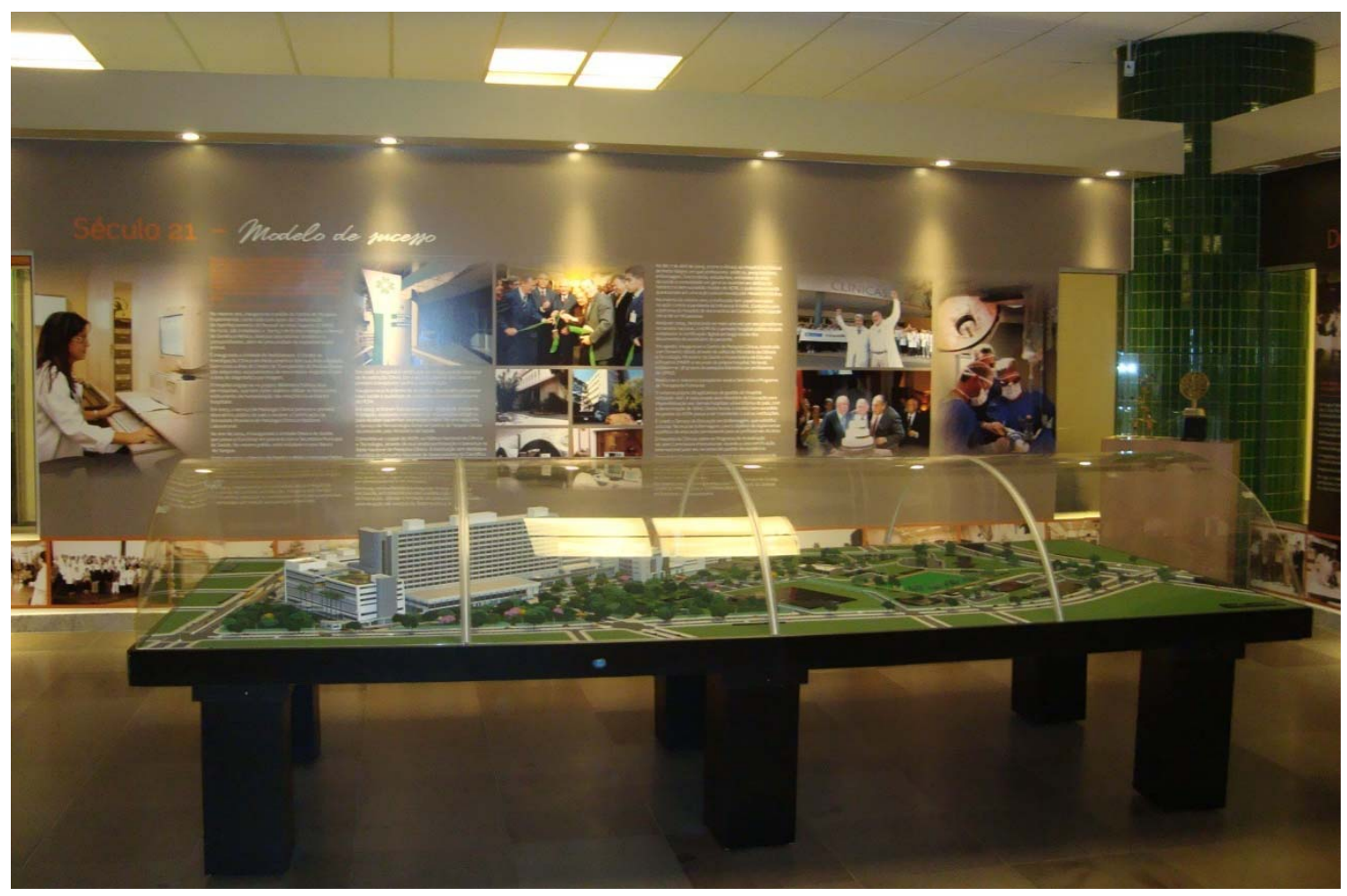

Figura 58. Sala de exposição do projeto, com a maquete do HCPA incluindo o projeto de intervenção. Foto: autora.

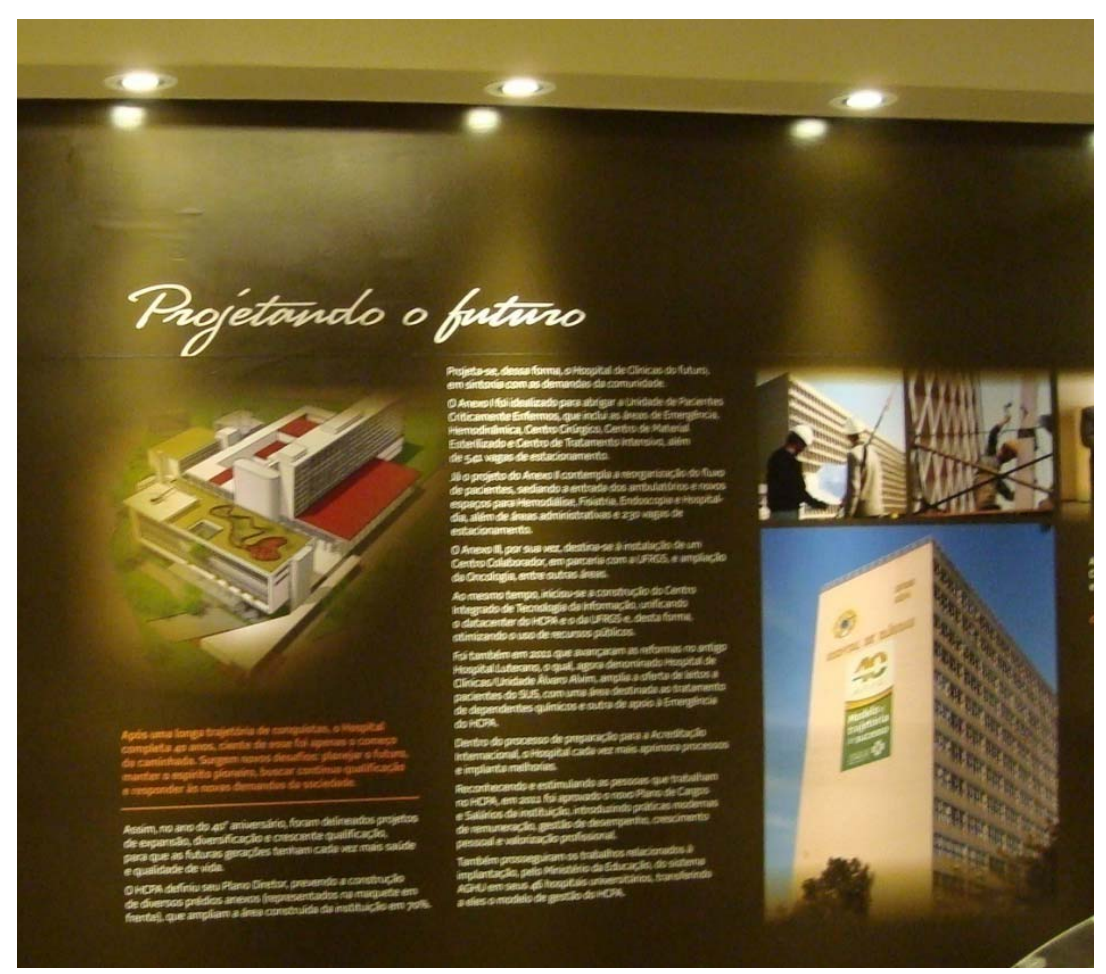

Figura 59. Sala de exposição do projeto, com detalhe para a explicação do projeto. Foto: autora. 


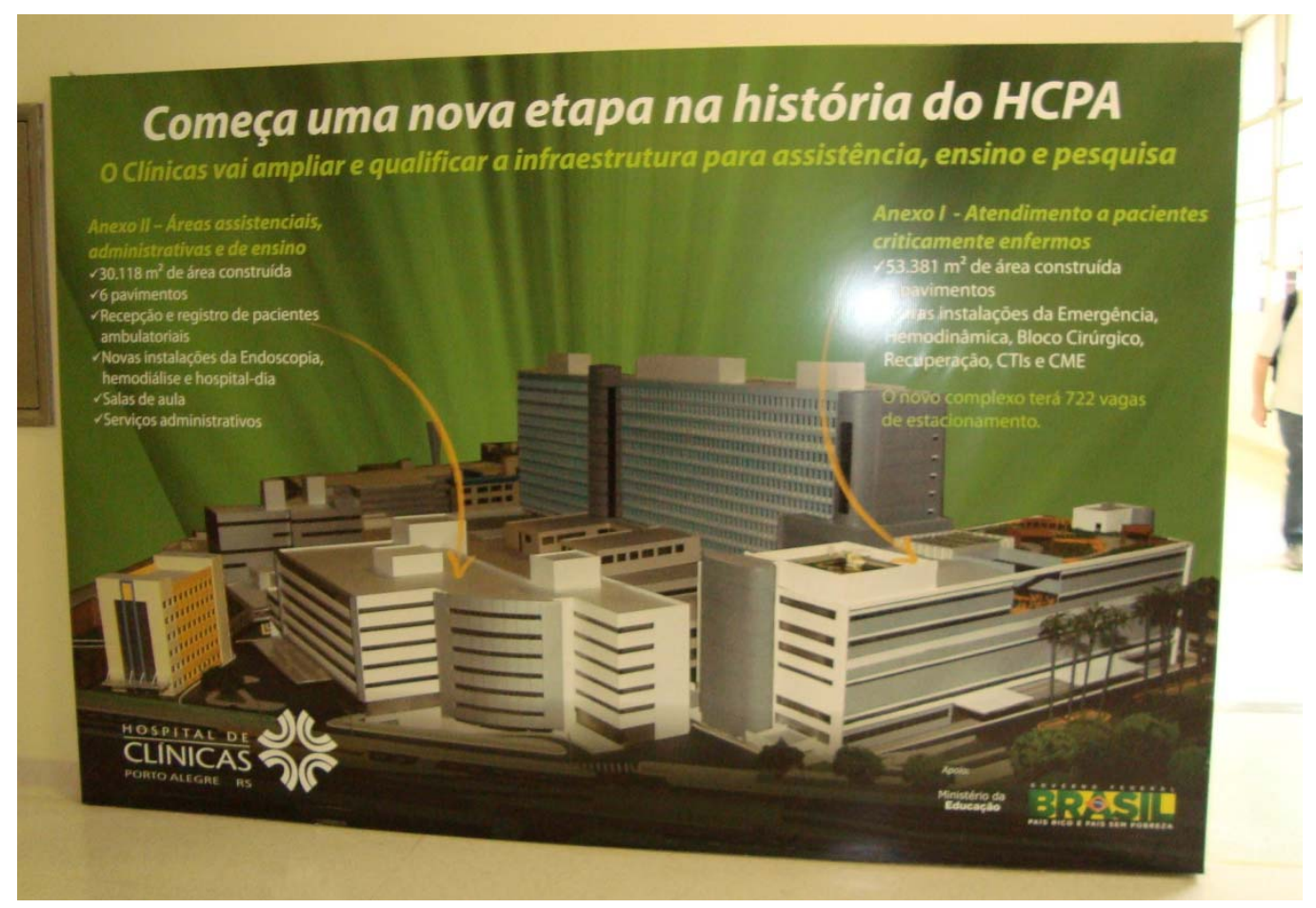

Figura 60. Painel instalado na circulação para informar usuários sobre a intervenção que ocorrerá no complexo do HCPA. Foto: autora.

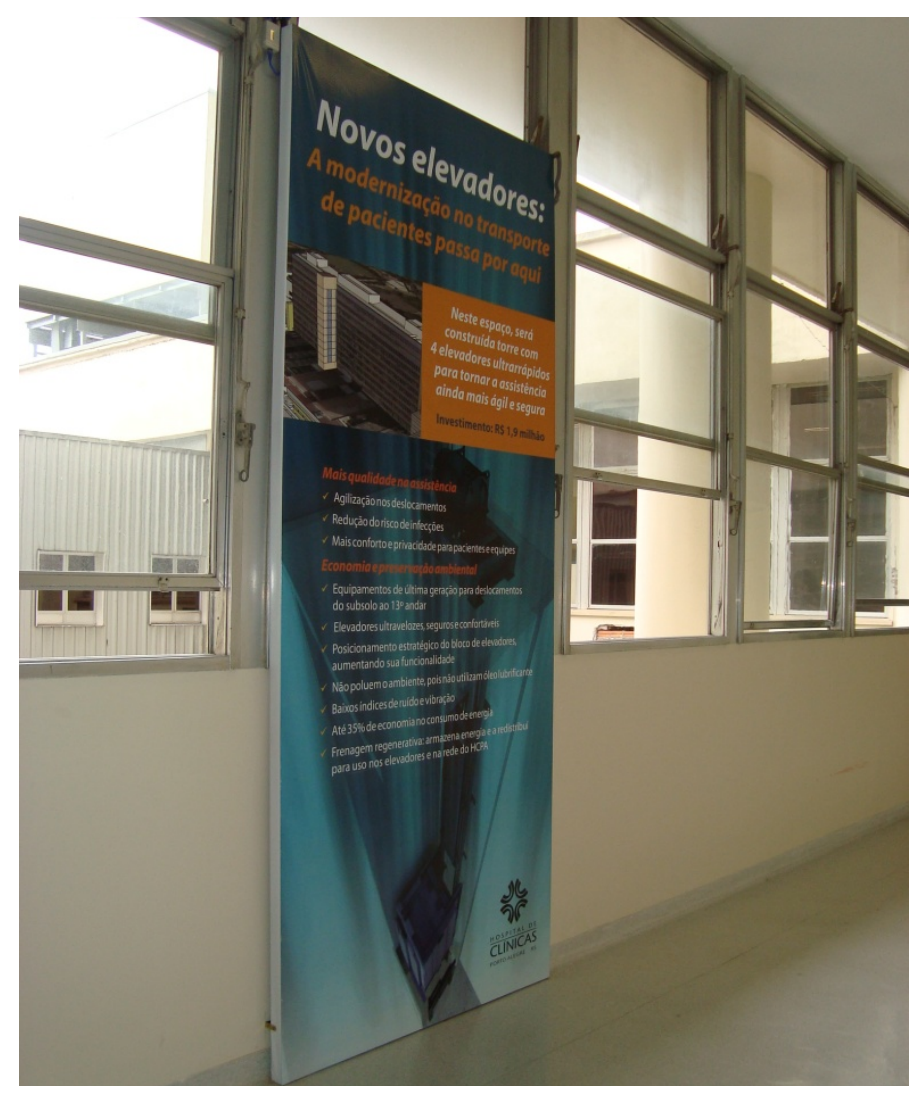

Figura 61. Painel instalado na circulação para informar usuários sobre a intervenção que ocorrerá no complexo do HCPA. Foto: autora. 
Um dos arquitetos entrevistados defende que o envolvimento do usuário é muito importante durante as fases iniciais até a definição do projeto. Após esta etapa, quanto menos o usuário interferir é melhor.

Foi realizada uma licitação para desenvolvimento do projeto executivo, que levou à contratação de um consórcio formado por outras empresas de projeto, distintas da Bross. Atualmente, a obra está sendo realizada, e tem previsão de conclusão para novembro de 2017.

\subsubsection{Análise Intra-Caso - EC-1}

Os resultados do estudo de caso denotam o papel importante dos usuários de edifícios de assistência à saúde no desenho das atividades e fluxos para o projeto dos serviços, o que está de acordo com a revisão bibliográfica. Deste modo, pode-se dizer que o envolvimento dos usuários pode ser benéfico e trazer melhorias para a eficiência operacional dos edifícios, uma vez que o projeto dos serviços pode ser beneficiado pela experiência dos usuários, por viabilizar o ajuste do edifício ao melhor modo de realização das atividades de atendimento à saúde. Por outro lado, o projeto do edifício propriamente dito requer conhecimentos específicos nas disciplinas relacionadas às áreas de arquitetura e engenharia, e sua linguagem tem caráter técnico. Muitas vezes, os usuários não estão acostumados a esta linguagem e às questões que envolvem o projeto, o que dificulta o envolvimento.

Em relação ao tipo de usuário que deve ser envolvido, o EC-1 ressalta a importância de envolver indivíduos que trabalham no edifício de saúde, para aumentar a eficiência operacional, reduzir desperdícios e atender aos requisitos destes usuários. Pela sua experiência no setor, a Empresa acredita que os benefícios do envolvimento da equipe interna do edifício de saúde sejam mais garantidos, porque ela possui conhecimento e experiência sobre a operação do edifício e a cadeia de suprimentos. No entanto, a empresa defende que é mais difícil alcançar benefícios reais com o envolvimento de usuários externos, como pacientes e visitantes, tanto pela grande quantidade e variedade de perfis destes usuários como pelo fato da maior parte deles não permanecer no edifício por tempo suficiente para trazer contribuições importantes para o processo.

Ressalta-se também a importância do envolvimento da presidência do edifício de saúde no processo de projeto, como observado neste EC. O presidente do HCPA foi o coordenador dos usuários e foi envolvido efetivamente no processo. Segundo Rabner (2012), apesar de em muitos casos o presidente do hospital delegar o acompanhamento do projeto a 
terceiros, ele é quem possui qualificações 'excepcionais' para gerenciar a disputa entre as forças políticas e as necessidades organizacionais e conduzir o projeto de forma a refletir as estratégias, os valores e os objetivos operacionais da organização da melhor maneira possível.

Considera-se muito importante que os profissionais de projeto conheçam os processos de realização de serviços, ou seja, quais são as atividades realizadas desde o momento em que o paciente entra no edifício de saúde até o momento que deixa a edificação. Isto permite o alinhamento entre o projeto do espaço físico e o projeto dos serviços. Também permite detectar gargalos e configurações que trazem desperdício de tempo, para redesenhar a cadeia de suprimentos do edifício de saúde, propondo melhorias nos serviços por meio de fluxos estruturados mais adequadamente e da aproximação ou afastamento de setores, de acordo com as necessidades das atividades. Estas melhorias podem gerar valor para os usuários.

Pelos dados levantados no EC-1, o envolvimento dos usuários pode ser descrito pela figura 62. Os resultados sugerem um nível maior de envolvimento dos usuários no projeto dos serviços e menor no projeto da edificação propriamente dita.

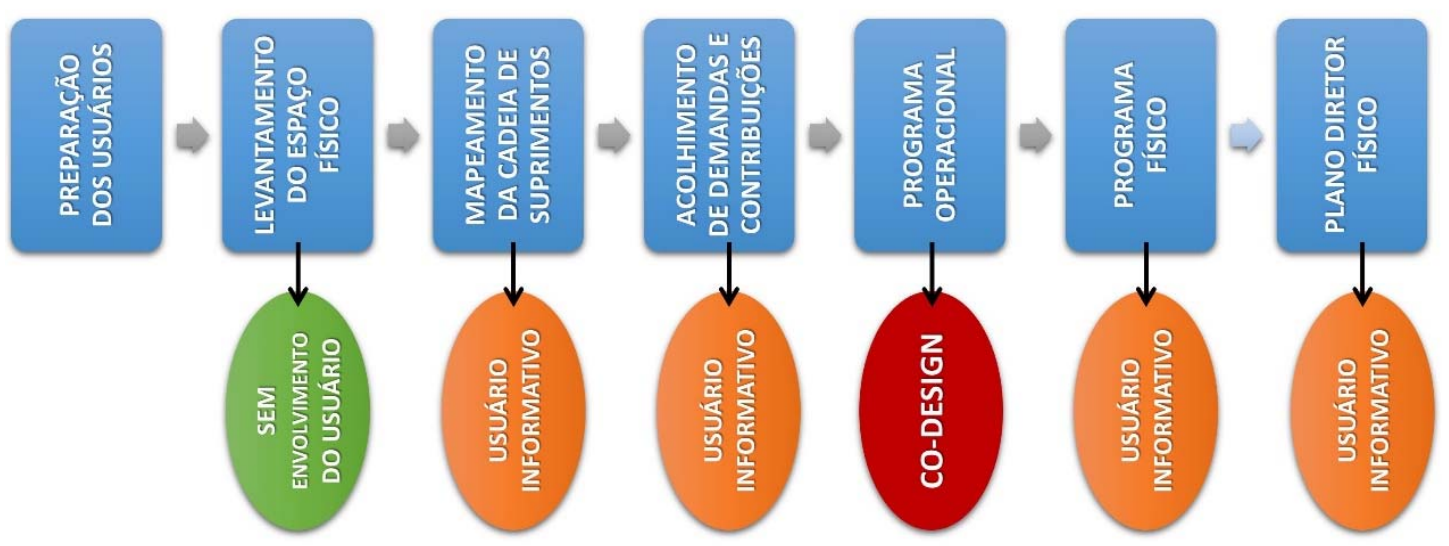

Figura 62. Fases do envolvimento dos usuários ao longo do processo de projeto de intervenção e ampliação do HCPA. Fonte: Elaborada pela autora.

Há certa sobreposição de fases, uma vez que o mapeamento da cadeia de suprimentos ocorreu, em parte, paralelamente ao levantamento do espaço físico. O envolvimento dos usuários se inicia no mapeamento da cadeia de suprimentos, no nível informativo, uma vez que os usuários fornecem as informações necessárias para que os profissionais de projeto realizem este mapeamento. Não há dados disponíveis sobre o número de usuários envolvidos nesta fase, mas sabe-se que todos os setores forneceram as informações necessárias. 
A fase seguinte foi o acolhimento das demandas e contribuições. Nesta fase foram levantados os requisitos norteadores do projeto. Os dados levantados indicam que todos os funcionários do hospital receberam os formulários para expressarem suas opiniões e demandas, mas não há registros de quantos responderam ao questionário, a informação disponível é apenas que foram "muitos". Neste ponto, ressalta-se a importância do coordenador da equipe de usuários para resolver os requisitos conflitantes e determinar os mais importantes. No caso do EC-1, este coordenador foi o presidente do HCPA.

Durante o desenvolvimento do programa operacional, houve o envolvimento dos usuários em nível de co-design. Os representantes dos usuários participaram das reuniões de projeto junto aos representantes dos arquitetos. Não há registro do número exato de representantes dos usuários que participaram, a Empresa apenas informa que foram no máximo cinco pessoas. Um número maior que este, segundo a empresa, inviabiliza o processo, pela dificuldade de coordenação.

Para viabilizar o co-design, o instrumento utilizado foi o diagrama de bolhas. $\mathrm{Na}$ literatura, a definição encontrada para o diagrama de bolhas é a colocada a seguir.

\footnotetext{
Um diagrama de bolha é uma técnica gráfica adotada pelos arquitetos para investigar o edifício como uma rede de elementos funcionais. Usualmente, espaços destinados às atividades previstas no programa são representados como bolhas, cujas medidas podem indicar a sua área e insinuar sua forma preterida. As diversas bolhas são conectadas por linhas que podem indicar propriedades como acessibilidade, conexão visual ou adjacência (VELOSO, 2014, p.115)
}

O uso de instrumentos para promover o co-design foi ressaltado tanto na literatura como no estudo de caso, pois muitos usuários não estão preparados para trazer os resultados esperados pelo seu envolvimento no processo de projeto. Portanto, a grande barreira para o envolvimento efetivo, observada tanto na revisão bibliográfica quanto nas pesquisas de campo, é a linguagem. O diagrama de bolhas é um instrumento que permite que os usuários projetem, expressem suas ideias e entendam o que está sendo projetado pelos demais, devido à linguagem acessível, simplificada e que não demanda conhecimentos em desenho técnico.

Para Steen et al. (2007), a organização de equipes de trabalho multidisciplinares e conversas permitem que os usuários tenham voz no processo e que os arquitetos possam ser inspirados por eles. Caso contrário, o envolvimento de usuários não traz valor ao processo. De 
acordo com o EC-1, o treinamento prévio dos usuários, aliado a esforços para simplificar a representação do projeto, facilitam o envolvimento dos usuários no processo de projeto.

O método utilizado pela empresa, que faz o mapeamento da cadeia de suprimentos e propõe um plano diretor com base num programa operacional, desenvolvido em conjunto com a equipe interna, resultou num projeto que atendeu as expectativas dos usuários, segundo o presidente do HCPA.

Outro ponto observado foi a importância de envolver os usuários para que eles entendessem e aceitassem certas limitações de projeto, aumentando a satisfação com o projeto resultante. Como exemplo, o presidente do HCPA ressaltou que os médicos professores tinham como requisito possuírem salas individuais dentro do HCPA. Entretanto, não havia espaço suficiente para isto, e foi necessário alocar apenas uma sala coletiva de professores. Como os usuários co-projetaram a intervenção e ampliação, eles entenderam e aceitaram a situação final. Segundo Fenker (2012), o aprendizado adquirido pelos usuários envolvidos ao longo do processo de projeto, faz com que o espaço tenha significado para eles e os ajuda a se apropriar deste espaço, pois entendem o porquê de cada decisão.

[...] é o artefato no processo de projeto que implica o envolvimento do cliente e usuário para se tornar um objeto ou espaço de trabalho útil e significativo. $\mathrm{O}$ objeto e sua utilidade para o usuário não é a manifestação de uma estrutura atemporal. É o produto de um processo contínuo de construção de significado que inclui a variedade de conhecimentos disponíveis através das partes envolvidas. 0 curso deste processo, que se iniciou muito antes da entrega do projeto, necessita de constantes correções de acordo com as mudanças das situações de uso (FENKER, 2012, p.240).

\subsection{EC-2: Envolvimento de Usuários nos Processos de Projeto da Kahn do Brasil e Projeto para Construção da Clínica Baum, de Santa CATARINA.}

O segundo estudo de caso foi realizado na Kahn do Brasil, empresa de arquitetura de São Paulo, tendo como objeto de estudo o projeto para a Clínica Baum de Santa Catarina. As fontes de evidência para coleta de dados foram descritas no capítulo 2 . 


\subsubsection{Descrição da Kahn do Brasil}

A empresa é parte de um grupo de sete empresas, cuja primeira foi fundada nos Estados Unidos, em 1895. Foi fundada, em São Paulo, em 1998, e fornece serviços de projetos, planejamento empresarial e consultoria para a América do Sul. É composta por uma equipe multidisciplinar, com especialidades em arquitetura, engenharias (mecânica, elétrica, estrutural e de sistema de TI), paisagismo, design de interiores, planejamento e administração. Possui certificação ISO 9001:2000 e ISO 14001:2004 e, segundo dados levantados junto à empresa, se empenham em documentar seus processos e promover melhorias nos mesmos ${ }^{45}$.

A empresa baseia sua atuação nos seguintes princípios:

- Lean Design, associados ao Lean Construction Institute ${ }^{46}$;

- Sustentabilidade, associados ao Green Building Council dos Estados Unidos ${ }^{47}$ e do Brasil $^{48}$. Em todas as empresas do grupo, mais de $50 \%$ da equipe técnica (cerca de 100 profissionais) são certificados em LEED $^{49}$, e possuem cerca de doze projetos registrados ou certificados em LEED;

- Projeto Baseado em Evidência (Evidence Based Design), através da fundamentação das decisões de projeto e análise de negócios em pesquisas;

- Projeto Centrado no Paciente, possuindo certificação Planetree ${ }^{50}$.

Segundo dados levantados no EC-2, praticamente todos os projetos desenvolvidos pela empresa envolvem os usuários em uma ou mais fases do processo de desenvolvimento, em diferentes níveis. As reuniões com os usuários são chamadas de User Groups, e possuem três modalidades, que ocorrem ao longo do processo de projeto.

\footnotetext{
${ }^{45}$ Fonte: http://www.albertkahn.com/br/index.php, Acesso em 15 ago. 2015.

${ }^{46}$ Fundado em 1997, o Lean Construction Institute (LCI) é uma organização sem fins lucrativos que busca transformar a indústria da construção, utilizando um sistema operacional baseado em princípios fundamentais, linguagem comum e melhores práticas da abordagem Lean (http://www.leanconstruction.org).

${ }^{47}$ USGBC é responsável pela certificação de sustentabilidade LEED, entre outras ações (http://www.usgbc.org).

${ }^{48} \mathrm{GBC}$ do Brasil (http://www.gbcbrasil.org.br).

${ }^{49}$ LEED (Leadership in Energy \& Environmental Design) é um programa de certificação para edifícios sustentáveis (http://www.usgbc.org/leed, acessado em 18 março 2015)

${ }^{50}$ Fundada em 1978 e com parceria com organizações de saúde, Planetree é uma organização sem fins lucrativos que busca o projeto centrado no paciente, para transformar o modo como os pacientes são cuidados (http://planetree.org).
} 
A primeira modalidade é denominada Kick-off, que são reuniões realizadas com os usuários para estabelecer seus requisitos, determinando o alinhamento de seus objetivos e expectativas em relação ao projeto.

Durante o desenvolvimento do projeto, são realizadas as reuniões de discussão de Estudo Preliminar, que configuram a segunda modalidade de User Groups empregada pela Empresa, para permitir ampla discussão sobre a organização espacial da edificação com os usuários.

No final do desenvolvimento do projeto, a terceira modalidade de User Groups são as reuniões de definição de Marcenaria e Mobiliário, em que se estabelecem, junto aos usuários, os recursos e configurações para equipamentos assistenciais.

Em alguns projetos, a Empresa também descreveu a utilização de outros instrumentos e métodos de envolvimento dos usuários. O primeiro exemplo foi do projeto de um centro de oncologia, em que foram realizadas reuniões com grupos de pacientes e familiares para debater expectativas e experiência do paciente. Neste caso, foram envolvidos no processo não apenas os usuários ligados à prestação de serviços, mas também aqueles que os utilizam.

Outro exemplo é o método Futurescan, que prevê a realização de reuniões com os usuários com o intuito de elencar e qualificar tendências que influenciarão o projeto do edifício de saúde, no futuro.

Por fim, outro método destacado é o Gaming, descrito na literatura como Design Game. Por este método, são realizadas sessões de projeto, com envolvimento dos usuários, utilizando um tabuleiro de fundo, com a delimitação do piso/setor, e peças com os tamanhos das salas, em escala, que permitem que o usuário experimente planejar sua área. Este método indica o envolvimento dos usuários em nível de co-design.

\subsubsection{Co-design com usuários: Projeto da Clínica Baum, Santa Catarina.}

Há poucos dados disponíveis para a descrição do projeto e do processo de projeto da Clínica Baum, de Santa Catarina, que se configura como um hospital de 100 leitos. Para a definição da organização interna da UTI deste hospital, foi realizado um Gaming, em que foi envolvida a equipe médica interna atuante no setor.

Algumas fotografias, tiradas durante a realização do Gaming, foram fornecidas pela empresa, e ilustram a dinâmica deste método (figuras 63 a 68). Pelas imagens, é possível visualizar a configuração do tabuleiro - com a delimitação do setor UTI - e das peças, que 
representam os ambientes necessários para conformação deste setor. Os usuários são convidados a dispor as peças sobre o tabuleiro e co-projetar a organização do setor com a equipe de arquitetos.

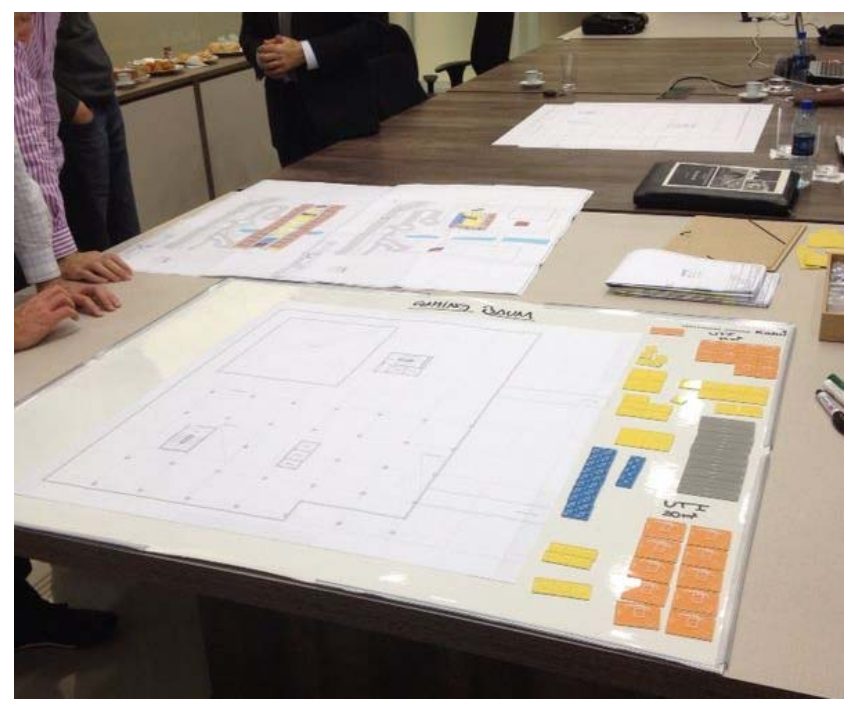

Figura 63. Os usuários observam os instrumentos disponíveis no início do Gaming. Observase o tabuleiro com a delimitação do setor UTI, as peças disponíveis representando os ambientes necessários, e o projeto da edificação, com a localização do setor. Fonte: Foto gentilmente cedida pela Kahn do Brasil.
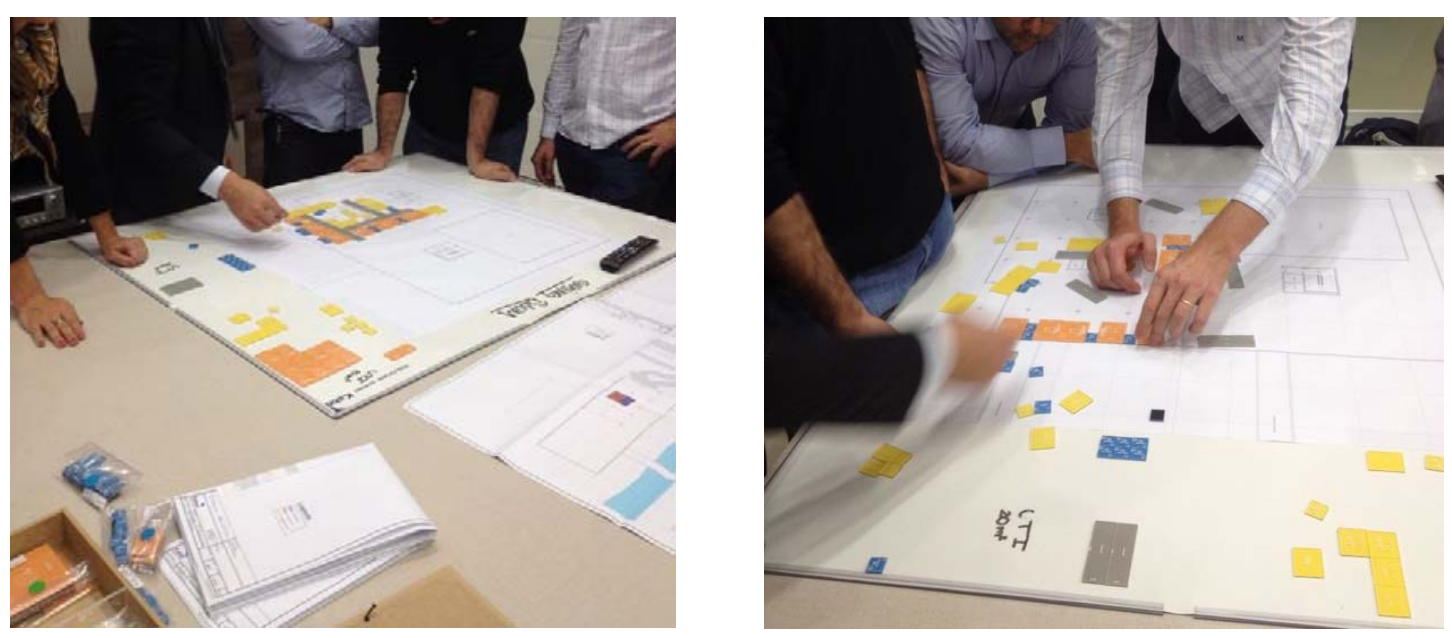

Figura 64. Gaming com usuários no projeto da UTI da Clínica Baum. Fonte: Foto gentilmente cedida pela Kahn do Brasil.

Figura 65. Idem. 

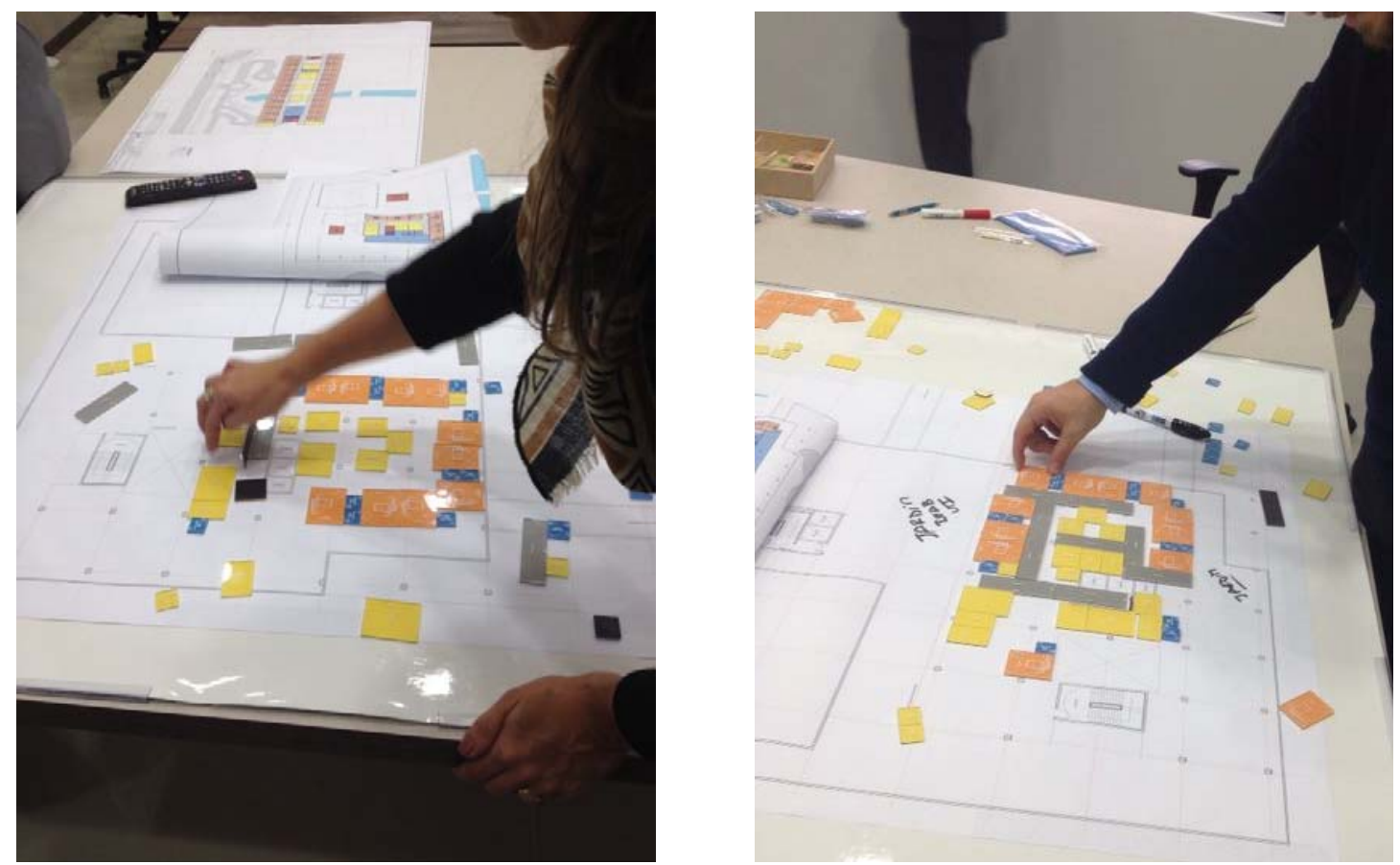

Figura 66. Usuários co-projetando a UTI da Clínica Baum. Fonte: Foto gentilmente cedida pela Kahn do Brasil.

Figura 67. Idem.

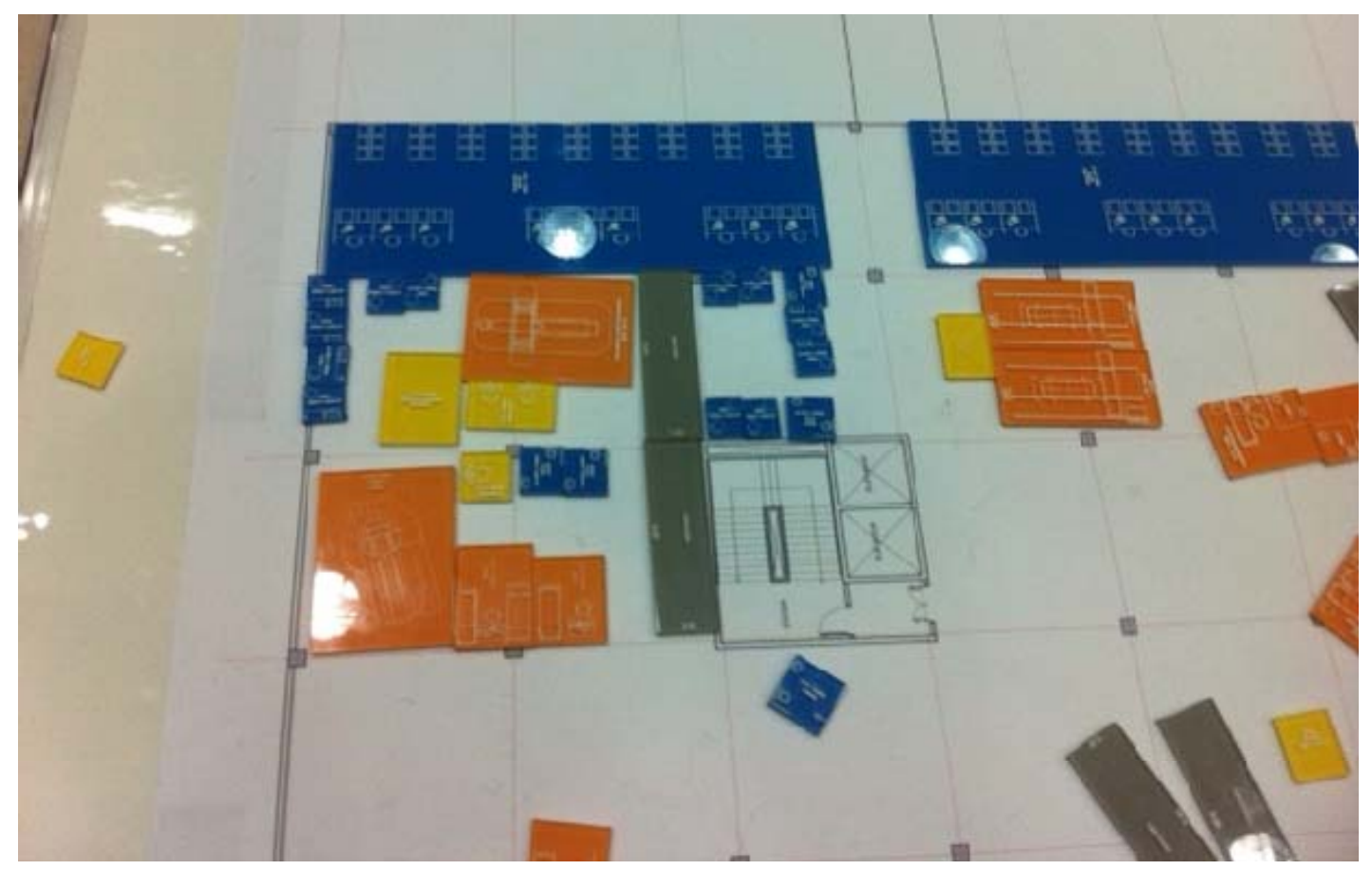

Figura 68. Detalhe do tabuleiro e das peças que compõem o Gaming. Fonte: Foto gentilmente cedida pela Kahn do Brasil. 


\subsubsection{Análise Intra-Caso - EC-2}

Apesar de não ter sido possível atingir a mesma quantidade de dados do EC-1, o EC-2 foi importante para conhecer outra abordagem de envolvimento dos usuários, praticada no Brasil.

O fato de a empresa ser subsidiária de uma grande empresa norte-americana explica as tendências de utilização da abordagem de projeto centrado no paciente - user-centred design - que foi difundida nos Estados Unidos. Esta influência é notada pelas diversas reuniões com usuários para levantamento de suas demandas, intituladas User Groups pela empresa, que ocorrem tanto no início como ao longo do desenvolvimento do projeto. É notada também no fato da empresa começar a envolver pacientes no processo de projeto, e não somente a equipe interna dos edifícios de assistência à saúde, com destaque para a certificação Planetree.

A maior contribuição do EC-2 foi a descrição do método Design Games, que já havia sido estudado na revisão bibliográfica, e foi complementado com imagens de uma situação real ocorrida no país. Apesar de, a princípio, o Design Game aparentar limitar a criação arquitetônica, na verdade ele contribui por abrir novas oportunidades de projeto, na medida em que possibilita ao arquiteto entender a fundo a organização espacial que o usuário está propondo. Assim, com maior conhecimento, o arquiteto pode propor configurações novas ou mobiliário novo, como é o caso da cama-maca, mostrada na Figura 1, projetada por Lelé. Sem este conhecimento aprofundado, o arquiteto pode ficar limitado às descrições contidas nas normas específicas, que determinam as configurações básicas.

Infelizmente, como limitação da pesquisa, não foi possível coletar mais informações sobre o número de participantes e sobre a avaliação dos usuários em relação ao método e ao resultado do projeto, que certamente enriqueceriam a discussão.

\subsection{DISCUSSÃO}

Esta pesquisa contou com a realização de dois estudos de caso. O primeiro e principal, EC-1, contou com múltiplas fontes de evidência, como entrevistas com pessoas-chave, visitas para observação direta, análise de documentos e análise de registros em arquivo. Este estudo teve como objeto o processo de projeto de intervenção e ampliação do HCPA, e foram analisados:

- O projeto desenvolvido; 
- O processo de projeto com diferentes níveis de envolvimento dos usuários ao longo de suas fases;

- A atuação da empresa de arquitetura responsável pelo projeto;

- As dificuldades de envolver os usuários e as saídas utilizadas para contorna-las seleção de usuários a participar e métodos de envolvimento;

- A avaliação do processo pelo ponto de vista do coordenador dos usuários.

O segundo estudo de caso, EC-2, contou com três fontes de evidência: entrevistas com o diretor executivo da empresa, análise de documentos e análise de registros em arquivo. 0 objeto deste estudo foram os métodos e instrumentos de envolvimento dos usuários utilizados pela empresa, citados a seguir:

- Usergroups;

- Futurescan;

- Gaming (Design Games).

O EC-1 permitiu mapear o processo de projeto com envolvimento dos usuários e observar os diferentes níveis de envolvimento ao longo das fases do projeto. Já o EC-2 permitiu apenas a visão geral dos métodos e instrumentos de envolvimento utilizados pela empresa, mas não foi possível mapear o processo de projeto. As empresas de arquitetura possuem perfis parecidos, conforme mostra o quadro 33.

Segundo os resultados dos estudos de caso, a Bross defende o envolvimento apenas dos usuários pertencentes à equipe interna dos edifícios de assistência à saúde, pois estes usuários permanecem mais tempo na edificação e seu envolvimento tem maiores chances de trazer dados relevantes para o projeto, principalmente em relação à eficiência operacional da edificação. Para esta empresa, o envolvimento de pacientes é mais complicado e tem menores chances de contribuição com o projeto. Já a Kahn do Brasil, com forte influência do projeto centrado no usuário norte-americano, já envolveu pacientes e visitantes em projeto, além da equipe interna. 
Quadro 33. Comparação do perfil das empresas participantes dos ECs. Fonte: Elaborado pela autora a partir de dados coletados nos ECs.

\begin{tabular}{|c|c|c|}
\hline & EC-1 & EC-2 \\
\hline $\begin{array}{l}\text { Localização da } \\
\text { Empresa }\end{array}$ & São Paulo - SP & São Paulo - SP \\
\hline Áreas de Atuação & $\begin{array}{c}\text { Planos Diretores, Projetos de Arquitetura } \\
\text { e Complementares, } \\
\text { Coordenação de Projetos, } \\
\text { Acompanhamento e Direção de Obra e } \\
\text { Consultorias. }\end{array}$ & $\begin{array}{c}\text { Planos Diretores, Projetos de Arquitetura } \\
\text { e Complementares, } \\
\text { Coordenação de Projetos, } \\
\text { Acompanhamento, Direção e } \\
\text { Administração de Obra. }\end{array}$ \\
\hline $\begin{array}{l}\text { Número de } \\
\text { Projetistas }\end{array}$ & Mais de 20 & 20 \\
\hline Tempo de atuação & 56 anos & 16 anos \\
\hline Raio de Atuação & Internacional & Nacional \\
\hline Tipos de Projeto & $\begin{array}{l}\text { Edifícios de assistência à saúde e de } \\
\text { Ensino }\end{array}$ & $\begin{array}{l}\text { Projetos Comerciais, Serviços, Industriais, } \\
\text { Edifícios de assistência à saúde }\end{array}$ \\
\hline Principais clientes & Públicos e Privados & Privados \\
\hline $\begin{array}{l}\text { Principal Nível de } \\
\text { Atend. dos Ed. } \\
\text { Saúde Projetados }\end{array}$ & Primário, Secundário e Terciário & Primário, Secundário e Terciário \\
\hline
\end{tabular}

As duas empresas incluem no projeto uma fase de análise de tendências da prestação de serviços, realizada em conjunto com os usuários, que na Kahn do Brasil é denominada Futurescan. Em termos de métodos e instrumentos, as duas empresas realizam reuniões com os usuários, onde acontece o envolvimento. O principal instrumento de co-design descrito pela Bross foi o diagrama de bolhas, enquanto no caso da Kahn foi o gaming. Nos dois casos, destaca-se que o objetivo do emprego de métodos e instrumentos para viabilizar o co-design é a simplificação da linguagem, para permitir que usuários e arquitetos co-projetem e possam ter suas ideias e propostas compreendidas por toda a equipe.

De um modo geral, destaca-se como limitação de pesquisa a dificuldade de se conseguir realizar estudos de caso como estes nas empresas e nos edifícios de assistência à saúde no Brasil. Outros dois estudos de caso foram iniciados e não foi possível levantar dados relevantes para esta pesquisa. Mesmo nos casos aqui apresentados, apesar da gentileza e disposição das empresas que participaram, houve dificuldade de acompanhar os processos

\footnotetext{
${ }^{51}$ O campo relativo ao nível de atendimento das unidades de saúde se refere a: Nível Primário: Postos e Centros de Saúde; Nível Secundário: Unidades Mistas, Ambulatórios Gerais, Hospitais Locais e Regionais com as 4 clínicas básicas; Nível Terciário: Hospitais Regionais e Especializados.
} 
pelo tempo que levam para sua conclusão. No entanto, a escolha do método de Estudo de Caso para aprofundamento da investigação do co-design na prática do país foi avaliada como apropriada e positiva, por permitir compreender como esta abordagem tem sido empregada e registrar detalhes da mesma em âmbito nacional, que ainda não estão disponíveis na literatura. A escolha de dois casos, apesar de possuírem características distintas, foi importante para ampliar os dados levantados e complementar as informações. Como previsto na abordagem DSR, a cooperação entre arquitetos atuantes na prática e o pesquisador foi fundamental para a realização desta pesquisa. 

Tendo em vista o foco do presente trabalho no aspecto organizacional do processo de projeto, para projetar edifícios de assistência à saúde cujo espaço físico esteja alinhado aos serviços realizados para aumentar a eficiência operacional dos serviços de saúde, o presente capítulo apresenta uma proposição inovadora, em forma de modelo do processo de projeto, para viabilizar o co-design com usuários. Considera-se, como já estudado, a potencialidade que envolvimento dos usuários no processo tem em contribuir para o alinhamento almejado entre edificação e serviços.

Um modelo "é um conjunto de proposições ou declarações que expressam as relações entre os constructos" (MARCH; SMITH, 1995, p.256). Com um modelo do processo, as fases que o projeto deve seguir podem ser especificadas, bem como seus pontos de revisão (COOPER, 2001; TZORTZOPOULOS; SEXTON, 2007).

A escolha de um modelo como proposição inovadora tem como base a necessidade de clareza da metodologia de projeto arquitetônico quando o edifício a ser projetado tem funções complexas, como os edifícios de assistência à saúde, requerendo métodos que equacionem as diversas variáveis que estão envolvidas (CARVALHO, 2012). Segundo Vink et al. (2006), um dos fatores responsáveis para o sucesso de um processo é uma abordagem passo a passo. Na mesma linha, van Aken (2005), afirma que é necessário organizar e planejar explicitamente as operações de projeto quando os processos de projeto são complexos ou em larga-escala. Segundo este autor, apesar de a abordagem profissional poder beneficiar processos individuais ou com equipes pequenas, ela é importante principalmente em projetos complexos e de grande escala, em que possíveis falhas dificilmente poderão ser corrigidas por contatos informais entre os membros da equipe. Outros autores defendem também a necessidade de uma estrutura que oriente e organize o envolvimento, como é o caso de (BRANDT, 2006), para que as diversas competências envolvidas - da equipe multidisciplinar e dos usuários - possam ser, de fato, utilizadas.

O presente capítulo apresenta os resultados que atendem aos seguintes objetivos específicos:

- Parte do objetivo específico 1 , referente à determinação das fases do processo de projeto em que o co-design é adequado - ver seção 7.2. (As partes de entendimento 
das questões referentes ao envolvimento dos usuários e ao processo de projeto já foram atendidas nos capítulos anteriores);

- Objetivo específico 3, referente às delimitações dos focos para os quais o modelo se destinará - ver seção 7.1;

- Objetivo específico 5, que prevê a proposição de um modelo de envolvimento dos usuários no processo de projeto de edifícios de assistência à saúde - apresentado na seção 7.3;

- Objetivo específico 6, que se refere à avaliação do modelo proposto, com o auxílio de pesquisadores e projetistas com experiência em projetos de edifícios de assistência à saúde - ver seções 7.4 e 7.5 .

\subsection{DeLIMITAÇÃo dos Focos}

O modelo de processo de projeto com envolvimento de usuários, aqui apresentado, foi desenvolvido considerando focos específicos para projeto, usuários, nível de envolvimento e fases do processo de projeto. Estes focos, apresentados a seguir, foram importantes para permitir maior detalhamento e aprofundamento do modelo.

\subsubsection{Foco 1: Tipo de Projeto}

De acordo com a OMS e a ONU, saúde é um direito humano fundamental (GÓES, 2004). Os edifícios de assistência à saúde, mais precisamente os hospitais, são os componentes principais do sistema de atenção à saúde em países como o Brasil, de renda baixa e média, além de serem os mais onerosos, sendo a referência de todo o sistema de saúde e foco da capacitação profissional na área (LA FORGIA; COUTTOLENC, 2009). Conforme discutido na seção 3.1, a rede atual de atendimento à saúde no país não é suficientemente dimensionada para prestar a atenção necessária à população, principalmente na esfera pública. Some-se a isto a vasta complexidade do projeto destes edifícios (ver seção 3.2). Portanto, a escolha das edificações de saúde como foco do presente trabalho tem como justificativa a promoção de maior eficiência ao atendimento à saúde, através do estudo de meios de melhor adequar o espaço físico à realização dos serviços, e assim contribuir para a melhoria deste cenário. 
Para garantir a eficiência operacional, o projeto do espaço físico precisa estar alinhado ao projeto dos serviços, ou seja, precisa ser elaborado levando em conta os fluxos e as atividades desenvolvidas no edifício, conforme abordado em (FRANCIS, 2002; TZORTZOPOULOS et al., 2006; DICKERMAN; BARACH, 2008; TZORTZOPOULOS et al., 2009; JENSEN, 2011) e confirmado pelos estudos de caso. Portanto, o modelo abrange tanto o projeto do espaço físico como dos serviços.

\subsubsection{Foco 2: Tipos de Usuários}

Conforme abordado na seção 4.1.2, existem diversos tipos de usuários nos edifícios de assistência à saúde, cada um com suas peculiaridades e modos distintos de uso do edifício. Neste sentido, o nível de conhecimento da edificação e o ponto de vista de cada grupo em relação a esta são variáveis, e os resultados do envolvimento de cada grupo serão focados nos seus objetivos. Como a pesquisa aqui proposta busca a promoção de eficiência operacional dos serviços do edifício de saúde, seu foco volta-se para aqueles usuários que operam estes serviços, pois estes poderão contribuir com os dados adequados ao objetivo central deste trabalho. Além disto, a equipe interna é o grupo que mais tempo permanece na edificação, e, portanto, está mais familiarizada com seu funcionamento (BECKER; POE JR., 1980).

O EC-1 destacou que os benefícios do envolvimento da equipe interna são mais garantidos em relação aos outros grupos, porque esta equipe possui conhecimento e experiência sobre a operação do edifício e a cadeia de suprimentos. O envolvimento de usuários externos - por exemplo, pacientes e visitantes - além de trazer maior dificuldade de seleção devido à grande quantidade e variedade de perfis, torna mais difícil o alcance de benefícios, pois a maior parte destes usuários não permanece no edifício por tempo suficiente para conhecê-lo e trazer dados importantes para o processo.

Portanto, entre os grupos de usuários propostos na classificação de Olsson et al. (2010), mostrados no Quadro 21, da seção 4.1.2, o foco aqui é a categoria 'Organização Provedora dos Serviços'. Sua descrição é retomada no Quadro 34.

Quadro 34. Organização Provedora de Serviços. Fonte: Olsson et al. (2010).

\begin{tabular}{|c|l|l|}
\hline Categoria de usuário & \multicolumn{1}{|c|}{ Descrição } & \multicolumn{1}{c|}{ Exemplo } \\
\hline \multirow{2}{*}{$\begin{array}{c}\text { Organização Provedora do } \\
\text { Serviço }\end{array}$} & $\begin{array}{l}\text { Gerente: responsáveis pela administração da } \\
\text { organização provedora. }\end{array}$ & Gerência do EAS. \\
\cline { 2 - 3 } & $\begin{array}{l}\text { Empregados: proveem os serviços. } \\
\text { Médicos e Enfermeiros. }\end{array}$ & Mén. \\
\hline
\end{tabular}


Este recorte se faz necessário para direcionar o modelo aqui proposto, por considerar o perfil e os conhecimentos específicos destes usuários. Ainda assim, ressalta-se que os grupos ou categorias de usuários não são homogêneos, justificando o envolvimento de um número suficiente para representar a maioria, sem inviabilizar tal envolvimento no processo de projeto, pelo aumento dos custos e dos esforços de coordenação.

\subsubsection{Foco 3: Nível de Envolvimento}

Na seção 4.1.1, a revisão bibliográfica descreveu diversas abordagens sobre níveis de envolvimento de usuários, buscando uma convenção referenciada para ser usada na elaboração do modelo. Com base nesta revisão, o nível determinado para ser o foco da pesquisa foi o co-design. Além do co-design, adota-se a proposição de Damodaran (1996) para discussões sobre os demais níveis de envolvimento dos usuários. A figura 69 retoma sucintamente estes níveis.

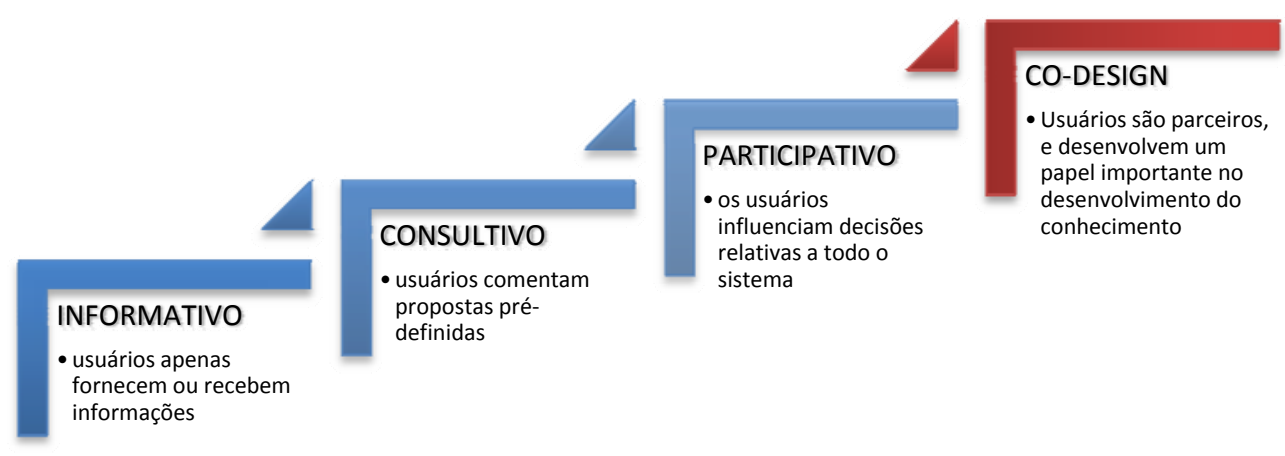

Figura 69. Níveis de envolvimento adotados, em escala crescente de envolvimento, culminando com o co-design. Fonte: Damodaran (1996) e Sanders e Stappers (2008).

Não se teve aqui a intenção de eleger algum nível como melhor em relação aos demais, mas sim de se estudar qual nível seria mais adequado para cada fase do processo de projeto. Como o foco é o co-design, buscou-se na literatura e nas pesquisas de campo estabelecer quando e em que situações este poderia trazer benefícios para o processo e para o produto final. 


\subsection{Níveis de Envolvimento X Fases do Processo de Projeto}

Com base nos resultados da revisão bibliográfica e das pesquisas de campo, já mostrados, levantou-se que o envolvimento efetivo dos usuários é fundamental no início do processo de projeto, quando as decisões que orientarão todo o processo são tomadas, e, segundo Watch, (2001) e Antunes e Calmon (2005), influenciarão definitivamente as etapas seguintes do ciclo de vida da edificação. Além disto, ao fim da fase de projeto conceitual - estudo preliminar - a maior parte dos custos do empreendimento já está comprometida (HICKS et al., 2015).

Ampliando esta discussão para atender ao objetivo específico de se estudar qual nível de envolvimento seria adequado ao longo do processo de projeto, esta seção apresenta a proposta de envolvimento para cada fase deste processo. A ilustração básica parte do texto de Kaulio (1998), que apresenta uma estrutura para analisar algumas abordagens de envolvimento de usuários, identificando-as num gráfico onde o eixo horizontal se refere às fases do processo de projeto em que são empregadas - 'especificação', 'projeto conceitual', 'projeto detalhado', 'prototipagem' e 'produto final' - enquanto o eixo vertical registra o nível de envolvimento - 'projeto para', 'projeto com' e 'projeto por' usuários (Figura 70).

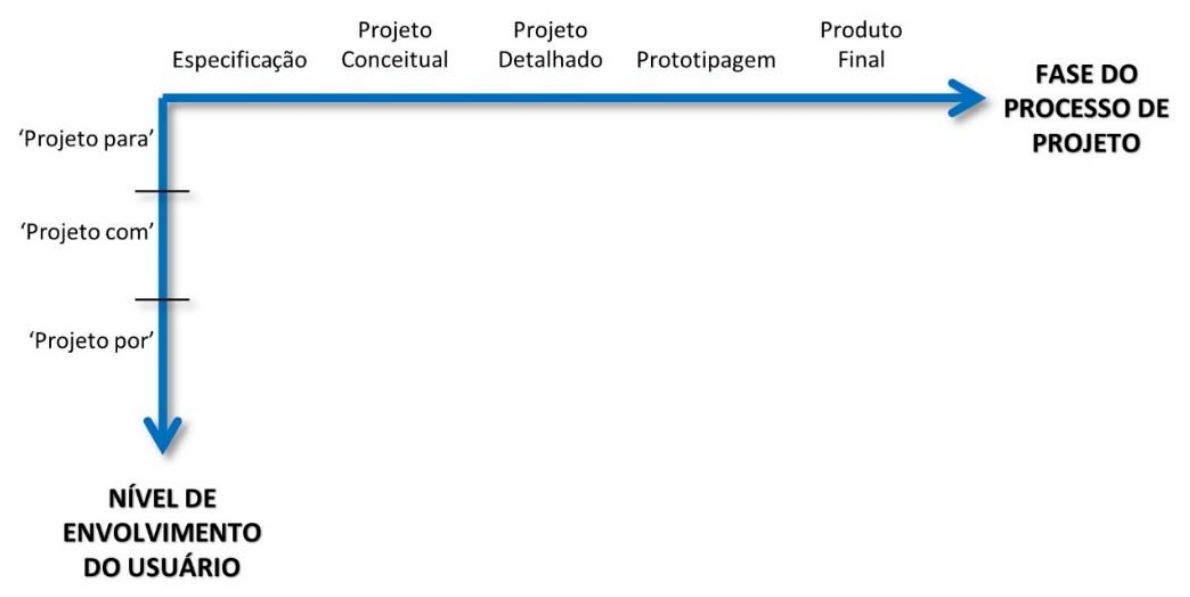

Figura 70. Estrutura para análise de métodos de envolvimento de usuários em desenvolvimento de produtos. Fonte: Kaulio (1998).

Propõe-se, então, uma estrutura similar para indicar o nível de envolvimento adequado para cada fase do processo de projeto, com base nos resultados obtidos através da revisão bibliográfica e das pesquisas de campo (Gráfico 8). Esta estrutura tem como eixo horizontal, portanto, as macrofases e fases do processo de projeto, definidas na seção 3.5, e como eixo vertical os níveis de envolvimento aqui adotados, mostrados na seção 7.1.3. 
Gráfico 8. Nível de envolvimento dos usuários ao longo do processo de projeto de edifícios de assistência à saúde. Fonte: Elaborado pela autora.

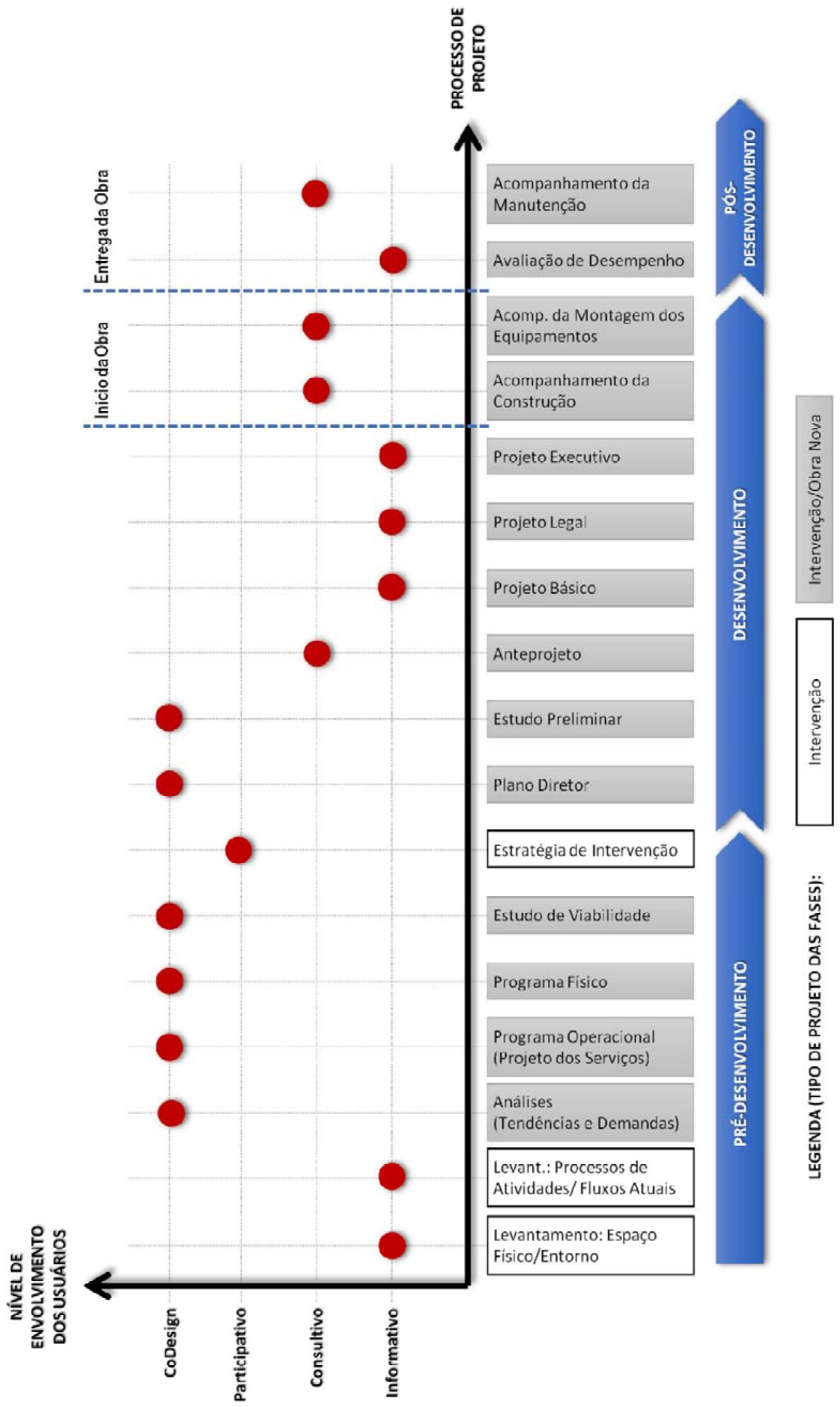


$\mathrm{Na}$ macrofase de pré-desenvolvimento, ocorrem os levantamentos. Como a atividade dos projetistas, nestas fases, se restringe a levantamento e registro dos dados, não há tomada de decisões, e, portanto, os usuários podem contribuir apenas fornecendo informações para os projetistas. Considera-se como nível de envolvimento adequado, portanto, o informativo.

$\mathrm{Na}$ análise de tendências e de mercado, a participação conjunta de profissionais de projeto e dirigentes EASs é importante, para se garantir o fluxo de informações da área necessárias e o conhecimento técnico em projeto, essenciais para estas análises. O nível de envolvimento dos usuários adequado para esta fase, portanto, é o co-design.

Na fase de desenvolvimento do Programa Operacional, em que se esboça o projeto dos serviços, o nível de envolvimento adequado é o co-design, tanto pela contribuição valiosa do conhecimento dos usuários, como para legitimar as decisões tomadas, que impactarão diretamente as atividades diárias da equipe interna.

A fase seguinte é a determinação do programa físico. Novamente, o nível de envolvimento considerado adequado para esta fase é o co-design, dada a necessidade de a equipe interna ter voz ativa no dimensionamento da edificação.

Na sequência, a fase é a de estudo de viabilidade econômica. Segundo dados levantados no EC-1, este estudo é realizado, em geral, por consultores externos. Os profissionais de projeto e a direção do empreendimento de saúde fornecem os dados necessários para a realização do estudo. Neste sentido, os usuários seriam informativos. No entanto, os dados levantados no EC-1 mostram que, caso os resultados apontem a inviabilidade do empreendimento, podem ser feitas alterações no planejamento, requerendo atuação integrada de membros do empreendimento, profissionais de projeto e outros profissionais consultores, com o intuito de viabilizar o empreendimento. Podem ser realizadas simulações tanto com alteração de valores do terreno, construção e equipamentos, para reduzir investimentos, quanto através da busca por outras fontes de captação de recursos, para ampliar receitas (BROSS, 2010). Assim, o nível de envolvimento adequado é o co-design, pois estas simulações podem impactar a configuração do edifício, em termos de operação e espaço físico.

Em caso de obras de intervenção, a fase seguinte é a de determinação da estratégia de intervenção. O que se defende aqui é o nível participativo, pois os usuários podem influenciar decisões sobre quais setores são críticos para as atividades específicas do edifício de saúde em questão, mas a decisão final sobre a estratégia cabe aos profissionais de projeto, por possuírem conhecimentos técnicos necessários para planejar a obra. 
Pelo modelo do processo de projeto aqui considerado, a macrofase de desenvolvimento se inicia pelo plano diretor do espaço físico do empreendimento. Para tanto, faz-se necessário, novamente, a atuação conjunta de profissionais de projeto e membros da organização provedora dos serviços de saúde, para que a soma de seus conhecimentos possa resultar num plano diretor físico viável. O nível de envolvimento adequado, portanto, é o codesign.

No estudo preliminar (de arquitetura), o que se propõe é que os profissionais de projeto utilizem instrumentos para viabilizar o co-design como nível de envolvimento adequado durante a produção do estudo preliminar. Entretanto, a representação final do estudo preliminar deverá permanecer a cargo dos profissionais de projeto, por se tratar de desenho técnico, que requer conhecimentos específicos de arquitetura, o que dificulta a participação dos usuários.

Já o anteprojeto (de arquitetura) é uma fase que requer a atuação de arquitetos, em que os usuários pouco podem contribuir, segundo a pesquisa. O nível de envolvimento adequado aqui proposto é o consultivo, para que os usuários possam aprovar decisões que forem necessárias, ou escolher entre alternativas possíveis, quando for o caso.

Pode-se dizer que as definições que pressupõem envolvimento dos usuários são tomadas até este momento do processo de projeto e, nas demais fases de projeto desenvolvimento de projetos básico, legal, complementares e executivos - as decisões são de caráter técnico construtivo e ficam a cargo dos profissionais de projeto, pois estas fases contemplam a preparação dos desenhos para aprovação junto aos órgãos competentes e para construção. Se forem necessárias alterações na concepção do espaço físico, geralmente é necessário que o projeto retorne a fases anteriores, em que os usuários podem compartilhar decisões. Mediante o exposto, o nível de envolvimento considerado adequado para estas fases é o informativo, para que os usuários possam estar a par da evolução do processo de projeto.

Após o início da obra, as fases são acompanhamento da construção e da montagem dos equipamentos. O nível proposto como adequado é o consultivo, pois nesta fase, muitas vezes surgem situações que pressupõem intervenção dos profissionais de projeto, e estes podem consultar os usuários sobre suas preferências dentre as soluções possíveis.

Após a entrega da obra, na macrofase de pós-desenvolvimento, as fases são de avaliação de desempenho e acompanhamento da manutenção. Na avaliação de desempenho, os usuários são envolvidos como informantes, pois a avaliação exige conhecimentos técnicos específicos, com coleta de informações junto aos usuários.

O acompanhamento da manutenção por profissionais de projeto com conhecimento da edificação é importante para garantir a qualidade da manutenção. O nível considerado 
adequado para o envolvimento do usuário é o consultivo, uma vez que podem ser necessárias decisões sobre determinadas ações de manutenção, que envolvem recursos físicos e podem gerar interferências nas atividades. Neste caso, a organização responsável pelo EAS deve ser consultada sobre as opções de que dispõe.

\subsection{VERSÃo INICIAL DO MODELO}

Propõe-se aqui um modelo genérico de processo de projeto para viabilizar o co-design com usuários em projetos de edifícios de assistência à saúde, que funciona como um 'passo a passo' para orientar os arquitetos no envolvimento da equipe interna destes edifícios durante as fases iniciais do processo de projeto (figura 71). Baseado no Gráfico 8 e nos focos já definidos, o modelo aqui proposto se restringe, portanto, às fases onde o co-design foi indicado como nível adequado:

- Análise de Tendências e Demandas;

- Programa Operacional (Projeto dos Serviços);

- Programa Físico;

- Estudo de Viabilidade (EV)

- Plano Diretor Físico;

- Estudo Preliminar.

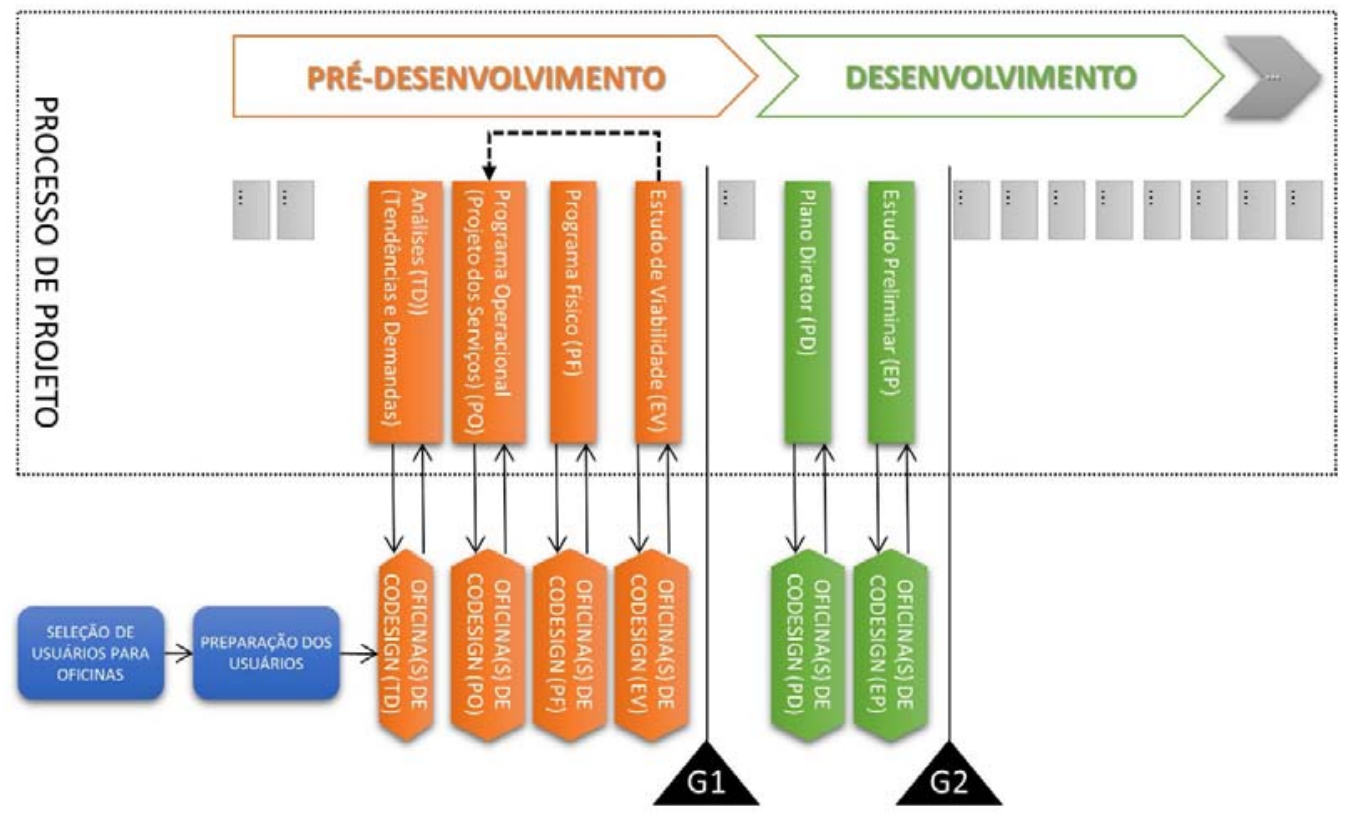

Figura 71. Modelo conceitual de processo de projeto com co-design. Fonte: Elaborado pela autora. 
O modelo conta também com a descrição do processo de seleção dos representantes dos usuários que participarão das oficinas de co-design, indicando as questões que devem ser consideradas pela coordenação. Descreve como os usuários deverão ser preparados para o processo, apresentando os pontos que devem ser esclarecidos antes de seu início, para aumentar a efetividade do mesmo. Apresenta ainda uma estrutura para orientar as oficinas e as revisões de fases, indicando quais devem ser as entradas, os métodos e instrumentos utilizados, e as saídas esperadas, no caso das oficinas, e os subprodutos para análise, os critérios de passagem e o conteúdo dos relatórios de revisão, no caso das revisões de fase.

\subsubsection{Seleção de Representantes dos Usuários}

\begin{tabular}{|l|c|}
\hline \multicolumn{2}{|c|}{ FUNDAMENTAÇÃo } \\
\hline Revisão bibliográfica & Seção 4.2.3 \\
\hline Pesquisa Empírica & Seções 5.1.3, 6.1.4 e 6.1.5 \\
\hline
\end{tabular}

Nesta fase, deverão ser selecionados representantes dos usuários para participarem das oficinas de co-design. Deve-se considerar que as diversas categorias de usuários da organização prestadora de serviços deverão ser representadas, no entanto, deve-se também balizar que um grande número de representantes dificulta a realização das oficinas por aumentar a necessidade de coordenação do projeto. Apurou-se, no EC-1, que o número de representantes geralmente selecionados por aquela empresa é, no máximo, cinco.

Dada a diversidade de foco das oficinas de cada fase, é recomendado que os representantes dos usuários sejam escolhidos considerando suas habilidades específicas em relação a estes diferentes focos. Isto significa que, para cada fase, diferentes representantes podem ser escolhidos.

Os representantes dos usuários serão encarregados tanto por levantar informações junto aos usuários que representam, para discuti-las nas oficinas, como por tomar decisões em nome deles. Após as oficinas, são encarregados de transmitir as decisões para os representados.

É importante ressaltar o papel destes representantes como co-projetistas durante as oficinas, por meio de ferramentas fornecidas pela coordenação do processo de projeto. Caso contrário, esta participação pode ter pouca influência, como apontado por Cotton et al.(1988), que classifica a participação por representantes como formal, mas com média ou baixa influência nos resultados, pois o poder dos representantes tende a variar desde um voto na diretoria a até mesmo apenas dar conselhos. 


\subsubsection{Preparação dos Usuários}

\begin{tabular}{|l|c|}
\hline \multicolumn{2}{|c|}{ FUNDAMENTAÇÃo } \\
\hline Revisão bibliográfica & Seção 4.2.2 \\
\hline Pesquisa Empírica & Seções 6.1.4 e 6.1.5 \\
\hline
\end{tabular}

A preparação dos usuários é importante para o sucesso no envolvimento, pois, juntamente com o uso de ferramentas que viabilizem a comunicação entre usuários e profissionais de projeto, faz com que estes usuários entendam o processo e possam participar efetivamente do mesmo. Caso contrário, a abordagem pode não gerar benefícios ou, segundo Malard et al.,(2002), servir apenas como meio para dar legitimidade às decisões dos arquitetos.

Propõe-se neste modelo genérico que esta fase seja composta por reuniões com os usuários e material de apoio para que os mesmos possam obter o entendimento necessário sobre o processo de projeto que ocorrerá e o papel que cada um deverá desempenhar durante o mesmo. Segundo Tzortzopouloset al. (2006), é necessário prover os usuários dos seguintes conhecimentos:

- Fases do projeto e da construção;

- Atividades que irão desempenhar;

- Tipos de decisões a serem tomadas em cada fase;

- Consequências das alterações de projeto para o processo;

- Nível de detalhes das informações que devem fornecer.

Segundo os autores mencionados, o bom esclarecimento dos usuários nestes tópicos pode leva-los ao alocamento de recursos apropriados, ao fornecimento de apoio e informações quando necessários e aos esforços demandados para o projeto.

Além disto, muitas vezes os usuários se acostumam a executar o serviço numa configuração não apropriada, e no novo projeto tendem a reproduzir esta configuração. Neste sentido, durante a preparação dos usuários, é necessário estimulá-los a pensar em como o novo ambiente facilitaria seu trabalho. Os profissionais de projeto também precisam ter as normas e regulamentações técnicas em vigor como orientadoras das configurações dos ambientes, e orientar os usuários sobre suas restrições. 


\subsubsection{Oficinas de Co-design}

\begin{tabular}{|l|c|}
\hline \multicolumn{2}{|c|}{ FUNDAMENTAÇÃo } \\
\hline Revisão bibliográfica & Seção 4.2.4 \\
\hline Pesquisa Empírica & Seções 6.1.4, 6.1.5 e 6.2.1 \\
\hline
\end{tabular}

As oficinas precisam ser planejadas levando em consideração horários e locais que facilitem o comparecimento dos usuários. O trabalho de Carayon e Smith (2000) destaca a necessidade de mais pesquisas neste campo para estudar os impactos negativos - como, por exemplo, aumento de pressão e jornada de trabalho - que podem ser gerados pelo envolvimento dos usuários. Neste sentido, no projeto relatado em Garde e van der Voort (2012), os usuários participaram durante seus expedientes para não aumentar suas cargas horárias.

No modelo aqui desenvolvido, são previstas Oficinas nas seis fases onde o co-design foi proposto como nível de envolvimento adequado. 0 quadro 35 apresenta estas fases e a descrição das entradas, instrumentos e subprodutos de cada oficina.

Quadro 35. Descrição das Oficinas de Co-design - Versão inicial. Fonte: Elaborado pela autora.

\begin{tabular}{|c|c|c|c|}
\hline OFICINA & ENTRADAS & $\begin{array}{c}\text { MÉTODOS/INSTRUMENT } \\
\text { OS }\end{array}$ & SUBPRODUTO \\
\hline $\begin{array}{l}\text { Análises de } \\
\text { Tendências e } \\
\text { Demandas } \\
\text { (TD) }\end{array}$ & $\begin{array}{l}\text { Levantamentos de tendências e } \\
\text { de perfil dos consumidores } \\
\text { potenciais }\end{array}$ & Discussões em grupo & $\begin{array}{l}\text { Memorial com Diretrizes de } \\
\text { Projeto, indicando serviços a } \\
\text { oferecer, sua capacidade inicial e } \\
\text { previsões de expansão. }\end{array}$ \\
\hline $\begin{array}{l}\text { Programa } \\
\text { Operacional } \\
\text { (PO) }\end{array}$ & Subproduto de TD & $\begin{array}{l}\text { Instrumentos Generativos para } \\
\text { lembrar, pensar (ex. Análise do } \\
\text { fluxo de tarefas), mapear e } \\
\text { imaginar (ex. Diagrama de } \\
\text { Bolhas); } \\
\text { - Design Games Exploratórios } \\
\text { (Cenário) }\end{array}$ & $\begin{array}{lcr}\text { Diagrama dos } & \text { serviços } \\
\text { oferecidos, com a } & \text { previsão e } \\
\text { subdivisão dos } & \text { setores, } \\
\text { atividades e fluxos } & \end{array}$ \\
\hline $\begin{array}{l}\text { Programa } \\
\text { Físico (PF) }\end{array}$ & $\begin{array}{l}\text { Subprodutos de TD e PO; } \\
\text { Tabelas de dimensionamento e } \\
\text { quantificação de ambientes da } \\
\text { RDC n } 50\end{array}$ & Discussões em grupo & $\begin{array}{l}\text { Descrição e Quantificação dos } \\
\text { setores e ambientes que } \\
\text { comporão a edificação. }\end{array}$ \\
\hline $\begin{array}{l}\text { Estudo de } \\
\text { Viabilidade } \\
\text { (EV) }\end{array}$ & Subprodutos de PO e PF. & Discussões em grupo & $\begin{array}{l}\text { Relatório do EV (planilhas de } \\
\text { custos do empreendimento/ fluxo } \\
\text { de caixa/ etc.) }\end{array}$ \\
\hline $\begin{array}{l}\text { Plano Diretor } \\
\text { Físico (PD) }\end{array}$ & Subprodutos do PO, PF e TD. & $\begin{array}{l}\text { Instrumentos Generativos para } \\
\text { mapear e imaginar (ex. Modelos } \\
\text { 3D); } \\
\text { Design Games Exploratórios; }\end{array}$ & $\begin{array}{l}\text { Implantação da edificação no } \\
\text { terreno, com propostas de } \\
\text { crescimento possíveis. Os } \\
\text { desenhos serão desenvolvidos } \\
\text { posteriormente pelos arquitetos } \\
\text { para apresentação final. }\end{array}$ \\
\hline $\begin{array}{l}\text { Estudo } \\
\text { Preliminar } \\
\text { (EP) }\end{array}$ & Subprodutos do PO, PF e PD. & $\begin{array}{l}\text { Instrumentos Generativos para } \\
\text { mapear e imaginar (ex. Modelos } \\
\text { 3D); } \\
\text { Design Games Exploratórios. } \\
\text { Brainstorming }\end{array}$ & $\begin{array}{l}\text { Proposta esquemática de } \\
\text { Plantas dos pavimentos e } \\
\text { fachadas, que serão } \\
\text { posteriormente desenvolvidas } \\
\text { pelos arquitetos apara o nível de } \\
\text { EP. Perspectivas, Maquetes e } \\
\text { outros produtos são opcionais. }\end{array}$ \\
\hline
\end{tabular}


Os instrumentos e método indicados foram apresentados na seção 4.2 .4 e são sucintamente descritos no quadro 36 .

Quadro 36. Resumo dos instrumentos e métodos indicados. Fonte: Elaborado pela autora.

\begin{tabular}{|c|c|c|c|}
\hline $\begin{array}{c}\text { MÉTODO/ } \\
\text { INSTRUMENTO }\end{array}$ & DESCRIÇÃO & EXEMPLO & FONTE \\
\hline $\begin{array}{l}\text { Instrumentos } \\
\text { Generativos (IG) } \\
\text { (Ver Quadro 24, } \\
\text { seção 4.2.4) }\end{array}$ & $\begin{array}{c}\text { Uma nova linguagem de projeto } \\
\text { para o co-design, a ser utilizada } \\
\text { pelos stakeholders e projetistas } \\
\text { nas primeiras fases do processo } \\
\text { de projeto, para se } \\
\text { comunicarem de modo visual e } \\
\text { direto. }\end{array}$ & $\begin{array}{c}\text { IG para lembrar (imagens e } \\
\text { textos); para pensar (diagramas } \\
\text { para ciclos); para mapear } \\
\text { (diagramas para criar soluções, } \\
\text { modelos 3D); para imaginar uma } \\
\text { situação futura (modelos 3D) e } \\
\text { para sentir - expressar emoções } \\
\text { (figuras, etc.) }\end{array}$ & (Sanders, 2006) \\
\hline $\begin{array}{l}\text { Design Games } \\
\text { Exploratórios (DGE) } \\
\text { (baseado em } \\
\text { Cenários) }\end{array}$ & $\begin{array}{c}\text { O método DGE pode ser usado } \\
\text { para estruturar as atividades de } \\
\text { projeto sem restringir a } \\
\text { criatividade, através da } \\
\text { delimitação de 'regras do jogo'. } \\
\text { O instrumento cenário descreve } \\
\text { uma situação de uso, em que se } \\
\text { permitem alterações e } \\
\text { negociações. }\end{array}$ & $\begin{array}{l}\text { Jogos de Tabuleiros } \\
\text { representando: - o terreno do } \\
\text { edifício, onde as peças podem } \\
\text { configurar os ambientes; } \\
\text { - O pavimento tipo, com peças } \\
\text { representando os usuários, para } \\
\text { descrever as atividades; } \\
\text { - Etc. }\end{array}$ & $\begin{array}{l}\text { (Brandt e } \\
\text { Messeter, 2004; } \\
\text { Brandt, 2006; } \\
\text { Garde e Van der } \\
\text { Voort, 2012; } \\
\text { Vaajakallio, } \\
\text { 2012) }\end{array}$ \\
\hline Brainstorming & $\begin{array}{l}\text { "(literalmente: "tempestade } \\
\text { cerebral" em inglês) ou } \\
\text { tempestade de ideias, mais que } \\
\text { uma técnica de dinâmica de } \\
\text { grupo, é uma atividade } \\
\text { desenvolvida para explorar a } \\
\text { potencialidade criativa de um } \\
\text { indivíduo ou de um grupo - } \\
\text { criatividade em equipe - } \\
\text { colocando-a a serviço de } \\
\text { objetivos pré-determinados" }\end{array}$ & & $\begin{array}{c}<\text { http://pt.wikip } \\
\text { edia.org/wiki/Br } \\
\text { ainstorming>, } \\
\text { acesso em } 04 \\
\text { nov. } 2010 .\end{array}$ \\
\hline
\end{tabular}

7.3.4 Gates - Revisões de Fases

FUNDAMENTAÇÃO

\begin{tabular}{l|l} 
Revisão bibliográfica & Seção 3.3 .5
\end{tabular}

São propostas duas revisões de fases, ou gates, denominados G1 e G2, que tem como finalidade verificar se os subprodutos já produzidos atendem aos requisitos dos usuários. Portanto, são estruturados por três elementos principais, baseados em Cooper (2011):

- Subprodutos para análise;

- Critérios de passagem: critérios previamente estabelecidos;

- Relatório de revisão: aprovação dos subprodutos ou indicação de revisões. 
O Quadro 37 traz a estrutura das duas revisões de fases propostas, indicando sua localização no processo de projeto e descrevendo os elementos supracitados. O G1 acontece após o Estudo de Viabilidade porque este pode implicar em alterações nos programas operacional e físico.

Quadro 37. Estrutura das Revisões de Fases. Fonte: Elaborado pela autora.

\begin{tabular}{|c|c|c|c|c|}
\hline GATE & QUANDO? & $\begin{array}{l}\text { SUBPRODUTOS } \\
\text { PARA ANÁLISE }\end{array}$ & CRITÉRIOS DE PASSAGEM & RELATÓRIO DE REVISÃO \\
\hline G1 & $\begin{array}{l}\text { Ao final do Estudo } \\
\text { de Viabilidade } \\
\text { (Macrofase de } \\
\text { Planejamento) }\end{array}$ & $\begin{array}{l}\text { - Programa } \\
\text { Operacional; } \\
\text { - Programa Físico; }\end{array}$ & $\begin{array}{l}\text { Análise de Tendências e de } \\
\text { Demandas; } \\
\text { Requisitos dos Usuários, } \\
\text { levantados ao longo das } \\
\text { Oficinas; }\end{array}$ & $\begin{array}{l}\text { - Aprovar os subprodutos } \\
\text { ou indicar revisões; } \\
\text { - Definir critérios de } \\
\text { passagem para o G2 }\end{array}$ \\
\hline G2 & $\begin{array}{l}\text { Ao final do Estudo } \\
\text { Preliminar } \\
\text { (Macrofase de } \\
\text { Projeto) }\end{array}$ & $\begin{array}{l}\text { - Plano Diretor; } \\
\text { - Estudo Preliminar. }\end{array}$ & Definidos na revisão do G1 & $\begin{array}{lr}\text { - Aprovar os subprodutos } \\
\text { ou indicar revisões; } \\
\text { - Avaliar a experiência de } \\
\text { co-design, } \\
\text { aprendizado } \\
\text { retroalimentação } \\
\text { processo. }\end{array}$ \\
\hline
\end{tabular}

\subsection{AvaliaçÃo do Modelo InICIAL}

\subsubsection{Avaliação do Modelo: Resultados}

O processo de avaliação do modelo, descrito na seção 2.2.3, teve como objetivo checar a potencialidade do modelo em auxiliar os arquitetos no envolvimento dos usuários em codesign, tendo potencialidade para aplicação em projetos reais, e também aprimorá-lo com base nas críticas dos avaliadores. Os resultados obtidos são apresentados a seguir.

\subsubsection{Avaliador 1}

O Avaliador 1 respondeu à avaliação por contato telefônico, complementado por imagem enviada por correio eletrônico. Este avaliador é o arquiteto diretor de uma empresa em São Paulo, com mais de 50 anos no mercado.

Sobre as fases do modelo, o Avaliador 1 ressalta que o 'Programa Físico' não é definitivo, e precisa passar por reciclagens ao longo do processo de projeto. Este programa é a peça-chave para o arquiteto trabalhar. Assim, este avaliador defende que, durante o pré- 
desenvolvimento, seja realizado um 'esboço' do Programa Operacional, seguido de um 'esboço' do Programa Físico e do partido arquitetônico, que permitem dimensionar o terreno a ser adquirido para o empreendimento. De posse deste esboço e do terreno idealizado, é possível realizar a 'pré-viabilidade econômica'. Esta pré-viabilidade permite avaliar os custos de construção e de operação do empreendimento, e se as receitas geradas serão suficientes para cobrir o investimento e os custos de operação.

Se a pré-viabilidade indicar que não haverá retorno suficiente, devem ser realizadas simulações para adequar o empreendimento. Estas simulações podem alterar o programa operacional, ou o programa físico, os tipos de serviços, a 'quantidade' de serviços prestados, etc.

- Simular programa operacional: se o entrave for a produção;

- Simular programa físico: se o entrave for espaço;

- Simular investimento: se o entrave for os recursos financeiros.

É justamente neste momento de simulações que o Avaliador 1 considera fundamental o codesign - que ele denomina co-decisão. A presença dos usuários para 'ajustar' os serviços ao orçamento é considerada fundamental. O diagrama apresentado na Figura 72 mostra as fases do Pré-desenvolvimento propostas pelo Avaliador 1, ilustrando o 'loop' de esboço dos programas e as simulações de viabilidade possíveis.

De acordo com o Avaliador 1, se não houver esta pré-viabilidade para ajustar o planejamento do empreendimento, ou seja, este estudo de investimento frente ao retorno de receitas, corre-se o risco de tornar a operação do empreendimento inviável financeiramente, uma vez que, mesmo edifícios bem resolvidos arquitetonicamente e com o empreendimento operando em todo seu potencial, pode-se não conseguir o retorno dos investimentos. 


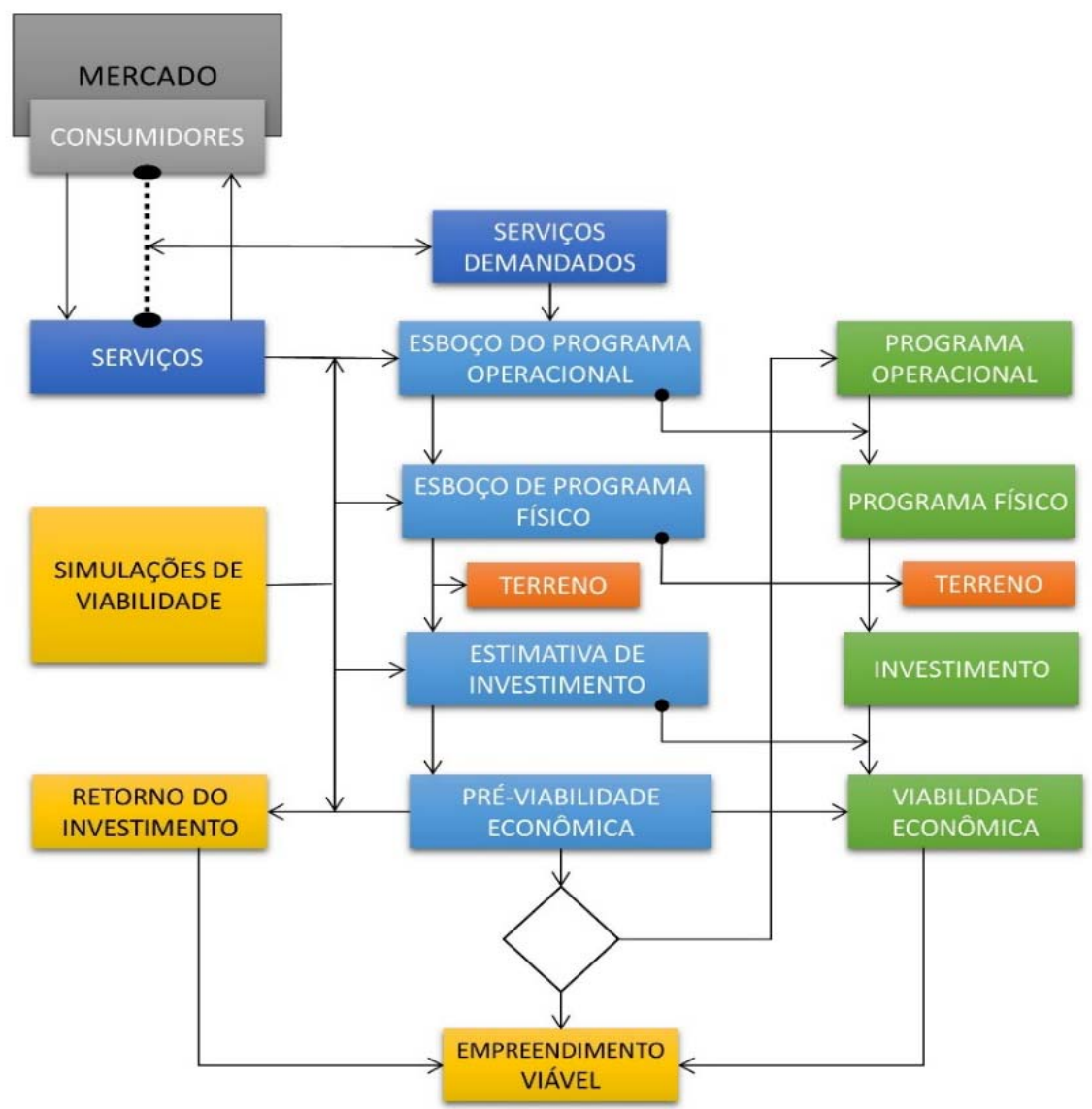

Figura 72. Fases do pré-desenvolvimento. Fonte: Avaliador $\mathbf{1}^{52}$.

\subsubsection{Avaliador 2}

O Avaliador 2 é uma arquiteta de Porto Alegre, que participou do projeto que foi objeto do EC-

1. Tem vasta experiência na área de projetos de EAS, além de ter sido diretora regional da ABDEH no Rio Grande do Sul. Também ministra aulas sobre arquitetura de EAS em cursos de pós-graduação em gestão de saúde.

O questionário enviado para avaliação foi respondido por correio eletrônico (ver Anexo IV).

O Avaliador 2 considerou que foram pertinentes as fases do processo de projeto em que o co-design foi indicado como nível de envolvimento adequado, sendo que esta definição clara é uma característica positiva a ser destacada. Este avaliador também considerou que o modelo pode facilitar o co-design com usuários e que utilizaria o modelo, pois o mesmo

52 Imagem de autoria do Avaliador 1. Publicação eletrônica [mensagem pessoal]. Mensagem recebida por <michele.caixeta@gmail.com> em 3 ago. 2015. 
identifica o papel dos partícipes do processo e define suas atribuições, além de especificar uma metodologia para os projetos de EAS.

Como dificuldades de aplicação do modelo, o Avaliador 2 pondera que "a dificuldade é pertinente ao projetar", uma vez que existe dificuldade em transmitir para as equipes internas que um novo espaço físico significa revisão nos processos. "Projeto novo=processo novo (revisado)". E é justamente esta revisão dos processos operacionais que é destacada como maior desafio do arquiteto pelo avaliador.

Como falha do modelo, o Avaliador 2 aponta que não está claro "em que momento o processo de produção é revisado/definido pela equipe interna". Também alerta para o fato de que o desconhecimento das normas, por parte dos usuários, os induz a realizar as atividades de modo errado e repetir estes erros no projeto. $\mathrm{O}$ avaliador cita uma frase muito comum entre os usuários: "mas nós fazemos assim desde sempre!".

Por fim, entre as observações finais o avaliador destaca que as nomenclaturas dos ambientes e a forma correta de uso destes devem ser informadas a todos os membros da equipe interna. Sem o treinamento e a informação adequada sobre o uso dos espaços, ocorrem situações como a utilização do DML - Depósito de Material de Limpeza - como um depósito geral, ou a ociosidade do ambiente.

\subsubsection{Avaliador 3}

O Avaliador 3 é arquiteto e pesquisador doutor em arquitetura de ambientes de saúde, com vasta experiência em projetos e pesquisas na área, além de ser presidente da ABDEH e membro de diversas entidades voltadas à produção de $\mathrm{EASs}^{53}$. A avaliação do modelo ocorreu por contato telefônico, após análise do material enviado.

O primeiro ponto destacado pelo avaliador é a necessidade de um olhar menos focado no 'negócio', e mais voltado para as questões humanas do EAS. Por outro lado, avalia como positivo e pertinente a proposição de um método para o processo de projeto e 0 envolvimento do usuário.

No tocante ao recorte de usuários proposto para foco do modelo, o Avaliador 3 considera muito pertinente, e acredita que o modelo deveria ir além à restrição ao número de usuários participantes do projeto, para garantir que o número de pessoas envolvidas não inviabilize o processo de projeto. Neste sentido, considera fundamental a escolha de representantes da equipe interna para participar, uma vez que EASs de grande porte chegam a

\footnotetext{
${ }^{53}$ Fonte: http://buscatextual.cnpq.br/buscatextual/visualizacv.do?id=K4716187P9; Acesso em 11 ago. 2015.
} 
ter mais de mil pessoas na equipe interna. Neste ponto, o avaliador propõe que a pesquisa utilize os setores funcionais listados na RDC no 50 (ANVISA, 2002) para determinar o número mínimo de representantes, garantindo que todos os setores sejam representados e uma caracterização mais específica da representatividade. Basear-se nesta norma é uma forma de sistematizar a escolha de representantes, além de orientar o coordenador de cada processo de projeto e permitir que este determine o número necessário de acordo com os setores existentes no projeto específico em que está trabalhando.

Concluindo, o Avaliador 3 destacou a necessidade de verificabilidade do processo. 0 modelo deve definir claramente quem são os atores e suas responsabilidades, além de propor que indique uma ideia de cronologia, com tempo estimado para cada fase.

\subsubsection{Avaliador 4}

O Avaliador 4 é arquiteto e pesquisador doutor na Universidade de Bath, Inglaterra, com vasta experiência em pesquisas em arquitetura de edifícios de assistência à saúde. $\mathrm{O}$ foco de suas pesquisas se dá em projeto baseado em evidência, BIM e Lean Design, principalmente nos impactos gerados pelo ambiente construído sobre a saúde e o bem-estar dos indivíduos ${ }^{54}$.

A avaliação do modelo foi realizada por respostas ao questionário enviado, transmitidas por correio eletrônico (ver Anexo IV).

Como características positivas do modelo, o Avaliador 4 destaca a união dos stakeholders no processo, bem como a ênfase de se trabalhar o projeto dos serviços, pois assim como é necessário esclarecer os stakeholders sobre o processo de projeto, os projetistas precisam ser esclarecidos sobre os serviços.

De acordo com o Avaliador 4, as fases em que o co-design foi indicado como nível de envolvimento adequado foram pertinentes, mas talvez precisem de aprofundamento, no sentido de esclarecer os pontos de início e término de cada uma, bem como seus produtos se são desenhos, documentos, ou diretrizes, por exemplo.

O avaliador não utilizaria o modelo, pois avalia que este ainda precisa de outros aprofundamentos, uma vez que ainda há questões sem resposta. Além dos pontos já colocados, cita a questão da relação de hierarquia dentro das instituições, que deve ser considerada para permitir que se chegue à melhor solução de projeto. Por exemplo, "enfermeiras sempre vão concordar com os médicos se as reuniões de co-design forem organizadas com os dois grupos juntos".

\footnotetext{
${ }^{54}$ Fonte: http://www.researchgate.net/profile/Ricardo Codinhoto. Acesso em: 17 ago. 2015.
} 
Ressalta também a questão da mudança de poder e de influência dos stakeholders ao longo do processo, que não está prevista no modelo. Se, por um lado, é interessante a ideia de co-design por se basear num processo democrático, por outro lado a realidade não é tão democrática quanto o modelo, pois existem questões de poder na tomada de decisões que precisam ser consideradas.

Segundo este avaliador, o desenvolvimento de uma única solução de projeto "pode não ajudar com a questão de tempo", pois os usuários muitas vezes só conseguem entender 'o que querem' e 'o que não querem' quando visualizam a solução. Neste sentido, o Avaliador 4 recomenda a adoção do set-based design $(\mathrm{SBD})^{55}$ para auxiliar projetistas e usuários na avaliação dos trade-offs ${ }^{56}$.

Outro ponto destacado é a necessidade de se estabelecer claramente as metas que se deve atingir com o projeto, desde o início do processo. É também recomendável que exista uma base de comparação, com a descrição dos cenários anteriores e posteriores ao projeto, para que se possa avaliar a efetividade do projeto frente às metas estabelecidas.

Há ainda a questão da responsabilidade sobre as decisões, não discutida pelo modelo. O avaliador coloca que esta questão precisa estar clara, pois relata, por sua experiência, que é comum usuários desejarem 'ter voz' no processo de projeto, mas sem assumirem responsabilidade sobre suas escolhas, que fica a cargo dos diretores de projeto, principalmente em casos de falhas.

Assim como o Avaliador 3, o Avaliador 4 ressalta a necessidade de maior clareza na seleção dos usuários para participar. O detalhamento desta seleção é importante para que o modelo possa facilitar o co-design com usuários.

\footnotetext{
55 "Set-based Design (SBD) é um método de projeto complexo que exige uma mudança na forma como se pensa e gerencia o projeto". O paradigma do SBD pode substituir o point based design em projetos. O SBD também "permite que se use mais do esforço de projeto para avançar simultaneamente e adia especificações detalhadas até que os trade-offs estejam completamente compreendidos" (SINGER; DOERRY; BUCKLEY, 2009).
}

56 "Trade-off ou tradeoff é uma expressão em inglês que significa o ato de escolher uma coisa em detrimento de outra e muitas vezes é traduzida como 'perde-e-ganha'. O trade-off implica um conflito de escolha e uma consequente relação de compromisso, porque a escolha de uma coisa em relação à outra, implica não usufruir dos benefícios da coisa que não é escolhida. Isso implica que para que aconteça o trade-off, elemento que faz a escolha deve conhecer os lados positivos e negativos das suas oportunidades". Fonte: http://www.significados.com.br/trade-off/. Acesso em 17 ago. 2015. 


\subsubsection{Avaliação do Modelo: Discussão}

Os avaliadores consideraram adequadas as fases do processo de projeto em que o co-design foi indicado como nível de envolvimento adequado, concentradas no início do processo de projeto.

Como falhas do modelo levantadas pelos avaliadores, têm-se:

1. Necessidade de maior trabalho nos programas operacionais e físicos, que não podem ser definitivos, mas dever contar com um estágio inicial de esboços e avaliações de viabilidade, para que possam melhor se adequar aos recursos disponíveis e as receitas previstas para operação (Avaliador 1);

2. O modelo não deixa claro o momento em que o processo de produção é revisado/definido pela equipe interna (Avaliador 2);

3. A equipe interna tende a repetir os erros na realização de atividades no projeto, por falta de conhecimento das normas (Avaliador 2);

4. Necessidade de treinar os usuários para garantir que os espaços sejam utilizados conforme previsto em projeto, garantindo a funcionalidade prevista (Avaliador 2).

5. Necessidade de um processo com um olhar mais focado no fator humano, e menos no 'negócio' de saúde (Avaliado 3);

6. Necessidade de o modelo apresentar maior clareza na seleção dos representantes dos usuários para participar do processo (Avaliadores 3 e 4);

7. Definição clara dos atores do processo de projeto e de suas responsabilidades (Avaliadores 3 e 4);

8. Definição de tempos estimados para cada fase (Avaliador 3);

9. Definição dos pontos de início e término de cada fase (Avaliador 4);

10. Definição dos produtos de cada fase (Avaliador 4);

11. Necessidade de trabalhar a hierarquia de poder dentro da instituição, para permitir que os usuários expressem seus verdadeiros requisitos durante o co-design (Avaliador 4);

12. Necessidade de considerar a questão da mudança de poder e de influência dos stakeholders ao longo do processo (Avaliador 4);

13. Necessidade de definição das metas que o projeto deve atingir, no início do processo, para avaliar a efetividade do projeto (Avaliador 4);

14. O modelo deveria considerar o SBD, para auxiliar projetistas e usuários na avaliação dos trade-offs (Avaliador 4). 
Os avaliadores focaram suas análises em pontos distintos do processo, com algumas críticas comuns entre dois avaliadores (itens 6 e 8). Todos os pontos levantados foram considerados pertinentes e contribuições potenciais à qualidade do modelo final. Com base nestas críticas, as alterações realizadas no modelo foram as apresentadas no quadro 38.

Quadro 38. Falhas indicadas pelos avaliadores e soluções propostas. Fonte: Elaborado pela autora.

\begin{tabular}{|c|c|}
\hline $\begin{array}{c}\text { FALHA } \\
\text { INDICADA }\end{array}$ & SOLUÇÃO PROPOSTA \\
\hline 1 & $\begin{array}{l}\text { Foram acrescentadas fases de Revisão do Programa Operacional e Físico na Macrofase de } \\
\text { Desenvolvimento, para amadurecimento dos mesmos antes do início do plano diretor. }\end{array}$ \\
\hline 2 & $\begin{array}{l}\text { Estas revisões ocorrem nos Gates ou Revisão de Fases, anotados como G1 e G2. Foi acrescentado } \\
\text { o texto da seção 7.5.4 para enfatizar as revisões e apresentar a versão final dos gates. }\end{array}$ \\
\hline 3 & As normas foram enfatizadas como Entrada nas Oficinas de co-design. \\
\hline 4 & $\begin{array}{l}\text { Foi acrescentada uma fase de apresentação do projeto para usuários, após a revisão de fase G2, } \\
\text { para que todos os membros da equipe interna possam ser informados dos resultados do projeto, } \\
\text { esclarecendo as decisões tomadas e o uso previsto para o edifício (ver seção 7.5.5). }\end{array}$ \\
\hline 5 & O texto da presente pesquisa foi revisado para evitar este tipo de associação. \\
\hline 6 & $\begin{array}{l}\text { Foi acrescentado o texto da seção } 7.5 .1 \text {, seguindo a sugestão do Avaliador } 3 \text {, de basear a seleção } \\
\text { nos setores funcionais da RDC no } 50 \text { para garantir a representatividade de todos os setores no } \\
\text { processo de projeto. }\end{array}$ \\
\hline 7 & $\begin{array}{l}\text { Esta questão foi abordada na seção 7.5.1, descrevendo o papel dos representantes dos usuários } \\
\text { e indicando necessidade de apresentar e esclarecer a toda a equipe multidisciplinar quem serão } \\
\text { seus membros e qual será o papel de cada um, antes do início das oficinas de co-design. }\end{array}$ \\
\hline 8 & $\begin{array}{l}\text { Durante a pesquisa, não foi possível levantar dados suficientes para atender a esta questão com } \\
\text { a consistência necessária, ficando como sugestão de pesquisa futura. }\end{array}$ \\
\hline 9 & A questão foi trabalhada na seção 7.5 . \\
\hline 10 & $\begin{array}{l}\text { Como o foco do modelo é o co-design, optou-se por indicar apenas os subprodutos do processo } \\
\text { de projeto que são resultados das oficinas de co-design e das revisões de fase (PROCESSO DE CO- } \\
\text { DESIGN). Foram acrescentadas como subproduto as metas norteadoras do projeto, definida na } \\
\text { primeira fase da versão final do modelo. }\end{array}$ \\
\hline 11 & $\begin{array}{l}\text { Esta questão foi trabalhada no item 7.5.1, estabelecendo a necessidade de determinar o papel e } \\
\text { a responsabilidade de cada e um antes do início das oficinas de co-design. }\end{array}$ \\
\hline 12 & $\begin{array}{l}\text { Conforme apresentado na seção 7.3.1, a diversidade de foco das oficinas de cada fase requer } \\
\text { que a escolha dos representantes dos usuários para cada oficina considere suas habilidades } \\
\text { específicas em relação a estes diferentes focos. A questão foi trabalhada também na seção 7.5.1. }\end{array}$ \\
\hline 13 & $\begin{array}{l}\text { Foi adicionada uma fase no processo, destinada ao estabelecimento das metas norteadoras do } \\
\text { projeto (seção 7.5.2). }\end{array}$ \\
\hline 14 & $\begin{array}{l}\text { Apesar da teoria do SBD ser interessante e ter potencial para facilitar a tomada de decisões, ela é } \\
\text { vasta e pressupõe métodos complexos de aplicação, que não podem ser contemplados dentro } \\
\text { do tempo disponível para conclusão da presente pesquisa, ficando como sugestão para } \\
\text { pesquisas futuras. Levanta-se também a questão de como os usuários seriam envolvidos no } \\
\text { processo, pois se forem incumbidos de escolher entre soluções pré-determinadas, o nível de } \\
\text { envolvimento será o consultor, e não o co-design. }\end{array}$ \\
\hline
\end{tabular}

\section{A versão final do modelo é apresentada na seção a seguir.}




\subsection{Versão FinAl do MOdelo}

Com base nas avaliações recebidas e na literatura, o modelo inicial sofreu algumas alterações para seu aprimoramento, e sua versão final é apresentada na figura 73.

Em relação ao processo de projeto em si, foram incluídas duas fases na macrofase de desenvolvimento: Revisão do Programa Operacional e Revisão do Programa Físico. Esta inclusão tem como base a crítica do Avaliador 1, que ressaltou que estes programas - que são elaborados no pré-desenvolvimento e são peças-chave para o trabalho do arquiteto - não são definitivos, mas precisam passar por adequações ao longo do processo de projeto. Esta crítica encontra bases na literatura, com diversos autores destacando a importância do briefing dinâmico, como um processo contínuo com o foco mudando em diferentes fases, ao invés de um documento estático (PRINS et al., 2006; JENSEN, 2006; 2011). A inserção destas fases segue o Protocolo Genérico do Processo de Projeto e Construção (KAGIOGLOU et al., 2000) Figura 9 - que indica a revisão do briefing na fase 4 - Delineamento do Projeto Conceitual que está dentro do estágio 'Pré-construção', após a fase de estudo de viabilidade.

As fases se iniciam conforme determinação do coordenador de projeto, desde que suas entradas estejam disponíveis, e terminam quando seus subprodutos estiverem concluídos. Ressalta-se aqui que as fases do modelo conceitual de processo de projeto com codesign podem ser realizadas subsequentemente ou simultaneamente, de acordo com o que o coordenador do projeto considerar necessário, podendo assim aumentar a eficiência de projetos de menor escala (KAGIOGLOU et al., 2000). 


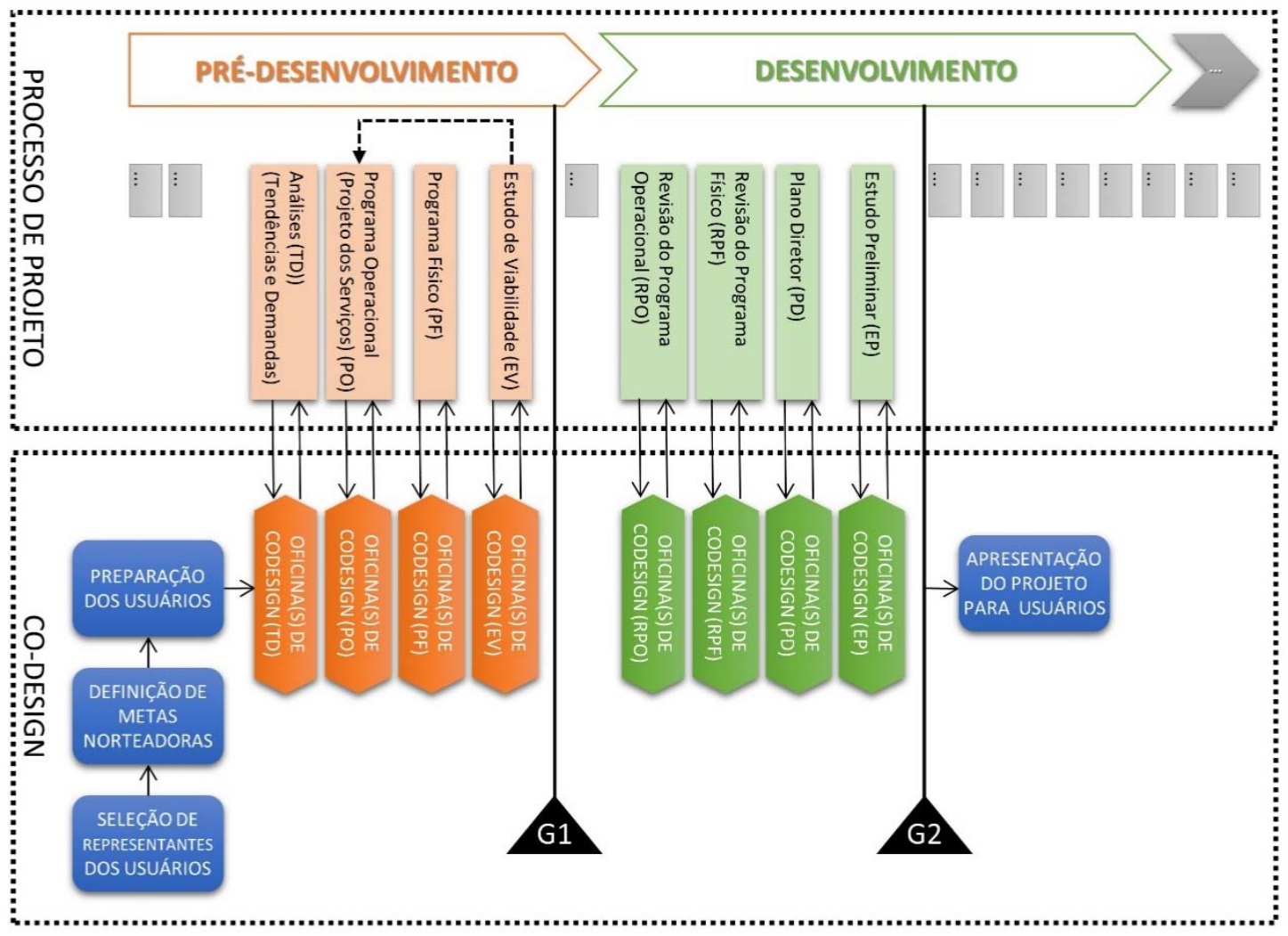

Figura 73. Versão final do modelo conceitual de processo de projeto com co-design. Fonte: Elaborado pela autora.

A seguir é apresentado o delineamento da versão final da seleção de representantes dos usuários, definição das metas norteadoras, oficinas de co-design, gates de verificação e apresentação do projeto para usuários.

\subsubsection{Seleção de Representantes dos Usuários- Versão Final do Modelo}

Além do texto apresentado na seção 7.3.1, acrescenta-se aqui um detalhamento dos setores dos EAS, para orientar os coordenadores do processo de projeto na seleção dos usuários, de modo a garantir que as diversas categorias de usuários da organização prestadora de serviços sejam representadas.

A RDC no 50 (ANVISA, 2002) divide a organização físico-funcional dos EASs em oito atribuições, sendo quatro atribuições fim - que são funções ligadas diretamente ao atendimento à saúde - e quatro atribuições meio, que viabilizam o desenvolvimento de todas as atribuições dos EASs.

Entre as atribuições fins, estão: 
- Atendimento em regime ambulatorial e de hospital-dia;

- Atendimento imediato;

- Atendimento em regime de internação;

- Apoio ao diagnóstico e terapia - "atendimento a pacientes internos e externos em ações de apoio direto ao reconhecimento e recuperação do estado da saúde (contato direto)".

E como atribuições meio, tem-se:

- Apoio técnico - "atendimento direto a assistência à saúde em funções de apoio (contato indireto)";

- Ensino e pesquisa;

- Apoio administrativo;

- Apoio logístico - "atendimento ao estabelecimento em funções de suporte operacional”.

Com base nestas atribuições/unidades funcionais e suas atividades, descritas na RDC nำ50, o quadro 39 busca orientar a seleção de representantes dos usuários para garantir representatividade da equipe interna no co-design. Com o objetivo de garantir a representatividade de todas as unidades funcionais, subdivididas em diversas atividades, mas sem indicar um número de representantes que inviabilize o co-design, alguns grupos de atividades foram agrupados em um único representante. Este agrupamento teve como critério a semelhança de atividades exercidas.

Cabe ressaltar que, apesar do quadro 39 indicar vinte e dois representantes, este não deverá ser o número de usuários participantes das oficinas de co-design. A seleção para as oficinas deverá levar em consideração, em primeiro lugar, as unidades funcionais e as atividades desenvolvidas pelo EAS em questão, uma vez que geralmente os EASs não contam com todas as atividades apresentadas, pois o quadro foi elaborado levando em consideração todos os grupos de atividades elencados na RDC 50, que podem ser realizados nos diversos tipos de EAS. Em segundo lugar, conforme já abordado na seção 7.3.1, a seleção deverá considerar o foco das oficinas de cada fase, destacando representantes cujas habilidades específicas estejam de acordo com este foco. Portanto, para cada fase, diferentes representantes podem ser escolhidos. 
Quadro 39. Representantes dos usuários por unidade funcional. Fonte: Elaborado pela autora.

\begin{tabular}{|c|c|c|}
\hline $\begin{array}{l}\text { UNIDADE } \\
\text { FUNCIONAL } \\
\left.\text { (RDC } n^{\circ} 50\right)\end{array}$ & $\begin{array}{l}\text { GRUPO DE ATIVIDADES } \\
\left.\text { (RDC } n^{\circ} 50\right)\end{array}$ & REPRESENTANTES \\
\hline \multirow{2}{*}{$\begin{array}{c}\text { Ambulatório I } \\
\text { Hospital-dia }\end{array}$} & Atendimento Médico / outros & \multirow{6}{*}{ 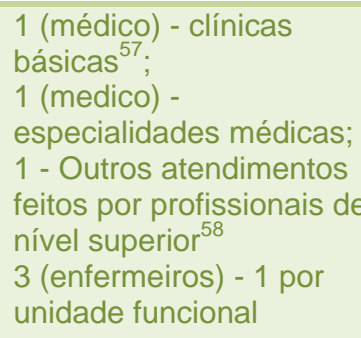 } \\
\hline & Enfermagem & \\
\hline \multirow{2}{*}{$\begin{array}{l}\text { Atendimento } \\
\text { Imediato }\end{array}$} & Atendimento Médico / outros & \\
\hline & Enfermagem & \\
\hline \multirow{2}{*}{ Internação } & Atendimento Médico / outros & \\
\hline & Enfermagem & \\
\hline \multirow{7}{*}{$\begin{array}{l}\text { Apoio ao } \\
\text { Diagnóstico e } \\
\text { Terapia }\end{array}$} & Patologia Clínica/ Anatomia patológica e citopatologia & 1 \\
\hline & Imagenologia/Métodos Gráficos & 1 \\
\hline & $\begin{array}{l}\text { Medicina Nuclear / Radioterapia / Quimioterapia / } \\
\text { Hemoterapia e Hematologia/ Diálise/ Oxigenoterapia } \\
\text { Hiperbárica }\end{array}$ & 1 \\
\hline & Cirurgia e Endoscopia & 1 \\
\hline & Parto Normal / Cirúrgico / Intercorrências Obstétricas & 1 \\
\hline & Reabilitação de Pacientes & 1 \\
\hline & Banco de Leite & 1 \\
\hline \multirow{2}{*}{ Apoio Técnico } & Assistência Alimentar (Refeições) / Esterilização & 1 \\
\hline & Assistência Farmacêutica & 1 \\
\hline \multirow{2}{*}{$\begin{array}{l}\text { Ensino e } \\
\text { Pesquisa }\end{array}$} & Ensino & 1 \\
\hline & Pesquisa & 1 \\
\hline $\begin{array}{c}\text { Apoio } \\
\text { administrativo }\end{array}$ & $\begin{array}{l}\text { Administração do Estabelecimento / planejamento } \\
\text { clínico, de enfermagem e técnico / Documentação e } \\
\text { informação em saúde }\end{array}$ & 1 \\
\hline \multirow[t]{2}{*}{ Apoio logístico } & $\begin{array}{l}\text { Lavanderia / Limpeza do Edifícios / Higiene e conforto } \\
\text { (pacientes, doadores, funcionários, alunos e público) / } \\
\text { Armazenamento de materiais e equipamentos / } \\
\text { Revelação, impressão e guarda de chapas e filmes / } \\
\text { Guarda, conservação, velório e retirada de cadáveres }\end{array}$ & 1 \\
\hline & $\begin{array}{l}\text { Manutenção do Estabelecimento (predial / } \\
\text { equipamentos) / Infraestrutura predial / Segurança e } \\
\text { Vigilância }\end{array}$ & $\begin{array}{l}1 \text { (arquitetura) } \\
1 \text { (engenharias) } \\
1 \text { (operador) }\end{array}$ \\
\hline
\end{tabular}

No contexto de gerenciamento de stakeholders, Ackermann e Eden (2011) desenvolvem uma matriz de poder e interesse dos stakeholders, utilizada para identificar os stakeholders e tornar mais realistas os esforços de coordenação do projeto (Figura 74). Os estudos destes autores indicam que não necessariamente os stakeholders com maior poder são os mais interessados nas estratégias da organização, e o contrário também é verdadeiro. Classificar os stakeholders conforme proposto por Ackermann e Eden, para cada fase do processo de projeto, pode facilitar na escolha dos representantes mais adequados por fase, quando há muitos usuários

\footnotetext{
${ }^{57}$ Clínica médica, clínica cirúrgica, clínica gineco-obstétrica e clínica pediátrica (BRASIL, 1985).

${ }^{58}$ Como Nutricionista, Fonoaudiólogo, Odontólogo etc.
} 
para selecionar. Ressalta-se aqui, entretanto, que o foco da escolha deve ser no interesse no projeto em questão, uma vez que se procura viabilizar o maior atendimento possível aos interesses de todos os usuários, independentemente de seu poder na tomada de decisões.

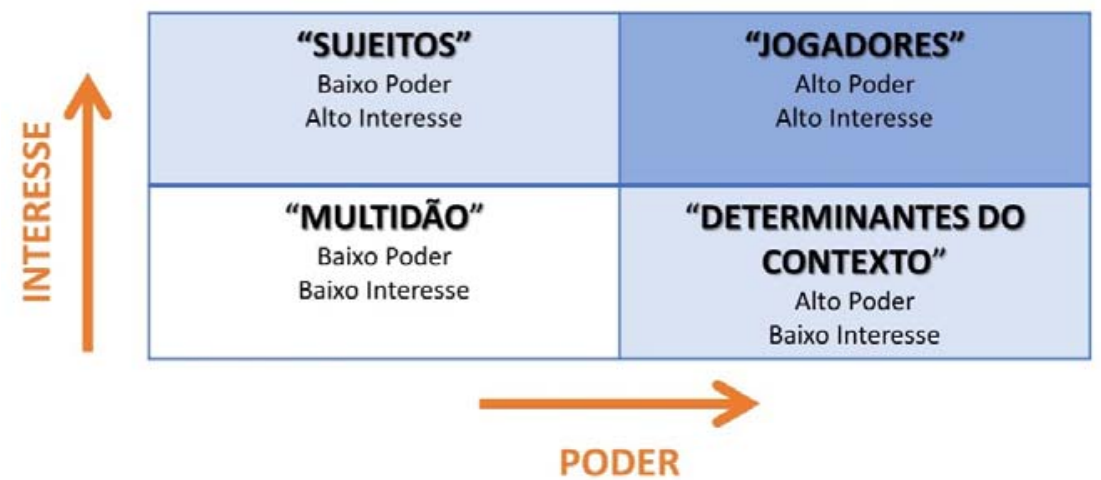

Figura 74. Matriz de poder e interesse para classificação de stakeholders. Fonte: Ackermann e Eden (2011).

Além da definição dos representantes dos usuários, é preciso deixar claro o papel de cada um no processo de projeto, e suas responsabilidades, conforme destacado pelos avaliadores 3 e 4 . Os representantes dos usuários são responsáveis, com já colocado, por levantar informações junto aos usuários que representam, para discuti-las nas oficinas, por tomar decisões em nome deles e, após as oficinas, transmitir as decisões para os representados. Como co-projetistas, são co-responsáveis pelas decisões de projeto. É preciso ainda deixar claro quem são os demais membros da equipe de projeto - coordenador, arquitetos, engenheiros, etc. - e o papel de cada um, antes do início das oficinas de co-design, com o intuito de facilitar a comunicação e o entendimento entre a equipe multidisciplinar.

\subsubsection{Definição de Metas Norteadoras do Projeto}

Foi acrescentada uma fase de definição de metas norteadoras do projeto no início do processo, em atendimento à questão levantada pelo Avaliador 4 , referente à necessidade de um referencial orientador para o projeto, que também permita avaliar, durante e ao final do processo, sua efetividade.

A abordagem para realização desta fase ${ }^{59}$ considera levantamento de requisitos para o futuro espaço físico junto aos usuários do EAS (equipe interna, já caracterizada). Este

\footnotetext{
${ }^{59}$ Baseada nos dados levantados no EC-1, cujo processo de projeto contou com levantamento de demandas junto aos diversos setores do HCPA.
} 
levantamento deve considerar o conjunto de usuários, e não apenas seus representantes. Os requisitos levantados deverão ser reduzidos pelos representantes dos usuários, até formarem um corpo de metas que servirá de base para orientar o projeto, representando as necessidades dos usuários, que deverá ser registrado em documento para ser entrada do processo de projeto e critério de passagem das revisões de fases. Apesar de muitos autores questionarem a possibilidade de atender as necessidades dos diversos tipos de usuários - por serem numerosas, variáveis e conflitantes - os estudos de Kujala e Kauppinen (2004) mostraram que, em muitos casos, pode-se identificar um conjunto básico de necessidades comuns, como mostra a Figura 75.

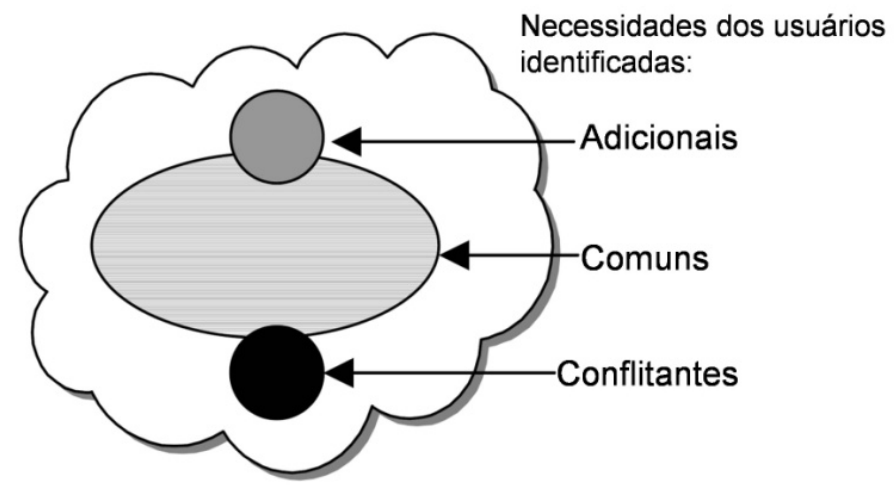

Figura 75. Nuvem das possíveis necessidades dos usuários. Fonte: Kujala e Kauppinen (2004).

Nesta fase, o nível de envolvimento dos usuários é co-design no sentido que as metas são estabelecidas em conjunto com os representantes dos usuários. No entanto, o envolvimento dos demais usuários se dá em nível informativo, uma vez que estes apenas informam suas necessidades e requisitos. Para o levantamento destas necessidades e requisitos, podem ser utilizados instrumentos como entrevistas, questionários ou pesquisa survey, já bem detalhados na literatura ${ }^{60}$.

\subsubsection{Oficinas de Co-design - Versão Final}

Esta seção complementa o texto da seção 7.3.3 com as alterações para atender às questões levantadas nas avaliações. No modelo aqui desenvolvido, são previstas, portanto, Oficinas nas oito fases onde o co-design foi proposto como nível de envolvimento adequado. 0 quadro 40

\footnotetext{
60 Ver, por exemplo, Günther (2003) para questionário, Duarte (2004) para entrevista e Freitas (2000) e Pinsonneault e Kraemer(1993) para pesquisa survey.
} 
apresenta estas fases e a descrição das entradas, instrumentos e subprodutos de cada uma, em sua versão final.

\section{Quadro 40. Descrição das Oficinas de Co-design - Versão Final. Fonte: Elaborado pela} autora.

\begin{tabular}{|c|c|c|c|}
\hline OFICINA & ENTRADAS & $\begin{array}{c}\text { MÉTODOS/INSTRUMENT } \\
\text { OS }\end{array}$ & SUBPRODUTO \\
\hline $\begin{array}{l}\text { Análises de } \\
\text { Tendências e } \\
\text { Demandas } \\
\text { (TD) }\end{array}$ & $\begin{array}{l}\text { - Levantamentos de tendências } \\
\text { dos serviços de saúde e de } \\
\text { perfil/demandas dos usuários } \\
\text { que o EAS irá atender }\end{array}$ & Discussões em grupo & $\begin{array}{l}\text { Memorial com Diretrizes de } \\
\text { Projeto, indicando serviços a } \\
\text { oferecer, sua capacidade inicial e } \\
\text { previsões de expansão. }\end{array}$ \\
\hline $\begin{array}{l}\text { Programa } \\
\text { Operacional } \\
\text { (PO) }\end{array}$ & $\begin{array}{l}\text { - Metas Norteadoras do Projeto; } \\
\text { - Memorial de Diretrizes de } \\
\text { Projeto (Subproduto de TD); } \\
\text { - Legislação e Normas } \\
\text { Pertinentes. }\end{array}$ & $\begin{array}{l}\text { Instrumentos Generativos para } \\
\text { lembrar, pensar (ex. Análise do } \\
\text { fluxo de tarefas), mapear e } \\
\text { imaginar (ex. Diagrama de } \\
\text { Bolhas); } \\
\text { - Design Games Exploratórios } \\
\text { (Cenário) }\end{array}$ & $\begin{array}{lrr}\text { Diagrama dos } & \text { serviços } \\
\text { oferecidos, com a previsão e } \\
\text { subdivisão dos } \\
\text { atividades e fluxos }\end{array}$ \\
\hline $\begin{array}{l}\text { Programa } \\
\text { Físico (PF) }\end{array}$ & $\begin{array}{l}\text { - Metas Norteadoras do Projeto; } \\
\text { - Subprodutos de TD e PO; } \\
\text { - Tabelas de dimensionamento e } \\
\text { quantificação de ambientes da } \\
\text { RDC n050; } \\
\text { - Outras legislações e normas } \\
\text { pertinentes. }\end{array}$ & Discussões em grupo & $\begin{array}{l}\text { Descrição e Quantificação dos } \\
\text { setores e ambientes que } \\
\text { comporão a edificação. }\end{array}$ \\
\hline $\begin{array}{l}\text { Estudo de } \\
\text { Viabilidade } \\
\text { (EV) }\end{array}$ & $\begin{array}{l}\text { - Metas Norteadoras do Projeto; } \\
\text { - Subprodutos de PO e PF. }\end{array}$ & Discussões em grupo & $\begin{array}{l}\text { Relatório do EV (planilhas de } \\
\text { custos do empreendimento/ fluxo } \\
\text { de caixa/ etc.) }\end{array}$ \\
\hline $\begin{array}{l}\text { Revisão do } \\
\text { Programa } \\
\text { Operacional } \\
\text { (RPO) }\end{array}$ & $\begin{array}{l}\text { - Metas Norteadoras do Projeto; } \\
\text { - Subproduto de TD, PO, PF e } \\
\text { EV; } \\
\text { - Legislação e Normas } \\
\text { Pertinentes; } \\
\text { - Relatório do G1. }\end{array}$ & Discussões em grupo & $\begin{array}{l}\text { Diagrama revisado dos serviços } \\
\text { oferecidos, com a previsão e } \\
\text { subdivisão dos setores, } \\
\text { atividades e fluxos }\end{array}$ \\
\hline $\begin{array}{l}\text { Revisão do } \\
\text { Programa } \\
\text { Físico (RPF) }\end{array}$ & $\begin{array}{l}\text { - Metas Norteadoras do Projeto; } \\
\text { - Subproduto de TD, PO, PF e } \\
\text { EV; } \\
\text { - Tabelas de dimensionamento e } \\
\text { quantificação de ambientes da } \\
\text { RDC n05; } \\
\text { - Outras legislações e normas } \\
\text { pertinentes; } \\
\text { - Relatório do G1. }\end{array}$ & Discussões em grupo & \begin{tabular}{lccc} 
Descrição & e & \multicolumn{2}{c}{ Quantificação } \\
revisada & dos & setores & e \\
ambientes & que & comporão & a \\
edificação. & & &
\end{tabular} \\
\hline $\begin{array}{l}\text { Plano Diretor } \\
\text { Físico (PD) }\end{array}$ & $\begin{array}{l}\text { - Metas Norteadoras do Projeto; } \\
\text { - Subprodutos do TD, RPO e } \\
\text { RPF; } \\
\text { - Legislação e Normas } \\
\text { Pertinentes; } \\
\text { - Relatório do G1. } \\
\text { - Dados sobre o terreno/ entorno. }\end{array}$ & $\begin{array}{l}\text { Instrumentos Generativos para } \\
\text { mapear e imaginar (ex. Modelos } \\
\text { 3D); } \\
\text { Design Games Exploratórios; }\end{array}$ & $\begin{array}{l}\text { Delimitação geral da implantação } \\
\text { da edificação no terreno, com } \\
\text { propostas de crescimento } \\
\text { possíveis. Os desenhos serão } \\
\text { desenvolvidos posteriormente } \\
\text { pelos arquitetos para } \\
\text { apresentação final. }\end{array}$ \\
\hline $\begin{array}{l}\text { Estudo } \\
\text { Preliminar } \\
\text { (EP) }\end{array}$ & $\begin{array}{l}\text { - Metas Norteadoras do Projeto; } \\
\text { - Subprodutos do RPO, RPF e } \\
\text { PD. } \\
\text { - Legislação e Normas } \\
\text { Pertinentes; } \\
\text { - Relatório do G1. } \\
\text { - Dados sobre o terreno/ entorno. }\end{array}$ & $\begin{array}{l}\text { Instrumentos Generativos para } \\
\text { mapear e imaginar (ex. Modelos } \\
\text { 3D); } \\
\text { Design Games Exploratórios. } \\
\text { Brainstorming }\end{array}$ & $\begin{array}{l}\text { Proposta esquemática de } \\
\text { Plantas dos pavimentos e } \\
\text { fachadas, que serão } \\
\text { posteriormente desenvolvidas } \\
\text { pelos arquitetos apara o nível de } \\
\text { EP. Perspectivas, Maquetes e } \\
\text { outros produtos são opcionais. }\end{array}$ \\
\hline
\end{tabular}


Os instrumentos e método indicados foram apresentados na seção 4.2 .4 e são sucintamente descritos no Quadro 36, apresentado na seção 7.3.3.

\subsubsection{Gates - Revisões de Fase - Versão Final}

Esta seção completa o texto apresentado na seção 7.3.4, e apresenta a versão final dos gates. Ressalta-se que nestas revisões de fase ocorrem as revisões do processo de produção e de seus produtos, tanto pela equipe interna quanto pelos usuários, de acordo com os critérios de passagem pré-estabelecidos (Quadro 41).

\section{Quadro 41. Estrutura das Revisões de Fase - Versão Final. Fonte: Elaborado pela} autora.

\begin{tabular}{|c|c|c|c|c|}
\hline GATE & QUANDO? & $\begin{array}{l}\text { SUBPRODUTOS } \\
\text { PARA ANÁLISE }\end{array}$ & CRITÉRIOS DE PASSAGEM & RELATÓRIO DE REVISÃO \\
\hline G1 & $\begin{array}{l}\text { Ao final do } \\
\text { Estudo de } \\
\text { Viabilidade } \\
\text { (Macrofase de } \\
\text { Planejamento) }\end{array}$ & $\begin{array}{l}\text { - Programa } \\
\text { Operacional (PO); } \\
\text { - Programa Físico } \\
\text { (PF); }\end{array}$ & $\begin{array}{l}\text { - Metas Norteadoras; } \\
\text { - Análise de Tendências e } \\
\text { de Demandas (TD); } \\
\text { - Estudo de Viabilidade } \\
\text { (EV). }\end{array}$ & $\begin{array}{l}\text { - Aprovar os subprodutos } \\
\text { ou indicar revisões; } \\
\text { - Definir critérios de } \\
\text { passagem para o G2. }\end{array}$ \\
\hline G2 & $\begin{array}{l}\text { Ao final do } \\
\text { Estudo } \\
\text { Preliminar } \\
\text { (Macrofase de } \\
\text { Projeto) }\end{array}$ & $\begin{array}{l}\text { - Revisão do } \\
\text { Programa } \\
\text { Operacional (RPO); } \\
\text { - Revisão do } \\
\text { Programa Físico } \\
\text { (RPF); } \\
\text { - Plano Diretor (PD); } \\
\text { - Estudo Preliminar } \\
\text { (EP). }\end{array}$ & Definidos na revisão do G1 & $\begin{array}{l}\text { - Aprovar os subprodutos } \\
\text { ou indicar revisões; } \\
\text { - Avaliar a experiência de } \\
\text { co-design, para } \\
\text { aprendizado e } \\
\text { retroalimentação do } \\
\text { processo. }\end{array}$ \\
\hline
\end{tabular}

\subsubsection{Apresentação do Projeto para Usuários}

Esta fase foi incluída no modelo conceitual de processo de projeto com co-design com dois objetivos. O primeiro é informar a todos os usuários sobre os resultados das oficinas e mostrar-Ihes o projeto, para que possam ter conhecimento das mudanças que acontecerão em seu ambiente de trabalho - em caso de intervenções - ou conhecer suas futuras instalações em casos de obras novas. É um meio também de demonstrar aos usuários como os requisitos levantados como metas norteadoras foram atendidos, e, no caso de impossibilidade de atendimento de alguma questão, justificar as razões impeditivas, para aumentar a satisfação dos usuários em relação ao espaço físico final. 
Além de apresentar o projeto do espaço físico, o segundo objetivo de inclusão desta fase foi demonstrar para os usuários como a realização das atividades foi planejada, ou seja, o projeto dos serviços. Espera-se, com isto, que os usuários tenham conhecimento suficiente para utilizar os espaços como foram projetados, para garantir a funcionalidade prevista.

São propostas aqui algumas abordagens para realização desta fase, as quais podem ser escolhidas de acordo com o contexto do EASs em questão:

- Palestras de apresentação do projeto dos serviços e do espaço físico, aberta à equipe interna do EAS em questão;

- Material impresso explicativo sobre o projeto dos serviços e do espaço físico, em linguagem adequada à leitura por pessoas sem formação em arquitetura ou engenharias;

- Exposição dos projetos físicos e de serviços, em local de fácil acesso à equipe interna;

- Vídeos explicativos sobre os projetos físicos e de serviços, disponibilizados à equipe interna, pelo meio conveniente. 
A necessidade de garantir funcionalidade aos edifícios de assistência à saúde influencia seu projeto arquitetônico, demandando alinhamento entre espaço físico e serviços e atividades realizadas (TZORTZOPOULOS et al., 2009; CARVALHO, 2012; CAIXETA; FABRICIO, 2013). Para tanto, é necessário um amplo conhecimento acerca dos usuários e dos fluxos e atividades que compõem os serviços prestados nestes edifícios. Os projetistas geralmente não possuem estes conhecimentos acerca dos usuários e serviços em EASs, principalmente devido às grandes variações que ocorrem neste tipo de edificação. A abordagem do envolvimento efetivo dos usuários no processo de projeto destas edificações, neste sentido, é vista como um meio de ajudar os projetistas a conhecer o perfil e as necessidades dos usuários em cada contexto específico de projeto, e a entender os serviços, contribuindo para o aumento da eficiência operacional dos EASs.

O déficit de serviços de atenção à saúde e de espaço físico para os mesmos, no Brasil, e principalmente na esfera pública, é muito divulgado, conforme apresentado na seção 3.1.1. Neste contexto, a busca por eficiência operacional no atendimento à saúde torna-se ainda mais relevante, para aumentar a disponibilidade e a qualidade dos serviços oferecidos à população. Como visto acima, o envolvimento efetivo dos usuários, num processo de projeto consistente, pode contribuir para o aumento da eficiência operacional dos serviços nestas edificações e para melhor compreensão dos limites e trade-offs do projeto, ajudando na assimilação do projeto pelos usuários. No entanto, a abordagem do envolvimento efetivo dos usuários no processo de projeto, o co-design, exige mais esforços do arquiteto, tanto em termos de coordenação, pelo maior número de pessoas e habilidades envolvidas (HOYER et al., 2010; STEEN; MANSCHOT; DE KONING, 2011), quanto em termos da linguagem utilizada, para permitir que os usuários, sem habilidades em linguagem arquitetônica, possam compreender e participar das discussões (MALARD et al., 2002). Outras dificuldades na promoção do co-design foram levantadas, como necessidade de motivar os usuários a participar (WAGNER; PICCOLI, 2007; IEDEMA et al., 2010; GARDE; VAN DER VOORT, 2012) e prepará-los para isto (REICH et al., 1996; SVETOFT, 2006; TZORTZOPOULOS et al., 2006).

Portanto, o problema de pesquisa identificado foi a falta de amparo e dificuldades de promover o co-design no processo de projeto de EAS. A partir desta identificação, a pesquisa buscou, como objetivo principal, uma proposição inovadora de solução, voltada ao aspecto organizacional do processo de projeto, para projetar edifícios de assistência à saúde cujas 
configurações espaciais auxiliem a realização das atividades, aumentando a eficiência operacional dos serviços de saúde. Para tanto, valeu-se da potencialidade que envolvimento dos usuários no processo tem em contribuir para o alinhamento entre edificação e serviços.

A abordagem DSR foi então considerada apropriada para a pesquisa, por se basear na resolução de problemas enfrentados no mundo real, através de construções inovadoras, e, por fim, contribuir com a teoria da área em questão (LUKKA, 2003). Os métodos utilizados para levantamento de dados foram revisão bibliográfica e pesquisas de campo - estudo exploratório e estudo de caso. Os dados levantados foram apresentados e discutidos, e formaram um corpo teórico que embasou a proposta do modelo conceitual de processo de projeto com co-design, apresentado na seção 7.3. O modelo foi então avaliado por quatro profissionais, que são arquitetos com experiência em projetos de edifícios de assistência à saúde e pesquisadores da área. Com base nos resultados das avaliações, o modelo foi aprimorado e sua versão final foi apresentada na seção 7.5. Junto do modelo, apresenta-se a descrição do processo de seleção dos representantes dos usuários para as oficinas de codesign, indicando as questões que devem ser consideradas pela coordenação; a preparação dos usuários, com os pontos que devem ser esclarecidos; uma estrutura para orientar as oficinas e as revisões de fases, indicando quais devem ser as entradas, os métodos e instrumentos utilizados, e as saídas esperadas, no caso das oficinas, e os subprodutos para análise, os critérios de passagem e o conteúdo dos relatórios de revisão, no caso das revisões de fase.

Como principais resultados da pesquisa, pode-se destacar:

- A sistematização dos termos relativos ao envolvimento dos usuários em processos de projeto, tendo como critério os níveis de envolvimento;

- A apresentação dos benefícios do co-design, para instigar os projetistas a utilizá-lo em função de um melhor atendimento às reais necessidades dos usuários;

- A descrição das dificuldades de utilização desta abordagem, para dar margem a novas pesquisas que busquem solucioná-las;

- A documentação de exemplos de envolvimento de usuários em processos de projeto de EASs no contexto nacional, levantados, de um modo geral, através do estudo exploratório, e aprofundados nos estudos de caso;

- O estudo dos níveis de envolvimento adequados para cada fase do processo de projeto, sendo o co-design indicado para as fases iniciais deste processo;

- O estudo de métodos e instrumentos que possam auxiliar os projetistas a viabilizar o co-design; 
- O modelo conceitual de processo de projeto de EAS com co-design, para orientar os arquitetos a viabilizar tal prática.

\subsection{CONTRIBUIÇÕES DA PESQUISA}

Pelos resultados da presente pesquisa, algumas contribuições no campo da arquitetura podem ser destacadas, referentes à teoria, prática e metodologia. Em primeiro lugar, têm-se as contribuições teóricas, referentes à sistematização dos termos relativos ao envolvimento dos usuários em processos de projeto. Para esta sistematização, foram levantadas as propostas de vários autores, de diferentes áreas, quanto à classificação em níveis de envolvimento, que foram a base para a sistematização. As diferentes propostas foram analisadas e comparadas, chegando-se a quatro níveis de envolvimento: informativo, consultivo, participativo e codesign. Tais níveis foram descritos, de acordo com a literatura, e serviram de base para o estudo do envolvimento ao longo da pesquisa.

Ainda no campo teórico, a pesquisa compilou diversos modelos de processo de projeto, extraídos da literatura e de normas em vigor. Estes também foram analisados e comparados, apresentando-se um resumo das principais fases e questões a se destacar ao longo do processo de projeto. A discussão sobre os níveis de envolvimento apropriados para cada fase do processo de projeto busca ampliar a discussão levantada na revisão bibliográfica, em que vários autores estudados apontam o envolvimento efetivo como apropriado para o início do processo de projeto, mas sem especificar fases.

O modelo conceitual de processo de projeto de EAS com co-design, desenvolvido como principal resultado da pesquisa, contribui para o atual estado da arte em modelos de processo de projeto por acrescentar a abordagem de co-design ao processo, com algumas fases específicas e outras complementares às fases do processo de projeto tradicional. 0 modelo é um guia teórico-prático para co-design nas fases iniciais do processo de projeto de EAS, que foi desenvolvido e avaliado, sendo inovador em relação à literatura existente.

Além da contribuição teórica, o modelo também representa uma contribuição para a prática de arquitetura, uma vez que se apresenta como um método para auxiliar os arquitetos a envolverem os usuários em co-design no processo de projeto de EAS, orientando sobre as fases, os instrumentos disponíveis, a necessidade de revisões, entre outras questões importantes, que devem ser observadas. Assim, o modelo é didático e acessível para profissionais brasileiros, sendo baseado no contexto nacional, mas incluindo as boas práticas internacionalmente documentadas. 
Por último, destaca-se a contribuição metodológica, pela aplicação de uma abordagem inovadora na área, como o Design Science Research, contribuindo para sua disseminação e incrementação de métodos de avaliação dos constructos na área específica de arquitetura e urbanismo.

\subsection{Limitações de PESQUisa}

Como principais limitações desta pesquisa, destaca-se aqui a dificuldade de se conseguir realizar estudos de caso no desenvolvimento de processos de projeto de edifícios de assistência à saúde no país. Foram iniciados contatos com várias empresas de arquitetura ao longo da realização da pesquisa, mas a maior parte não se disponibilizou a participar. Isto se evidenciou desde o estudo exploratório, quando vinte e três empresas foram contatadas e solicitadas para participar, mas apenas cinco se dispuseram a responder o questionário. A articulação entre academia e prática profissional ainda precisa ser trabalhada no país.

Mesmo nos casos em que as empresas se dispuseram gentilmente a colaborar, como no EC-1 e EC-2, destaca-se a dificuldade de acompanhamento do processo como um todo, pois, principalmente na esfera pública, o processo de projeto demanda um grande espaço de tempo, devido aos processos de licitações, aprovações e liberação de recursos, excedendo os prazos determinados para realização do doutorado. Tomando como exemplo o processo de projeto do HCPA, descrito no EC-1, o processo como um todo, entre anúncio da meta e previsão de conclusão da obra, levará aproximadamente nove anos, sendo que a fase de desenvolvimento levou cerca de quatro anos. Desta forma, torna-se inviável o acompanhamento pessoal de todo o processo pelo pesquisador, que fica dependente dos relatos dos participantes e dos eventuais documentos disponíveis.

Pelas mesmas razões - falta de disponibilidade das empresas de projeto e demora do processo - outra limitação evidente foi a dificuldade de validar o modelo proposto na prática, com sua aplicação num projeto real, para testá-lo e aprimorá-lo por meio do acompanhamento do processo. A validação precisou, portanto, ser substituída por uma avaliação, que contou com a experiência prática de arquitetos que atuam no setor e com os conhecimentos de pesquisadores renomados. 


\subsection{RECOMENDAÇõES DE TRABALHOS FUTUROS}

Como sugestões de trabalhos futuros, recomenda-se o aprofundamento do detalhamento do modelo proposto. Para tanto, indica-se maiores estudos do processo de projeto de EASs e do co-design, para permitir que as fases sejam descritas com mais detalhes, incluindo, por exemplo, os tempos estimados para cada uma.

Como levantado na avaliação do modelo, sugere-se uma pesquisa sobre a possibilidade de utilização do SBD nos estudos iniciais de projeto, para facilitar a tomada de decisões pelos usuários e projetistas, determinando métodos que auxiliem na escolha das opções.

Outro ponto de grande importância são os estudos e o desenvolvimento de outros instrumentos para dar suporte ao co-design, focados na utilização de uma linguagem de projeto acessível para os usuários que não estão habituados com as representações arquitetônicas.

Por fim, indica-se o teste do modelo numa situação real, para sua validação, em que se possam acompanhar os benefícios que o mesmo venha a gerar, bem como as dificuldades enfrentadas durante sua aplicação, do ponto de vista dos projetistas, do coordenador do projeto e dos usuários. Recomenda-se avaliar também o potencial do modelo em promover, de fato, o co-design no processo de projeto, e avaliar os benefícios desta prática para a qualidade e eficiência operacional da edificação final. 



\section{REFERÊNCIAS BIBLIOGRÁFICAS}

ACKERMANN, F.; EDEN, C. Strategic management of stakeholders: Theory and practice. Long Range Planning, v. 44, p. 179-196, 2011.

AGÊNCIA NACIONAL DE VIGILÂNCIA SANITÁRIA. RDC № 50: Regulamento Técnico para planejamento, programação, elaboração e avaliação de projetos físicos de estabelecimentos assistenciais de saúde. Brasília, 2002.

AL ZAROONI, S.; ABDOU, A.; LEWIS, J. Improving the Client Briefing for UAE Public Healthcare Projects: Space Programming Guidelines. Architectural Engineering and Design Management, v. 7, n. 4, p. 251-265, 2011.

ALAM, I. An Exploratory Investigation of User Involvement in New Service Development. Journal of the Academy of Marketing Science, v. 30, n. 3, p. 250-261, 2002.

ALBUQUERQUE, C. et al. A situação atual do mercado da saúde suplementar no Brasil e apontamentos para o futuro.Ciência \& Saúde Coletiva, v. 13, n. 5, p. 1421-1430, 2008.

AMORA, D. $64 \%$ dos setores de emergência sempre têm mais pacientes que vagas, diz TCU. Folha de São Paulo, Brasília, 26 mar. 2014. Cotidiano. Disponível em: <http://www1.folha.uol.com.br/cotidiano/2014/03/1431271-64-dos-setores-deemergencia-tem-mais-pacientes-que-vagas-diz-tcu.shtml> Acesso em: 04 ago. 2015.

ANDRADE, C. et al. Users' views of hospital environmental quality: Validation of the Perceived Hospital Environment Quality Indicators (PHEQIs). Journal of Environmental Psychology, v. 32, n. 2, p. 97-111, 2012.

ANTUNES, G. B. S.; CALMON, J. L. Manutenção de Edifícios. Importância no projeto e influência no desempenho segundo a visão dos projetistas.VIII Congreso Latinoamericano de Patología de la Construcción e X Congreso de Control de Calidad en la Construcción. Asunción, 2005.

ARIAS, E. et al. Transcending the individual human mind-creating shared understanding through collaborative design. ACM Transactions on Computer-human Interactions, v. 7, n. 1, p. 84-113, 2000.

ARNSTEIN, S. R. A Ladder of Citizen Participation. Journal of the American Intitute of Planners, v. 35, n. 4, p. 216-224, 1969.

ASARO, P. M. Transforming society by transforming technology: the science and politics of participatory design. Accounting, Management and Information Technologies, v. 10, n. 4, p. 257-290, 2000. 
ASSOCIAÇÃO BRASILEIRA DE NORMAS TÉCNICAS. NBR 13531: Elaboração de Projetos de Edificações - Atividades Técnicas. Rio de Janeiro 1995a.

. NBR 13532: Elaboração de Projetos de Edificações - Arquitetura.Rio de Janeiro 1995b.

BAEK, J.-S.; LEE, K.-P. A participatory design approach to information architecture design for children. CoDesign: International Journal of CoCreation in Design and the Arts, v. 4, n. 3, p. 173-191, 2008.

BAGGOTT, R. A funny thing happenned on the way to the forum? Reforming patient and public involvement in the NHS in England. Public Administration, v. 83, n. 3, p. 533-551, 2005.

BAKER, M.; COAFFEE, J.; SHERRIFF, G. Achieving successful participation in the new UK spatial planning system. Planning Practice \& Research, v. 22, n. 1, p. 79-93, 2007.

BAMFORD, G. From analysis/synthesis to conjecture/analysis: a review of Karl Popper's influence on design methodology in architecture. Design Studies, v. 23, n. 3, p. 245261, 2002.

BARRETO, F. F. P. B. A Temática da projetação participativa: nexos entre a psicologia ambiental e o projeto de arquitetura e urbanismo. P@ranoá (UnB), v. 7, p. 15-36, 2005.

BATE, P.; ROBERT, G. Toward More User-Centric OD : Lessons From the Field of ExperienceBased Design and a Case Study. The Journal of Applied Behavioral Science, v. 43, n. 1, 2007.

BECKER, F. D.; POE JR., D. B. The Effects of User-Generated Design Modifications in a General Hospital. Journal of Nonverbal Behavior, v. 4, n. 4, p. 195-218, 1980.

BERGVALL-KAREBORN, B.; STAHLBROST, A. Participatory design: one step back or two steps forward? In: Proceedings of the Tenth Anniversary Conference on Participatory Design 2008. Anais... Simonsen, J.; Robertson, T., et al. Bloomington, USA: Indiana University: 2008. p. 102-111.

BERTELSEN, S.; EMMITT, S. The Client as a Complex System. In: 13th Annual Conference on Lean Construction, IGLC, 2005, Sydney. Anais... Australia: 2005. p. 73-79.

BIBBY, L.; BOUCHLAGHEM, D.; AUSTIN, S. Delivering learning and tools to improve design management in practice. In: CIB Conference on Measurement and Management of Architectural Value in Performance-Based Buildings, 2002, Hong Kong. Anais... Hong Kong, 2002.

BLYTH, A.; WORTHINGTON, J. Managing the Brief for better Design. London, UK: Spon Press, 2001.

BRADWELL, P.; MARR, S. Making the most of collaboration: An international survey of public service co-design. Londres: DEMOS/PriceWaterhouseCoopers, 2008. 
BRANDT, E. Designing exploratory design games: a framework for participation in Participatory Design? In: Ninth conference on Participatory design: Expanding boundaries in design, 2006, Trento. Anais... Trento, Italy: ACM, 2006. p. 57-66.

BRANDT, E.; MESSETER, R. Facilitating collaboration through design games. In: Eighth conference on Participatory design: Artful integration: interweaving media, materials and practices, 2004, Toronto. Anais... Toronto, Canada: ACM, 2004. p. 121-130.

BRASIL. Lei no 10.257, de 10 de julho de 2001. Estatuto da Cidade e Legislação Correlata. 2. ed., atual. Brasília: Senado Federal, Subsecretaria de Edições Técnicas, 2002.

BRASIL. MINISTÉRIO DA SAÚDE. Secretaria-Geral. Grupo de Trabalho - Unidade de Sistema de Desenvolvimento de Serviços de Saúde. Terminologia básica em saúde. Brasília: Centro de Documentação do Ministério da Saúde, 1985.

BRITTO, P. Com saúde em crise, Ceará atende pacientes no chão. Folha de São Paulo, Recife, 12 mai. 2015.2 Cotidiano. Disponível em: <http://www1.folha.uol.com.br/cotidiano/2015/05/1627805-com-saude-em-criseceara-atende-pacientes-no-chao.shtml> Acesso em: 04 ago. 2015.

BRODY, S. D.; GODSCHALK, D. R.; BURBY, R. J. Mandating Citizen Participation in Plan Making: Six Strategic Planning Choices. Journal of the American Planning Association, v. 69, n. 3, p. 245-264, 2003.

BROMLEY, E. Building patient-centeredness: Hospital design as an interpretive act. Social Science \& Medicine, v. 75, n. 6, p. 1057-1066, 2012.

BROSS, J. C. Notas de Aula do Curso de Gestão do Espaço Físico para Saúde. São Paulo: FGV/EAESO/CEAHS. 2008.

Compreendendo o Edifício de Saúde. São Paulo: Editora Atheneu, 2013.

BUENO, F. S. Minidicionário da língua portuguesa. São Paulo: Editora Lisa, 1990.

CAIXETA, M. C. B. F. Processo de Projeto: Intervenções em Edifícios de Saúde. 2011. Dissertação (Mestrado). Escola de Engenharia de São Carlos, Universidade de São Paulo, São Carlos, 2011.

CAIXETA, M. C. B. F. et al. Value Generation Through User Involvement in Healthcare Design. In: Annual Conference of the International Group for Lean Construction, 21, 2013, Fortaleza. Anais... Fortaleza, Brazil: Universidade Federal do Ceará, 2013. p. 1: 299308.

CAIXETA, M. C. B. F.; Fabricio, M. M. Gestão de projetos complexos: edifícios de saúde. In: Kowaltowski, D. C. C. K.; Moreira, D. C., et al (Ed.). O processo de projeto em arquitetura: da teoria à tecnologia. São Paulo: Oficina de Textos, 2011. p.293-302.

A conceptual model for the design process of interventions in healthcare buildings: a method to improve design. Architectural Engineering and Design Management, v. 9, n. 2, p. 95-109, 2013. 
CAMPION, E. W.; MORRISSEY, S. A Different Model - Medical Care in Cuba. The New England Journal of Medicine, v. 368, p. 297-299, 2013.

CAMPOBASSO, F. D.; HOSKING, J. E. Two factors in project success: a clear process and a strong team. Journal of Healthcare Management, v. 49, n. 4, p. 221-225, 2004.

CARVALHO. A. P. A. Métodos para auxílio de projetos arquitetônicos de estabelecimentos assistenciais de saúde. Ambiente Hospitalar, v. 6, n. 9, p. 11-20, 2012.

CARVALHO, L. T. A.; SALGADO, M. S.; BASTOS, L. E. G. Projeto de Reabilitação das Edificações: Estudo de Caso no Solar da Imperatriz. In: Simpósio Brasileiro de Qualidade do Projeto no Ambiente Construído, 1, \& Workshop Brasileiro de Gestão do processo de projeto na construção de edifícios, 9, 2009, São Carlos. Anais... São Carlos: Rima Editora 2009.

CHANDRA, V.; LOOSEMORE, M. Communicating about organizational culture in the briefing process: case study of a hospital project. Construction Management and Economics, v. 29, n. 3, p. 223-231, 2011.

CHOGUILL, M. B. G. A ladder of community participation for underdeveloped countries. Habitat International, v. 20, n. 3, p. 431-444, 1996.

CLEMENT, A.; VAN DEN BESSELAAR, P. A Retrospective Look at PD Projects. Communications of the ACM, v. 36, n. 4, p. 29-37, 1993.

CLIVER, M. et al. Design for the Clinic Experience: Concepts for UPMC Presbyterian Neurosurgery Clinic. Carnegie Mellon School of Design. 2007. Disponível em: <http://kipworks.com/upmc_holisticbook.pdf> Acesso em : 17 dez. 2014.

COLLINGE, W. H. The role of the design artefact in hospital briefing and design works. In: HaCIRIC 12: Transforming Healthcare Infrastructure and Services in an Age of Austerity, 2012, Cardiff. Anais... Cardiff, UK: HaCIRIC, 2012.

COMMISSION OF ARCHITECTURE AND THE BUILT ENVIRONMENT. The role of hospital design in the recruitment, retention and performance of nurses in England. London: 2004, p.1-12.

CONSELHO FEDERAL DE MEDICINA. Falta de leitos e de estrutura de atendimento agravam crise na rede pública. Brasília, 24 out. 2011. Disponível em: <http://portal.cfm.org.br/index.php?option=com content\&id=22337:falta-de-leitose-de-estrutura-de-atendimento-agravam-crise-na-rede-publica> Acesso em: 04 ago. 2015.

COOPER, R. G. Winning at New Products: Creating Value Through Innovation. 4th. New York: Basic Books, 2011.

COSTA, C. Falta de médicos e enfermeiros revolta pacientes no interior do Piauí. G1, Piauí, 12 jan. 2015. Disponível em: <http://g1.globo.com/pi/piaui/noticia/2015/01/falta-demedicos-e-enfermeiros-revolta-pacientes-no-interior-do-piaui.html>. Acesso em: 19 mai. 2015. 
CRESWELL, J. W. Qualitative inquiry and research design: choosing among five approaches. 3 ed.. Thousand Oaks, CA: Sage Publications, 2012.

DAMER, S.; HAGUE, C. Public Participation in Planning: A Review. The Town Planning Review, v. 42, n. 3, p. 217-232, 1971.

DAMODARAN, L. User involvement in the systems design process - A practical guide for users. Behaviour \& Information Technology, v. 15, n. 6, p. 363-377, 1996.

DAVIES, R. C. Adapting Virtual Reality for the Participatory Design of Work Environments. Computer Supported Cooperative Work (CSCW), v. 13, n. 1, p. 1-33, 2004.

DAVIES, U.; WILSON, K.Design methods for developing service: An introduction to service design and a selection of service design tools.: Design Council and Technology Strategy Board, s. d.

DE BLOIS, M. et al. Relationships between Construction Clients and Participants of the Building Industry: Structures and Mechanisms of Coordination and Communication. Architectural Engineering and Design Management, v. 7, n. 1, p. 3-22, 2011.

DEL NORD, R. New dimensions for future healthcare facilities. In: Design \& Health World Congress, 4, 2005, Frankfurt. Anais... Frankfurt, 2005.

DICKERMAN, K.; BARACH, P. We shape our buildings, then they kill us: why healthcare buildings contribute to the error pandemic. World Health Design, v. 1, n. 1, p. 49-55, 2008.

DUARTE, R. Entrevistas em pesquisas qualitativas. Educar, Curitiba, n. 24, p. 213-225, 2004.

EHN, P. Scandinavian design: On participation and skill. In: ADLER, P.; WINOGRAD, T. (Ed.). Usability: Turning Technologies into Tools. New York: Oxford University Press, 1992. p.96.

ERIKSSON, J.; FRÖST, P.; RYD, N. Mapping a framework for co-design in healthcare projects: An empirical study. In: International Conference ARCH2012, 2012, Gothenburg. Anais... Gothenburg: Chalmers University of Technology, 2012.

EVBUONWAN, N. F. O.; SIVALOGANATHAN, S.; JEBB, A. A survey of design philosophies, models, methods and systems. Proceedings Institute of Mechanical Engineers, $v$. 210, p. 301-320, 1996.

FAGUNDES, E. Ministério da Saúde estima que Brasil tenha déficit de 54 mil médicos. 0 Globo, Belo Horizonte, 23 mai. 2013. Disponível em: $<$ http://oglobo.globo.com/brasil/ministerio-da-saude-estima-que-brasil-tenhadeficit-de-54-mil-medicos-8477395\#ixzz3abnmjMcm>. Acesso em 19 mai. 2015.

FARRELL, M. J. The measurement of productive efficiency. Journal of Royal Statistical Society (Series A), v. 120, n. 3, p. 253-281, 1957.

FENKER, M. Design and management of buildings as learning processes. In: Joint CIB W070, W092 \& TG72 International Conference: Delivering Value to the Community, 2012. 
Anais... Michell, K.; Bowen, P., et al. Cape Town, South Africa: Department of Construction Economics and Management, University of Cape Town, 2012. p. 234240.

FINK, A. How to conduct surveys: a step-by-step guide. 3 ed. Thousand Oaks, USA: Sage Publications, 2006.

FORLIZZI, J.; BATTARBEE, K. Understanding experiences in interactive systems. In: Conference on designing interactive systems: Processes, practices, methods and techniques, 2004, Cambridge. Anais... Cambridge: ACM Press, 2004. p. 261-268.

FOTTLER, M. et al. Creating a healing environment: The importance of the service setting in the new consumer-oriented healthcare system. Journal of Healthcare Management, v. 45 , n. 2, p. 91-106, 2000.

FRANCIS, S. The Architecture of Health Buildings: providing care: can architects help? The British Journal of General Practice, v. 52, n. 476, p. 254-255, 2002.

FREITAS, H. et al. O método de pesquisa survey. Revista de Administração, v. 35, n. 3, p. 105112, 2000.

GARDE, J. A.; VAN DER VOORT, M. C. Co-designing better work organization in healthcare. In: Duffy, V. G. (Ed.). Advances in Human Aspects of Healthcare. Boca Raton, FL: CRC Press, 2012. p.23-32.

GESLER, W. et al. Therapy by design: evaluating the UK hospital building program. Health \& Place, v. 10, n. 2, p. 117-128, 2004.

GIL, A. C. Como elaborar projetos de pesquisa. 4aㅡ Ed. São Paulo: Atlas, 2002.

GÓES, R. Manual prático de arquitetura hospitalar. São Paulo: Edgard Blücher, 2004.

GRANATH, J.; LINDAHL, G.; REHAL, S. From Empowerment to Enablement: an evolution of new dimensions in participatory design. Logistik und Arbeit, 1996, p.1-5.

GRUNER, K. E.; HOMBURG, C. Does Customer Interaction Enhance New Product Success? Journal of Business Research, v. 49, n. 1, p. 1-14, 2000.

GÜNTHER, H. Como elaborar um questionário. (Série: Planejamento de pesquisa nas ciências sociais, n. 1). Brasília: UnB, Laboratório de Psicologia Ambiental, 2003. Disponível em: www.dcoms.unisc.br/portal/upload/com arquivo/como elaborar um questionario. pdf Acesso em: 24 ago. 2015.

HANINGTON, B. Methods in the making: A perspective on the state of human research in design. Design Issues, v. 19, n. 4, p. 9-18, 2003.

HANID, M. Design Science Research as an Approach to Develop Conceptual Solutions for Improving Cost Management in Construction. 2014. Tese (Doutorado). School of the Built Environment, College of Science and Technology, University of Salford, Salford, UK, 2014. 
HARON, S. N.; HAMIDA, M. Y.; TALIB, A. Towards Healthcare Service Quality: An Understanding of the Usability Concept in Healthcare Design. Procedia - Social and Behavioral Sciences, v. 42, p. 63-73, 2012.

HART, R. Children's participation: From tokenism to citizenship. Florence: UNICEF International Child Development Centre, 1992.

HEVNER, A. A three-cycle view of design science research. Scandinavian Journal of Information Systems, v. 19, n. 2, p. 87-92, 2007.

HEVNER, A. R. et al. Design Science in Information Systems Research. MIS Quarterly, v. 28, n. 1, p. 75-105, 2004.

HICKS, C., et al., Applying lean principles to the design of healthcare facilities. International Journal of Production Economics (2015), http://dx.doi.org/10.1016/j.ijpe.2015.05.029i (no prelo).

HILLIER, W.; MUSGROVE, J.; O'SULLIVAN, P. Knowledge and design. In: Cross, N. G. (Ed.). Developments in design methodology. Chichester: Wiley, 1984. p.245-264.

HO, D. K. L.; LEE, Y. C. The Quality of Design Participation: Intersubjectivity in Design Practice. International Journal of Design, v. 6, n. 1, p. 71-83, 2012.

HOLLINGSWORTH, B. The measurement of efficiency and productivity of health care delivery. Health Economics, v. 17, p. 1107-1128, 2008.

HOLMSTRÖM, J.; KETOKIVI, M.; HAMERI, A.-P. Bridging Practice and Theory: A Design Science Approach. Decision Sciences, v. 40, n. 1, 2009.

HOYER, W. D. et al. Consumer Cocreation in New Product Development. Journal of Service Research, v. 13, n. 3, p. 283-296, 2010.

HUISMAN, E. R. C. M. et al. Healing environment: A review of the impact of physical environmental factors on users. Building and Environment, v. 58, p. 70-80, 2012.

IEDEMA, R. et al. Codesigning as a Discursive Practice in Emergency Health Services: The Architecture of Deliberation. Journal of Applied Behavioral Science, v. 46, n. 73, p. 73-91, 2010.

INSTITUTO DOS ARQUITETOS DO BRASIL; PROCEL/ELETROBRÁS. Edificações de Saúde. Caderno de boas práticas: eficiência energética em edificações brasileiras. Rio de Janeiro: IAB/RJ; Eletrobrás, 2005.

IVES, B.; OLSON, M. User Involvement and MIS Success: A Review of Research. Management Science, v. 30, n. 5, p. 586-603, 1984.

JÄRVINEN, P. On Reviewing of Results in Design Research. In: European Conference on Information Systems, 15, 2007, St. Gallen. Anais... St. Gallen: University of St. Gallen, 2007. p. 1388-1397. 
JENSEN, P. A. Continuous Briefing and User Participation in Building Projects. Adaptables'06. Rotterdam (Netherlands): in-house publishing: 12, p. 119-123, 2006.

. Inclusive Briefing and User Involvement: Case Study of a Media Centre in Denmark. Architectural Engineering and Design Management, v. 7, n. 1, p. 38-49, 2011.

JOHNSON, J. A plain man's guide to participation. Design Studies, v. 1, n. 1, p. 27-30, 1979.

KAGIOGLOU, M. et al. Rethinking construction: the Generic Design and Construction Process Protocol. Engineering, Construction and Architectural Management, v. 7, n. 2, p. 141-153, 2000.

KASANEN, E.; LUKKA, K.; SIITONEN, A. The constructive approach in management accounting. Journal of Management Accounting Research, v. 5, p. 243-264, 1993.

KAULIO, M. A. Customer, consumer and user involvement in product development: A framework and a review of. Total Quality Management, v. 9, n. 1, p. 141-149, 1998.

KIRBY, P. et al. Building a Culture of Participation: Involving Children and Young People in Policy, Service Planning, Development and Evaluation: A Research Report. London: Department for Education and Skills, 2003.

KLEINSMANN, M.; Valkenburg, R. Barriers and enablers for creating shared understanding in co-design projects. Design Studies, v. 29, n. 4, p. 369-386, 2008.

KORKMAZ, S. et al. High-Performance Green Building Design Process Modeling and Integrated Use of Visualization Tools. Journal of Architectural Engineering, v. 16, n. 1, p. 37-45, 2010.

KOSKELA, L. et al. Do we need one science of production in healthcare? In: HaCIRIC 12: Transforming Healthcare Infrastructure and Services in an Age of Austerity, 2012, Cardiff. Anais... Cardiff, UK: HaCIRIC, 2012. p. 60-66.

KUHN, S.; MULLER, M. Participatory Design. Communications of the ACM, v. 36, n. 6, p. 24-28, 1993.

KUJALA, S. User involvement: a review of the benefits and challenges. Behaviour \& Information Technology, v. 22, n. 1, p. 1-16, 2003.

KUJALA, S.; KAUPPINEN, M. Identifying and Selecting Users for User-centered Design. In: Nordic conference on Human-computer interaction, 3, 2004. Anais... Tampere, Finland: ACM: 2004. p.297-303.

LA FORGIA, G. M.; COUTTOLENC, B. F. Desempenho Hospitalar no Brasil: em busca da excelência. São Paulo: Singular, 2009.

LAHTINEN, M. et al. Rehabilitation centers in change: Participatory methods for managing redesign and renovation. Health Environments Research \& Design Journal, v. 7, n. 2, p. 57-75, 2014. 
LANA, S. M. O arquiteto e o processo de projeto participativo: o caso do RSV. 2007. Dissertação (Mestrado). Escola de Arquitetura, Universidade Federal de Minas Gerais, Belo Horizonte, 2007.

LUCCAS, L. H. H. A escola carioca e a arquitetura moderna em Porto Alegre. Arquitextos. São Paulo: Vitruvius. 07.073, 2006.

LUKKA, K. The constructive research approach. In: Ojala, L. e Hilmola, O.-P. (Ed.). Case study research in logistics: Publications of the Turku School of Economics and Business Administration, 2003. p. 83-101.

MAGNUSSON, P. R.; MATTHING, J.; KRISTENSSON, P. Managing User Involvement in Service Innovation: Experiments with Innovating End Users. Journal of Service Research, v. 6, n. 2, p. 111-124, 2003.

MALARD, M. L. et al. Avaliação pós-ocupação, participação de usuários e melhoria de qualidade de projetos habitacionais: uma abordagem fenomenológica. In: Abiko, A. K. e Ornstein, S. W. (Ed.). Inserção Urbana e Avaliação Pós-Ocupação (APO) da Habitação de Interesse Social. São Paulo: ANTAC, v.1, 2002. p.242-267. (Coletânea Habitare).

MALLORY-HILL, S. M. Supporting Strategic Design of Workplace Environments with CaseBased Reasoning. 2004. Tese (Doutorado). Technische Universiteit Eindhoven, Eindhoven, 2004.

MALTA, D. C. et al. Perspectivas da regulação na saúde suplementar diante dos modelos assistenciais. Ciência \& Saúde Coletiva, v. 9, n. 02, p. 433-444, 2004.

MARCH, S.; SMITH, G. Design and Natural Science Research on Information Technology. Decision Support Systems, v. 15, p. 251-266, 1995.

MARINHO, A.; FAÇANHA, L. O. Programas Sociais: Efetividade, Eficiência e Eficácia como Dimensões Operacionais da Avaliação. Rio de Janeiro: IPEA, 2001.

MELLO, E. et al. Processo de desenvolvimento de produtos e o sistema Stage-Gate. Gestão Contemporânea, Edição especial, 2012.

MIQUELIN, L. C. Anatomia dos edifícios hospitalares. São Paulo: CEDAS, 1992.

MORITZ, S. Service design: Practical access to an evolving field. Cologne: Koln International School of Design., 2005.

NEWCOMBE, R. From client to project stakeholders: a stakeholder mapping aproach. Construction Management and Economics, v. 21, n. 8, p. 841-848, 2003.

OLSSON, N. O. E.; BLAKSTAD, S. H.; HANSEN, G. K. Who is the user? In: FM in the Experience Economy - CIB W70. Anais... DA GRACA, M. E. A. São Paulo, Brasil: Departamento de Engenharia Civil, Escola Politecnica, Universidade de São Paulo, 2010. p. 25-36. 
OSTROWSKI, L.; HELFERT, M.; GAMA, N. Ontology engineering step in design science research methodology: a technique to gather and reuse knowledge. Behaviour \& Information Technology, p. 1-9, 2013. DOI: 10.1080/0144929X.2013.815276

OYEGOKE, A. The constructive research approach in project management research. International Journal of Managing Projects in Business, v. 4, n. 4, p. 573 - 595, 2011.

PALMER, S.; TORGERSON, D. J. Definitions of efficiency. BMJ: British Medical Journal, v. 318, n. 7191, p. 1136, 1999.

PEFFERS, K. et al. The Design Science Research Process: A Model for Producing and Presenting Information Systems Research. In: International Conference on Design Science in Information Systems and Technology (DESRIST), 1, 2006. Anais... CHATTERJEE, S.; HEVNER, A. Claremont, USA: 2006.

PERRIN, F. Ampliação de cursos não resolve déficit de médicos, dizem especialistas. Folha de São Paulo, São Paulo, 11 Mai. 2015. Disponível em: <http://www1.folha.uol.com.br/seminariosfolha/2015/05/1627477-ampliacao-decursos-nao-resolve-deficit-de-medicos-dizem-especialistas.shtml> Acesso em: 19 mai. 2015.

PINSONNEAULT, A.; KRAEMER, K. L. Survey Research Methodology in Management Information Systems: An Assessment. Journal of Management Information Systems, v. 10, n. 2, p. 75-106, 1993.

PRINS, M.et al. Briefing: Static or Dynamic? In: Joint CIB, Tensinet, IASS International Conference on Adaptability in Design and Construction, 2006. Anais... Eindhoven: Eindhoven University of Technology, 2006.

PROJECT MANAGEMENT INSTITUTE. A Guide to the Project Management Body of Knowledge: PMBOK Guide. Newton Square, PA: PMI, 2000.

RABNER, B. S. How to help hospitals achieve their mission through good design. HERD, v. 5, n. 3, p. 7-11, 2012.

REDE INTERAGENCIAL DE INFORMAÇÃO PARA A SAÚDE - RIPSA. Indicadores básicos para a saúde no Brasil: conceitos e aplicações. 2 ed. Brasília: Organização Pan-Americana da Saúde, 2008.

REICH, Y. et al. Varieties and issues of participation and design. Design Studies, v. 17, n. 2, p. 165-180, 1996.

RISSE, G. B. Mending Bodies, Saving Souls: a History of Hospitals. New York: Oxford University Press, 1999.

ROCHA, C. G. A Conceptual Framework for Defining Customisation Strategies in the Housebuilidng Sector. 2011. Tese (Doutorado). Programa de Pós-graduação em Engenharia Civil, UFRGS, Porto Alegre, 2011.

RODERS, A. R. G. M. M. P. Re-architecture: Lifespan rehabilitation of built heritage, basis. 2007. Tese (Doutorado). Technische Universiteit Eindhoven., Eindhoven, 2007. 
ROMANO, F. V. Modelo de referência para o gerenciamento do processo de projeto integrado de edificações. 2003. Tese (Doutorado). Universidade Federal de Santa Catarina, Florianópolis, 2003.

Modelo de referência para o gerenciamento do processo de projeto integrado de edificações. Gestão e Tecnologia de Projetos, v. 1, n. 1, p. 23-47, 2006.

ROOKE, C. N. Improving Wayfinding in Old and Complex Hospital Environments. 2012. Tese (Doutorado). School of the Built Environment, University of Salford, Salford, 2012.

ROOZENBURG, N. F. M.; Cross, N. G. Models of the design process: integrating across the disciplines. Design Studies, v. 12, n. 4, p. 215-220, 1991.

ROZENFELD, H. et al. Gestão de desenvolvimento de produtos: uma referência para melhoria do processo. São Paulo: Editora Saraiva, 2006.

SAMPAIO, A. V. C. F. Arquitetura Hospitalar: Projetos ambientalmente sustentáveis, conforto e qualidade. Proposta de um instrumento de avaliação. 2005. Tese (Doutorado). Faculdade de Arquitetura e Urbanismo, Universidade de São Paulo, São Paulo, 2005.

SANDER, B. Gestão da educação na América Latina: construção e reconstrução do conhecimento. São Paulo: Autores Associados, 1995.

SANDERS, E. B.-N. Generative Tools for CoDesigning. In: Scrivener;Ball, et al (Ed.). Collaborative Design. London: Springer-Verlag London Limited, 2000.

Design Research in 2006. Design Research Quarterly, v. 1, n. 1, p. 1-8, 2006.

Exploring co-creation on a large scale. In: Symposium: Designing for, with and from user experience. Anais... Stappers, P. J. e Szita, J. Delft: Faculty of Industrial Design Engineering, 2009. p. 10-26.

SANDERS, E. B.-N.; STAPPERS, P. J. Co-creation and the new landscapes of design. CoDesign: International Journal of CoCreation in Design and the Arts, London, v. 4, n. 1, p. 518, 2008.

SANOFF, H. Multiple views of Participatory Design. METU Journal of the Faculty of Architecture, v. 23, n. 2, p. 131-143, 2006.

SANTOS, M.; BURSZTYN, I., (Eds). Saúde e Arquitetura: caminhos para a humanização dos ambientes hospitalares. Rio de Janeiro: Editora Senac Rioed, 2004.

SCHRAMM F. K. Projeto de Sistemas de Produção na Construção Civil Utilizando Simulação Computacional como Ferramenta de Apoio à Tomada de Decisão.. Tese (Doutorado em Engenharia Civil) - Escola de Engenharia, Universidade Federal do Rio Grande do Sul, Porto Alegre, 2009.

SFANDYARIFARD, E. An investigation into the consideration of children and young people's preferences in children's hospital design. 2013. Tese (Doutorado). School of Construction and Property Management, University of Salford, Salford, UK. 
SFANDYARIFARD, E.; TZORTZOPOULOS, P. Supporting Value Generation In Children's Hospital Design Through Participatory Approaches. In: Annual Conference of the International Group for Lean Construction, 19, 2011. Anais... Lima: IGLC, 2011, p. 1-10.

SHIER, H. Pathways to participation: openings, opportunities and obligations. Children \& Society, v. 15, n. 2, p. 107-117, 2001.

SILVA, M. M. O Hospital de Clínicas de Porto Alegre: a presença de Jorge Moreira na arquitetura da capital gaúcha. 2006. Dissertação (Mestrado). Pós-graduação em Arquitetura, Universidade Federal do Rio Grande do Sul, Porto Alegre, 2006.

SINCLAIR, R. Participation in practice: making it meaningful, effective and sustainable. Children \& Society, v. 18, n. 2, p. 106-118, 2004.

SINGER, D. J.; DOERRY, N.; BUCKLEY, M. E. What Is Set-Based Design? Naval Engineers Journal, v. 121, n. 4, 31-43(13), 2009.

SLEESWIJK VISSER, F. et al. Contextmapping: experiences from practice. CoDesign: International Journal of CoCreation in Design and the Arts, v. 1, n. 2, p. 119-149, 2005.

SOUZA, D. V. S. A conceptual framework and best practices for designing and improving construction supply chains. 2015. Tese (Doutorado). School of the Built Environment, College of Science and Technology, University of Salford, Salford, UK, 2015.

SOUZA, R. R. O sistema público de saúde brasileiro. In: Seminário Internacional Tendências e Desafios dos Sistemas de Saúde nas Américas, São Paulo, 2002. Anais... Brasília: Ministério da Saúde; 2002. 44p.

SPINUZZI, C. The Methodology of Participatory Design. Technical Communication, v. 52, n. 2, p. 163-174, 2005.

STEEN, M.; KUIJT-EVERS, L.; KLOK, J. Early user involvement in research and design projects - A review of methods and practices. EGOS Colloquium (European Group for Organizational Studies), 23. Anais... Vienna: Vienna University of Economics and Business Administration, 2007. p. 1-21.

STEEN, M.; MANSCHOT, M.; DE KONING, N. Benefits of Co-design in Service Design Projects. International Journal of Design, v. 5, n. 2, p. 53-60, Aug 2011.

STERN, A. L. et al. Understanding the consumer perspective to improve design quality. Journal of Architectural and Planning Research, v. 20, n. 1, p. 16-28, 2003.

SVETOFT, I. The architect's role in the dynamic design process: Possibilities and obstacles. In: Adaptables2006: International Conference On Adaptable Building Structures, 2006. Anais... Eindhoven, The Netherlands: 2006. p. 95-102.

THYSSEN, M. H. et al. Facilitating Client Value Creation in the Conceptual Design Phase of Construction Projects: A Workshop Approach. Architectural, Engineering and Design Management, v. 6, n. 1, p. 18-30, 2010. 
TOMPKINS, J. A. et al. Facilities Planning. 4th ed. UK: John Wiley \& Sons, 2010.

TREBILCOCK, M. Integrated design process: From analysis/synthesis to conjecture/analysis. In: Conference on Passive and Low Energy Architecture, 26, 2009. Anais... Quebec City, 2009.

TRITTER, J. Q.; McCALLUM, A. The snakes and ladders of user involvement: Moving beyond Arnstein. Health Policy, v. 76, n. 2, p. 156-168, 2006.

TZORTZOPOULOS, P. et al. The gaps between healthcare service and building design: a state of art review. Ambiente Construído, v. 9, n. 2, p. 47-55, 2009.

. Clients' activities at the design front-end. Design Studies, v. 27, n. 6, p. 657-683, 2006.

TZORTZOPOULOS, P.; SEXTON, M. An investigation on the implementation of product development process models in construction companies. Construction Management and Economics, v. 25, n. 11, p. 1153-1164, 2007.

VAAJAKALLIO, K. Design games as a tool, a mindset and a structure. 2012. Tese (Doutorado). School of Arts, Design and Architecture, Aalto University, Helsinki, Finland, 2012.

VAISHNAVI, V.; KUECHLER, W. Introduction to Design Science Research in Information and Communication Technology. In: VAISHNAVI, V.; KUECHLER, W. (Ed.). Design science research methods and patterns : innovating information and communication technology. Boca Raton, USA: Auerbach Publications, 2007. p.7-30.

VAN AKEN, J. E. Management Research Based on the Paradigm of the Design Sciences: The Quest for Field-Tested and Grounded Technological Rules. Journal of Management Studies, v. 41, n. 2, p. 219-246, 2004.

VAN AKEN, J. E. Valid knowledge for the professional design of large and complex design processes. Design Studies, v. 26, n. 4, p. 379-404, 2005.

VELOSO, P. L. A. Explorando o diagrama de bolhas. In: Conference of the Iberoamerican Society of Digital Graphics - SIGraDi: Design in Freedom, 18, 2014. Anais... Montevideo Uruguay: Blucher Design Proceedings, 2014. p. 115-119.

VENABLE, J. R. The role of theory and theorizing in Design Science Research. In: International Conference on Design Science in Information Systems and Technology (DESRIST), 1, 2006. Anais... CHATTERJEE, S.; HEVNER, A. Claremont, USA: 2006. p. 1-18.

VIDAL, L. A.; MARLE, F. Understanding project complexity: implications on project management. Kybernetes, v. 37, n. 8, p. 1094-1110, 2008.

VINK, P.; KONINGSVELD, E. A. P.; MOLENBROEK, J. F. Positive outcomes of participatory ergonomics in terms of greater comfort and higher productivity. Applied Ergonomics, v. 37, n. 4, p. 537-546, 2006.

VISCHER, J. C. Towards a user-centred theory of the built environment. Building Research \& Information, v. 36, n. 3, p. 231-240, 2008. 
VOORDIJK, H. Construction management and economics: the epistemology of a multidisciplinary design science. Construction Management and Economics, v. 27, n. 8, p. 713-720, 2009.

WAGNER, E. L.; PICCOLI, G. Moving beyond user participation to achieve successful is design. Communications of the ACM, v. 50, n. 12, p. 51-55, 2007.

WATCH, D. D. Building type basics for research laboratories. New York: John Wiley \& Sons., 2001.

WHITE, S. C. Depoliticising development: the uses and abuses of participation. Development in Practice, v. 6, n. 1, p. 142-155, 1996.

WILCOX, D. The guide to effective participation. London: Joseph Rowntree Foundation, 1994.

WILLIAMS, A. Priority setting in public and private health care: A guide through the ideological jungle. Journal of Health Economics, v. 7, p. 173-183, 1988.

WILSON, S. et al. Helping and hindering user involvement - a tale of everyday design. In: ACM SIGCHI Conference on Human factors in computing systems, 1997. Anais... Atlanta, USA: ACM, 1997. p. 178-185.

WINTER, R. Design science research in Europe. European Journal of Information Systems, v. 17 , n. 5, p. 470-475, 2008.

WULZ, F. The concept of participation. Design Studies, v. 7, n. 3, p. 153-162, 1986.

YIN, R. K. Case Study Research: Design and Method. Thousand Oaks, CA: Sage Publications, 1994. 


\section{ANEXO I. Termos e EXPREssões Empregadas na Pesquisa}

Para elucidar os termos relativos ao desempenho dos serviços de atenção de saúde, apresentam-se brevemente os significados assumidos neste estudo. Três termos frequentemente encontrados na literatura com relação ao desempenho são eficiência, eficácia e efetividade. Segundo Marinho e Façanha (2001), eficiência refere-se à produção do máximo de resultados com o mínimo de recursos. Eficácia diz respeito a resultados desejados de experimentos e a condições controladas. Por fim, efetividade denota a competência de atingir resultados pretendidos. Semelhantemente, Haron, Hamida e Talib (2012) relacionam efetividade como a possibilidade de os usuários alcançarem certo produto, e eficiência como o tempo necessário para isto acontecer.

Para a presente pesquisa, o termo que melhor se adéqua é eficiência, pois o que se busca justamente é aumentar a entrega de serviços de qualidade e também diminuir os desperdícios do sistema. Isto se justifica porque cada vez mais os provedores de serviços de saúde são desafiados a conciliar os fundos disponíveis com a demanda crescente por atenção à saúde (WILLIAMS, 1988). Eficiência vem do latim efficientia, que significa força, ação, virtude de produzir (SANDER, 1995). As definições dadas por Farrell (1957), num estudo que influenciou fortemente a literatura posterior, indicam como eficiência técnica a capacidade de produção do máximo de resultados a partir de um conjunto de entradas disponíveis. Alternativamente, a capacidade de produzir um dado resultado, utilizando o mínimo possível de recursos (HOLLINGSWORTH, 2008). Em atenção à saúde, entende-se eficiência como a relação entre os recursos de entrada e a produção intermediária ou os resultados finais, relativos à saúde (PALMER; TORGERSON, 1999). Como recursos de entrada, estes autores citam os custos - relativos ao capital, os equipamentos ou o trabalho. Como produção intermediária, elencam itens como o tempo de espera e o número de tratamentos, e como resultados finais citam a qualidade de vida, os anos de vida acrescentados e as vidas salvas.

Outras expressões empregadas na pesquisa são 'edifícios de saúde', 'edifícios de assistência à saúde' ou 'edificações de saúde'. Na presente pesquisa, estas expressões têm o mesmo sentido que 'Estabelecimentos Assistenciais de Saúde' - EAS, proposto na RDC no 50, que se refere genericamente a edificações onde se prestam serviços de atenção à saúde, como 
por exemplo, postos de saúde, centros de saúde, hospitais, entre outros (AGÊNCIA NACIONAL DE VIGILÂNCIA SANITÁRIA - ANVISA, 2002). Ressalta-se ainda que cada EAS é único, mesmo os pertencentes à mesma tipologia, pois devem se adequar às condições do local em que são implantados, respeitando suas peculiaridades populacionais, epidemiológicas e geográficas. Assim, seus programas arquitetônicos variam caso a caso, de acordo com as atividades distintas que ocorram em cada um deles (ANVISA, 2002). 


\section{ANEXO II. QUESTIONÁRIO}

O link com o questionário publicado na versão online pode ser acessado em: https://docs.google.com/spreadsheet/viewform?pli=1\&formkey=dHdFUIA1OEVMS2VzeTREbzZsTXFGNF E6MQ\#gid=0

Empresa:

Nome do entrevistado:

Função:

1. Áreas de atuação da empresa:

[] Projeto de Arquitetura

[ ] Projetos Complementares (Estruturas, Instalações, Paisagismo, etc.)

[ ] Coordenação de Projetos

[ ] Acompanhamento de Obra/Direção de Obra

[ ] Administração de Obra

[ ] Construção

Outro:

2. Número de projetistas:

3. Há quanto tempo está no mercado?

4. Raio de Atuação:

() Municipal

() Regional

() Estadual

() Nacional

() Internacional

5. Principais clientes:

() Privados

() Públicos

6. Nicho de Mercado:

() Projetos Residenciais

() Projetos Comerciais/Serviços

()Projetos de Edifícios de Saúde

( )Projetos Industriais

Em relação aos projetos de edifícios de saúde:

7. Qual o principal nível de atendimento?

( ) Nível Primário (Postos e Centros de Saúde)

( )Nível Secundário (Unidades Mistas, Ambulatórios Gerais, Hospitais Locais e Regionais com as 4 clínicas básicas)

( ) Nível Terciário (Hospitais Regionais e Especializados)

8. A empresa já desenvolveu projetos de edifícios de saúde com participação de usuários?

() Sim ( ) Não

Se "Sim" na questão 8 responder abaixo

Se "Não" ir para página 28 
[Inclusão de usuários em processo de projeto de Edifícios de Saúde]

9. Quais as razões que levaram a empresa a envolver o usuário no desenvolvimento de projetos de edifícios de saúde?

10. Os projetos nos quais a empresa busca a participação dos usuários são os referentes a obras novas ou a intervenção em edifícios existentes?
() Somente em projetos de obras novas
( ) Os projetos são majoritariamente para obras novas
() Em todos os tipos de projeto
( ) Os projetos são majoritariamente de intervenção em edifícios existentes
( ) Somente em projetos de intervenção em edifícios existentes

11. Em quais etapas do empreendimento a empresa busca a inclusão do usuário?

[ ] Planejamento / Briefing

[ ] Estudo Preliminar

[ ] Anteprojeto

[ ] Projeto básico

[ ] Projeto executivo

[ ] Execução

[] Outro:

12. Das etapas citadas acima, em qual delas a empresa julga essencial a participação do usuário?

() Planejamento / Briefing

() Estudo Preliminar

( ) Anteprojeto

( ) Projeto básico

( ) Projeto executivo

( ) Execução

() Outro:

13. Que tipos de usuários são buscados pela empresa para participação no processo de projeto? [ ] Equipe médica

[ ] Enfermeiros

[ ] Funcionários administrativos

[ ] Pacientes internos

[ ] Pacientes externos

[ ] Familiares dos pacientes

[ ] Habitantes do raio de atendimento da unidade de saúde

[ ] Outros:

14. Dentre os tipos de usuários citados, qual o mais frequentemente buscado pela empresa?

( ) Equipe médica

( ) Enfermeiros

() Funcionários administrativos

( ) Pacientes internos

( ) Pacientes externos

( ) Familiares dos pacientes

( ) Habitantes do raio de atendimento da unidade de saúde

() Outros:

[Com relação ao projeto desenvolvido pela empresa que houve maior participação do usuário]

15. Qual foi o projeto (Nome e Local)?

16. Qual o tipo de relacionamento que a equipe de projeto manteve com os usuários durante a elaboração do mesmo? 
( ) Mínimo, os usuários foram contatados para obter respostas específicas, feedbacks.

( ) Moderado, os usuários foram consultados em muitas 0s do desenvolvimento do projeto.

( ) Completamente, os usuários foram consultados e envolvidos em todas as etapas da elaboração do projeto.

17. Em qual estágio do projeto o contato da equipe com os usuários começou?

( ) No planejamento: os usuários foram envolvidos nas discussões iniciais.

( ) Após o planejamento, porém antes do início da elaboração do projeto.

( ) Após o início da elaboração do projeto pela equipe de arquitetos e engenheiros.

( ) Durante a execução: os usuários não foram envolvidos no processo até o projeto estar finalizado.

18. Em sua opinião, qual o nível do aprendizado sobre os processos de projeto e serviços em edifícios de saúde dos usuários envolvidos neste processo?

( ) Aprendizado mínimo: os usuários aprenderam o necessário para poder participar

( ) Aprendizado moderado: os usuários foram expostos a situções em que aprenderam sobre planejamento de projetos e um pouco sobre a dinâmica de serviços de saúde.

( ) Aprendizado alto: os usuários obtiveram uma ampla visão sobre o processo de projeto de um edifício de saúde e de serviços de saúde.

19. Houve dificuldades na comunicação da equipe técnica da empresa com os usuários envolvidos?

20. Qual o nível de envolvimento que os usuários tiveram nas alterações do projeto?

( ) Nenhum: alterações julgadas necessárias pela equipe técnica foram feitas sem a consulta aos usuários.

( ) Os usuários foram apenas informados sobre as restrições e necessidade de alteração do projeto.

( ) Houve alguma forma de consulta aos usuários conforme alterações foram julgadas necessárias pela equipe técnica.

( ) Os usuários foram consultados para discutir as alterações necessárias no projeto.

21. Qual o nível de informação que os usuários receberam sobre as discussões de projeto realizadas pela equipe técnica, das quais eles não participaram?

( ) Nenhuma: informações das discussões internas à equipe de projeto foram confidenciais.

( ) Pouca informação

( ) Informação moderada

( ) Muita informação

( ) Informações totalmente disponíveis: todo o processo foi aberto a todos os envolvidos, tanto usuários quanto profissionais de projeto.

22. Em sua opinião, o que funcionou bem na inclusão dos usuários neste projeto da empresa?

23. Em sua opinião, quais foram as barreiras e dificuldades encontradas na implementação deste processo de participação dos usuários?

24. Quais você diria que são os maiores benefícios da abordagem de inclusão dos usuários?

25. Você possui algum comentário que não foi abordado nas perguntas, relevantes para a pesquisa?

Prosseguir para a página 29

[Não inclusão dos usuários em processos de projeto em edifícios de saúde]

09. Existem razões particulares pelas quais a empresa nunca optou por envolver o usuário no desenvolvimento de projetos de edifícios de saúde? 
10. Em sua opinião, dentre os serviços e processos desenvolvidos em um projeto de edifício de saúde, quais seriam as etapas de projeto em que a inclusão de pontos de vista do usuário beneficiaria o mesmo?

[ ] Planejamento / Briefing

[ ] Estudo Preliminar

[ ] Anteprojeto

[ ] Projeto básico

[ ] Projeto executivo

[ ] Execução

() Outro:

11. Que tipos de usuários você acredita que poderia fornecer informações relevantes para a melhoria de processos de projeto em edifícios de saúde?
( ) Equipe médica
( ) Enfermeiros
() Funcionários administrativos
() Pacientes internos
() Pacientes externos
( ) Familiares dos pacientes
( ) Habitantes do raio de atendimento da unidade de saúde
() Outros:

12. Você acredita que, em um futuro próximo, a empresa passará a incluir usuários em alguma etapa de projeto de edifícios de saúde?

() Dificilmente

() Provavelmente

( ) Certamente

Prosseguir para a página 29

Você pode sugerir outra empresa/projetista que poderia nos fornecer maiores informações para a realização desta pesquisa no assunto?

() Sim. Qual?

( ) Não

Agradecemos a colaboração. Os dados fornecidos serão muito importantes para o desenvolvimento da pesquisa. 


\section{ANEXO III. TRANSCRIÇÃO DAS RESPOSTAS DO QUESTIONÁRIO}

\begin{tabular}{|c|c|c|c|c|c|}
\hline & EMPRESA A & EMPRESA B & EMPRESA C & EMPRESA D & EMPRESA E \\
\hline $\begin{array}{c}\text { Áreas de atuação } \\
\text { da empresa }\end{array}$ & $\begin{array}{l}\text { Projeto de } \\
\text { Arquitetura }\end{array}$ & $\begin{array}{c}\text { Projetos } \\
\text { Complementares } \\
\text { (Estruturas, } \\
\text { Instalações, } \\
\text { Paisagismo, etc.), } \\
\text { Acompanhamento } \\
\text { de Obra/Direção de } \\
\text { Obra }\end{array}$ & $\begin{array}{c}\text { Projeto de } \\
\text { Arquitetura, } \\
\text { Coordenação de } \\
\text { Projetos, } \\
\text { Acompanhamento } \\
\text { de Obra/Direção de } \\
\text { Obra }\end{array}$ & $\begin{array}{l}\text { Projeto de } \\
\text { Arquitetura }\end{array}$ & $\begin{array}{l}\text { Projeto de } \\
\text { Arquitetura }\end{array}$ \\
\hline $\begin{array}{l}\text { Número de } \\
\text { Projetistas }\end{array}$ & 6 & 4 & 16 & 200 & 70 \\
\hline Tempo de atuação & 30 anos & 13 anos & 52 anos & 37 anos & 25 anos \\
\hline Raio de Atuação & Nacional & Nacional & Nacional & Nacional & Nacional \\
\hline Principais clientes & Públicos & Privados & Privados & Públicos & Privados \\
\hline Nicho de Atuação & $\begin{array}{c}\text { Projetos } \\
\text { Residenciais }\end{array}$ & $\begin{array}{l}\text { Projeto Rede de } \\
\text { Gases Medicinais }\end{array}$ & $\begin{array}{c}\text { Projetos } \\
\text { Residenciais, } \\
\text { Projetos } \\
\text { Comerciais/Serviços } \\
\text {, Projetos de } \\
\text { Edifícios de Saúde, } \\
\text { Projetos Industriais }\end{array}$ & $\begin{array}{c}\text { Projetos } \\
\text { Comerciais/Serviços } \\
\text {, Projetos de } \\
\text { Edifícios de Saúde, } \\
\text { Projetos Industriais }\end{array}$ & $\begin{array}{c}\text { Projetos } \\
\text { Residenciais, } \\
\text { Projetos } \\
\text { Comerciais/Serviços } \\
\text {, Projetos de } \\
\text { Edifícios de Saúde }\end{array}$ \\
\hline $\begin{array}{l}\text { Níveis de } \\
\text { empreendimento } \\
\text { (edificações de } \\
\text { saúde) }\end{array}$ & Nível Primário & $\begin{array}{l}\text { Níveis Primário, } \\
\text { Secundário e } \\
\text { Terciário }\end{array}$ & $\begin{array}{l}\text { Níveis Primário, } \\
\text { Secundário e } \\
\text { Terciário }\end{array}$ & $\begin{array}{c}\text { Níveis Secundário e } \\
\text { Terciário }\end{array}$ & $\begin{array}{l}\text { Níveis Primário, } \\
\text { Secundário e } \\
\text { Terciário }\end{array}$ \\
\hline $\begin{array}{c}\text { Desenvolve } \\
\text { projetos de EAS } \\
\text { com participação } \\
\text { de usuários? }\end{array}$ & Sim & Sim & Sim & Não & Sim \\
\hline $\begin{array}{c}\text { 9. Razões que } \\
\text { levaram a empresa } \\
\text { a envolver o } \\
\text { usuário no projetos } \\
\text { de EAS }\end{array}$ & $\begin{array}{c}\text { Melhorar o } \\
\text { conhecimento sobre } \\
\text { o assunto }\end{array}$ & $\begin{array}{l}\text { Uma definição } \\
\text { melhor da } \\
\text { necessidade de } \\
\text { pontos de consumo } \\
\text { para o usuário final } \\
\text { a Equipe de } \\
\text { Enfermagem }\end{array}$ & $\begin{array}{l}\text { Faz parte da nossa } \\
\text { metodologia de } \\
\text { trabalho, reuniões } \\
\text { para consolidar o } \\
\text { programa de } \\
\text { necessidades com } \\
\text { Cliente/ Usuário }\end{array}$ & - & $\begin{array}{c}\text { Os projetos são } \\
\text { desenvolvidos } \\
\text { juntamente com o } \\
\text { cliente e equipes } \\
\text { médicas e } \\
\text { administrativas dos } \\
\text { hospitais (reforma) }\end{array}$ \\
\hline $\begin{array}{l}\text { 10. Os projetos nos } \\
\text { quais a empresa } \\
\text { busca a } \\
\text { participação dos } \\
\text { usuários são os } \\
\text { referentes a obras } \\
\text { novas ou a } \\
\text { intervenção em } \\
\text { edifícios } \\
\text { existentes? }\end{array}$ & $\begin{array}{c}\text { Somente em } \\
\text { projetos de obras } \\
\text { novas }\end{array}$ & $\begin{array}{l}\text { Em todos os tipos } \\
\text { de projeto }\end{array}$ & $\begin{array}{l}\text { Em todos os tipos } \\
\text { de projeto }\end{array}$ & - & $\begin{array}{l}\text { Os projetos são } \\
\text { majoritariamente } \\
\text { de } \\
\text { intervenções/retrofi } \\
\text { t em edifícios } \\
\text { existentes }\end{array}$ \\
\hline $\begin{array}{l}\text { 11. Durante o } \\
\text { processo de } \\
\text { projeto, quais são } \\
\text { as etapas em que a } \\
\text { empresa busca a } \\
\text { inclusão do } \\
\text { usuário? }\end{array}$ & $\begin{array}{l}\text { Planejamento } \\
\text { /Briefing }\end{array}$ & $\begin{array}{l}\text { Planejamento } \\
\text { /Briefing }\end{array}$ & $\begin{array}{l}\text { Planejamento } \\
\text { /Briefing }\end{array}$ & - & $\begin{array}{l}\text { Estudo Preliminar, } \\
\text { Projeto executivo }\end{array}$ \\
\hline
\end{tabular}





\section{ANEXO IV. Avaliação do MODELO}

(Questionário enviado aos avaliadores)

1. Você considera que foram pertinentes as fases do processo de projeto em que o codesign foi indicado como nível de envolvimento adequado?

( ) Sim. ( ) Não.

Qual fase deveria ser incluída?

Qual deveria ser retirada?

2. Você usaria o modelo proposto? Por quê?

( ) Sim. ( ) Não.

3. Você indicaria falhas no modelo? Quais?

4. Existem dificuldades de aplicação do modelo? Quais?

5. Você indicaria características positivas no modelo? Quais?

6. Você acredita que o modelo possa facilitar o co-design com usuários? Por quê?

7. Observações finais: 


\section{ANEXO V. Respostas das Avaliações do Modelo}

\section{(Avaliador 2)}

Você considera que foram pertinentes as fases do processo de projeto em que o co-design foi indicado como nível de envolvimento adequado?

(x ) Sim. ( ) Não.

Qual fase deveria ser incluída?

Qual deveria ser retirada?

Você usaria o modelo proposto? Por quê?

(x ) Sim. ( ) Não.

_Identifica o papel dos partícipes do processo ; define atribuições e cria metodologia específica para EAS

Você indicaria falhas no modelo? Quais?

_Em que momento o processo de produção é revisado/definido pela equipe interna?o desconhecimento de normativas induz ao erro e repetição do erro.A célebre frase: mas nós fazemos assim desde sempre!!!!!

Existem dificuldades de aplicação do modelo? Quais?

_A dificuldade é pertinente ao projetar,as equipes internas custam a entender que projeto novo=processo novo(revisado).

_Revisar os processos operacionais é o maior desfio.

Você indicaria características positivas no modelo? Quais?

_Definição clara das etapas de envolvimento.

Você acredita que o modelo possa facilitar o co-design com usuários? Por quê?

SIM

Observações finais:

_Uso correto dos ambientes e suas nomenclaturas devem ser informados a todas as equipes e niveis de atuação.por exemplo: em um EAS que as equipes de higienização desconhecem a sigla DML, deve haver treinamento para uso correto do ambiente. Caso contrário, ou vai virar depósito ou ficar fechado, sem uso.

(Avaliador 2, 10/08/2015) 


\section{(Avaliador 4)}

Você considera que foram pertinentes as fases do processo de projeto em que o co-design foi indicado como nível de envolvimento adequado?

(X) Sim. ( ) Não.

Qual fase deveria ser incluída?

Acho que as fases nao precisam ser mudadas, mas talvez aprofundadas. A maneira como a divisão foi feita nao fica clara em relação a quando a fase termina e a outra começa. Existe algum processo de avaliação? Qual e o output da fase? Desenhos? Documentos? Diretrizes? Ajudaria se você ler com detalhes as fases do RIBA plano f work 2013.

Qual deveria ser retirada?

Você usaria o modelo proposto? Por quê?

( ) Sim. (X) Não.

_Acho que o modelo precisa amadurecimento. Existem questoes muito importantes que nao foram discutidas. Por exemplo, enfermeiras sempre vao concordar com o medicos se as reunioes de co-design forem organisadas com os dois grupos juntos. Existe uma relacao de hieraquia que se nao considerada nao levara a melhor solucao de design. Outra questao e relacionada a mudanca de poder/influencia durante o processo. Os poderes dos stakeholders muda com o tempo e isso nao e previsto no modelo (estou mandando anexo material que explica isso). Como disse, a questão do output de cada fase nao e clara. Por último, a ideia de que UMA solução de projeto sendo desenvolvida pode não ajudar com a questão de tempo. As pessoas só sabem o que querem e o que não querem quando veem a solução (problema típico do brief de projeto) por isso, a adoção de set-based design e recomendada para que as pessoas e os projetistas consigam avaliar os trade-offs.

Você indicaria falhas no modelo? Quais?

_Sim, veja resposta acima. Adicionando o que esta acima, as metas a serem atingidas tem que estar muito claras no inicio do projeto e uma baseline para comparação (antes e depois cenário) tem que estar disponível para saber-se se o projeto foi um sucesso ou fracasso ou um misto dos dois.

Existem dificuldades de aplicação do modelo? Quais?

$A$ idea de co-design e interessante e se baseia num processo democrático. No entanto, a vida real nao e tao democrática como o modelo se apresenta. Existem as questões de poder de tomada de decisão ja mencionados. Alem disso, existe a questão de responsibilidade, ou seja, se o projeto falhar, quem $e$ responsável pela falha. O modelo, como apresentado nao discute essa questão. Em geral, o que tenho visto aqui na Inglaterra e que todo mundo quer ter voz para dar opinião, mas quando se fala em responsabilidade, todos querem se abster e por nas costas do diretor de projeto a responsabilidade por falhas.

Você indicaria características positivas no modelo? Quais?

_Sim, a ideia de trazer os stakeholder juntos e de se trabalhar o projeto do serviço e muito importante. Da mesma maneira que e importante educar os stakeholder sobre o processo de projeto e importante educar os projetistas sobre os serviços (médicos e de manutenção do edifício que podem afetar a entrega do serviço). O modelo tem algo das questões discutidas na literatura de stakeholder management e parece haver contribuição nessa área.

Você acredita que o modelo possa facilitar o co-design com usuários? Por quê?

_Dificil dizer, pois o texto e apenas um resumo do trabalho feito e faltam muitos detalhes operacionais de como o processo vai funcionar. Por exemplo, um hospital vai ter milhares de pessoas das quais algumas serão selecionadas para representar o todo. Falta saber quais sao os grupos (medico clinico, medico operação, enfermagem, terapias, limpeza, facilities management, pacientes: câncer, aids, deficientes físicos, hemodiálise, doenças crônicas, idosos, doenças mentais, etc. Se detalhado, ha potencial.

Observações finais:

As quesotes principais foram discutidas acima, e me disponho a conversar mais se necessário, via email ou Skype.

(Avaliador 4, University of Bath, 15th Agosto 2015) 